\title{
Adolescents in Rajasthan 2012: Changing situation and needs
}

Shireen J. Jejeebhoy

Population Council

Rajib Acharya

Population Council

Follow this and additional works at: https://knowledgecommons.popcouncil.org/departments_sbsr-pgy

Part of the Demography, Population, and Ecology Commons, Family, Life Course, and Society Commons, and the International Public Health Commons How does access to this work benefit you? Let us know!

\section{Recommended Citation}

Jejeebhoy, Shireen J. and Rajib Acharya. 2014. "Adolescents in Rajasthan 2012: Changing situation and needs." New Delhi: Population Council. 


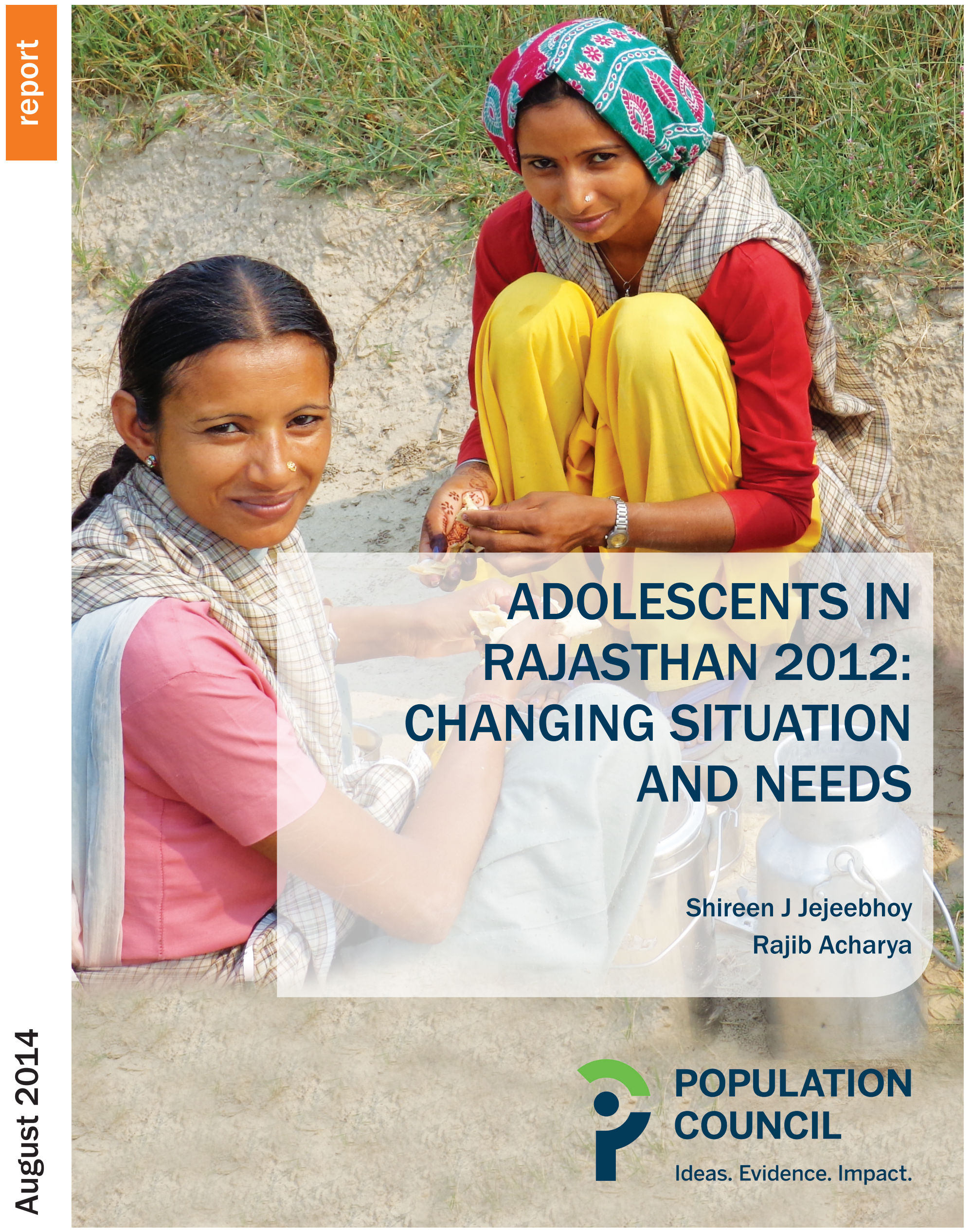




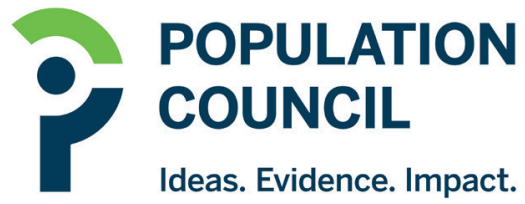

The Population Council confronts critical health and development issues-from stopping the spread of HIV to improving reproductive health and ensuring that young people lead full and productive lives. Through biomedical, social science, and public health research in 50 countries, we work with our partners to deliver solutions that lead to more effective policies, programs, and technologies that improve lives around the world. Established in 1952 and headquartered in New York, the Council is a nongovernmental, nonprofit organization governed by an international board of trustees.

\section{Population Council}

Zone 5A, Ground Floor

India Habitat Centre, Lodi Road

New Delhi, India 110003

Phone: 91-11-24642901

Email: info.india@popcouncil.org

Website: www.popcouncil.org

Suggested citation: Jejeebhoy. S. J. and R. Acharya. 2014. Adolescents in Rajasthan 2012: Changing Situation and Needs. New Delhi: Population Council. 


\section{ADOLESCENTS IN RAJASTHAN 2012: CHANGING SITUATION AND NEEDS}

Shireen J Jejeebhoy

Rajib Acharya

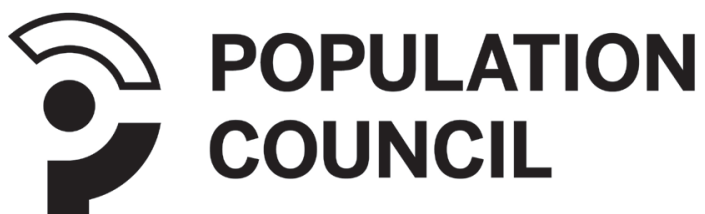

Ideas. Evidence. Impact. 


\section{Table of Contents}

List of Tables

List of Figures $\quad$ ix

Acknowledgements

Executive summary xiii

Chapter 1 Introduction 1

Chapter 2 Socio-demographic profile of adolescents 13

Chapter 3 Education 23

Chapter 4 Economic activity, skill acquisition and migration 37

Chapter 5 Media exposure, mobile phone use and access to pornographic materials 51

Chapter 6 Growing up 57

Chapter 7 Agency and gender role attitudes 70

Chapter 8 Awareness of sexual and reproductive health matters 86

Chapter 9 Romantic and sexual relationships 103

Chapter 10 Health and health-seeking behaviour 125

Chapter 11 Participation in civil society and political life 133

Chapter 12 Looking forward 144

$\begin{array}{lr}\text { References } & 149\end{array}$

$\begin{array}{lr}\text { Authors } & 153\end{array}$

$\begin{array}{lr}\text { List of investigators } & 154\end{array}$ 


\section{List of Tables}

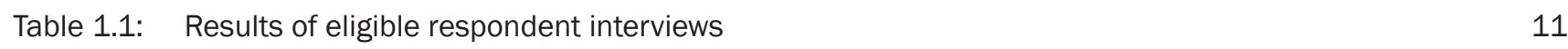

$\begin{array}{lll}\text { Table 2.1: } & \text { Housing characteristics } & 14\end{array}$

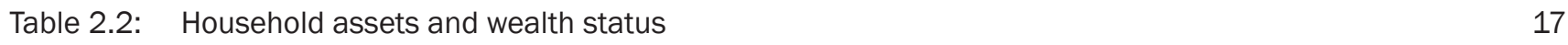

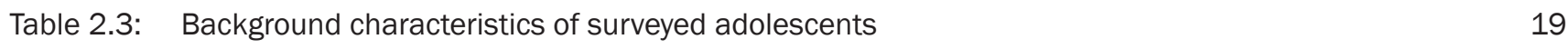

Table 2.4: $\quad$ Parental characteristics of surveyed adolescents 22

$\begin{array}{ll}\text { Table 3.1: } & \text { Educational attainment and current educational status } \\ \end{array}$

Table 3.2: Educational attainment of adolescents by selected background characteristics 25

Table 3.3: Reasons for school discontinuation by level of education 32

$\begin{array}{llr}\text { Table 4.1: } & \text { Economic activity } & 38\end{array}$

$\begin{array}{lll}\text { Table 4.2: } & \text { Employment seeking } & 40\end{array}$

Table 4.3: Employment seeking by selected background characteristics 41

$\begin{array}{ll}\text { Table 4.4: } & \text { Migration and mobility experiences }\end{array}$

Table 4.5: Participation in vocational training programmes 45

Table 4.6: Experience of exposure to vocational training 46

Table 4.7: Willingness of adolescents to participate in vocational training programmes 48

Table 5.1: Mass media exposure and mobile phone access 52

Table 5.2: $\quad$ Exposure to pornographic materials $\quad 55$

$\begin{array}{lll}\text { Table 6.1: } & \text { Perceptions of parental reactions to selected activities } & 58\end{array}$

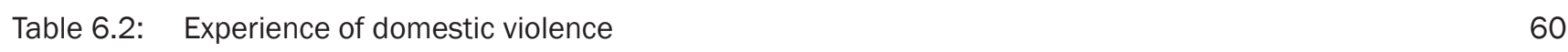

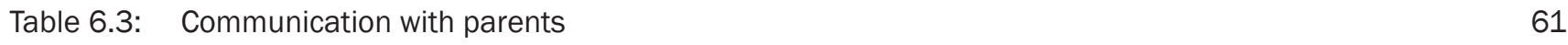

Table 6.4: Communication with parents about marriage-related plans and adolescents' involvement in marriage-related decisions $\quad 64$

$\begin{array}{ll}\text { Table 6.5: } & \text { Size of peer networks } \\ \end{array}$ 
Table 6.6: Leading confidante on personal matters

$\begin{array}{lll}\text { Table 7.1: } & \text { Decision-making } & 70\end{array}$

Table 7.2: Decision-making autonomy by selected background characteristics 72

$\begin{array}{lll}\text { Table 7.3: } & \text { Freedom of movement } & 74\end{array}$

Table 7.4: $\quad$ Freedom of movement by selected background characteristics 76

$\begin{array}{lll}\text { Table 7.5: } & \text { Access to money } & 79\end{array}$

$\begin{array}{lll}\text { Table 7.6: } & \text { Gender role attitudes } & 80\end{array}$

Table 7.7: $\quad$ Attitudes towards wife beating 83

Table 8.1: $\quad$ Awareness of sex- and pregnancy-related matters 87

Table 8.2: $\quad$ Awareness of sex- and pregnancy-related matters by selected background characteristics 88

Table 8.3: $\quad$ Awareness of contraceptive methods $\quad 89$

Table 8.4: Perceptions of selected issues related to condom use 92

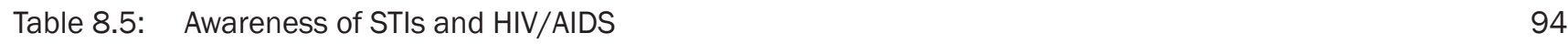

Table 8.6: Comprehensive knowledge of HIV/AIDS by selected background characteristics 96

Table 8.7: Knowledge of legal issues concerning age at marriage and sex selection 98

Table 8.8: Sources of information on sexual matters 99

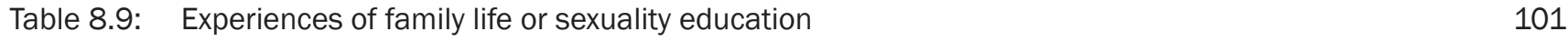

$\begin{array}{llr}\text { Table 9.1: } & \text { Romantic relationships } & 105\end{array}$

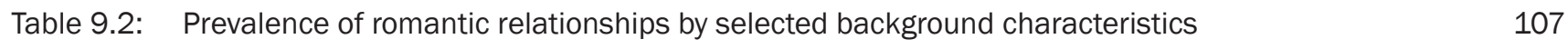

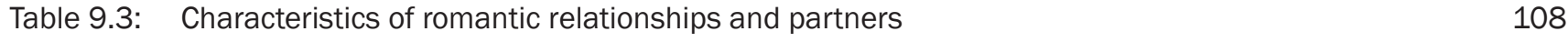

Table 9.4: Physical intimacy and sexual experiences in romantic relationships 110

Table 9.5: Characteristics of sexual experiences within romantic relationships 112

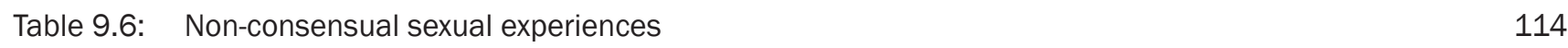

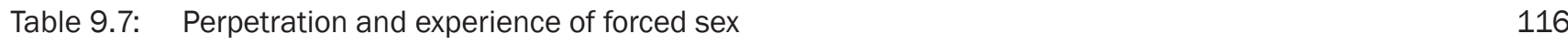


$\begin{array}{llr}\text { Table } 9.8 & \text { Overall sexual experience } & 118\end{array}$

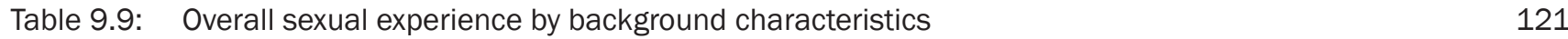

$\begin{array}{lr}\text { Table 9.10: Age at sexual initiation } & 122\end{array}$

Table 9.11: Sexual risk behaviours 123

$\begin{array}{lr}\text { Table 10.1: } & 125\end{array}$

$\begin{array}{ll}\text { Table 10.2: } & \text { Reported symptoms or behaviours suggestive of mental health disorders } \\ \end{array}$

$\begin{array}{lr}\text { Table 10.3: Self-reported sexual and reproductive health problems } & 129\end{array}$

Table 10.4: Care and/or advice-seeking by girls for reported health problems 130

Table 10.5: Hesitation to access contraceptive supplies 131

Table 11.1: Awareness of and access to government schemes to support education of adolescents 134

Table 11.2: Awareness of and access to government-sponsored adolescent leadership $\begin{array}{ll}\text { development programmes } & 135\end{array}$

Table 11.3: Awareness of and access to government-sponsored economic empowerment programmes $\begin{array}{ll}\text { for rural adolescents } & 136\end{array}$

Table 11.4: Awareness of and access to government-sponsored health services 137

$\begin{array}{lr}\text { Table 11.5: Participation in community-led programmes } & 138\end{array}$

Table 11.6: Participation in political activities and perceptions about political processes 139

Table 11.7: Physical fights in the village/neighbourhood 141 


\section{List of Figures}

Figure 3.1: Percentage of adolescents who were in school at ages 12 and 15, according to residence, Rajasthan, 2007 and 2012

Figure 3.2a: Cumulative percentage of adolescents who had completed each year of education (Classes 1 to 15), Rajasthan (Combined), 2007 and 2012

Figure 3.2b: Cumulative percentage of adolescents who had completed each year of education (Classes 1 to 15), Rajasthan (Urban), 2007 and 2012

Figure 3.2c: Cumulative percentage of adolescents who had completed each year of education (Classes 1 to 15), Rajasthan (Rural), 2007 and 2012

Figure 3.3a: Percentage of adolescent boys who had discontinued schooling by class when discontinued and reasons for discontinuation, Rajasthan, 2007 and 2012

Figure 3.3b: Percentage of adolescent girls who had discontinued schooling by class when discontinued and reasons for discontinuation, Rajasthan, 2007 and 2012

Figure 4.1a: Economic activity and schooling status at ages 12-19 among adolescent boys aged 15-19, by age, Rajasthan, 2007 and 2012

Figure 4.1b: Economic activity and schooling status at ages 12-19 among adolescent girls aged 15-19, by age, Rajasthan, 2007 and 2012

Figure 4.2: Percentage of adolescents who ever attended a vocational training programme and percentage who were interested in participating in such programmes, according to residence, Rajasthan, 2007 and 2012

Figure 5.1: Percentage of adolescents exposed to television, print media and the internet, according to residence, Rajasthan, 2007 and 2012

Figure 6.1: Percentage of adolescents reporting that their parents would disapprove if they brought same- and opposite-sex friends home, Rajasthan, 2007 and 2012

Figure 6.2a: Percentage of adolescents who discussed various matters with their fathers, according to residence, Rajasthan, 2007 and 2012

Figure 6.2b: Percentage of adolescents who discussed various matters with their mothers, according to residence, Rajasthan, 2007 and 2012

Figure 6.3: Percentage of adolescents reporting at least one opposite-sex friend, according to residence, Rajasthan, 2007 and 2012

Figure 7.1: Percent distribution of adolescents by participation in decision-making on spending money, Rajasthan, 2007 and 2012 
Figure 7.2: Percentage of adolescents allowed to visit selected places within and outside the village/neighbourhood unescorted, Rajasthan, 2007 and 2012

Figure 7.3: Percentage of adolescents who expressed egalitarian gender role attitudes on selected issues, Rajasthan, 2007 and 2012

Figure 7.4: Percentage of adolescents who believed that wife beating is not justified in selected situations, Rajasthan, 2007 and 2012

Figure 8.1: Percentage of adolescents reporting awareness of selected sex- and pregnancy-related matters, Rajasthan, 2007 and 2012

Figure 8.2: Percentage of adolescents who reported correct specific knowledge of oral pills, emergency contraceptive pills and condoms, Rajasthan, 2007 and 2012

Figure 8.3: Percentage of adolescents by awareness of HIV/AIDS, comprehensive knowledge about HIV/AIDS and awareness of STIs, Rajasthan, 2012

Figure 9.1: Percentage of adolescents who had made or received a "proposal" for forming a romantic partnership and percentage who had an opposite-sex romantic partner, Rajasthan, 2007 and 2012

Figure 9.2: Among adolescents reporting a romantic relationship, percentages who reported peer and parental awareness of their first romantic relationship, Rajasthan, 2007 and 2012

Figure 9.3: Percentage of adolescents reporting experiences of physical intimacy and sex with a romantic partner, Rajasthan, 2007 and 2012

Figure 9.4: Percentage of adolescents reporting any sexual experience (in face-to-face interviews or anonymously), according to residence, Rajasthan, 2007 and 2012

Figure 10.1: Percentage of adolescents reporting symptoms/behaviours suggestive of mental health disorders in the month preceding the interview, according to residence, Rajasthan, 2007 and 2012 


\section{Acknowledgements}

The Adolescents and Youth in Rajasthan 2012: Changing Situation and Needs study was supported by the John D. and Catherine T. MacArthur Foundation. We are grateful to the Foundation for their support, and to Dipa Nag Chowdhury for her suggestions and comments are various stages of the project.

In this report, we compare the situation of adolescents in Rajasthan in 2012 with that reported in 2007 in the Youth in India: Situation and Needs 2006-2007 study, supported by the John D. and Catherine T. MacArthur Foundation and the David and Lucile Packard Foundation, and conducted by the International Institute for Population Sciences, Mumbai, and the Population Council, New Delhi. We would like to acknowledge the valuable contributions of these organisations in making the earlier study possible.

The project has benefitted immeasurably from the inputs of many. We would like to thank our team of young investigators who painstakingly collected the survey and qualitative data, and our field coordinator, Binit Jha, for his dedicated supervision of research activities, his attention to detail, and his commitment to collecting quality data.

At the Population Council, several colleagues have supported us in both the technical and administrative aspects of this study and we acknowledge their huge contribution in making this study possible. We are grateful to Shilpi Rampal for her help in preparing tables and figures, M.A. Jose for ably managing the administrative aspects of the project, and Santosh Kumar Singh for support in monitoring fieldwork.

KG Santhya was responsible for conceptualising and developing the project, and offered valuable comments and suggestions in the course of the preparation of the report. We are deeply indebted to her for so generously sharing her ideas and for her guidance throughout the project.

We would like to thank Jyoti Moodbidri, our technical editor and Komal Saxena of the Population Council for their editorial contributions, which have made the report more readable and accurate. Additionally, Komal Saxena coordinated the printing of the report; we are grateful to her for her eye for perfection and her commitment to ensuring that the report was printed in a timely way. We also appreciate the efforts of Vikram Aditya, Systems Vision printers, who worked around the clock, made several rounds of revisions, and delivered the report to us in a timely manner.

Most of all, we would like to place on record our appreciation of all the adolescents who generously gave us their time and shared their views and experiences with us. We hope that the insights from and recommendations of this report will be useful to policy makers and programme managers to better address the needs of adolescents and youth in Rajasthan and in India, more generally, to make a successful transition to adulthood.

Shireen J. Jejeebhoy

Rajib Acharya 


\section{Executive summary}

Several national policies and programmes, formulated since 2000, have underscored India's commitment to addressing the multiple needs of youth. Recognising for the first time, that adolescents constitute an underserved group with special sexual and reproductive health needs, the National Population Policy 2000 advocates special programme attention to addressing this young population (Ministry of Health and Family Welfare, 2000). The National Youth Policies of 2003 and 2014 recognise adolescents as a special group requiring a different approach from that appropriate for young adults, and promote strategies to meet youth needs in areas including education, training and employment, health, recreation and sports, and good citizenship (Ministry of Youth Affairs and Sports, 2003; 2014). The Eleventh and Twelfth Five-Year Plans have also articulated the nation's commitment to meet the needs of young people (Planning Commission 2006, 2011). The Rashtriya Madhyamik Shiksha Abhiyan (RMSA), launched in 2009, aims to enhance secondary school education, physical access to secondary schools and the quality of secondary school education (http://mhrd.gov.in/rashtriya_madhyamik_ shiksha_abhiyan, accessed July 2014). The National Skill Development Policy 2009 aims to improve livelihood skills and has special relevance for young people (http://www.skilldevelopment.gov.in /sites/ default/files/resource/ NationalSkillDevelopmentPolicyMar09.pdf, accessed July 2014). The Adolescent Reproductive and Sexual Health strategy, launched in 2006, and the recent Rashtriya Kishor Swasthya Karyakram, launched in 2014, provide the the framework for services for young people's health in general, and their sexual and reproductive health, mental health, and prevention and care of non-communicable diseases, in particular (Ministry of Health and Family Welfare, 2006; 2014).

Until the mid-2000s, evidence was limited on the situation and needs of young people, and the extent to which national commitments had succeeded in addressing their needs. The Youth in India: Situation and Needs 2006-07 study implemented by the International Institute for Population Sciences, Mumbai, and the Population Council, New Delhi, was the first-ever sub-nationally representative study conducted to identify key transitions experienced by married and unmarried youth in India. The study was conducted in six states, including Rajasthan (International Institute for Population Sciences and Population Council, 2010). The study focused on married and unmarried young women and unmarried young men aged 15-24 and, because of the paucity of married young men in the younger ages, married men aged 15-29 in both rural and urban settings. The study collected information pertaining to key transitions experienced by youth, including those related to education, work participation, sexual activity, marriage, health and civic participation; the magnitude and patterns of young people's sexual and reproductive practices within and outside of marriage as well as related knowledge, decision-making and attitudes. Indeed, its evidence provided not only a blueprint for the programming needs of youth in the country but also a baseline by which to measure changes in the situation of young people over time, and in the course of social changes and programmes intended to address their needs (International Institute for Population Sciences and Population Council, 2010).

The goal of the Adolescents and Youth in Rajasthan 2012: Changing Situation and Needs study (hereafter referred to as the Adolescents and Youth in Rajasthan 2012 study), is to shed light on the situation and needs of adolescents and youth some five years following the earlier study. Youth in India: Situation and Needs, 2006-07 (hereafter referred to as the Youth in India study), and to establish trends in key markers of the transition to young adulthood, and changes over time in the life of young people. The Adolescents and Youth in Rajasthan 2012 study comprised two components, a panel and a cross-sectional design. The study had two specific objectives: (a) to follow up a significant subsample of young people who participated in the Youth in India study and provide a truly longitudinal view of the process of moving from adolescence to adulthood; and (b) to establish levels of key markers of the life of adolescents aged 15-19 and their transitions to adulthood and assess, using successive cross-sectional data at two points in time during which a number of programmes have been implemented to address adolescents' needs, the extent to which the situation of successive cross-sections of adolescents has changed over time. The study was conducted in the same sites as in the 2007 survey, offering an opportunity to assess changes in the situation of adolescents over a five-year period. Unfortunately, due to logistical challenges, maps, questionnaires and consent forms were preserved only for respondents in one-half of all of the 2007 locations, and our study therefore drew its samples from these primary sampling units (PSUs); reanalysis of 2007 data for 15-19 year-olds residing in these PSUs compared with those residing in PSUs that were not included in the 2012 survey suggests that the situation of girls and boys in the selected PSUs was virtually identical to that of their counterparts in PSUs that were not included. 
In this report, we focus on the second objective, that is, the situation of 15-19 year-old unmarried adolescents in 2012, and compare them with the situation of similarly aged adolescents five years earlier. The survey was undertaken between February and November 2012, and comprised a survey of a total of 1,908 unmarried adolescent girls and boys aged 15-19.

\section{Characteristics of the household population}

Housing characteristics of the surveyed population of adolescents aged 15-19 underscore poor living conditions among the majority of the state's population at both times, that is, in 2007 and 2012. Overall, about one-fifth of adolescents lived in kachcha houses (19\%) constructed from mud, thatch or other low-quality materials; another one-fifth (19\%) lived in semi-pucca houses (constructed using a mix of low- and high-quality materials) and the large majority, 62 percent lived in pucca houses (constructed entirely from cement, masonry or other high-quality materials, similar to what was reported in the 2007 survey (65\%).

As many as 91 percent of adolescents' households had electricity in 2012, significantly more than in 2007 when just 75 percent of households had electricity, attributable mainly to rural electrification during the inter-survey period: by 2012, 87 percent of rural households had electricity, up from 67 percent in 2007; 97-99 percent of urban households had electricity. For the majority of households in $2012(86 \%)$, the main source of drinking water was either piped water, water obtained from a hand-pump or a covered well, about the same as that reported in 2007 (89\%). These facilities were reported as self-owned by 49 percent of all adolescents in 2012, compared to 44 percent in 2007. Access to a toilet facility of any kind was reported by a few -just 45 percent of adolescents in 2012, compared to 37 percent in 2007. Finally, distributions of adolescents' households by type of fuel used for cooking suggest a significant change between 2007 and 2012. The main source of cooking fuel was coal, charcoal, wood, crop residue or dung cakes, reported by 69 percent of adolescents in 2012, compared to 79 percent in 2007. A notable increase in the use of liquid petroleum gas was reported: from 64 percent to 76 percent in urban areas, and from four percent to nine percent in rural areas.

The distribution of households by wealth quintiles shows a stark rural-urban divide: 41 percent of urban adolescents resided in households in the wealthiest (fifth) quintile; in contrast, just 10 percent of rural adolescents resided in households in this quintile. Conversely, more than one-quarter of adolescents from rural households (27\%) were in the poorest (first) quintile of the index compared to only five percent of adolescents from urban households. Overall, change over time in wealth status was mild in rural areas, although urban households appear to be significantly more likely to fall into the first quintile in 2012 than in 2007.

\section{Situation of adolescents}

A total of 745 unmarried boys and 1,164 unmarried girls were interviewed in 2012, compared to 774 and 1,487, respectively, in 2007. Age profiles suggest that a larger proportion of boys was concentrated in the three ages 15-17 than in the two ages 18-19 (68\% versus 32\%) with little change over time. Girls, in contrast, were disproportionately concentrated in the younger age group at both times (75\% and 80\% in 2012 and 2007, respectively). The distribution of adolescents by religion was fairly identical at both points in time. In 2012, 94 percent of adolescent boys were Hindu, five percent were Muslim and one percent belonged to other religions (compared to 93\%, 5\% and $2 \%$, respectively, in 2007). Among adolescent girls, distributions were also similar at both times; 82 percent were Hindu, 14 percent were Muslim, and four percent belonged to other religions (compared to $83 \%, 13 \%$ and 4\%, respectively, in 2007). Caste distributions in 2012 show that the majority (43-45\%) fell into other backward castes, 20-23 percent into scheduled castes, 11-15 percent into scheduled tribes and 17-24 percent into general castes. Caste distributions were similar in 2007 as well.

For over 90 percent of adolescents at both times, both parents were surviving (90\% in 2007 and 92\% in 2012). For those with just one parent surviving, this parent was more likely to be the mother ( $5-7 \%$ at both times) than the father (2-3\%).

\section{Education}

While attainment of a high school education was far from universal among surveyed boys and girls in Rajasthan even in 2012, considerable improvements were observed in school enrolment rates, educational attainment rates 
and schooling status of surveyed adolescents at the time of the interview in 2012 compared to 2007. Almost all adolescents had been to school in 2012. Indeed, just two percent of boys and eight percent of girls had never been enrolled in school, considerably fewer than in 2007 (8\% and 20\%). While rural-urban differences narrowed in 2012 compared to 2007, more girls in rural than urban areas had never been to school among those aged 15-19 in 2012 (11\% versus $3 \%)$.

By 2012, school completion rates were near universal for both boys and girls up to Class 7 , that is, the final year of primary school at the time the survey was undertaken. Thereafter, a steep decline in was observed among both boys and girls between Classes 8 and 12, during which completion rates declined by 15 to 24 points per year among boys, and by 14 to 25 points per year among girls. Patterns were, by and large, similar for the 2007 and 2012 cohorts; however, more boys and girls from the 2012 cohort had completed each class from Class 8 to 12 than had their counterparts from the cohort of 2007. Gender differences were milder in 2012 than in 2007. However, while the rural disadvantage was relatively mild for boys in 2012, it remained substantial for girls, among whom rural-urban differences were wide after Class 7. Changes over time among urban adolescents were negligible for the most part; however, among rural adolescents, between 2007 and 2012, considerable increases in completion rates were observed among both boys and girls in Classes 8 to 12.

While gender disparities persisted, striking increases were observed in percentages of adolescents who had completed high school; from 38 percent to 53 percent of boys, and from 22 percent to 39 percent of girls between 2007 and 2012. Even though increases were observed in percentages of adolescents in school at the time of the interview between 2007 and 2012, gender disparities persisted: almost four in five boys compared to just three in five girls were still in school or college.

Among those who had ever been to school, several reasons were offered for discontinuation, and patterns differed somewhat by sex of the respondent and level at which schooling was discontinued. Among boys who had discontinued their education in Classes 1-6, for over one-half, reasons for discontinuation related to attitudes and perceptions, and largely lack of interest in studies; many fewer cited economic or school-related reasons. Among girls, leading reasons were both attitude- and perception-related (lack of interest in studies, as well as safety concerns and perceptions that education was unnecessary for girls) as well as housework-related. Significant changes since 2007 included a decline in percentages of boys reporting economic and housework reasons; among girls, changes were not significant, however, we note that somewhat smaller percentages of girls reported housework-related reasons in 2012 than in 2007.

In contrast, among those who had discontinued their education in Classes 7-9, attitude- and perception-related reasons continued to dominate reasons for school discontinuation among boys, cited by one-half of all boys; 43 percent had specifically cited lack of interest in studies. Economic reasons and school-related reasons were cited by over one-quarter each, notably academic failure was cited by as many as one-quarter. For girls, the leading issues were attitude or perception-related factors as well as school-related factors, although about one-sixth reported economic reasons (largely the household's inability to cover the cost of their education) and one-fifth cited housework responsibilities. Among respondents who discontinued their education before Class 7 , significant changes observed since 2007 among boys reflected a decline in percentages reporting economic and housework reasons; and among girls, an increase in percentages reporting safety concerns, and a decline in percentages reporting failure as a reason for discontinuation.

Gender disparities in reasons for discontinuation were evident. Lack of interest in studies was considerably more likely to have been cited as a reason for school discontinuation among boys than girls, irrespective of the level at which discontinuation took place; among those who discontinued their education in Classes 7-9, academic failure was far more likely to have been indicated by boys, and distance to school by girls. Housework responsibilities were more likely to have been cited by girls than boys at each level. While economic reasons were, on the whole, more likely to have been cited by boys than girls, specific economic reasons varied: wage labour was more likely to be cited by boys than girls, and parental inability to afford the cost of their education more likely to have been cited by girls than boys.

\section{Work}

Paid work participation in the 12 months prior to the interview resembles lifetime work profiles. About one-quarter of surveyed boys (27\%) and girls (26\%) had at some time engaged in paid work, largely similar to the paid work 
reported in 2007 (26\% and 21\%, respectively). While rural-urban differences were not observed among boys in 2012 (26\%-29\%), somewhat fewer urban than rural girls had been engaged in paid work (22\% versus 28\%). Paid work was initiated in childhood or early adolescence, that is, before age 15, for about one in ten adolescents-more girls than boys in 2012 (12\% versus 6\%), and largely similar to percentages reported in 2007 . What had changed dramatically was the time spent in wage work among adolescents who were so engaged in the year preceding the interview. Working adolescents were significantly less likely in 2012 than in 2007 to have worked for the most part of the year: 47 percent and 23 percent of boys and girls, respectively, had worked for most of the year, compared to 83 percent and 59 percent, respectively, in 2007. In contrast, about one-tenth of boys (11\%) and fewer girls (6\%) were seeking employment at the time of the interview, compared to $9 \%$ and $4 \%$ in 2007 ).

Occupational distributions of those engaged in remunerated work in the 12 months preceding the interview suggest considerable gender disparities. Among boys, most were engaged in unskilled non-agricultural labour (63\%), and skilled manual work (24\%), and even in rural areas, very few were engaged in agriculture (5\%); this distribution was almost identical to the situation in 2007. Among girls in contrast, the leading occupation was agricultural labour (47\%), followed by skilled manual work (22\%) and unskilled non-agricultural labour (20\%).

\section{Migration and mobility}

Most surveyed adolescents, that is, 84 percent of boys and 89 percent of girls, resided in their place of birth in 2012, with slightly more rural than urban adolescents so reporting. More boys than girls reported that migration had taken place in the five years preceding the interview (11\% versus 5\%), and most of those who reported migration had migrated with their parents. With regard to adolescents' work- or education-related mobility, that is, residence outside of their village or urban area for work or education in the 12 months preceding the interview, ten percent of boys and two percent of girls had lived away from their home setting in the 12 months preceding the interview.

\section{Exposure to and preferences for vocational skill training}

Relatively few adolescents had undergone any vocational training even in 2012, but while percentages of boys who had done so had increased since 2007 (from 8\% to 15\%), the corresponding percentages of girls remained similar to those in 2007 (23\% and 21\%, respectively). Urban adolescents were more likely to have received training than their rural counterparts. The pattern of training programmes to which adolescents were exposed in 2012 was quite different from that observed in 2007, and gender and rural-urban differences were apparent. Among boys, training had increasingly focused on computer skills, and declined for all other skills for which programmes were offered. Among girls, there was a shift away from traditional (tailoring, handicrafts) to more modern skills (computer skills), although the former continued to dominate.

The characteristics of adolescents who received training suggest that they were, on average, aged 15-16 years when they joined a vocational training programme, with girls a year younger than boys (15 versus 16). Just over one-half (55-56\%) of those who had taken a vocational course reported completing it, just one-third of boys (33\%) and one-fifth of girls (18\%) reported having received a certificate for the course, and even fewer-four percent of boys and 17 percent of girls had earned money from the skill they had acquired through the course in the 12 months preceding the interview.

Adolescents in our survey were clearly interested in acquiring skills that would connect them to jobs; three-fifths of boys and four-fifths of girls reported interest in vocational skills training. The kinds of training that adolescents wished to take had changed considerably over the five-year period, suggesting a shift towards more modern skills. For example, boys continued to express interest in engaging in training on computer skills and auto mechanics or electrical work. Preferences of girls have also shifted away from traditional (tailoring and handicrafts) to more modern skills, such as computer use.

\section{Mobile phone access and media exposure}

Findings suggest that almost all surveyed adolescents had access to mobile phones by 2012 . Indeed, as many as 93 percent of boys and 89 percent of girls reported that they either owned a mobile phone or could use a mobile phone owned by someone in their family. While rural-urban differences were negligible for boys, fewer rural than urban girls reported access to a mobile phone (86\% versus 95\%). 
With regard to mass media exposure, large proportions of all surveyed adolescents in Rajasthan were exposed to television (88-90\%), and, among adolescents with five or more years of education, to newspapers, magazines and/or books ( $91 \%$ of boys and $82 \%$ of girls). Exposure to the internet, among those with five or more years of education, was reported by considerably fewer adolescents (37\% of boys and $11 \%$ of girls). At the same time, significant increases were observed in exposure to all three media for both girls and boys between 2007 and 2012. Most notably, internet access increased from five percent to 37 percent among boys and from four percent to 11 percent among girls. Gender differences were apparent, with boys typically more likely to be exposed to television, newspapers, magazines and/or books than girls. Rural-urban differences persisted, with urban adolescents more likely to report frequent exposure to television and print media, and far more likely to have been exposed to the internet than their rural counterparts.

Findings also suggest that 48 percent of all boys and eight percent of girls had watched pornographic films, and 22 percent of boys and seven percent of girls had accessed pornographic books and magazines. Differences by ruralurban residence were apparent in 2012 for boys, with 48 percent and 36 percent of those in urban and rural areas, respectively, reporting exposure to pornographic materials on the internet; a similar comparison is not possible for girls because of small numbers of rural girls who had accessed the internet.

\section{Socialisation experiences and communication with parents}

The Adolescents and Youth in Rajasthan 2012 study findings suggest that parents controlled both boys' and girls' social interactions, particularly those involving members of the opposite sex. For example, over 90 percent of surveyed adolescents expected parental disapproval if they had a love marriage, and 66-89 percent of boys and 82-88 percent of girls expected parental disapproval if they brought an opposite-sex friend home, talked to a person of the opposite-sex who did not belong to the family, or went to a mela or film with an opposite-sex individual. Notably, while changes over time were, by and large, insignificant among boys, percentages of girls perceiving parental disapproval about activities relating to boys had increased significantly between 2007 and 2012 . In contrast, girls were significantly less likely in 2012 than in 2007 to report that their parents would disapprove of their joining a club or mandal, or taking a job. In both surveys, rural adolescents were considerably more likely than their urban counterparts to expect parental disapproval for activities relating to the opposite-sex.

Young people's family lives were marked by violence, both experienced and witnessed. About one in ten boys and one in six girls had observed their father beating their mother. Many respondents reported experiencing a beating by a parent during adolescence; one-fifth of boys and one-sixth of girls reported such experiences, representing a significant decline from 2007 among boys and a significant increase among girls, and with urban boys and girls somewhat more likely than their rural counterparts to so report.

Findings regarding communication of surveyed adolescents with their parents on issues relevant to adolescentssuch as school performance, friendships, being teased or bullied, romantic relationships and reproductive processes-reiterate that such communication was far from universal at both times. Indeed, sensitive topics, such as romantic relationships, reproduction and contraception were rarely discussed with either parent. However, on non-sensitive issues such as school performance and friendships, communication with mothers and fathers had increased significantly among both boys and girls, suggesting some increase in overall communication between parents and children over the five-year period. While girls were significantly more likely to have discussed romantic relationships with their father and mother in 2012 compared to 2007, we note that percentages were, overall, small at both times.

That parent-child communication was restricted was also evident from responses to questions probing the most likely confidante on one non-sensitive topic, that is, taking a job, and one sensitive topic, that is, boy-girl relationships.

Parents, particularly fathers, were mentioned as leading confidantes on the topic of taking a job, but were rarely cited as leading confidantes on the more sensitive matter of boy-girl relationships. Notably, far fewer adolescents in 2012 than 2007 reported that they had no one in whom to confide on these two matters.

\section{Marriage-related planning}

Marriage-related planning had already commenced for more than two in five girls and one in six boys; in rural areas, almost one-half of all girls and one-fifth of all boys so reported in 2012. Findings confirm that marriage-related planning started early, particularly among girls: for example, 22 percent of girls compared to nine percent of boys 
reported that such planning had begun before they attained age 15. More than one-half of all girls and boys for whom marriage-related planning was in progress, reported that at least one potential spouse had been proposed for them, and one-third of all girls and one-quarter of all boys reported that three or more potential spouses had already been proposed for them.

As many as 15 percent of girls and four percent of boys-somewhat more rural than urban-were already engaged to be married or reported that their marriage had already been fixed. For well over 90 percent of these adolescents, the choice of the partner was made by the parents and excluded the adolescent.

\section{Peer networks and interaction}

Growing up was associated with close peer networks, especially among boys. For example, while almost all surveyed boys reported having some close same-sex friends, almost one-fifth of the surveyed girls reported having no close friends. In 2012, girls reported an average of one close same-sex friend, down from two in 2007; boys reported an average of two in both 2012 and 2007. That same-sex peer networks were wider among boys than girls is evident from the finding that 15 percent of boys had five or more friends, compared to just two percent of girls. Opposite-sex peer networks were less common but reported by about one-quarter of boys and girls, reflecting significant increases over the 2007 to 2012 period (from 15\% to 27\% among boys, and from 11\% to 23\% among girls). Indeed, findings suggest that adolescents derived an important measure of support from their peer networks on personal matters: friends were, by far, the leading confidante on boy-girl relationships for both boys and girls.

\section{Agency}

Findings clearly highlight girls' limited agency, but suggest that there has indeed been an increase in agency between cohorts in 2007 and 2012. For example, while, in 2007, just one-third of girls reported making independent decisions on spending money that they had, this percentage had increased to almost three-fifths by 2012 . Likewise, freedom of movement even within the village or neighbourhood was not universal among girls, and in this case, the increase between 2007 and 2012 was moderate; while 79-82 percent of girls had the freedom to visit a shop or a friend within their own village or neighbourhood unescorted in 2012, 71-78 percent had so reported in 2007. Likewise, percentages permitted to visit a health centre in the village or neighbourhood unescorted increased from 17 percent to 31 percent. Overall, while just 16 percent of girls had been permitted to visit all three locations within the village unescorted in 2007, this percentage had increased to 31 by 2012 . Freedom to visit a friend or relative outside the village or neighbourhood unescorted was particularly restricted for girls; just 23 percent reported such freedom of movement, just slightly more than did so in 2007 (19\%). Access to and control over financial resources had increased considerably; while still far from universal, by 2012, improvements over 2007 were apparent: by 2012, more than two in five reported some savings, more than one-quarter owned a bank or post office savings account, and of these, more than one-half operated it themselves.

While boys were not as disadvantaged as girls, findings indicate that many boys were also not able to exercise agency in their everyday lives. For example, only 79 percent of boys reported independent decision-making. Boys had considerable freedom of movement, yet 22 percent were not permitted to visit a friend or relative outside their village or neighbourhood unescorted. Compared to the experience of girls, changes in agency between 2007 and 2012 were not pronounced among boys. Access to and control over financial resources among boys suggest that by 2012, one-fifth of boys reported some savings, more than one-quarter owned a bank or post office savings account, and of these, four in five operated it themselves.

Indeed, there continues to be a striking gender divide in the various dimensions of adolescents' agency explored in the survey. For example, even the least educated boys were more likely than the most educated girls to have made money-related decisions independently, and boys belonging to the poorest wealth quintile were almost as likely as girls in the wealthiest quintile to so report. Likewise, although girls were more likely than boys to have money saved (42\% and $21 \%$, respectively), they were as likely as boys to own a bank or post office savings account (27\%), and less likely than them to operate these accounts themselves (56\% versus $80 \%$ of those who had an account).

\section{Gender role attitudes}

Gender role attitudes had become more egalitarian among both boys and girls, although many adolescents, particularly boys, continue to express inegalitarian attitudes. Indeed, even the perception that educating boys is no

xviii 
more important than educating girls was not universally expressed by 2012, although increases since 2007 were apparent (87\% versus 66\% among boys; 92\% versus $80 \%$ among girls). Just 56-61 percent believed that there is nothing wrong in a girl having male friends. On many attitude indicators however, girls were more likely than boys to express egalitarian attitudes: for example, 77 percent of girls compared to 55 percent of boys disagreed that only the husband should decide about how to spend money, and 39 percent compared to 16 percent, respectively, believed that a woman should obtain her husband's permission for most things.

Attitudes towards wife beating highlight that boys are far more likely than girls to justify violence against women and girls, and that shifts towards more egalitarian attitudes towards violence are far more spectacular among girls than among boys. About two in five boys and three-quarters of girls rejected the notion that wife beating is justifiable in a variety of situations ranging from if a woman disagrees with her husband's opinion to if a husband suspects his wife of being unfaithful. While significantly more girls in 2012 than 2007 rejected the acceptability of wife beating, shifts among boys were observed only among those in urban areas.

\section{Awareness of sexual and reproductive health matters}

Even in 2012, awareness levels among surveyed adolescents about various sexual and reproductive matters-how pregnancy occurs, contraception, HIV and safe sex practices, and abortion-related matters-were mixed. At the same time, impressive increases in awareness had taken place over time among successive cohorts of adolescents.

In 2012, for example, fewer than one-half of boys and girls were aware that a woman can get pregnant at first sex (46\%) or that they are most likely to become pregnant mid-cycle (51\% of boys; $28 \%$ of girls), yet $83-84$ percent were aware that it is possible to detect the sex of the foetus; overall, just 38 percent of boys and 29 percent of girls were aware of all three sex- and pregnancy-related matters. While the vast majority of adolescents had heard of at least one modern contraceptive method (90-93\%), girls were typically less well informed than boys about particular methods well suited to adolescents (condoms and emergency contraception, for example), and correct specific awareness of even one method (out of condoms, oral contraceptive pills, emergency contraceptive pills) was reported by 79 percent of boys, and far fewer, 37 percent of girls, and even among those aware of condoms, misperceptions about its use were widespread, particularly among girls. Awareness of STIs was particularly limited, and again, girls fared far worse than boys: just 30 percent of boys and 15 percent of girls had heard of diseases spread through sexual contact (aside from HIV/AIDS) and just 22 percent and five percent could also name at least one such infection. While larger proportions of adolescents had heard about HIV/AIDS, comprehensive awareness was reported by fewer and gender differences were wide, with girls faring far worse than boys $(62 \%$ versus $88 \%$ had heard about HIV/AIDS; 45\% versus 70\% had comprehensive awareness).

A key issue of relevance to adolescents, namely knowledge about the legal minimum age at marriage was also not universal: 90-93 percent of boys and 78-85 percent of girls were aware that 21 and 18 are the legal minimum age at marriage for boys and girls, respectively. Boys were also more aware than girls that sex selection is not a legal ground for pregnancy termination: 90 percent of boys and 72 percent of girls were aware that sex-selective abortion is illegal. Findings of considerable gender differences in awareness of the law as well as in comprehensive awareness about sex and pregnancy, contraception and HIV/AIDS raise concern about the vulnerability of girls, in particular.

At the same time, impressive increases had taken place in awareness levels of surveyed adolescents between 2007 and 2012. For example, correct knowledge of sex- and pregnancy-related matters increased from just 4-5 percent of boys and girls in 2007 to 38 percent among boys and 29 percent among girls by 2012. In-depth awareness about various contraceptive methods had also increased impressively: in-depth awareness of emergency contraception increased from 1-2 percent in 2007 to 42 percent among boys and 24 percent among girls; in-depth awareness of oral contraceptive pills increased from 17 percent to 40 percent among boys, but no such change was observed among girls, and conversely, in-depth awareness of condoms increased from 21 percent to 30 percent among girls but did not change much among boys. Likewise, improvements were observed in awareness of the legal minimum age at marriage for males and females, and the fact that sex-selective abortion is not legally permitted.

\section{Exposure to sexuality education}

By 2012, almost all surveyed boys and girls had received information on sex and reproduction from various sources; indeed, unlike in 2007 when one-third of boys and three-fifths of girls had reported that they had never received 
any information on sexual matters, by 2012, 95 percent of both had received such information from one or more sources. As in 2007 , such less reliable sources of information as friends and relatives, and the media were reported by large proportions of boys ( $82 \%$ and $56 \%$, respectively) and girls ( $54 \%$ and $62 \%$, respectively) in 2012 . Notably, while girls were far more likely in 2012 than in 2007 to obtain information from a family member (50\% compared to $4 \%$ ), hardly any boys, at both times, reported receiving information from a family member (1\% at both times). Notwithstanding the government's Adolescent Reproductive and Sexual Health programme, just five percent of surveyed boys and one percent of surveyed girls obtained information from a health care provider, or from healthrelated messages displayed on billboards and posters (4-8\%).

One of the most significant findings with regard to sources of information about sexual matters is the huge increase between 2007 and 2012 in percentages of adolescents who reported that they had obtained their information from teachers and schools: from 37 percent to 82 percent among boys, and from seven percent to 54 percent among girls. Corresponding with this huge increase, there has been a considerable increase in percentages of adolescents reporting exposure to family life or sexuality education: from one percent to 62 percent among boys, and from four percent to 50 percent among girls. Almost all (99\%) of those who received such education had done so in the school or college setting rather than through special programmes sponsored by the government or NGOs. In 2012, the majority of adolescents who had received sexuality education reported having received it for the first time at ages 13-14 (56\% and 51\% of boys and girls), corresponding to the age at which adolescents are in Class 9 , that is, when the first year of the Adolescence Education Programme is delivered. Gender differences were apparent with regard to the topics covered. For example, topics related to HIV transmission and prevention were reported by almost all boys who received such education, compared to about three-quarters of girls. Pregnancy-related information and information about boy-girl relationships was imparted to more than one-half of all boys, compared to two-fifths and one-quarter of girls, respectively. Physical maturation issues-menstruation for girls and nocturnal emission for boyswere, in contrast, far more likely to have been imparted to girls than to boys (84\% versus $19 \%)$. The limited quality of the programmes to which surveyed adolescents had been exposed is evident from findings suggesting that just 15-18 percent of adolescents who attended these programmes had received information about all key topics about which we probed (physical maturation, boy-girl relationships, pregnancy and HIV/AIDS).

\section{Pre-marital romantic relations}

Findings confirm that despite strict norms prohibiting opposite-sex mixing among the unmarried, opportunities do exist for the formation of romantic relationships among them; indeed, not only had the experience of romantic relationships increased over the five years for both surveyed boys and girls, but gender differences had considerably narrowed. For example, 23 percent of boys and 38 percent of girls had made or received a "proposal" for a romantic relationship, and about one-fifth of both boys and girls had reported that they had been involved in a romantic partnership. Reports of engaging in a romantic relationship increased considerably over 2007, when just 7-8 percent of boys and girls had reported a romantic relationship. Patterns of romantic partnerships suggest that where partnerships occurred, they were initiated at an early age, typically around age 15, and were usually hidden from parents but not from peers, and patterns in 2012 resembled those observed in 2007 for both boys and girls.

Findings confirm that at both times, romantic relationships among surveyed adolescents almost always included some form of physical intimacy. They also confirm that there has been a systematic increase in sexual relations among adolescents in a romantic relationship over the five-year period between 2007 and 2012. There was a clear progression in reported physical intimacy and sexual experience with romantic partners at both times: in 2012, while 86 percent of boys had held hands with a romantic partner, 51 percent had experienced sex with their partner; among girls, while three-quarters had held hands with a romantic partner, two in five (41\%) had engaged in sexual relations. While boys continued to be more likely than girls to report sex with a romantic partner, gender differences had narrowed considerably-from 45 percent versus 16 percent in 2007 to 53 percent versus 41 percent in 2012. This narrowing may suggest both that more boys and girls were engaging in sexual relations with romantic partners closer in age to themselves, and that adolescents, notably girls, may have become more likely than earlier to report reliably about the activities in which they engaged with their romantic partners.

\section{Pre-marital sexual experiences in romantic and other relationships}

Sexual experience was reported by considerably larger proportions of surveyed boys and girls in 2012 than in 2007. In total, in 2012, in face-to-face and anonymous reporting, 15 percent of boys and nine percent of girls reported 
sexual experiences within romantic and/or other partnerships, up from six percent and two percent, respectively, in 2007. Early sexual initiation was also evident: 19 percent of boys and 13 percent of girls had initiated first sex before age 18 , compared to six percent and two percent, respectively, in 2007. As in 2007, however, adolescents in rural areas tended to initiate sexual activity earlier than their urban counterparts.

While sex with a romantic partner characterised experiences for many of the sexually experienced respondents, findings suggest that boys, but not girls, also engaged in sex in other contexts; other partners reported by boys included, mainly, casual partners, sex workers and married women (1-2\% each). Many of the sexual experiences reported by adolescents were risky, for example, 37 percent of boys and nine percent of girls who reported engaging in sex, had experienced sex with more than one partner, and 22 percent and five percent, respectively, reported more than one sexual partner in the 12 months preceding the interview. Moreover, consistent condom use was limited-only 21-22 percent of boys and girls reported condom use in all sexual encounters.

The vast majority of surveyed adolescents who had engaged in sexual relations with a romantic partner had engaged in unprotected sex. Contraceptive use in a romantic relationship remained limited, although there are indications of increases over time. In 2012, more girls than boys reported contraceptive use at first sex with a romantic partner (37\% versus 29\%); consistent condom use was reported by far fewer adolescents (21-22\% of boys and girls).

\section{Non-consensual sexual experiences}

Verbal harassment, unwanted sexual touch and even forced sex had been experienced by considerable proportions of surveyed girls and perpetrated by considerable proportions of surveyed boys in 2012, compared to corresponding proportions in 2007. For example, in 2012, verbal harassment was experienced by 59 percent of all girls and perpetrated by 27 percent of all boys; in 2007, 12\% and 14\%, respectively, had so experienced. Non-consensual sexual touch was experienced by nine percent of girls and perpetrated by some four percent of boys.

Almost two-thirds of girls who had a boyfriend reported that their first sexual experience with their boyfriend was forced by the boyfriend, a huge increase from the one in six girls who had so experienced sex in 2007. At the same time, in face-to-face and anonymous reporting, nine percent of all girls reported the experience of forced sex by any male, including their boyfriend, and seven percent of boys reported perpetrating it on a girl, including their girlfriend.

\section{Substance use}

Findings show that about one-quarter of surveyed boys and about one in eight girls reported the consumption of tobacco, seven percent of boys and hardly any girls had consumed alcohol, and hardly any adolescents had used drugs, in 2012. Tobacco consumption in the recent past was reported, moreover, by almost all adolescents who reported ever having consumed tobacco products, and had increased significantly over time among both boys and girls.

\section{Health-seeking behaviour}

Although adolescence is a generally healthy period of life, significant minorities reported experiencing symptoms suggestive of mental and sexual and reproductive health problems in the period preceding the interview. With regard to mental health for example, seven percent of boys and 12 percent of girls reported symptoms suggestive of mental health disorders in the month prior to the interview (reported three or more problems in the GHQ-12). Among all boys, as well as those residing in rural and urban areas, percentages were remarkably similar over the five-year period. Among girls, in contrast, there was a significant decline in reporting of symptoms over time (from $17 \%$ to $12 \%)$, and those in rural areas remained slightly more likely than their urban counterparts to report scores indicative of mental disorders (13\% versus $10 \%)$.

With regard to sexual and reproductive health problems, that is, symptoms of genital infection and, among girls, menstrual problems, in the three months prior to the interview, eight percent of boys and 13 percent of girls reported the experience of symptoms of genital infection, and four percent of girls reported menstrual problems. A significant increase was observed over time among both boys and girls in reported symptoms of genital infection; percentages of girls reporting menstrual problems were, in contrast, identical both in 2007 and in 2012. HIV testing was rarely undertaken by both girls and boys at both times (0-2\%). 
Care and/or advice seeking among those reporting sexual and reproductive health problems was far from universal. For example, among the small number of boys reporting a problem, just 54 percent of those who had experienced symptoms of genital infection had sought care. Among girls who had experienced one or more symptoms of genital infection or a menstrual problem, only about one-quarter (27\%) had done so. Leading sources of treatment among girls who had experienced such problems in 2012 were a public (33\%) or private (39\%) sector facility or provider.

Findings suggest that adolescents were shy about seeking sexual and reproductive health services. For example, many adolescents, girls (61\%) and boys (56\%) alike, reported that they would indeed hesitate to approach a health care provider or a pharmacy/medical shop for contraceptive supplies. There was no evidence that levels of discomfort had reduced over time; on the contrary, in urban areas, significantly more adolescent girls reported discomfort in 2012 than in 2007.

\section{Awareness and use of various government programmes}

While a number of programmes and schemes are available that provide scholarships and conditional cash transfers to enable adolescents to pursue their education; build leadership and life skills; enable adolescents to access health information, services and supplies; and provide employment and economic empowerment opportunities, surveyed adolescents were aware of just a few, and had benefitted from even fewer. Specifically, awareness of programmes and schemes varied considerably, from about 90 percent or more reporting awareness of scholarship schemes and the MNREGA employment guarantee scheme, to less than 20 percent reporting awareness about NYKS Youth Clubs. At the same time, very few adolescents availed of the benefits and services offered by these schemes. Indeed, while 55-72 percent of adolescents reported that a family member had benefitted from the employment generation scheme, just 24-30 percent of adolescents had availed of scholarships; five percent and three percent, respectively, of girls had availed of the services of ASHAs and had received sanitary napkins distributed by the government; and one percent or fewer had been members of SABLA (or KSY) clubs or SHGs.

\section{Participation in civil society and political life}

Findings highlight the limited participation of surveyed adolescents in civil society. Although a number of programmes are organised by the government or NGOs at the community level in which adolescents can participate, just about one-third (32\%) of boys and one-fifth (20\%) of girls reported participating in such programmes. Most of these adolescents (62-80\%) participated in the celebration of national days, with fewer than ten percent reporting participation in other events, such as cleanliness drives, health promotion activities, celebrations of festivals and so on.

Few surveyed adolescents had participated in political activities: fewer than one percent were members of a political party, and almost one-quarter of boys, but hardly any girls (3\%) had participated in a political rally or protest. Considerable proportions of adolescents reported disillusionment with the political process. More specifically, 56 percent of boys and 66 percent of girls agreed that there would be no improvement in their village/neighbourhood irrespective of the political party governing the state. Disillusionment had increased among girls but remained about the same as in 2007 among boys; rural-urban differences were negligible. Notwithstanding these high levels of disillusionment with the political process, the overwhelming majority of adolescents believed in the fairness of the electoral process. Indeed, 97 percent and 89 percent of boys and girls, respectively, felt that one could vote freely and without fear or pressure.

Considerable proportions of surveyed boys and girls acknowledged that physical fights among boys, and to a lesser extent among girls, did occur in their village or urban neighbourhood, in 2012; however, just seven percent of boys and three percent of girls reported that they had been involved in a physical fight in the year preceding the interview. Although more rural than urban adolescents perceived that boys and girls, respectively, engaged in physical fights among themselves, more urban than rural adolescents reported having participated in physical fights in the year preceding the interview.

\section{Recommendations for programmes}

Findings presented in the sections above underscore that in many respects, adolescents aged 15-19 in 2012 resembled those aged 15-19 five years earlier, but that in many respects, they were different, and faced new 
challenges while making the transition to adulthood. These challenges call for programme interventions at the youth, family and service delivery levels. Key programme recommendations emerging from this study are highlighted below.

\section{Ensure a secondary school education for all}

The achievement of a minimum of a secondary school education is well recognised as necessary to equip adolescents to make a successful transition to adulthood. Indeed, in recognition of this imperative, the RMSA was launched in 2009 with the goal of promoting universal completion of secondary education by 2020. Findings suggest that in Rajasthan, while huge strides have been made in the achievement of educational milestones over the fiveyear period under study, these strides fall short of ensuring universal secondary education. Indeed, even by 2012, just 53 percent of surveyed boys and 39 percent of surveyed girls had completed a secondary school education, up from 38 percent and 22 percent, respectively, five years earlier. Moreover, the gender gap prevails, with secondary school attainment among girls in 2012 reaching levels achieved by boys in 2007. At the pace of change observed in our study, the goals of the RMSA may not be reached by 2020. Efforts must be made to both hasten the pace of universalising secondary school completion and narrowing the gender gap.

A number of factors have been identified in the Adolescents and Youth in Rajasthan 2012 study that inhibit secondary school enrolment and completion. Gender differences were apparent, although lack of interest in studies was a leading obstacle for both boys and girls. In addition, boys cited academic failure and wage work requirements, and girls cited the inability of parents to cover the cost of their education, housework requirements and perceptions of parents' concerns about their safety. Multiple activities are needed to address these barriers. Clearly, many adolescents are first-generation students, and efforts are needed that enable them to prioritise the need to complete their education, provide them special coaching as appropriate, and recognise the need for flexibility given the competing demands on their time. Efforts are also needed that engage parents in prioritising the education of their children; that emphasise the importance of regular school attendance, of communicating with children about their school life, about carving time for children to complete their homework; and that place special value on educating daughters. Conditional grants and targeted subsidies that encourage school continuation and completion and dissuade parents from marrying their daughters off early, must also be made more easily available. School-related obstacles must also be overcome; as recommended in the RMSA, secondary schools must be available in closer proximity to adolescents' residences, and other barriers, such as poor infrastructure, paucity of teachers and quality of education must be addressed. The inclusion of livelihood skills building opportunities within the school setting would clearly enhance perceptions about the value of education.

\section{Fulfill the skilling needs of the next generation}

Although relatively few surveyed adolescents reported wage work before they were aged 15, about one-quarter had been engaged in wage work in the year preceding the interview. For the most part, wage work comprised agricultural and unskilled non-agricultural labour and exposure to livelihood skills building opportunities, and was reported by just 15-18 percent of boys and girls. While increasing proportions of boys had obtained training in computer skills, skills in which girls, in particular, had received training-tailoring, for example-were not linked with market needs. These findings raise questions about the need to prioritise livelihood skills training opportunities for adolescents, both those in school and those who have discontinued their education. Formal mechanisms must be developed that provide opportunities to adolescents to acquire skills for which there is an established demand, and that link eligible adolescents to market opportunities. Providing such opportunities for school-going adolescents would have the added advantage of addressing the concerns of parents and adolescents about the utility of a secondary education. Also required are efforts to ensure that existing programmes aimed at addressing the skilling needs of India's population do indeed reach adolescents, and pay particular attention and adapt to the special constraints faced by girls in acquiring skills and accessing employment opportunities.

\section{Ensure that the transition to sexual life is safe and wanted}

Percentages of surveyed boys and girls reporting pre-marital sexual experience had more than doubled over the cohorts of 2007 and 2012. Pre-marital sexual experiences were, moreover, largely unsafe-experienced with both romantic partners as well as, for boys, married women and sex workers, with consistent condom use being reported by no more than a minority. These findings, together with those highlighting that adolescents tended to initiate sexual activity uninformed, reinforce the need for the RKSK and call for multipronged action-sexuality education, 
counselling, provision of contraceptive supplies and so on-that is adolescent friendly and emphasises the importance of informed choice. Findings suggest persistent misconceptions about the condom, calling for bold and imaginatively designed messages that communicate the importance of condoms and the location of supplies.

Also disturbing are widespread reports of the perpetration (boys) and experience (girls) of non-consensual sexual relations and attitudes. Comprehensive sexuality education, counselling and other efforts are needed that convey the importance of consensuality to boys and girls; these may include the dissemination of information on the penalties boys may face for violations; the development of safety plans that provide girls a road map to follow in case of potential harassment; and the engagement of adolescents, parents and communities to support and not blame girls who report the experience of sexual harassment and violence.

\section{Promote safe social spaces for adolescent girls}

Although by 2012, many more surveyed girls reported agency in terms of decision-making, freedom of movement, and access to and control over financial resources, percentages who reported such agency continued to be limited. Marriage-related planning had commenced early for far too many girls. Peer networks continued to be small for girls, and about one-fifth reported not having a single close friend. Clearly, few girls have access to safe and social spaces outside their homes and schools in which they can make and meet friends and strengthen peer support networks. What is needed is to shape programmes for girls, including such existing programmes as SABLA, to offer girls a safe social space apart from home and school; a friendship network; mentors and role models; life skills education; agency-building activities; information about services and health, social, and economic rights; financial literacy and savings; self-protection plans; livelihood skills building opportunities and knowledge of what community resources exist to access when needed.

\section{Develop new concepts of masculinity among boys}

Findings have suggested that while surveyed boys were not as disadvantaged as surveyed girls, many were not able to exercise agency in their everyday life; at the same time, far more boys than girls expressed inegalitarian gender role attitudes and justified violence against women and girls, and changes in these attitudes were far less marked among boys than girls. In particular, findings have highlighted the extent to which boys perpetrate violence-by way of physical fights with other boys, and by way of harassment and sexual violence perpetrated on women and girls. Thus far, programmes have, by and large, neglected boys, and what is needed are school and community-based programmes that encourage boys to question traditional gender norms, adopt new behaviours, such as supporting their mothers and sisters in housework, encouraging sisters to complete schooling, underscoring the unacceptability of the perpetration of violence and adopting nonviolent forms of conflict resolution, and more generally, respecting new and egalitarian concepts of masculinity. Platforms such as, for example, the NYKS programme and the proposed SAKSHAM programme, and other NGO schemes must focus on building boys' life skills, prosocial values, and promote new concepts of masculinity and femininity. To reinforce new notions of masculinity among young people, corresponding efforts to break down traditional notions of masculinity must be directed at the adults who influence young people-ranging from community leaders to teachers and health care providers, to parents.

\section{Reinforce commitment to 'no tolerance for violence'}

Findings from our survey have highlighted that adolescents grow up in a culture of considerable violence, at the community, family and individual levels. They witness parental violence and violence among young people in their communities. They experience corporal punishment inflicted by parents as a form of discipline and a few admit participating in such violence. Girls experience various forms of sexual violence-verbal harassment, unwanted touch and forced sex, and boys admit perpetrating these forms of violence on girls. In many instances-for example, the experience of verbal harassment and forced sex among girls, and the perpetration of these acts by boys-reports of sexual violence have increased over the five years between the two surveys. The alarming situation of sexual violence among young people has drawn the attention of the nation, and most recently of the Prime Minister himself, who spoke out against violence against women and girls in his Independence Day address to the nation.

Action is needed at many levels. Comprehensive sexuality education must emphasise non-violent forms of conflict resolution while at the same time, breaking down accepted norms of femininity and masculinity that perpetuate gender stereotypes, and underscoring the equal right of boys and girls to exercise choice. Other forums, including the RKSK's peer educator model, the NYKS structure, the SABLA programme, and girls' and boys' groups more generally, 
provide appropriate opportunities to instil new norms and ensure that adolescents commit themselves to a "no tolerance for violence' community.

At the same time, behaviour change communication activities must reach parents and communities more generally with messages about their various roles in halting the acceptability and perpetration of violence. Parents must themselves be oriented not only about egalitarian spousal relations, but also about egalitarian socialisation of sons and daughters on the one hand and the effect of parental violence on their children's healthy development, and the need to protect their children from sexual exploitation on the other. Health sector outreach workers, PRIs and influential individuals in each community, and even teachers may be tasked with promoting these messages and taking action to stop violence taking place in their communities; at the same time, their capacity to deal sensitively and non-judgementally with reports and experiences of violence against women and girls must be sharpened. Finally, mechanisms for reporting violence against women and girls must become more adolescent and youth friendly, respecting young people's confidentiality and enabling reporting procedures in a non-threatening environment.

\section{Promote comprehensive sexuality education for all adolescents}

Adolescent girls and boys in our surveys continued to be generally uninformed or misinformed about their bodies, sexuality and health-promoting behaviours. This limited awareness persisted notwithstanding some impressive increases in 2012 over 2007 among both boys and girls, and notwithstanding the huge increase in percentages of adolescents reporting exposure to sexuality education in the school setting or at the community level through the Adolescent Reproductive and Sexual Health programme (the precursor to the RKSK). These findings suggest that exposure to comprehensive sexuality education is not universal or comprehensive and raise questions about the quality of the school-based programmes imparted to adolescents.

Concerns about the appropriateness of sexuality education programmes and suggestions about discontinuing such education must be reconsidered in light of findings that awareness is limited while early and unsafe sex is experienced by growing numbers of adolescents. Comprehensive sexuality education programmes are needed that go beyond addressing only the human biology of pregnancy, or only HIV/AIDS, or abstinence only until marriage. What is needed is to learn from available curricula that provide information about biology and maturation, sexuality, contraception, prevention of STIs and HIV/AIDS, relationships and marriage, as well as skills building for gender equality, non-violence, and respect for human rights. Such programmes not only reduce misinformation but also help adolescents to make informed decisions about engaging in sex and using contraception. In addition, special attention needs to be paid to the training of trainers. It is important that teachers, health care providers and others engaged in educating adolescents undergo training that enables them to overcome their reluctance to communicate with adolescents on sensitive sexual and reproductive matters, that dispels their misconceptions on these matters, and that enhances their technical knowledge of these issues. There is no evidence that comprehensive sexuality education, appropriately delivered, can lead to increased risk taking; rather, it has positive health outcomes, including reductions in STIs and unintended pregnancies.

\section{Ensure that the RKSK addresses adolescents' health information, counselling and service needs}

Our survey has highlighted that considerable proportions of adolescents have experienced symptoms suggestive of mental health as also sexual and reproductive health problems. Yet, not only are adolescents poorly informed about health-promoting practices and the location of available services, but few are aware of or have accessed Adolescent Friendly Health Clinics for information, counselling or services. Numerous obstacles to health-promoting practices are evident from our findings. For one, many boys and especially girls are not permitted to visit a health centre unescorted, suggesting that few youth would be able to attend Adolescent Friendly Health Clinics for sexual and reproductive health counselling or services. Several adolescents, moreover, expressed shyness about accessing health services, and few had received information or counselling from a health care provider.

The recently launched RKSK promises to overcome these obstacles. It has outlined a comprehensive strategy that addresses key aspects of adolescent health: physical maturation and sexual and reproductive health, noncommunicable diseases and lifestyle issues, mental health, nutrition, violence and substance misuse, in particular. It is to be delivered through community-based peer educators and clinic-based facilities, including a strengthened network of Adolescent Friendly Health Clinics. It has emphasised the need for service delivery in ways that are appealing to adolescents, that pay attention to the training of providers from periphery to facility, that underline the importance of non-judgemental and confidential services for adolescents, and make provision for appropriate 
referral as necessary. Our findings underscore the need for such a comprehensive programme and call for its rollout and careful monitoring.

\section{Engage parents}

Findings highlight that parenting practices are typically hierarchical, controlling and gender inegalitarian. Many adolescents witness and experience violence in the home. Parent-child interaction and communication are limited, and communication about sexual and reproductive health matters is virtually non-existent. While some changes had taken place over the five-year period, by and large, effective parenting practices were reported by very few surveyed adolescents at both times. Efforts must be made to raise parental awareness about adolescent health and development, and change traditional attitudes about the socialisation of children. Programmes are needed that encourage parents to adopt gender-egalitarian socialisation practices and openness in their relations with their children, and enable them to play an active role in educating their children about physical maturation and sexual and reproductive health matters. Interventions that address parents are scarce. However, given the key role parents play and given evidence that adolescents wish to engage with their parents on issues of sexual and reproductive health, what is needed are activities that support parents with information, skills and resources, notably about adolescent health and development, sex, substance use, communication skills, and information about local resources.

\section{Intensify efforts to eliminate the practice of early marriage}

Findings indicate that marriage-related planning had already been initiated for about two in five surveyed girls; for one in five, it had been initiated even before they were aged 15; and for one in seven, the marriage had already been fixed and was almost entirely the choice of parents. These findings call for measures that go beyond information campaigns to address the underlying factors-social norms and economic constraints-driving early marriage and to better enforce existing laws prohibiting early marriage in the state. Strategies are needed that mobilise communities and influential community leaders to help parents resist pressures that foster the practice of early marriage. Conditional cash transfer programmes that incentivise families for keeping girls in school and/or not marrying them till after they are aged 18 need to be implemented and their effectiveness reviewed. Efforts to delay marriage also require providing girls with viable alternatives to marriage, in the form of accessible schools and livelihood skills training opportunities. Equally important is the need to ensure greater commitment on the part of law enforcement agencies to enforce existing laws on the minimum age at marriage and the registration of marriages, and to levy penalties on violators. Allowing anonymous reporting, making law enforcement agencies and others aware that the practice of early marriage is not a minor violation, and making the guidelines for penalties clear to enforcement agencies and the wider community are possible steps in this direction.

\section{Capitalise on parents' and adolescents' access to mobile phones and the internet}

Findings have shown a phenomenal increase in mobile phone ownership at household level, from 40 percent in 2007 to 95 percent in 2012, and in internet access among surveyed adolescents who had five or more years of schooling from five percent to 37 percent among boys and from four percent to 11 percent among girls. Findings suggest that mobile phones and the internet may be promising ways of reaching adolescents, particularly boys, and their parents with news ideas and information, and call for new strategies and messaging techniques through which to convey information of relevance to adolescent health and development to both parents and adolescents themselves. Schools must be better equipped to build adolescents' skills in using the internet, and the school curriculum must enable adolescents opportunities to become familiar with the use of the internet.

\section{Expand the reach of programmes for adolescents}

While a number of programmes and schemes are available to enable adolescents to further their education; build leadership skills; access health information, services and supplies; and gain economic empowerment opportunities, surveyed adolescents were aware of just a few, and very few had benefited from these programmes and schemes. Reasons underlying this limited use must be sought. At the same time, efforts must be undertaken to raise awareness among adolescents themselves, as well as parents, teachers, health care providers and community leaders about the availability of these programmes, and remove barriers inhibiting adolescents from availing of them; for example, with regard to proving eligibility for various schemes and facilitating enrolment. 


\section{Directions for future research}

Findings presented in this report provide a broad picture of the situation and needs of adolescents in Rajasthan, and highlight that the availability of successive cross-sectional data permits rich insights into areas of rapid changes experienced by adolescents over a five-year span, and areas in which change has been imperceptible. A number of key changes were observed over the five-year period: secondary school completion increased hugely; access to mobile phones and the internet improved, particularly among boys; and pre-marital sexual relations were reported by far more adolescent girls and boys in 2012 than in 2007, for example. At the same time, gender role attitudes did not become uniformly more egalitarian, parent-child relations continued to be hierarchical, sexually active adolescents continued to engage in unprotected sex, and violence continued to pervade the life of many adolescents. Given the dynamic nature of adolescent life, a key recommendation is to institutionalise such successive surveys on a regular basis that enables researchers to track and explain changes and their correlates, and analyse factors impeding change in critical issues.

A general research recommendation is the urgent need for prospective or panel study designs that follow a cohort of adolescents at regular intervals up to age 24. Prospective study designs would enable researchers to take a life course approach; identify, with compelling data, the factors responsible for healthy transitions to adulthood; and point to the ways in which the situation and experiences of youth in adolescence influence their life course at later ages.

More specifically, research is needed that explores adolescents' access to the various programmes and schemes implemented by the government to enhance their health, education, skill acquisition, economic opportunities, leadership skills and citizenship roles, and those that aim to change traditional norms of masculinity and femininity and provide comprehensive sexuality education, for example. Additionally, research is needed that addresses the extent to which adolescents have made use of these opportunities, their assessment of the quality of these programmes and obstacles faced in accessing them, and above all, objective indicators of the impact of participation in these programmes, preferably measured not only immediately following exposure to the programme but also some years thereafter.

In brief, the Adolescent and Youth in Rajasthan 2012 study has documented the heterogeneity of adolescents-boys versus girls, rural versus urban adolescents, school-going versus out-of-school adolescents, and so on. It has also highlighted the dynamic nature of adolescents' transition to adulthood, underscored that in many respects the life of 15-19 year olds in 2012 was very different to that of those in 2007, and raised questions about programmes needed to address the evolving needs of adolescents. Finally, the study alerts us to the many challenges continuing to confront adolescents and their ability to make a successful transition to adulthood, and provides a baseline through which to measure the impact of programmes intended to address adolescents' needs. 


\section{Chapter 1 Introduction}

\subsection{Rationale}

Several national policies and programmes, formulated since 2000, have underscored India's commitment to addressing the multiple needs of youth. Recognising for the first time that adolescents constitute an under-served group with special sexual and reproductive health needs, the National Population Policy 2000 advocates special programme attention to addressing this young population (Ministry of Health and Family Welfare, 2000). The National Youth Policies of 2003 and 2014 recognise adolescents as a special group requiring a different approach from that appropriate for young adults, and promote strategies to meet youth needs in areas including education, training and employment, health, recreation and sports, and good citizenship (Ministry of Youth Affairs and Sports, 2003; 2014). Also notable is the commitment to address the needs of adolescents and young people articulated in the Eleventh and Twelfth Five-Year Plans (Planning Commission, 2006; 2011).

In addition, with regard to health too, the commitment is obvious; the Rashtriya Kishor Swasthya Karyakram (RKSK), launched in 2014, provides the framework for services for young people's health in general, and their sexual and reproductive health, mental health, and prevention and care of non-communicable diseases, in particular (Ministry of Health and Family Welfare, 2014).

There is a strong rationale for a continued focus on the situation and needs of youth. According to India's census of 2011, youth (aged 15-24) constitute 231.9 million and represent 19 percent of the Indian population (Office of the Registrar General and Census Commissioner, n.d). Not only does this cohort represent India's future in the socioeconomic and political realms, but its experiences will largely determine India's achievement of its population stabilisation goal articulated in the National Population Policy 2000 (Ministry of Health and Family Welfare, 2000) and the extent to which the nation will be able to harness its demographic dividend. In addition, it is clear that the realisation of the Millennium Development Goals (United Nations Development Programme, 2000) depends, to a considerable extent, upon the situation of young people. It is also clear that new ideas and behaviours are fast proliferating among youth and it is important to track how these changes have affected their situation and needs, and shape new programmes that respond to the changing needs they imply.

The Youth in India: Situation and Needs 2006-2007 study (hereafter referred to as the Youth in India study) was the first-ever sub-nationally representative study conducted to identify key transitions experienced by married and unmarried youth in India. The study, conducted in the states of Andhra Pradesh, Bihar, Jharkhand, Maharashtra, Rajasthan and Tamil Nadu, contributed to describing the levels and patterns in key markers of youth transitions to adulthood, alerted the nation to the many challenges confronting youth and their ability to make a successful transition to adulthood, and emphasised the heterogeneity of youth, not only in terms of their situation but also with regard to their stated needs and preferred mechanisms to address these needs. Indeed, its evidence provided not only a blueprint for the programming needs of youth in the country but also a baseline by which to measure the impact of social change and programmes intended to address youth needs (International Institute for Population Sciences and Population Council, 2010). Data have now become available from a repeated survey conducted in 2012 in one state, Rajasthan, about the situation of unmarried 15-19 year-old adolescents from the same sites as in the 2007 survey, offering an opportunity to assess changes in the situation of adolescents over a five-year period. This report draws upon data from this survey.

\subsection{Study objectives}

The Adolescents and Youth in Rajasthan 2012: Changing Situation and Needs study (hereafter referred to as the Adolescents and Youth in Rajasthan 2012 study) comprises two components, a panel and a cross-sectional design. The study has two specific objectives: (a) to follow up a significant subsample of young people who participated in the Youth in India study and provide a truly longitudinal view of the process of moving from adolescence to adulthood; and (b) to establish levels of key markers of the life of adolescents aged 15-19 and their transitions to adulthood 
and assess, using successive cross-sectional data at two points in time during which a number of programmes have been implemented to address adolescents' needs, the extent to which the situation of successive cross-sections of adolescents has changed over time. It is this second objective that is the subject of this report.

This study of successive cross-sections of adolescents has two specific aims. The first is to explore the situation of unmarried adolescents aged 15-19 in 2012, notably with reference to work roles, educational attainment levels, citizenship and group engagement, health-promoting knowledge, marriage planning, entry into sexual life, peer networks, agency and parental relationships, and the changes in the situation of this cohort over the five-year period between the two surveys. The second is to assess the extent to which the current cohort of 15-19 year-olds was exposed to various programmes implemented by government and non-governmental organisations (e.g., Sarva Shiksha Abhiyan, SABLA/Kishori Shakti Yojana, the National Skill Development Initiative, the National Adolescent Reproductive and Sexual Health Strategy, the Adolescence Education Programme, and so on), and explore whether the situation of those exposed to these programmes differed from those not exposed in terms of educational attainment, school continuation, acquisition of vocational skills training, awareness of sexual and reproductive matters, exercise of agency in personal matters and so on.

Unlike the Youth in India study, which included youth aged 15-24 and both married and unmarried youth, the Adolescents and Youth in Rajasthan 2012 study focuses only on unmarried girls and boys, and is limited to adolescents aged 15-19.

Funding for the original Youth in India study was provided by the David and Lucile Packard Foundation and the John D. and Catherine T. MacArthur Foundation. The study was conducted jointly by the International Institute for Population Sciences, Mumbai, and the Population Council, New Delhi. Funding for the Adolescents and Youth in Rajasthan 2012 study was provided by the John D. and Catherine T. MacArthur Foundation, and it was conducted by the Population Council, New Delhi.

\subsection{Rajasthan: Overview of demographic and socioeconomic features}

Rajasthan, situated in the northwest of India, is India's largest state in terms of geographical area. It covers a total of 342,239 square kilometres and contains 33 districts (Office of the Registrar General and Census Commissioner, 2001a). The districts are divided into seven divisions, namely Ajmer, Bharatpur, Bikaner, Jaipur, Jodhpur, Kota and Udaipur. Geographically, the state contains three distinct regions: a desert region (Western Rajasthan, comprising $60 \%$ of its land area and $34 \%$ of its population), a hilly region (Southern Rajasthan, containing $11 \%$ of its land area and $14 \%$ of its population) and the plains region (consisting of the remaining $29 \%$ of its land area and $52 \%$ of its population) (Government of Rajasthan, n.d.; Mathur, 2008). Rajasthan, with a population of 68.5 million in 2011, ranks eighth in terms of total population among states in India (Office of the Registrar General and Census Commissioner, India, 2013). With 928 females per 1,000 males in 2011, the state registered a lower sex ratio than the national average (943) (Office of the Registrar General and Census Commissioner, India, 2013). Its population density was 200 persons per square kilometre in 2011, compared to 382 persons per square kilometre in India (Office of the Registrar General and Census Commissioner, India, 2013). A distribution of the population in 2001 by religion (corresponding information from the 2011 Census is not yet available) indicates that about 89 percent of the state's population was Hindu, nine percent was Muslim and the remaining three percent belonged to other religions, including Buddhists, Christians, Jains and Sikhs (Office of the Registrar General and Census Commissioner, 2001b). Scheduled tribes and scheduled castes constituted substantial proportions-13 percent and 18 percent, respectively-of the state's total population (Office of the Registrar General and Census Commissioner, India, 2013).

The state is characterised by a large rural population; just 25 percent of Rajasthan's population lives in urban areas (Office of the Registrar General and Census Commissioner, India, 2013). Both intra- and inter-state migration are high. Indeed, according to the 2001 Census, the state ranked third in terms of the number of inter-state migrants, and during the decade 1991-2001, 2.6 million persons migrated to states outside of Rajasthan (Office of the Registrar General and Census Commissioner, 2001c).

The state, however, reports poor economic indicators. For example, Rajasthan's contribution to the national Gross Domestic Product (GDP) was about 4.5 percent in 2010-11 (Ministry of Statistics and Programme Implementation, 2012). Its per capita income of Rs. 26,882 and Rs. 47,506 in 2007-08 and 2011-12, respectively, were one of the lowest among states in India and well below the national average of Rs. 40,775 and Rs. 60,603, correspondingly (Ministry of Finance, n.d). Rajasthan's Gross State Domestic Product (GSDP) at current prices stood at Rs. 4,16,755 
crore in 2011-12 (Government of Rajasthan, n.d); at constant prices (2004-05), the GSDP increased by 6.11 percent between 2010-11 to 2011-12. The services sector contributes around 47 percent in GSDP followed by the industry and agriculture sectors at 27 percent and 26 percent, respectively (PHD Research Bureau, 2011).

Poverty levels remain high in the state. As of 2009-10, almost one-fourth of the state's population (24.8\%) was estimated to live below the poverty line, with significant differences between those residing in urban (33.2\%) and rural (26.4\%) areas (Planning Commission, 2012). Unemployment rates are lower in rural areas of the state compared to urban areas, and the highest among urban females. For example, in 2011-12, two percent and five percent of rural and urban females, respectively, were unemployed for a major part of the year, as measured by the usual status adjusted definition; the corresponding figures for males were two percent and three percent, respectively (National Sample Survey Organization, 2014).

Rajasthan lags behind the rest of India in terms of social indicators as well. For example, the state's overall literacy rate was 66.1 percent in 2011, ranking 33rd among India's 35 states and union territories. While the male literacy rate at 79 percent was similar to the national average of 81 percent, the female literacy rate was considerably lower than that recorded at the national level, namely, 52 percent compared to 65 percent (Office of the Registrar General and Census Commissioner, India, 2013).

The state's performance in the health sector has also been poor. Life expectancy of males and females in the state is similar to that observed for India as a whole (65 years for males and 68 years for females) (Registrar General, India, 2012). The state's infant mortality rate fell from 65 in 2007 to 49 in 2012; even so, it was the fifth highest infant mortality rate in the country in 2012. Fertility rates are also considerably higher in Rajasthan than in India, on average; indeed, while the total fertility rate declined between 2007 and 2012 in the state (from 3.4 to 2.9), it remained considerably higher, at both times, than in India more generally (2.7 and 2.4, correspondingly) (Office of the Registrar General, India, 2013), and was the sixth highest total fertility rate among states in India at both times. Comparable data suggest, correspondingly, that the contraceptive prevalence rate was lower than the national average in 2005-06 (47\% versus 56\%; at the same time, the proportion of women reporting an unmet need for contraception in the state was similar to that reported for India as a whole (15\% versus 13\%) (International Institute for Population Sciences and Macro International, 2007a). While more recent data are unavailable for India as a whole, there is evidence that Rajasthan's contraceptive prevalence rate has increased considerably since 2005-06 and reached 66 percent in 2013 (Registrar General, India, n.d.).

\subsection{Situation of youth in Rajasthan}

Young people in Rajasthan aged 10-24 constitute a total of 22.1 million, and account for 32 percent of the state's population. Adolescents aged 15-19 numbered 7.3 million in 2011, accounting for about 11 percent of the state's population (Office of the Registrar General and Census Commissioner, India, n.d.). The share of the youth population as a proportion of the total population of Rajasthan is projected to increase to 21 percent by 2011 and remain at 21 percent till 2016 before beginning to decline (Office of the Registrar General and Census Commissioner, 2006).

The lack of educational facilities for youth is a major concern acknowledged in many state documents (see, for example, Department of Education, Government of Rajasthan, n.d.). Indeed, educational attainment levels among youth are considerably lower in the state than in India overall, and gender differences in enrolment substantially wider. Among young people (aged 10-24), only 92 percent of men and 77 percent of women were literate in 2011 (Office of the Registrar General and Census Commissioner and United Nations Population Fund (UNFPA), 2014). Data on gross enrolment ratios also highlight the state's poor performance in the educational field. The gross enrolment ratio in 2010 among children aged $6-10$ years was 110 percent; among those aged 11-13, it was 82 percent; and among 14-15 year-olds, the ratio was 62 percent, relatively similar to the ratios recorded at the national level (116\%, 86\% and 65\%, respectively). The Gender Parity Index (GPI) at the elementary (Classes 1-8), secondary (Classes 9-10) and higher secondary (Classes 11-12) levels of education indicates limited access to educational opportunities for girls in the state; in 2010, the GPI score ranged from 0.93 at the elementary level to 0.69 at the secondary and 0.63 at the higher secondary level, considerably lower than the national average (Ministry of Human Resource Development, 2012).

Rajasthan has few employment opportunities for youth and, as elsewhere in the country, unemployment rates are slightly higher among young people than among the general population discussed above. For example, among the population aged 15-29, unemployment rates, as measured in terms of the usual status (adjusted), were 5.1 percent 
and 7.1 percent among young men in rural and urban settings, respectively, during 2011-12; the corresponding rates among young women were 2.2 percent and 6.4 percent, respectively (National Sample Survey Organization, 2014).

Available evidence on the sexual and reproductive health profile of young people in Rajasthan highlights their vulnerability. Marriage continues to take place before the legal minimum age for both young women and men; as recently as 2005-06, 65 percent of women aged 20-24 were married by age 18 and 57 percent of men aged 25-29 were married by age 21. Moreover, about one in six 15-19 year-old girls (16\%) had begun childbearing (International Institute for Population Sciences and Macro International, 2008). At the same time, evidence from the Youth in India study suggests that few young women (just 10\%) reported a preference for early marriage (International Institute for Population Sciences and Population Council, 2009); so too did many parents recognise the disadvantages of early marriage, although many of them reported a range of constraints that inhibited them from acting on this recognition (Santhya, Haberland and Singh, 2006).

While it is clear that sexual relations are initiated early and within the context of marriage for large proportions of young men and women in Rajasthan, the Youth in India study confirmed that sexual risk-taking before marriage is not unknown among young people in the state: nine percent and two percent of unmarried young men and women, respectively, aged 15-24, had engaged in sexual relations (International Institute for Population Sciences and Population Council, 2009).

Despite the early onset of sexual relations within or before marriage among significant proportions of youth, available evidence suggests that in Rajasthan, young people's knowledge of sexual and reproductive health matters tends to be limited. For example, data from the Youth in India study indicate that only 49 percent of young men and even fewer (27\%) young women in the state had comprehensive knowledge about HIV/AIDS, and just 41 percent and 47 percent, respectively, were aware that a woman can become pregnant at first sex (International Institute for Population Sciences and Population Council, 2009). Similarly, sexual and reproductive healthcare seeking is limited among young people in Rajasthan: two-fifths and almost three-fifths of married and unmarried young men and young women, respectively, reported they would be uncomfortable about approaching a health care provider for contraceptives (International Institute for Population Sciences and Population Council, 2009). Maternal care-seeking among married adolescent girls in rural areas of the state was far more limited than that experienced by adult women (Santhya, 2009).

\subsection{Youth-related policy and programme environment in Rajasthan}

Over the interval of five years between the Youth in India and the Adolescents and Youth in Rajasthan 2012 studies, the state continued to implement its Policy for Women, the National Rural Health Mission and other programmes and policies that placed special emphasis on the health, education and citizenship roles of young people, and girls in particular (Department of Women and Child Development, Government of Rajasthan 2006; Department of Medical, Health and Family Welfare, Government of Rajasthan, 1999). Over the intervening period, however, several new programmes were initiated that have special relevance for adolescents: these include the Rashtriya Madhyamik Shiksha Abhiyan that promotes secondary education for girls and boys, as well as the Adolescent Reproductive and Child Health (ARSH) programme intended to provide information, counselling, contraceptive supplies and services to young people, and the SABLA scheme, intended to address the nutrition, health and empowerment of adolescent girls. During this time, also, a draft Youth Policy (2010) was developed, which was finally launched in 2014 (Ministry of Health and Family Welfare, 2014) and makes special mention of addressing the health and development of adolescents. In this section, we briefly describe these selected initiatives.

The National Youth Policy 2014 (and the draft Youth Policy of 2010) focuses on the population aged 15-29 and aims to address their multiple needs, or, in its words, to "empower youth to achieve their full potential." One of the key objectives is the development of a strong and healthy generation, and greater inclusiveness and social justice with special reference to girls and young women (Ministry of Health and Family Welfare, 2014). While its vision does not explicitly discuss sexual and reproductive health, gender disparities, and the vulnerabilities and rights of girls, it does argue for greater pregnancy-related care for adolescents, access to health care facilities and health-promoting education, and the inclusion of health and nutrition in school curricula.

In the area of education, over the last 25 years, the state has made considerable efforts to expand educational opportunities for young people, including the Shiksha Karmi Project, launched in the late 1980s and the Sarva 
Shikhsa Abhiyan that was formally launched in 2001-02. Under these programmes, efforts have been made to improve infrastructure and teacher skills as well as the quality of education, and universalise the enrolment and retention of children aged 6-14. More relevant to adolescents, the Rashtriya Madhyamik Shiksha Abhiyan, launched in 2008, is aimed at universalising secondary school education, providing access to secondary school and senior secondary school within a range of five and 7-10 kilometres, respectively, from adolescents' homes, and paying special attention to those who are economically disadvantaged or socially excluded (Rajasthan Council of Secondary Education, 2013). A number of incentives have been provided, moreover, to encourage the secondary education of girls. For example, a number of girls' schools have been established and upgraded (Kasturba Gandhi Balika Vidyalaya); motivational camps have been organised at Gram Panchayat level to encourage the enrolment of girls; and such initiatives as scout-guide activities, vocational training and computer education have been provided for girls. To address transport challenges, bicycles have been provided to girls in Classes 9 and 10 travelling to distant schools (more than 58,000 girls had received bicycles by December 2011), and girls whose schools are more than five $\mathrm{km}$ away from their home have benefitted from transport vouchers (almost 28,000 girls had collected transport vouchers by December 2011) (Government of Rajasthan, 2012).

In the health arena, the Ministry of Health and Family Welfare launched the Rashtriya Kishor Swasthya Karyakram in 2014 to address multiple dimensions of adolescent health-non-communicable diseases, nutrition, mental health, violence, substance abuse and sexual and reproductive health-through a network of community-based outreach workers notably through peer educators, as well as clinic-based facilities, notably Adolescent Friendly Health Clinics (Ministry of Health and Family Welfare, 2014). Preceding the launch of the RKSK, and at the time of our survey, young people's health needs were addressed through the Adolescent Reproductive and Sexual Health strategy launched in 2006, and delivered under the National Rural Health Mission (NRHM) and the Reproductive and Child Health Programme II. Under this programme, a wide range of sexual and reproductive health services was provided to adolescents and youth during routine sub-centre visits and through once-a-week Teen Clinics to be held on fixed days and times at the Primary Health Centre or Community Health Centre level in selected districts across the country, through its Adolescent Reproductive and Sexual Health (ARSH) strategy (Ministry of Health and Family Welfare, 2006). The ARSH strategy, however, did not make significant inroads into providing services for youth as evident from a Population Council study in three states including Rajasthan; cumulatively, in these three states, fewer than 10 percent of young people had heard about Adolescent Friendly Health Clinics and the services they provided to adolescents, and fewer than one percent had availed of the services (Santhya et al., 2014).

Other schemes have also been implemented to counter discrimination against girls. Under the Ministry of Women and Child Development, a new programme, the Rajiv Gandhi Scheme for the Empowerment of Adolescent Girls, SABLA, was launched in 2010 to address the multiple health, nutrition and development needs of out-of-school girls aged 11-18 years; it merged elements from two previously implemented schemes, namely the Kishori Shakti Yojana and Nutrition Programme for Adolescent Girls (AGS). This scheme is conducted in ten districts of the state and encompasses nutritional supplementation and provision of iron and folic acid, health-related counselling and services, and life skills education and livelihood training; its reach is wide, and in 2011-2012, a total of 656,733 adolescent girls were covered under it (Press Information Bureau, Government of India, Ministry of Women and Child Development, 2012). The Kishori Shakti Yojana is a programme parallel to the Adolescent Girls' Scheme (AGS), implemented in 165 blocks of Rajasthan, and is also focused on raising awareness, addressing nutrition and health, and linking girls to life skills training opportunities. The Kishori Balika Yojana is a modified version of the Kishori Shakti Yojana and has been introduced in 66 blocks of the state, among girls aged 11-14 and 15-18. Its focus is on school drop-outs and girls belonging to scheduled castes, scheduled tribes and other backward castes with the objective of promoting their health and development (Department of Planning, Government of Rajasthan, 2006).

The leading programme intended to build citizenship among young people continues to be the Nehru Yuva Kendra Sangathan (NYKS) programme sponsored by the Ministry of Youth Affairs and Sports. (Ministry of Youth Affairs and Sports, n.d. a). This programme, launched in 1987-88, is implemented through Youth Clubs, established at the village level for all those aged 13-35, with the aim of building awareness, providing leadership development opportunities and building leadership skills, and engaging its members in community development activities.

Although not so mandated, the large majority of Youth Club members are boys and young men. Rajasthan has more than 3,000 such clubs (Ministry of Youth Affairs and Sports, n.d. b).

In addition, a number of non-governmental organisations (NGOs), including Rajasthan-based and national NGOs, implement programmes intended to meet the needs of young people in the state. These programmes have focused 
on providing sexual and reproductive health-related information, counselling and services, including condoms, to young people; providing opportunities to build livelihood skills; and mobilising communities to support young people's access to information and services.

\subsection{The survey and questionnaires}

Field work was undertaken between February and November 2012, and comprised an extensive household listing exercise and a survey of a total of 1,909 unmarried adolescent girls and boys.

The household listing exercise comprised the following activities: a listing and mapping of entire primary sampling units (PSUs) (or selected segments of PSUs in large villages), and a complete listing of all unmarried adolescent girls and boys, aged 15-19, in the household.

For the survey, separate questionnaires were prepared for girls and boys; however, the content was virtually identical. Questionnaires were largely similar to those fielded in 2007, but included a greater focus on such thematic areas as migration and mobility, mobile phone access, gender role attitudes, sexual experience, access to sexuality education and participation in government programmes. The survey instrument was finalised after extensive pre-testing and collected information on the following topics:

Background characteristics: Questions were asked regarding the respondent's age, education and schooling, work patterns including housework and paid employment, vocational training, migration, and characteristics of parents.

Additionally, as in the Youth in India study, a Life Event Calendar (LEC) was administered to all respondents. In addition to information on education, work and living arrangements, this calendar also obtained information about migration, starting from the age of 12 years. This system of recording life events is considered one of the most effective approaches to minimise recall error (Sathar et al., 2003).

Migration and mobility: In 2012, an extensive set of questions was asked to assess migration and mobility, including migration histories and reasons for migration, as well as work- and education-related mobility in the 12 months preceding the interview.

Media exposure: Respondents were asked whether they were exposed to newspapers, television or the internet, and whether they watched pornographic films or read pornographic magazines. Given the proliferation of mobile phones, questions about access to mobile phones were also posed.

Parental interaction/relationship: Detailed questions were asked on the extent of parent-child communication on everyday activities as well as sexual and reproductive issues. Questions were also asked to assess the extent to which a respondent had witnessed parental violence or been the victim of violence perpetrated by a parent while the respondent was growing up.

Communication, mobility and decision-making: This section collected information on the person with whom adolescents were most likely to confide matters related to getting a job, growing up, boy-girl relationships and personal problems. Detailed questions were also asked on decision-making and mobility.

Gender and self-efficacy: In order to evaluate the respondent's gender role attitudes and level of self-efficacy, questions were asked to probe opinions about a range of gender-related issues, such as, for example, the importance of boys' vis-à-vis girls' education, housework and freedom of movement, and the extent to which adolescents justified violence against women. The set of questions measuring adolescents' gender role attitudes was expanded from the set asked in 2007 to include a wider range of issues, such as, for example, the acceptability of having opposite sex friends, the importance of dowry, whether girls like to be teased by boys, preference for early marriage versus higher secondary education for girls, the acceptability of a woman earning more than her husband, responsibilities of women and men with regard to childcare and contraception, and the acceptability of extramarital sexual relations for men.

Awareness of sexual and reproductive matters: This section probed adolescents' awareness about sexual relations, pregnancy, contraceptive methods, HIV/AIDS and sexually transmitted infections (STIs) as well as the legal minimum age at marriage, and whether gender-biased sex selection is legally permitted. It also probed adolescents' sources of information on sexual matters and contraception, the extent to which they had obtained formal sex or family life education, and their experiences and perceptions about this education. 
Connectedness and friendship: Questions relating to connectedness and friendship explored respondents' friendship networks among those of the same sex and activities in which they participated with their friends. This was followed in a gradual fashion by questions on interaction with the opposite sex, whether or not the respondent had exchanged a "proposal" of romantic partnership with someone of the opposite sex and whether the respondent had ever met someone of the opposite sex secretly in a number of likely places.

Pre-marital romantic heterosexual relationships: This was a highly sensitive section, conducted only if complete privacy was assured. Adolescents were asked about their own experiences of pre-marital romantic partnership and, if reported, detailed questions were asked on the nature of such relationships with the first partner and the last or most recent partner (if more than one partner was reported). Questions were designed to gradually probe sensitive behaviours, for example, starting with whether the respondent had ever held hands with a romantic opposite-sex partner, and continuing with questions on hugging, kissing and finally having sex with the partner. We believe this gradual progression of questions was more culturally appropriate than a single question on pre-marital sex and provided insights into the range of behaviours youth experienced. If sex with a pre-marital romantic partner was reported, a host of questions followed that probed the age at sexual initiation, the consensuality of first sex with this partner, and condom use. Questions were also asked about the characteristics of the romantic partner and parental awareness of the romantic relationship.

Marriage planning: Questions in this section covered marriage planning, the participation of the respondent in decision-making related to marriage and the respondent's feelings about his or her own marriage.

Sexual experiences with persons other than a romantic partner: This was the second highly sensitive section in which respondents were asked a series of questions on their personal experience of several types of sexual encounters; for example, paid or exchange sex, forced sex perpetrated on the respondent and casual sex. In the case of male respondents, additional questions were asked about relations with sex workers and married women and whether they had ever perpetrated forced sex. Respondents who reported any of these experiences were probed for their age at first experience of such a sexual encounter and whether or not they had used condoms in their sexual encounters.

Health and health seeking: This section collected information on respondents' experience of symptoms of genital infections in the three months preceding the interview. In addition, respondents were asked whether they had sought treatment for these health issues and, if so, from what source. Respondents' mental health in the last one month was assessed using the 12-item General Health Questionnaire (GHQ) developed for use in field conditions (Goldberg, 1992). Girls were asked an additional question about menstrual hygiene.

Substance use and violence: A series of questions were asked about consumption of tobacco products, alcohol and/or drugs. Additional questions sought respondents' assessments of the frequency with which young people in their neighbourhoods engaged in violence (fights or beatings) and their own participation in such violence.

Programmes and participation: The final section of the questionnaire collected information on programmes available to young people in the village or neighbourhood in which they resided, and the extent to which they participated in such programmes. In addition, respondents were asked about the role of panchayats or community groups in decisions affecting young people's lives. All respondents were asked about their participation in community activities and opinions about political processes.

Sealed envelope response: However carefully designed and culturally sensitive the survey questions may have been, the possibility that young people would deliberately withhold information about their sexual experiences in a face-toface interview could not be discounted. Drawing from other research in the field, an anonymous reporting method was included in our survey to obtain responses to two questions: Have you ever had sex with anyone? and Has any boy or man ever forced you to have sex with him? (girls) and Have you ever forced anyone to have sex with you? (boys). In comparison, the 2007 survey asked only the first of the two questions described above. Interviewers first explained the technique to respondents, noting in particular its confidential nature. The interviewer then gave each respondent two cards and asked him or her to simply mark a " $\sqrt{ }$ " or an " $\times$ " on the card to indicate that s/he had or had not experienced pre-marital sex, had or had not been forced to have sex/forced someone to have sex. Once marked, the respondent placed the cards inside an envelope provided by the interviewer; the envelope was sealed by the respondent and returned to the interviewer. Unique identification numbers linked the individual's questionnaire with his or her responses in the sealed envelope. Envelopes were opened only at the central office at the time of data entry. 


\subsection{Study design and sample size for individual interviews}

As mentioned earlier, the Adolescents and Youth in Rajasthan 2012 study was undertaken in the same locations as the earlier Youth in India study. Unfortunately, due to logistical challenges, maps, questionnaires and consent forms were preserved only for respondents in half of all of these locations, and our study, therefore, drew its samples from the PSUs for which household level information and maps were available; reanalysis of 2007 data for 15-19 year-olds residing in these PSUs compared with those residing in PSUs that were not included in the 2012 survey suggests that the situation of girls and boys in the selected PSUs was virtually identical to that of their counterparts in PSUs that were not included.

In all, of the 300 PSUs from which our sample was selected in 2007, maps and questionnaires were available from just 147 PSUs for this survey; of these, 74 were from rural areas and 73 from urban areas. The sample covered all the 33 districts of Rajasthan.

In 2007, we had interviewed an average of 11 boys aged 15-19 in a PSU (ranging from 1 to 26) and an average of 20 girls (ranging from 6 to 56). A detailed discussion on the sampling strategy used in the Youth in India study is available elsewhere (International Institute for Population Sciences and Population Council, 2009). The sample size achieved in the Youth in India study was 774 boys and 1,487 girls.

In the Adolescents and Youth in Rajasthan 2012 study, a sample of similar size was envisioned. Thus, on average, 12 boys and 20 girls from the same PSUs as in 2007 were targeted to be interviewed. The target sample size was 1,500 girls from 76 PSUs and 850 boys from 71 PSUs.

\subsubsection{Sample selection strategy}

In 2007, the Youth in India study treated rural and urban areas of each state as independent sampling domains and, therefore, drew sample areas independently for each of these two domains. In order to avoid potential risks associated with interviewing both women and men from the same PSU, we had decided to conduct interviews in separate PSUs for female and male respondents. The number of male and female PSUs was further divided equally into rural and urban areas. Within each sampling domain, a systematic multi-stage sampling design was adopted. Sample selection procedures differed somewhat in rural and urban areas, a detailed description of which can be found in the Youth in India study report (International Institute for Population Sciences and Population Council, 2009: sections 1.8.1.a and 1.8.1.b). As mentioned above, in 2012, we returned to these PSUs.

\subsubsection{Selection of individual respondents}

Selection of individual respondents differed somewhat between the two surveys.

In the survey conducted for the Youth in India study, within each PSU, households were first selected by systematic random sampling and the value of the interval (between one selected household and the next) was determined in advance to ensure a self-weighing design. Since fewer unmarried males than available were required to be interviewed, a further interval was computed, using the target sample for unmarried males. No such interval was necessary for unmarried females, and one unmarried girl from each selected household in the PSU containing one or more unmarried girls was selected for interview.

Given the sensitive nature of the survey, within each selected household, no more than one unmarried respondent was interviewed. In 2007, in case more than one respondent was found in the household, one respondent was selected randomly using the Kish table. No replacement of the respondent thus selected was allowed.

In the survey carried out for the Adolescents and Youth in Rajasthan 2012 study, within each PSU, at the time of household listing, we recorded the name, sex and age of all adolescents aged 15-19 residing in each household. Following the household listing exercise, a list of all eligible adolescents living in a PSU was prepared and the systematic random sampling method was used to select 12 boys (in the case of a male PSU) and 20 girls (in the case of a female PSU) for interview. No replacement of the respondent thus selected was allowed.

\subsubsection{Sample weights}

In both surveys, the sample was weighted at the level of the sampling domain, that is, urban and rural males and females, respectively, making for a total of four sampling domains. In order to consider differential non-response 
rates in different geographical areas, non-response rates were calculated in smaller sub-domains of 4-5 PSUs within each domain.

A detailed discussion of the calculation of sampling weights in the Youth in India survey may be found elsewhere (International Institute for Population Sciences and Population Council, 2009: section 1.8.3). We note, however, that because of the slightly different approaches taken to select individual respondents in the two surveys (for example, in 2007, we used a two-step procedure to select adolescents-first a household was selected and one adolescent per household, if available, was interviewed; however, in 2012 adolescents were directly selected from a list of adolescents prepared for each PSU), the calculation of weights for the 2012 survey was slightly different from that for the 2007 survey. Specifically, in 2012, unlike in 2007, the adjustment for selecting one respondent per household using the Kish table was not necessary since adolescents were selected directly from the list, and hence weights were calculated on the basis of the probability of selecting an adolescent within a PSU.

\subsection{Recruitment, training and fieldwork}

Some 35 young men and women underwent interviewer training; of these, on the basis of performance, 28 were recruited as field investigators. Additionally, eight individuals were recruited and underwent training for mapping and household-listing exercises.

Training of interviewers was conducted by the principal investigators. Household-listing staff underwent a one-day training, during which they were familiarised with household-listing procedures in both classroom and field situations. Training of field investigators for the main survey lasted ten days. It included lectures and interactive sessions on a range of issues, such as the sexual and reproductive health situation of youth in India, an overview of gender issues, ethical issues in research, violence against women, mental health, as well as detailed explanations of sex and contraception. Efforts were also made to enable the trainees to overcome their inhibitions about discussing sexual and reproductive health matters. The trainees were familiarised with each module of the questionnaire, complicated concepts and questions and their underlying rationale. Role-plays and mock interviews were conducted with reference to each module. Towards the end of the training programme, field practice sessions were organised in which trainees were taken to a village and an urban slum and asked to conduct interviews. The training team monitored each trainee's progress on a regular basis and selected as interviewers only those trainees who demonstrated a full understanding of the questionnaire as well as the ability to ask questions appropriately and record responses accurately.

The interviewers were divided into eight teams, four each to interview young men and young women, respectively. Male interviewers interviewed young men and female interviewers interviewed young women. Each team comprised one field editor who was responsible for field editing, back-checks and quality control of interviews; and one supervisor, responsible for the overall management of fieldwork and team-related logistics as well as assisting in field editing and back-checking.

A research coordinator was deputed to oversee fieldwork and ensure that correct survey procedures were followed and data quality maintained. Principal investigators made frequent visits to monitor and supervise data collection operations. Each team filled quality control sheets regularly, giving the team, the coordinator and principal investigators a quick view of the quality of ongoing fieldwork. These quality control sheets were designed to provide information on response rates in each PSU covered, and track reporting of sensitive issues and interviewer performance.

\subsection{Ethical considerations}

We followed the same ethical procedures in the Adolescents and Youth in Rajasthan 2012 study that had been used in the Youth in India study. A number of ethical issues arose which influenced the design and implementation of the studies.

First, to address concerns that if interviews with young women and men are conducted in the same PSU, it could lead to teasing, harassment, harm to girls' reputations and even violence, the 2007 Youth in India study was undertaken in one set of PSUs for young men and in a completely different set of PSUs for young women; the same procedure was followed in the Adolescents and Youth in Rajasthan 2012 study since our sample was drawn from these PSUs. Second, interviewers underwent extensive training in ethical issues. Emphasis was laid on explaining the 
content of the questionnaire, the respondent's right to refuse to participate or answer any question, and informed consent. At the same time, we trained interviewers on how to ask sensitive questions-regarding sexual experience, domestic violence and forced sex, in particular-in empathetic and non-judgemental ways, and emphasised the importance of offering to refer those in need to appropriate nearby organisations. Third, before entering a PSU, teams were instructed to apprise community leaders of the study and seek their support for its implementation in the community. This step ensured that community support was forthcoming and enabled team members to build rapport within the community easily. We note that despite the sensitive nature of the questions, not a single PSU in Rajasthan refused permission to our teams on the grounds of study content.

Fourth, even though consent was sought from each individual to be interviewed, in the case of adolescents aged 15-17, consent was also sought from a parent or guardian. Research assistants explained to respondents and parents the purpose, the study procedures, risks and benefits of participating in the study, voluntariness of participation and the steps taken to ensure confidentiality, and obtained their written consent. They also informed the parent/guardian that the adolescent retained the right to decline to participate in the study fully or partially, and that the parent/guardian would not have access to any information provided by the adolescent. If the parent gave permission to participate in the study but the adolescent did not give informed consent, the adolescent was not included in the study.

Fifth, all questionnaires were anonymous and names were never recorded on them. In order to preserve the confidentiality of the respondent or the parent/guardian, signing the consent form was optional; however, the interviewer was required to sign that she or he had explained the content of the consent form to the respondent or parent. Consent forms were detached and stored separately from the questionnaires.

Sixth, every effort was made to maintain privacy in the course of the interview. Interviewers were permitted to skip to relatively non-sensitive sections in case the interview was observed by parents or other family members. If possible, particularly in the case of young men, interviews were held outside the home-often in a nearby field-in order to ensure privacy. Each team was trained to assign one interviewer to conduct parallel discussion sessions with bystanders, thereby providing privacy to the interview. This proved particularly useful in the case of interviews with girls. Finally, the interviewers were instructed that if privacy could not be ensured, the interview must be terminated without asking sensitive questions. Due to these strategies, a few interviews had to be terminated for want of privacy and in no case was an adolescents' privacy breached.

Finally, if an adolescent requested help, the study teams made efforts to link them to appropriate NGOs or government facilities.

\subsection{Data processing}

All completed questionnaires were sent to the Council's office in New Delhi for editing and data processing. Completed questionnaires were rechecked and further edited in the office for omissions and consistency. Responses to open-ended questions were scrutinised and common responses were provided codes. For entering the edited data, a special software package was developed using CSPro 4.0. Data were entered twice by different entry operators to minimise entry problems. The raw data were validated and cleaned to remove possible inconsistencies. The analysis of data was carried out using STATA 12.0.

\subsection{Interview outcomes}

Table 1.1 provides the outcome of interviews with eligible male and female respondents from rural and urban areas. In 2007, a total of 2,423 adolescents were selected for interview (1,597 girls and 826 boys), and interviews were completed with 2,261 of these adolescents (1,487 girls and 774 boys), resulting in an overall response rate of 93 percent (93-94\% among boys and girls). In 2012, a total of 2,018 adolescents were selected for interview (1,224 girls and 794 boys), and interviews were completed with 1,909 of these adolescents (1,164 girls and 745 boys), resulting in an overall response rate of 95 percent (94-95\% among girls and boys). The response rate in 2012 was thus slightly higher than the response rate observed in 2007. Response rates did not vary much by residence in both the surveys. The main reason for non-response in both surveys was that the respondent was not at home (4-5\% among boys and $3-6 \%$ among girls in the two surveys). We attribute the low refusal rates to the strategies described earlier to address ethical concerns, which, at the same time, enabled the development of considerable rapport and trust between study communities and our interview teams. 


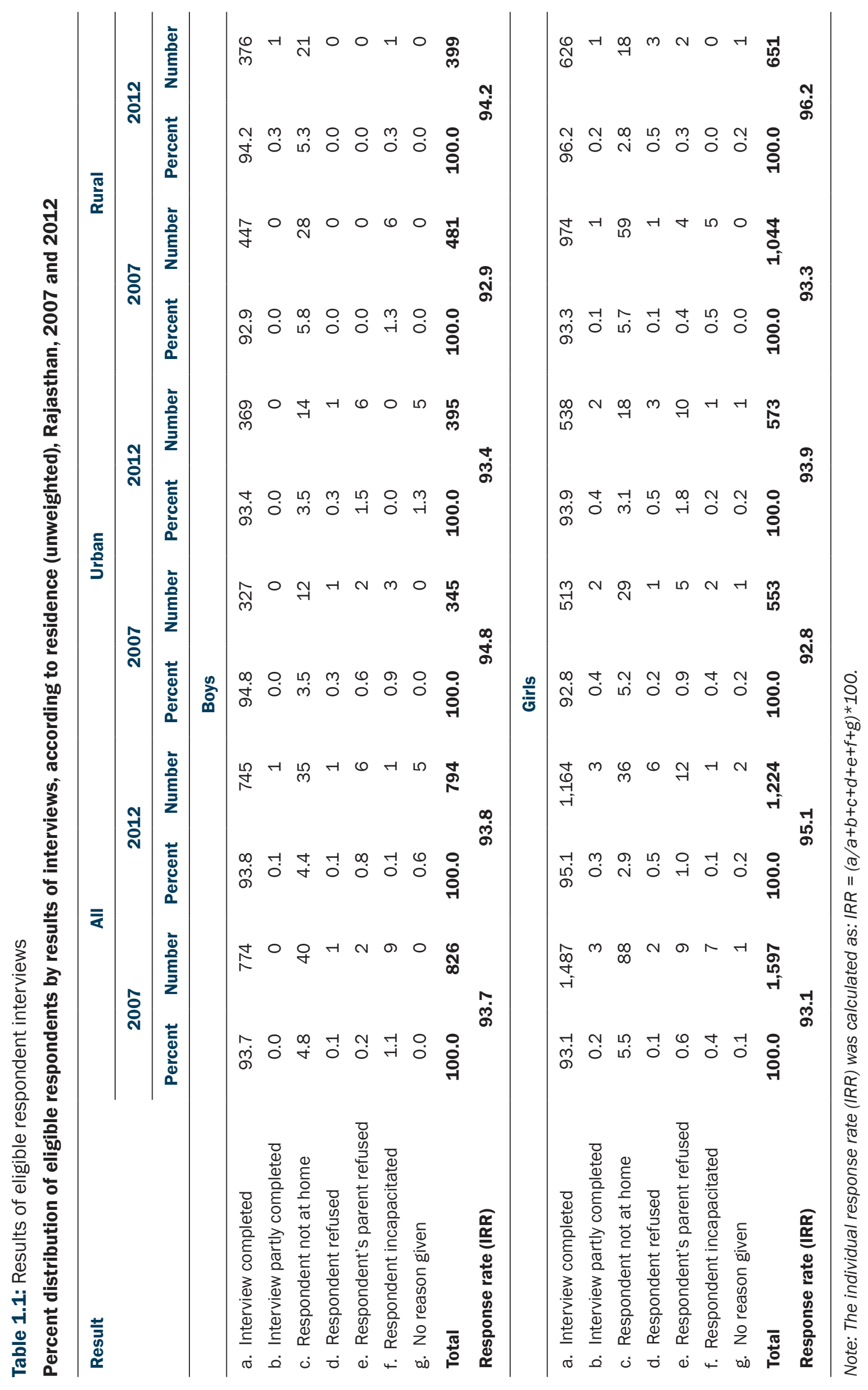




\subsection{Structure of the report}

In this report, we compare the situation, experiences and needs of adolescents aged 15-19 in 2012, with those reported by 15-19 year-old adolescents surveyed five years earlier. As such, this report is structured as follows. Chapter 2 provides a socio-demographic profile of the surveyed population and respondents in the 2007 and 2012 surveys. Chapters 3, 4 and 5 discuss young people's educational attainment patterns, economic activity, skill acquisition and migration experiences and media exposure, respectively. Chapter 6 discusses growing up issues, including young people's relationships with parents and peers, communication with parents about marriage-related planning and adolescents' involvement in planning their marriage. Chapters 7 and 8 focus, respectively, on young people's autonomy and gender role attitudes, and awareness of sexual and reproductive health matters. Chapter 9 describes the formation of romantic relationships and sexual experience with romantic and non-romantic partners. Chapter 10 presents information on health and health-seeking behaviour and substance use. Chapter 11 focuses on civic and political participation and related attitudes. A summary of each chapter (Chapters 3-11) is provided at its conclusion. Finally, Chapter 12 offers recommendations for programmes and research.

In each chapter, we present levels of comparable indicators for both the 2007 and 2012 surveys and indicate the statistical significance of the change from 2007 to 2012 in the levels of these indicators. As noted earlier, in several instances, additional questions had been posed in 2012, and the levels of these indicators are also presented. Differentials by such background characteristics as age, religion, ethnicity (caste), educational level, work and wealth quintiles are presented for the 2012 survey only. All means, medians and percentages indicated in the tables have been weighted using normalised weights for the total population. However, in order to show the total number of adolescents interviewed, unweighted numbers of respondents (Ns) are provided in each table. Because numbers are unweighted and percentages are weighted, we caution readers against deriving numbers based on the percentages provided in the tables. 


\section{Chapter 2 \\ Socio-demographic profile of adolescents}

This chapter presents a socio-demographic profile of the households in which the adolescents who participated in our study resided as well as the adolescents' own socio-demographic profile and the characteristics of their parents.

\subsection{Characteristics of adolescents' households}

Table 2.1 provides information on the quality of housing and access to basic amenities in the households in which the surveyed adolescents resided. Information was obtained from responses to the household questionnaire fielded in 2007 and from adolescents themselves in 2012 and may not, therefore, be completely comparable. In the case of housing type, responses were obtained from interviewer observations. Information is presented by rural-urban residence separately for all households containing adolescents who were interviewed in the two surveys.

Overall, the interviewers observed that in 2012 over 90 percent of adolescents' residences were owned by a household member, and while more rural than urban adolescents so reported, changes over time were not observed in either rural or urban areas. In addition, about one-fifth of adolescents lived in kachcha houses (19\%) constructed from mud, thatch or other low-quality materials, another one-fifth (19\%) lived in semi-pucca houses (constructed using a mix of low- and high-quality materials) and the large majority (62\%) lived in pucca houses (constructed entirely from cement, masonry or other high-quality materials, a somewhat higher proportion than that obtained in the 2005-06 National Family Health Survey-3 (NFHS-3) (50\%) (International Institute for Population Sciences and Macro International, 2007a), and similar to what was reported in the 2007 survey (65\%). As expected, urban adolescents were far more likely than the rural to reside in a pucca home (93\% versus $48 \%$ ). We note that housing quality had declined significantly over time among both all households and rural households in which the adolescents resided.

One-half of all residential structures contained 2-3 rooms (51\%) and about one-quarter (26\%) contained just one room. There appears to have been a decline over time in the number of rooms per residential structure: for example, in 2012, 23 percent of adolescents resided in homes with four or more rooms, compared to 34 percent in 2007. Rural-urban differences suggest that somewhat more urban than rural adolescents lived in homes with four or more rooms in 2012 (27\% versus 21\%). Along with the decline in the number of rooms, there was an increase in the number of persons per room between 2007 and 2012, from 2.0 in 2007 to 3.0 in 2012. Rural households contained somewhat more persons per room than did urban households (3.0 and 2.5, respectively).

As Table 2.1 shows, 91 percent of adolescents' households had electricity in 2012, significantly more than in 2007 when just 75 percent of households had electricity, and more than Rajasthan as a whole as assessed in NFHS-3 in 2005-06 (66\%) (International Institute for Population Sciences and Macro International, 2007a). While almost all urban households reported the availability of electricity at both times (97-99\%), over the five-year period, rural households with electricity had increased considerably from 67 percent in 2007 to 87 percent in 2012. For the majority of households (86\%), the main source of drinking water was either piped water or water obtained from a hand-pump or a covered well; about the same as that reported in 2007 (89\%). While not entirely comparable, 82 percent of households in 2005-06 (NFHS-3) had access to an improved source of drinking water, defined to include piped water, tube-well or borehole water, protected well or spring water, rainwater or bottled water (International Institute for Population Sciences and Macro International, 2007a). These facilities were reported as self-owned by 49 percent of all adolescents in 2012, compared to 44 percent reporting so in 2007. Again, rural-urban differences were marked and similar in 2007 and 2012: while virtually all (99-100\%) of urban adolescents' households had access to safe sources of drinking water, just 80-85 percent of rural adolescents, reported as such.

Access to a toilet facility of any kind was reported by a few-just 45 percent of adolescents in 2012, compared to 37 percent in 2007 and 31 percent as assessed in NFHS-3 in 2005-06 for the state as a whole (International Institute for Population Sciences and Macro International, 2007a). Notably, significantly more households reported having a 
toilet facility in 2012 than 2007 in both urban and rural areas. Even so, large rural-urban differences continued to be observed: 74 percent of rural households, compared to 14 percent of urban households, had no access to toilet facilities.

Finally, distributions of adolescents' households by type of fuel used for cooking suggest a significant change between 2007 and 2012 in both rural and urban areas. The main source of cooking fuel was coal, charcoal, wood, crop residue or dung cakes, reported by 69 percent of adolescents in 2012, compared to 79 percent in 2007, and 77 percent for Rajasthan as a whole in 2005-06, as assessed in NFHS-3 (International Institute for Population Sciences and Macro International, 2007a). A notable increase in the use of liquid petroleum gas was reported-in urban areas, use increased from 65 percent to 76 percent and, in rural areas, while impressive increases over time were also observed, very few rural adolescents reported the use of liquid petroleum gas even in 2012 (from $4 \%$ to $9 \%$ between 2007 and 2012).

Table 2.1: Housing characteristics

Percent distribution of the households of surveyed adolescents by selected housing characteristics, according to residence, Rajasthan, 2007 and 2012

\begin{tabular}{|c|c|c|c|c|c|c|}
\hline \multirow[b]{2}{*}{ Housing characteristics } & \multicolumn{2}{|c|}{ All (\%) } & \multicolumn{2}{|c|}{ Urban (\%) } & \multicolumn{2}{|c|}{ Rural (\%) } \\
\hline & 2007 & 2012 & 2007 & 2012 & 2007 & 2012 \\
\hline \multicolumn{7}{|l|}{ Ownership of residence } \\
\hline Yes & 94.5 & 92.9 & 84.8 & 81.7 & 98.1 & 98.0 \\
\hline No & 5.5 & 7.1 & 15.2 & 18.3 & 1.9 & 2.0 \\
\hline Significance level & \multicolumn{2}{|c|}{ * } & \multicolumn{2}{|c|}{-} & \multicolumn{2}{|c|}{-} \\
\hline \multicolumn{7}{|l|}{ Type of house } \\
\hline Kachcha & 20.8 & 19.0 & 2.4 & 2.0 & 27.5 & 26.7 \\
\hline Semi-pucca & 13.8 & 19.0 & 5.6 & 5.1 & 16.7 & 25.4 \\
\hline Pucca & 65.4 & 62.0 & 92.1 & 92.8 & 55.7 & 47.8 \\
\hline Significance level & \multicolumn{2}{|c|}{ * } & \multicolumn{2}{|c|}{-} & \multicolumn{2}{|c|}{$* * *$} \\
\hline \multicolumn{7}{|l|}{ Numbers of rooms in the house ${ }^{1}$} \\
\hline 1 & 14.1 & 25.8 & 10.6 & 22.7 & 15.4 & 27.2 \\
\hline $2-3$ & 51.8 & 51.2 & 46.9 & 50.0 & 53.5 & 51.8 \\
\hline $4-5$ & 25.7 & 16.7 & 33.1 & 18.5 & 23.1 & 15.8 \\
\hline 6 or more & 8.4 & 6.3 & 9.4 & 8.9 & 8.0 & 5.2 \\
\hline Significance level & \multicolumn{2}{|c|}{$* * *$} & \multicolumn{2}{|c|}{ *** } & \multicolumn{2}{|c|}{$* * *$} \\
\hline \multicolumn{7}{|l|}{ Average number of persons per room } \\
\hline Up to 3 & 65.4 & 49.9 & 73.8 & 61.4 & 62.4 & 44.7 \\
\hline $3-4$ & 15.9 & 18.1 & 11.9 & 14.1 & 17.3 & 19.9 \\
\hline $4-5$ & 7.1 & 10.6 & 5.6 & 9.0 & 7.6 & 11.4 \\
\hline 5 or more & 11.6 & 21.4 & 8.6 & 15.5 & 12.7 & 24.1 \\
\hline Significance level & \multicolumn{2}{|c|}{$* * *$} & \multicolumn{2}{|c|}{$* * *$} & \multicolumn{2}{|c|}{ *** } \\
\hline Median number of persons per room & 2.0 & 3.0 & 2.0 & 2.5 & 2.3 & 3.0 \\
\hline \multicolumn{7}{|l|}{ Source of lighting } \\
\hline Electricity & 75.2 & 90.7 & 97.2 & 99.3 & 67.2 & 86.7 \\
\hline Kerosene & 24.6 & 8.8 & 2.7 & 0.6 & 32.5 & 12.5 \\
\hline Other lighting sources ${ }^{2}$ & 0.2 & 0.5 & 0.2 & 0.1 & 0.2 & 0.8 \\
\hline Significance level & \multicolumn{2}{|c|}{$* \star \star$} & \multicolumn{2}{|c|}{$* * *$} & \multicolumn{2}{|c|}{$* * *$} \\
\hline
\end{tabular}


Table 2.1: (Cont'd)

\begin{tabular}{|c|c|c|c|c|c|c|}
\hline \multirow[b]{2}{*}{ Housing characteristics } & \multicolumn{2}{|c|}{ All (\%) } & \multicolumn{2}{|c|}{ Urban (\%) } & \multicolumn{2}{|c|}{ Rural (\%) } \\
\hline & 2007 & 2012 & 2007 & 2012 & 2007 & 2012 \\
\hline \multicolumn{7}{|l|}{ Source of drinking water } \\
\hline $\begin{array}{l}\text { Owned piped water/Hand pu } \\
\text { well/Bore well }\end{array}$ & 43.8 & 48.8 & 80.2 & 81.6 & 30.7 & 33.7 \\
\hline $\begin{array}{l}\text { Public piped water/Hand pu } \\
\text { well/Bore well }\end{array}$ & 44.9 & 37.5 & 19.6 & 17.7 & 54.1 & 46.7 \\
\hline Own open well & 2.1 & 1.2 & 0.0 & 0.3 & 2.9 & 1.6 \\
\hline Public open well & 4.5 & 7.2 & 0.2 & 0.0 & 6.1 & 10.5 \\
\hline Others water sources ${ }^{3}$ & 4.6 & 5.3 & 0.0 & 0.5 & 6.3 & 7.5 \\
\hline Significance level & \multicolumn{2}{|c|}{ * } & \multicolumn{2}{|c|}{-} & \multicolumn{2}{|c|}{-} \\
\hline \multicolumn{7}{|l|}{ Toilet facility } \\
\hline Own flush toilet & 28.2 & 32.2 & 69.8 & 64.2 & 13.1 & 17.5 \\
\hline $\begin{array}{l}\text { Shared/Public/Common/Go } \\
\text { flush toilet }\end{array}$ & 2.8 & 6.5 & 8.7 & 16.9 & 0.6 & 1.8 \\
\hline Own pit toilet & 5.8 & 6.0 & 3.4 & 4.7 & 6.7 & 6.6 \\
\hline Shared pit toilet & 0.7 & 0.4 & 1.5 & 0.1 & 0.5 & 0.6 \\
\hline No toilet facility & 62.5 & 54.6 & 16.6 & 13.6 & 79.2 & 73.5 \\
\hline Significance level & \multicolumn{2}{|c|}{$* * *$} & \multicolumn{2}{|c|}{$* * *$} & \multicolumn{2}{|c|}{$* *$} \\
\hline \multicolumn{7}{|c|}{ Main type of fuel used for cooking } \\
\hline Liquid petroleum gas (LPG) & 20.3 & 29.9 & 64.5 & 76.1 & 4.4 & 8.6 \\
\hline Kerosene & 0.8 & 0.8 & 1.6 & 1.8 & 0.5 & 0.3 \\
\hline Bio-gas & 0.0 & 0.1 & 0.0 & 0.1 & 0.0 & 0.1 \\
\hline \multicolumn{7}{|c|}{ Wood/Crop residue/Dung cakes/Coal/ } \\
\hline Charcoal/Leaves & 78.9 & 68.9 & 33.9 & 21.3 & 95.1 & 90.7 \\
\hline Other types of fuel ${ }^{4}$ & 0.1 & 0.4 & 0.1 & 0.7 & 0.0 & 0.3 \\
\hline Significance level & \multicolumn{2}{|c|}{$* * *$} & \multicolumn{2}{|c|}{$* * *$} & \multicolumn{2}{|c|}{$* * *$} \\
\hline Number of households & 2,261 & 1,909 & 840 & 907 & 1,421 & 1,002 \\
\hline
\end{tabular}

Note: All Ns are unweighted. -, ${ }^{*},{ }^{* *}$ and ${ }^{* * *}$ indicate that differences between 2007 and 2012 are not significant, and significant at $p \leq 0.05, p \leq 0.01$ and $p \leq 0.001$, respectively. Column totals may not equal $100 \%$ due to missing cases or "don't know" responses. ${ }^{1}$ Excludes toilets/bathrooms but includes kitchen. ${ }^{2}$ Includes oil, gas, etc. ${ }^{3}$ Includes water of a spring, river, stream, pond, lake or dam, rain water and tanker/truck water. ${ }^{4}$ Includes electricity, straw, shrubs and grass.

\subsection{Characteristics of adolescents' households: Overall economic status}

Household economic status was measured using a wealth index composed of household asset data on ownership of selected durable goods, including means of transportation as well as data on access to a number of amenities. The wealth index was constructed by allocating the following scores to a household's reported assets or amenities:

Type of house: 2 for pucca; 1 for semi-pucca; 0 for kachcha.

Agricultural land owned: 4 for more than 10 acres; 3 for 5.1-10.0 acres; 2 for 2.6-5.0 acres; 1 for less than 2.6 acres, or if the household owns some land but does not know how much; 0 for no land.

Irrigated land owned: 1 for any irrigated land; 0 for no land.

Access to a toilet facility: 4 for own flush toilet; 2 for shared flush toilet or own pit toilet; 1 for shared pit toilet or other types of toilet; 0 for no toilet facility. 
Cooking fuel used: 2 for liquid petroleum gas, electricity or bio-gas; 1 for kerosene, wood, crop residue, dung cakes, coal or charcoal; 0 for other types of cooking fuel, for example, straw, shrubs or grass.

Access to a drinking water facility: 4 for own piped water, hand-pump or covered well; 3 for own open well; 2 for public or shared piped water, hand-pump or covered well; 1 for public or shared open well; 0 for other sources of drinking water, for example, surface water, tanker/truck or rain water.

Access to electricity: 3 for electricity; 0 for no electricity.

Ownership of household assets: 4 for car or truck; 3 each for motorcycle or scooter, refrigerator, computer/laptop, telephone (landline or mobile), colour television; 2 each for bicycle, electric fan, radio or transistor, black-and-white television, sewing machine, water pump, animal-drawn cart; 1 for watch or clock; 0 for each of the above items that the household does not possess.

Index scores, so constructed, ranged from 0 to 54. The households were then ranked according to the index score. This ranked sample was divided into quintiles-that is, five groups, each containing an equal number of householdswith the first quintile representing households of the lowest (poorest) wealth status and the fifth quintile representing households with the highest (wealthiest) status. We note that in the Youth in India 2006-2007 study (International Institute for Population Sciences and Population Council, 2009; 2010), wealth quintiles were developed at the state level on the basis of the weighted sample for the whole state and calculated for all households, irrespective of whether they contained an eligible youth respondent; in this report, however, because data were collected only from adolescents, for comparison purposes, wealth quintiles have been calculated only for households containing an adolescent aged 15-19.

The economic status of the households in 2007 and 2012 is presented in Table 2.2. A significant increase has taken place over time in the ownership of most household assets in both rural and urban areas. As far as ownership of household assets was concerned, by 2012, the ownership of a mobile (or landline) phone in adolescents' households increased spectacularly-from 40 percent in 2007 to 95 percent in 2012. Indeed, ownership of a telephone was reported by slightly more adolescents than was the ownership of a watch or clock (92\%) in 2012. Other assets owned by more than one-half of all households included an electric fan (87\%, up from 70\% in 2007), a colour television set (57\%, up from $27 \%$ in 2007) and a bicycle (54\%, down from 61\% in 2007). Also notable was the increase in ownership of such assets as a motorcycle or scooter (from $28 \%$ to $41 \%$ ), a refrigerator (from $18 \%$ to $31 \%$ ) and a computer (from $2 \%$ to 10\%). While rural-urban differences were observed for most assets, with rural households less likely than urban households to report ownership of most items, some notable changes were evident with regard to ownership patterns over the five-year period. For example, by 2012, rural-urban differences in the ownership of a mobile or landline telephone were negligible and had increased far more spectacularly among rural than urban adolescents (from 30\% to 94\% in rural areas, and from 69\% to 97\% in urban areas). Moreover, despite persisting rural-urban differences in the case of other assets, increases in ownership were greater among adolescents in rural than urban areas: for example, the ownership of a colour television set increased from 15 percent to 44 percent among rural adolescents compared to an increase from 63 percent to 86 percent among their urban counterparts. Also notable is the considerable increase in the ownership of a computer-from eight percent to 25 percent in urban areas compared to a negligible increase in rural areas (from 0\% to 4\%). Very few adolescents reported that their households did not contain a single asset; even so, percentages fell from 2007 to 2012 (from $5 \%$ to $1 \%$ overall; from $1 \%$ to $0 \%$ in urban areas, and from $6 \%$ to $2 \%$ in rural areas).

The distribution of households by wealth quintiles shows that 41 percent of urban adolescents resided in households in the wealthiest (fifth) quintile; in contrast, just 10 percent of rural adolescents resided in households in this quintile. Conversely, more than one-quarter of adolescents from rural households (27\%) were in the poorest (first) quintile of the index compared to only five percent of adolescents from urban households. Overall, change over time in wealth status was mild in rural areas, although urban households appear to be significantly more likely to fall into the first quintile in 2012 than in 2007. 
Table 2.2: Household assets and wealth status

Percentage of households of surveyed adolescents owning selected household assets and percent distribution of adolescents' households by wealth quintiles, according to residence, Rajasthan, 2007 and 2012

\begin{tabular}{|c|c|c|c|c|c|c|}
\hline \multirow[b]{2}{*}{ Housing characteristics } & \multicolumn{2}{|c|}{ All (\%) } & \multicolumn{2}{|c|}{ Urban (\%) } & \multicolumn{2}{|c|}{ Rural (\%) } \\
\hline & 2007 & 2012 & 2007 & 2012 & 2007 & 2012 \\
\hline \multicolumn{7}{|l|}{ Assets owned } \\
\hline Electric fan & 69.5 & $86.5^{* * *}$ & 96.3 & $99.2^{* * *}$ & 59.8 & $80.7^{* * *}$ \\
\hline Radio or transistor & 28.8 & $13.8^{* * *}$ & 32.3 & $22.8^{*}$ & 27.6 & $9.7^{* * *}$ \\
\hline Black-and-white television & 21.9 & $5.7^{* * *}$ & 23.4 & $5.6^{* * *}$ & 21.3 & $5.8^{* * *}$ \\
\hline Colour television & 27.3 & $57.1^{* * *}$ & 62.7 & $86.3^{* * *}$ & 14.6 & $43.7^{* * *}$ \\
\hline Sewing machine & 36.4 & $45.3^{* * *}$ & 62.5 & 65.6 & 27.0 & $36.0^{* * *}$ \\
\hline Telephone (landline/mobile) & 40.0 & $95.0^{* * *}$ & 69.1 & $97.4^{* * *}$ & 29.5 & $93.9^{* * *}$ \\
\hline Personal computer/Laptop & 2.2 & $10.2^{* * *}$ & 7.9 & $24.5^{* * *}$ & 0.1 & $3.6^{* * *}$ \\
\hline Refrigerator & 18.1 & $30.7^{* * *}$ & 47.5 & $61.6^{* * *}$ & 7.4 & $16.5^{* * *}$ \\
\hline Watch/Clock & 92.4 & 92.4 & 98.1 & 97.2 & 90.4 & 90.2 \\
\hline Bicycle & 60.9 & $54.1^{* *}$ & 75.2 & $59.5^{* * *}$ & 55.8 & 51.6 \\
\hline Motor cycle/Scooter & 28.1 & $40.5^{* * *}$ & 48.9 & $57.9^{* *}$ & 20.5 & $32.5^{* \star *}$ \\
\hline Animal-drawn cart & 6.5 & $4.4^{*}$ & 0.2 & 0.2 & 8.8 & 6.3 \\
\hline Car/Truck & 2.7 & $5.0^{* * *}$ & 7.1 & $10.3^{*}$ & 1.1 & $2.6^{* *}$ \\
\hline Water pump & 9.3 & $18.2^{* \star *}$ & 7.8 & $20.5^{* * *}$ & 9.8 & $17.1^{* * \star}$ \\
\hline Thresher & 1.7 & 1.5 & 0.0 & $0.5^{*}$ & 2.4 & 1.9 \\
\hline Tractor & 4.4 & 5.9 & 0.4 & $1.4^{*}$ & 5.9 & 8.0 \\
\hline None of the above & 4.5 & $1.1^{* \star *}$ & 0.6 & $0.0^{*}$ & 6.0 & $1.6^{* * *}$ \\
\hline \multicolumn{7}{|l|}{ Wealth quintile } \\
\hline First & 20.0 & 20.0 & 2.1 & 4.5 & 26.5 & 27.1 \\
\hline Second & 20.0 & 20.1 & 9.7 & 11.5 & 23.7 & 24.0 \\
\hline Third & 20.0 & 20.0 & 16.3 & 14.3 & 21.4 & 22.6 \\
\hline Fourth & 20.0 & 20.0 & 25.6 & 29.0 & 17.9 & 15.8 \\
\hline Fifth & 20.0 & 20.0 & 46.3 & 40.8 & 10.4 & 10.4 \\
\hline Significance level & \multicolumn{2}{|c|}{ - } & \multicolumn{2}{|c|}{ * } & \multicolumn{2}{|c|}{ - } \\
\hline Number of households & 2,261 & 1,909 & 840 & 907 & 1,421 & 1,002 \\
\hline
\end{tabular}

Note: All Ns are unweighted. -, ${ }^{*},{ }^{* \star}$ and ${ }^{* * *}$ indicate that differences between 2007 and 2012 are not significant, and significant at $p \leq 0.05, p \leq 0.01$ and $p \leq 0.001$, respectively.

\subsection{Profile of surveyed adolescents: Background characteristics}

A total of 1,909 adolescents aged 15-19 were interviewed in 2012, in study sites, compared with 2,261 adolescents interviewed in the 2007 survey. Table 2.3 presents the socio-demographic characteristics of the surveyed adolescents. Age profiles suggest that a larger proportion of boys was concentrated in the three ages 15-17 than in the two ages 18-19 (68\% versus 32\%) with little change over time. Girls, in contrast, were disproportionately concentrated in the younger age group at both times (75\% and 80\% in 2012 and 2007, respectively). Notably, however, age distributions, both among all girls, and those in rural areas, had changed significantly between 2007 and 2012; the decline in percentages aged 15-17 may be indicative of a decline in child (under 18) marriages during the inter-survey period. Rural-urban differences were, however, negligible, with almost identical percentages in each age group (for example, $69 \%$ versus $66 \%$ of boys, and $76 \%$ versus $72 \%$ of girls, were aged $15-17$ ); gender differences remained evident in both rural and urban areas. 
The distribution of adolescents by religion was fairly identical at both times. In 2012, 94 percent of adolescent boys were Hindu, 5 percent were Muslim and one percent belonged to other religions (compared to 93\%, 5\% and 2\%, respectively, in 2007). Among adolescent girls as well, distributions were similar at both times; 82 percent were Hindu, 14 percent were Muslim, and four percent belonged to other religions compared to 83 percent, 13 percent and four percent, respectively, in 2007). Besides, rural-urban differences were evident: adolescents in rural areas were more likely than their urban counterparts to be Hindu, and conversely, less likely to be Muslim.

Caste wise distributions were generally similar at both times, and among boys and girls; in 2012, for example, the majority of adolescents (43-45\%) fell into other backward castes, 20-23 percent into scheduled castes, 11-15 percent into scheduled tribes and 17-24 percent into general castes. Rural-urban differences were also evident: urban adolescents were more likely than rural adolescents to belong to general castes (38\% versus $9 \%$ among boys; and $32 \%$ versus $20 \%$ among girls), about as likely to belong to scheduled castes (22\% versus $23 \%$ among boys; and $18 \%$ versus $22 \%$ among girls) and far less likely to belong to scheduled tribes (3\% versus $19 \%$ among boys; and $7 \%$ versus 14\% among girls). Caste distributions were similar in 2007 as well.

Significant improvements were observed in adolescents' educational attainment levels between 2007 and 2012, although overall levels of educational attainment continued to be low. Distributions suggest that over the five-year inter-survey period, percentages of surveyed adolescents who had never been to school fell from eight percent to two percent among boys and from 20 percent to eight percent among girls. At the same time, levels of secondary education rose appreciably: secondary school completion was attained by 53 percent of boys and 39 percent of girls, up from 38 percent and 22 percent, respectively, in 2007, while percentages of those who had completed a higher secondary education (at least Class 12) also increased impressively-from 11 percent to 17 percent among boys and from eight percent to 16 percent among girls. Gender differences were wide, with girls far less likely than boys to have attained eight or more and ten or more years of education; indeed, in 2012, 70 percent of girls had attained eight or more years of education, and 39 percent had attained a high school education, percentages achieved five years earlier among boys ( $71 \%$ and $38 \%$, respectively). In contrast, gender differences had disappeared with regard to the attainment of a higher secondary education with 17 percent and 16 percent of boys and girls, respectively, having attained this level. Significant improvements in educational attainment were observed likewise, among girls both in rural and urban areas and among boys in rural areas. At the same time, differences persisted by ruralurban residence. Urban adolescents, particularly girls, were generally better educated than rural adolescents, but differences had narrowed between 2007 and 2012. For example, in 2012, 59 percent of urban boys compared to 50 percent of rural boys had completed Class 10, in comparison with 49 percent and 35 percent five years earlier. Among girls too, 51 percent and 32 percent of those in urban and rural areas, respectively, had completed high school in 2012, compared to 40 percent and 15 percent in 2007.

Wage work in the year preceding the interview was reported by similar percentages of boys and girls in 2012: 25 and 23, respectively, reflecting little or no change since 2007. Evidence also showed that while rural and urban boys were equally likely to have been engaged in wage work (25\%), rural girls were somewhat more likely to have been so engaged than their urban counterparts (26\% versus $18 \%)$. Clearly, gender differences were wider in urban than in rural areas.

Household economic status distributions, as measured by wealth quintiles, were generally similar for boys and girls; however, it appears that girls come from somewhat better off households than do boys. We attribute this difference to findings that because child marriage is concentrated among girls rather than boys, and those from poorer rather than better off households, unmarried girls may be disproportionately distributed among better off households than unmarried boys, who rarely marry in adolescence. For example, 22 percent and 18 percent of boys and girls, respectively, belonged to households in the poorest (first) quintile, and 16 percent and 23 percent, respectively, to households in the wealthiest (fifth) quintile. Rural-urban differences were wide, with rural adolescents (25-29\%) more likely than their urban counterparts (4-5\%) to belong to households in the poorest (first) quintile; conversely, more urban than rural adolescents belonged to households in the wealthiest (fifth) quintile (39-42\% versus $6-15 \%)$. Finally, we note that wealth distributions were different in 2007 and 2012, and also displayed different patterns for boys and girls. For example, wealth status appeared to be worse in 2012 than in 2007 for boys, in general, and in urban areas. For girls, in contrast, wealth status distributions, both overall and in rural areas, suggested a better situation in 2012 than in 2007. 
Table 2.3: Background characteristics of surveyed adolescents

Percent distribution of surveyed adolescents by selected background characteristics, according to residence, Rajasthan, 2007 and 2012

\begin{tabular}{|c|c|c|c|c|c|c|c|c|}
\hline \multirow{3}{*}{$\begin{array}{l}\text { Background } \\
\text { characteristics }\end{array}$} & \multicolumn{4}{|c|}{ Boys } & \multicolumn{4}{|c|}{ Girls } \\
\hline & \multicolumn{2}{|c|}{2007} & \multicolumn{2}{|c|}{2012} & \multicolumn{2}{|c|}{2007} & \multicolumn{2}{|c|}{2012} \\
\hline & Percent & Number & Percent & Number & Percent & Number & Percent & Number \\
\hline \multicolumn{9}{|c|}{ Combined } \\
\hline \multicolumn{9}{|l|}{ Age (years) } \\
\hline $15-17$ & 66.5 & 512 & 67.7 & 501 & 79.6 & 1,171 & 74.5 & 862 \\
\hline $18-19$ & 33.5 & 262 & 32.3 & 244 & 20.4 & 316 & 25.5 & 302 \\
\hline \multicolumn{9}{|l|}{ Religion } \\
\hline Hindu & 93.4 & 704 & 93.7 & 673 & 82.7 & 1,210 & 81.9 & 944 \\
\hline Muslim & 4.8 & 52 & 5.3 & 65 & 13.2 & 215 & 13.8 & 175 \\
\hline Other $^{1}$ & 1.8 & 18 & 1.0 & 7 & 4.2 & 62 & 4.4 & 45 \\
\hline \multicolumn{9}{|l|}{ Caste } \\
\hline SC & 21.9 & 172 & 22.9 & 164 & 17.8 & 261 & 20.4 & 231 \\
\hline ST & 13.5 & 89 & 14.8 & 88 & 11.1 & 156 & 11.3 & 123 \\
\hline $\mathrm{OBC}$ & 46.4 & 341 & 45.0 & 307 & 46.8 & 693 & 43.1 & 504 \\
\hline General $^{2}$ & 18.2 & 172 & 16.5 & 178 & 24.4 & 377 & 24.3 & 298 \\
\hline \multicolumn{9}{|c|}{ Educational level (years) } \\
\hline None $^{3}$ & 7.6 & 55 & 2.0 & 16 & 20.0 & 280 & 8.3 & 87 \\
\hline $1-7$ & 21.1 & 156 & 13.7 & 104 & 29.2 & 429 & 22.1 & 257 \\
\hline $8-9$ & 32.9 & 247 & 31.6 & 222 & 28.7 & 422 & 30.9 & 352 \\
\hline $10-11$ & 27.0 & 217 & 35.5 & 268 & 14.1 & 225 & 22.9 & 272 \\
\hline 12 and above & 11.4 & 99 & 17.2 & 135 & 7.9 & 131 & 15.8 & 196 \\
\hline \multicolumn{9}{|c|}{ Worked in last 12 months } \\
\hline Yes & 26.0 & 202 & 24.6 & 190 & 20.1 & 283 & 23.1 & 260 \\
\hline No & 74.0 & 572 & 75.4 & 555 & 79.9 & 1,204 & 76.9 & 904 \\
\hline \multicolumn{9}{|l|}{ Wealth quintile } \\
\hline First & 18.6 & 114 & 22.3 & 126 & 21.5 & 290 & 18.2 & 189 \\
\hline Second & 16.3 & 111 & 22.2 & 130 & 24.2 & 343 & 18.3 & 206 \\
\hline Third & 21.0 & 152 & 20.3 & 136 & 18.9 & 283 & 20.0 & 223 \\
\hline Fourth & 23.2 & 188 & 19.4 & 172 & 16.4 & 254 & 20.0 & 240 \\
\hline Fifth & 20.8 & 209 & 15.9 & 181 & 19.1 & 317 & 23.4 & 306 \\
\hline Total & 100.0 & 774 & 100.0 & 745 & 100.0 & 1,487 & 100.0 & 1,164 \\
\hline
\end{tabular}


Table 2.3: (Cont'd)

\begin{tabular}{|c|c|c|c|c|c|c|c|c|}
\hline \multirow{3}{*}{$\begin{array}{l}\text { Background } \\
\text { characteristics }\end{array}$} & \multicolumn{4}{|c|}{ Boys } & \multicolumn{4}{|c|}{ Girls } \\
\hline & \multicolumn{2}{|c|}{2007} & \multicolumn{2}{|c|}{2012} & \multicolumn{2}{|c|}{2007} & \multicolumn{2}{|c|}{2012} \\
\hline & Percent & Number & Percent & Number & Percent & Number & Percent & Number \\
\hline \multicolumn{9}{|c|}{ Urban } \\
\hline \multicolumn{9}{|l|}{ Age (years) } \\
\hline $15-17$ & 63.3 & 208 & 65.6 & 243 & 70.1 & 359 & 72.2 & 388 \\
\hline $18-19$ & 36.7 & 119 & 34.4 & 126 & 29.9 & 154 & 27.8 & 150 \\
\hline \multicolumn{9}{|l|}{ Religion } \\
\hline Hindu & 81.4 & 267 & 82.9 & 305 & 72.2 & 367 & 74.2 & 398 \\
\hline Muslim & 14.9 & 47 & 16.1 & 60 & 22.5 & 118 & 21.9 & 122 \\
\hline Other ${ }^{1}$ & 3.8 & 13 & 1.1 & 4 & 5.3 & 28 & 3.9 & 18 \\
\hline \multicolumn{9}{|l|}{ Caste } \\
\hline SC & 21.3 & 72 & 21.5 & 75 & 16.8 & 85 & 18.1 & 95 \\
\hline ST & 3.8 & 12 & 3.0 & 11 & 8.2 & 41 & 6.5 & 36 \\
\hline OBC & 38.4 & 122 & 36.1 & 132 & 42.2 & 218 & 42.6 & 231 \\
\hline General $^{2}$ & 36.5 & 121 & 37.7 & 145 & 32.7 & 169 & 32.4 & 174 \\
\hline \multicolumn{9}{|c|}{ Educational level (years) } \\
\hline None $^{3}$ & 6.5 & 21 & 3.0 & 10 & 10.7 & 55 & 2.5 & 15 \\
\hline $1-7$ & 16.6 & 55 & 13.0 & 47 & 25.0 & 128 & 18.5 & 105 \\
\hline $8-9$ & 27.9 & 90 & 25.0 & 92 & 24.0 & 123 & 28.1 & 150 \\
\hline $10-11$ & 31.5 & 103 & 38.0 & 142 & 23.6 & 121 & 28.0 & 146 \\
\hline 12 and above & 17.5 & 58 & 21.0 & 78 & 16.7 & 86 & 22.9 & 122 \\
\hline \multicolumn{9}{|c|}{ Worked in last 12 months } \\
\hline Yes & 28.3 & 92 & 24.9 & 89 & 13.4 & 69 & 18.2 & 97 \\
\hline No & 71.7 & 235 & 75.1 & 280 & 86.6 & 444 & 81.8 & 441 \\
\hline \multicolumn{9}{|l|}{ Wealth quintile } \\
\hline First & 0.8 & 3 & 3.6 & 13 & 3.5 & 18 & 5.4 & 30 \\
\hline Second & 6.1 & 20 & 9.5 & 34 & 14.0 & 72 & 13.7 & 73 \\
\hline Third & 13.7 & 45 & 13.0 & 47 & 19.3 & 99 & 15.9 & 87 \\
\hline Fourth & 28.9 & 94 & 31.8 & 116 & 21.8 & 112 & 25.8 & 135 \\
\hline Fifth & 50.5 & 165 & 42.1 & 159 & 41.4 & 212 & 39.2 & 213 \\
\hline Total & 100.0 & 327 & 100.0 & 369 & 100.0 & 513 & 100.0 & 538 \\
\hline
\end{tabular}


Table 2.3: (Cont'd)

\begin{tabular}{|c|c|c|c|c|c|c|c|c|}
\hline \multirow{3}{*}{$\begin{array}{l}\text { Background } \\
\text { characteristics }\end{array}$} & \multicolumn{4}{|c|}{ Boys } & \multicolumn{4}{|c|}{ Girls } \\
\hline & \multicolumn{2}{|c|}{2007} & \multicolumn{2}{|c|}{2012} & \multicolumn{2}{|c|}{2007} & \multicolumn{2}{|c|}{2012} \\
\hline & Percent & Number & Percent & Number & Percent & Number & Percent & Number \\
\hline \multicolumn{9}{|c|}{ Rural } \\
\hline \multicolumn{9}{|l|}{ Age (years) } \\
\hline $15-17$ & 67.7 & 304 & 68.5 & 258 & 83.0 & 812 & 75.7 & 474 \\
\hline $18-19$ & 32.3 & 143 & 31.5 & 118 & 17.0 & 162 & 24.3 & 152 \\
\hline \multicolumn{9}{|l|}{ Religion } \\
\hline Hindu & 97.8 & 437 & 97.7 & 368 & 86.4 & 843 & 85.9 & 546 \\
\hline Muslim & 1.1 & 5 & 1.3 & 5 & 9.8 & 97 & 9.5 & 53 \\
\hline Other ${ }^{1}$ & 1.1 & 5 & 1.0 & 3 & 3.7 & 34 & 4.6 & 27 \\
\hline \multicolumn{9}{|l|}{ Caste } \\
\hline SC & 22.1 & 100 & 23.4 & 89 & 18.2 & 176 & 21.7 & 136 \\
\hline ST & 17.1 & 77 & 19.1 & 77 & 12.1 & 115 & 13.8 & 87 \\
\hline OBC & 49.3 & 219 & 48.3 & 175 & 48.4 & 475 & 43.4 & 273 \\
\hline General $^{2}$ & 11.5 & 51 & 8.7 & 33 & 21.4 & 208 & 20.1 & 124 \\
\hline \multicolumn{9}{|c|}{ Educational level (years) } \\
\hline None $^{3}$ & 8.0 & 34 & 1.7 & 6 & 23.4 & 225 & 11.3 & 72 \\
\hline $1-7$ & 22.7 & 101 & 13.9 & 57 & 30.8 & 301 & 23.9 & 152 \\
\hline $8-9$ & 34.7 & 157 & 34.0 & 130 & 30.4 & 299 & 32.3 & 202 \\
\hline $10-11$ & 25.4 & 114 & 34.6 & 126 & 10.7 & 104 & 20.3 & 126 \\
\hline 12 and above & 9.2 & 41 & 15.8 & 57 & 4.7 & 45 & 12.1 & 74 \\
\hline \multicolumn{9}{|c|}{ Worked in last 12 months } \\
\hline Yes & 25.2 & 110 & 24.5 & 101 & 22.4 & 214 & 25.7 & 163 \\
\hline No & 74.8 & 337 & 75.5 & 275 & 77.6 & 760 & 74.3 & 463 \\
\hline \multicolumn{9}{|l|}{ Wealth quintile } \\
\hline First & 25.2 & 111 & 29.1 & 113 & 28.0 & 272 & 24.9 & 159 \\
\hline Second & 20.1 & 91 & 26.9 & 96 & 27.8 & 271 & 20.8 & 133 \\
\hline Third & 23.8 & 107 & 22.9 & 89 & 18.7 & 184 & 22.2 & 136 \\
\hline Fourth & 21.1 & 94 & 14.8 & 56 & 14.4 & 142 & 17.0 & 105 \\
\hline Fifth & 9.9 & 44 & 6.2 & 22 & 11.0 & 105 & 15.1 & 93 \\
\hline Total & 100.0 & 447 & 100.0 & 376 & 100.0 & 974 & 100.0 & 626 \\
\hline
\end{tabular}

Note: All Ns are unweighted. Column totals may not equal 100\% due to missing cases or "don't know" responses. OBC: Other backward caste. SC: Scheduled caste. ST: Scheduled tribe. ${ }^{1}$ Includes Christian, Buddhist/Neo-Buddhist, Sikh, Jain, Jewish, Parsi/ Zoroastrian, Sarana and no specified religion. ${ }^{2}$ Includes all those not belonging to SC, ST or OBC. ${ }^{3}$ Includes those who are nonliterate and literate with no formal schooling.

\subsection{Profile of surveyed adolescents: Parental characteristics}

Both studies inquired about the socio-demographic characteristics of the respondents' parents, including their survival status and education. Findings, presented in Table 2.4, suggest that for over 90 percent of adolescents at both times, both parents were surviving (90\% in 2007 and 92\% in 2012). Rural-urban differences were negligible. For those with just one parent surviving, this parent was more likely to be the mother (5-7\% at both times) than the father (2-3\%). Finally, fewer than one percent reported that neither parent was alive (not shown in table). 
Table 2.4: Parental characteristics of surveyed adolescents

Percent distribution of surveyed adolescents by parental characteristics, according to residence, Rajasthan, 2007 and 2012

\begin{tabular}{|c|c|c|c|c|}
\hline \multirow[b]{2}{*}{ Parental characteristics } & \multicolumn{2}{|c|}{ Boys (\%) } & \multicolumn{2}{|c|}{ Girls (\%) } \\
\hline & 2007 & 2012 & 2007 & 2012 \\
\hline \multicolumn{5}{|c|}{ Combined } \\
\hline Both parents alive & 90.4 & 91.5 & 90.4 & 92.1 \\
\hline Live with both parents & 87.5 & 86.3 & 86.1 & 85.8 \\
\hline \multicolumn{5}{|l|}{ Educational attainment } \\
\hline Median years of schooling of father & 5.0 & 7.0 & 6.0 & 7.0 \\
\hline Median years of schooling of mother & 0.0 & 0.0 & 0.0 & 0.0 \\
\hline Number of respondents & 774 & 745 & 1,487 & 1,164 \\
\hline \multicolumn{5}{|c|}{ Urban } \\
\hline Both parents alive & 91.0 & 92.4 & 90.6 & 91.0 \\
\hline Live with both parents & 83.8 & 84.7 & 86.8 & 83.1 \\
\hline \multicolumn{5}{|l|}{ Educational attainment } \\
\hline Median years of schooling of father & 9.0 & 9.0 & 9.0 & 9.0 \\
\hline Median years of schooling of mother & 2.0 & 5.0 & 0.0 & 0.0 \\
\hline Number of respondents & 327 & 369 & 513 & 538 \\
\hline \multicolumn{5}{|c|}{ Rural } \\
\hline Both parents alive & 90.2 & 91.2 & 90.4 & 92.6 \\
\hline Live with both parents & 88.9 & 86.9 & 85.9 & 87.3 \\
\hline \multicolumn{5}{|l|}{ Educational attainment } \\
\hline Median years of schooling of father & 3.0 & 5.0 & 5.0 & 5.0 \\
\hline Median years of schooling of mother & 0.0 & 0.0 & 0.0 & 0.0 \\
\hline Number of respondents & 447 & 376 & 974 & 626 \\
\hline
\end{tabular}

Note: All Ns are unweighted.

The educational attainment of the parents of surveyed adolescents increased between 2007 and 2012. For example, the median number of years of education completed by the fathers of boys and girls was seven years in 2012, compared with six and five years, respectively, in 2007. Rural-urban differences were wide with regard to paternal education at both times but had narrowed over time: in 2012, the median years of schooling ranged from five years among rural fathers to nine years among urban fathers, compared to three and nine years, respectively in 2007. In contrast to improvements in paternal educational levels, maternal education patterns did not display any change. Indeed, over one-half of the mothers, in both 2007 and 2012, had never been to school, and this was evident among mothers of both boys and girls in rural areas and among mothers of girls in urban areas. 


\section{Chapter 3 Education}

Adolescents in India are spending more of their adolescent years acquiring an education than ever before, and increases are rapid. Primary school enrolment is almost universal, educational attainment levels have increased, and gender differences in educational attainment levels have diminished (Ministry of Human Resource Development, 2014). Less clear are the extent to which secondary school education has been attained, and the extent to which disparities in educational attainment persist with regard to gender, caste, religion, region and poverty levels. This chapter examines the educational experiences of adolescents in terms of educational attainment, and reasons for discontinuation, and the changes encountered in this experience of those aged 15-19 in 2012 compared to those aged 15-19 in 2007.

\subsection{Educational attainment}

Both the 2007 and 2012 studies obtained information on whether the respondent had ever been to school and, if so, the number of years of schooling successfully completed. Current schooling status was also assessed, and a Life Event Calendar inquired about the schooling status of all respondents from the age of 12 . Findings are presented in Table 3.1.

Findings suggest a significant improvement in educational attainment among girls and boys, and those (aside from boys in urban areas) in rural and urban areas. By 2012, for example, well over 90 percent of boys and girls had been to school. Indeed, among boys, just two percent had never been enrolled, compared to eight percent among those interviewed in 2007; and urban-rural differences were narrow. Among girls the decline was marked: while 20 percent of the girls interviewed in 2007 had never been to school, this percentage had fallen to eight by 2012. Rural-urban differences were evident despite the fact that there was a considerable decline in percentages of girls in rural areas who had never been to school (23\% in 2007 to $11 \%$ in 2012); indeed, in 2012, 11 percent of rural girls compared to three percent of their urban counterparts had never been to school.

Gender disparities in educational attainment also declined over the experiences of the two cohorts under study. In general, however, it appears that school completion rates attained by girls in 2012 resembled those attained by boys five years earlier: in 2012, more than one-half of all boys (53\%) and almost two-fifths of girls (39\%) had completed ten or more years of education, an increase from 38 percent and 22 percent, respectively, in 2007. By 2012, the average boy had completed a high school education (median of 10 years of education), one year more than in 2007. Among girls, too, the median number of years of education increased by one year, from eight years in 2007 to nine years by 2012.

Rural-urban differences suggest that urban adolescents continued to be better educated than rural adolescents but that disparities had narrowed, particularly among boys. Among boys, 59 percent of those in urban areas compared to 50 percent of those in rural areas had completed Class 10 in 2012, compared with 49 percent and 35 percent, respectively, in 2007. Among girls, as of 2012, 51 percent of those in urban areas compared to just 32 percent of those in rural areas had completed Class 10; in comparison, 40 percent and 15 percent, respectively, had achieved this level in 2007. The average number of years of education in 2012 was 10 years among rural and urban boys and urban girls, among whom the average number of years of education had increased by one year between 2007 and 2012. While rural girls had completed, on average, nine years, that is, one year less than their urban counterparts, the increase between 2007 and 2012 was steeper, namely, two years (from 7 to 9).

Percentages currently pursuing an education also increased substantially. By 2012, 79 percent of boys and 61 percent of girls were in school or college at the time of the interview, compared with 66 percent and 42 percent, respectively, in 2007 , suggesting a considerable narrowing of gender differences over the five-year period. Ruralurban differences, moreover, were negligible at both times among boys (78\% versus $82 \%$ in 2012 as compared with $65 \%$ versus $69 \%$ in 2007), but remained wide among girls (55\% versus 73\% in 2012 as compared with $37 \%$ versus $56 \%$ in 2007). 
Table 3.1: Educational attainment and current educational status

Percent distribution of adolescents by years of schooling successfully completed, median years of schooling and percentage currently in school, according to residence, Rajasthan, 2007 and 2012

\begin{tabular}{|c|c|c|c|c|}
\hline \multirow[b]{2}{*}{ Schooling status } & \multicolumn{2}{|c|}{ Boys (\%) } & \multicolumn{2}{|c|}{ Girls (\%) } \\
\hline & 2007 & 2012 & 2007 & 2012 \\
\hline \multicolumn{5}{|c|}{ Combined } \\
\hline \multicolumn{5}{|c|}{ Completed years of schooling } \\
\hline None $^{1}$ & 7.6 & 2.0 & 20.0 & 8.3 \\
\hline $1-4$ & 3.3 & 3.3 & 7.1 & 6.0 \\
\hline $5-7$ & 17.7 & 10.4 & 22.1 & 16.1 \\
\hline $8-9$ & 32.9 & 31.6 & 28.7 & 30.9 \\
\hline $10-11$ & 27.0 & 35.5 & 14.1 & 22.9 \\
\hline 12 and above & 11.4 & 17.2 & 7.9 & 15.8 \\
\hline Significance level & \multicolumn{2}{|c|}{$* * *$} & \multicolumn{2}{|c|}{ *** } \\
\hline Median years of schooling & 9.0 & 10.0 & 8.0 & 9.0 \\
\hline Currently in school/college & 65.9 & $79.4^{* * *}$ & 42.2 & $60.9^{* * *}$ \\
\hline Number of respondents & 774 & 745 & 1,487 & 1,164 \\
\hline \multicolumn{5}{|c|}{ Urban } \\
\hline \multicolumn{5}{|c|}{ Completed years of schooling } \\
\hline None $^{1}$ & 6.5 & 3.0 & 10.7 & 2.5 \\
\hline $1-4$ & 4.3 & 3.4 & 3.5 & 5.5 \\
\hline $5-7$ & 12.3 & 9.6 & 21.4 & 13.0 \\
\hline $8-9$ & 27.9 & 25.0 & 24.0 & 28.1 \\
\hline $10-11$ & 31.5 & 38.0 & 23.6 & 28.0 \\
\hline 12 and above & 17.5 & 21.0 & 16.7 & 22.9 \\
\hline Significance level & \multicolumn{2}{|c|}{-} & \multicolumn{2}{|c|}{$* * *$} \\
\hline Median years of schooling & 9.0 & 10.0 & 9.0 & 10.0 \\
\hline Currently in school/college & 68.8 & $82.3^{* * *}$ & 56.2 & $72.5^{* * *}$ \\
\hline Number of respondents & 327 & 369 & 513 & 538 \\
\hline \multicolumn{5}{|c|}{ Rural } \\
\hline \multicolumn{5}{|l|}{ Completed years of schooling } \\
\hline None $^{1}$ & 8.0 & 1.7 & 23.4 & 11.3 \\
\hline $1-4$ & 3.0 & 3.3 & 8.4 & 6.2 \\
\hline $5-7$ & 19.7 & 10.6 & 22.4 & 17.7 \\
\hline $8-9$ & 34.7 & 34.0 & 30.4 & 32.3 \\
\hline $10-11$ & 25.4 & 34.6 & 10.7 & 20.3 \\
\hline 12 and above & 9.2 & 15.8 & 4.7 & 12.1 \\
\hline Significance level & \multicolumn{2}{|c|}{$* * *$} & \multicolumn{2}{|c|}{$* * *$} \\
\hline Median years of schooling & 9.0 & 10.0 & 7.0 & 9.0 \\
\hline Currently in school/college & 64.8 & $78.3^{* * *}$ & 37.2 & $54.8^{* * *}$ \\
\hline Number of respondents & 447 & 376 & 974 & 626 \\
\hline
\end{tabular}

Note: All Ns are unweighted. - and ${ }^{* * *}$ indicate that differences between 2007 and 2012 are not significant and significant at $p \leq 0.001$, respectively. ${ }^{1}$ Includes those who are non-literate and literate with no formal schooling. 


\subsection{Differentials in educational attainment}

Differentials observed in educational attainment levels of surveyed boys and girls in 2012, measured with respect to completed years of schooling, are presented in Table 3.2. Findings suggest a positive association between age and years of education completed among boys and girls. We acknowledge that part of this effect may be attributed to the fact that those in the younger ages were pursuing their education at the time of interview.

Differences by religion and caste, shown in Table 3.2, are considerable. As far as the attainment of a high school education (Class 10 or more) is concerned, 31 percent of Muslim boys compared to 54 percent of Hindu boys, and 26 percent of Muslim girls compared to 40 percent and 65 percent of Hindu girls and those from other religions, respectively, had completed a secondary education. A similar pattern was observed among adolescents residing in rural and urban areas. Rural-urban differences are difficult to discern among boys because of small numbers, although among Hindus, considerably fewer boys in rural than urban areas had completed a high school education (51\% versus $63 \%)$. Among girls, rural-urban differences in percentages who had completed a high school education were wide among Hindus (32\% versus 55\%), but narrow among Muslims (23\% versus 28\%). Caste differences

Table 3.2: Educational attainment of adolescents by selected background characteristics

Percent distribution of adolescents by educational level, according to selected background characteristics and residence, Rajasthan, 2012

\begin{tabular}{|c|c|c|c|c|c|c|c|c|}
\hline \multirow[b]{3}{*}{ Background characteristics } & \multicolumn{4}{|c|}{ Boys (\%) } & \multicolumn{4}{|c|}{ Girls (\%) } \\
\hline & \multicolumn{8}{|c|}{ Completed years of schooling } \\
\hline & None $^{1}$ & $1-7$ & $8-9$ & $10+$ & None $^{1}$ & $1-7$ & $8-9$ & $10+$ \\
\hline \multicolumn{9}{|c|}{ Combined } \\
\hline \multicolumn{9}{|l|}{ Age (years) } \\
\hline $15-17$ & 1.3 & 9.7 & 39.9 & 49.0 & 9.4 & 21.9 & 36.0 & 32.7 \\
\hline $18-19$ & 3.5 & 22.0 & 14.2 & 60.4 & 5.0 & 22.6 & 16.0 & 56.4 \\
\hline \multicolumn{9}{|l|}{ Religion } \\
\hline Hindu & 2.1 & 13.3 & 31.0 & 53.5 & 8.8 & 20.3 & 31.3 & 39.6 \\
\hline Muslim & 1.4 & 22.6 & 45.1 & 30.9 & 8.1 & 36.1 & 30.1 & 25.6 \\
\hline Other ${ }^{2}$ & $\#$ & $\#$ & $\#$ & $\#$ & $(0.0)$ & $(10.3)$ & $(24.6)$ & $(65.2)$ \\
\hline \multicolumn{9}{|l|}{ Caste } \\
\hline $\mathrm{SC}$ & 3.5 & 17.7 & 36.7 & 42.2 & 6.4 & 25.8 & 37.3 & 30.4 \\
\hline ST & 7.0 & 26.5 & 30.8 & 35.8 & 19.7 & 31.0 & 24.7 & 24.6 \\
\hline OBC & 0.3 & 7.6 & 33.2 & 58.9 & 8.8 & 22.6 & 31.9 & 36.7 \\
\hline General $^{3}$ & 0.0 & 10.3 & 21.8 & 67.9 & 2.4 & 13.9 & 27.6 & 56.1 \\
\hline \multicolumn{9}{|l|}{ Worked in last 12 months } \\
\hline Yes & 4.9 & 40.7 & 25.6 & 28.9 & 15.9 & 38.7 & 20.3 & 25.1 \\
\hline No & 1.1 & 4.9 & 33.6 & 60.5 & 6.0 & 17.1 & 34.1 & 42.9 \\
\hline \multicolumn{9}{|l|}{ Wealth quintile } \\
\hline First & 3.2 & 20.2 & 42.7 & 33.9 & 21.6 & 38.2 & 25.5 & 14.8 \\
\hline Second & 3.4 & 17.1 & 30.6 & 48.9 & 11.6 & 31.5 & 32.4 & 24.5 \\
\hline Third & 1.2 & 14.0 & 28.5 & 56.4 & 8.5 & 20.4 & 38.5 & 32.6 \\
\hline Fourth & 1.7 & 9.7 & 26.7 & 61.9 & 1.3 & 19.6 & 31.9 & 47.2 \\
\hline Fifth & 0.0 & 4.3 & 27.4 & 68.3 & 1.2 & 5.7 & 26.5 & 66.6 \\
\hline Total & 2.0 & 13.7 & 31.6 & 52.7 & 8.3 & 22.1 & 30.9 & 38.8 \\
\hline
\end{tabular}


Table 3.2: (Cont'd)

\begin{tabular}{|c|c|c|c|c|c|c|c|c|}
\hline \multirow[b]{3}{*}{ Background characteristics } & \multicolumn{4}{|c|}{ Boys (\%) } & \multicolumn{4}{|c|}{ Girls (\%) } \\
\hline & \multicolumn{8}{|c|}{ Completed years of schooling } \\
\hline & None $^{1}$ & $1-7$ & $8-9$ & $10+$ & None $^{1}$ & $1-7$ & $8-9$ & $10+$ \\
\hline \multicolumn{9}{|c|}{ Urban } \\
\hline \multicolumn{9}{|l|}{ Age (years) } \\
\hline $15-17$ & 2.8 & 10.8 & 33.2 & 53.2 & 2.6 & 19.2 & 34.0 & 44.2 \\
\hline $18-19$ & 3.3 & 17.2 & 9.5 & 70.0 & 2.2 & 16.9 & 12.8 & 68.1 \\
\hline \multicolumn{9}{|l|}{ Religion } \\
\hline Hindu & 3.2 & 10.4 & 23.2 & 63.2 & 3.0 & 14.0 & 27.7 & 55.3 \\
\hline Muslim & 1.7 & 27.7 & 32.8 & 37.8 & 1.3 & 37.0 & 33.8 & 27.9 \\
\hline Other ${ }^{2}$ & $\#$ & $\#$ & $\#$ & $\#$ & \# & \# & $\#$ & \# \\
\hline \multicolumn{9}{|l|}{ Caste } \\
\hline SC & 10.0 & 23.5 & 29.6 & 36.9 & 2.1 & 27.0 & 36.5 & 34.4 \\
\hline ST & \# & \# & $\#$ & $\#$ & $(6.4)$ & $(23.9)$ & $(29.6)$ & $(40.1)$ \\
\hline OBC & 1.4 & 9.7 & 29.6 & 59.4 & 3.1 & 18.0 & 29.1 & 49.8 \\
\hline General $^{3}$ & 0.0 & 9.2 & 19.1 & 71.7 & 1.2 & 13.1 & 22.2 & 63.4 \\
\hline \multicolumn{9}{|l|}{ Worked in last 12 months } \\
\hline Yes & 10.6 & 38.1 & 23.6 & 27.7 & 7.6 & 26.8 & 19.8 & 45.9 \\
\hline No & 0.4 & 4.7 & 25.5 & 69.3 & 1.4 & 16.7 & 30.0 & 51.9 \\
\hline \multicolumn{9}{|l|}{ Wealth quintile } \\
\hline First & \# & $\#$ & $\#$ & $\#$ & $(16.1)$ & $(50.5)$ & $(26.9)$ & (6.5) \\
\hline Second & $(5.3)$ & $(30.7)$ & $(35.7)$ & $(28.3)$ & 7.7 & 35.3 & 35.6 & 21.4 \\
\hline Third & $(6.9)$ & $(24.5)$ & $(30.0)$ & (38.6) & 2.8 & 21.9 & 41.7 & 33.5 \\
\hline Fourth & 3.9 & 10.4 & 25.2 & 60.5 & 0.0 & 19.8 & 25.9 & 54.3 \\
\hline Fifth & 0.0 & 6.1 & 21.7 & 72.2 & 0.4 & 6.0 & 21.7 & 72.0 \\
\hline Total & 3.0 & 13.0 & 25.0 & 59.0 & 2.5 & 18.5 & 28.1 & 50.8 \\
\hline \multicolumn{9}{|c|}{ Rural } \\
\hline \multicolumn{9}{|l|}{ Age (years) } \\
\hline $15-17$ & 0.8 & 9.4 & 42.3 & 47.5 & 12.8 & 23.3 & 36.9 & 27.0 \\
\hline $18-19$ & 3.6 & 23.8 & 16.0 & 56.5 & 6.7 & 26.1 & 18.0 & 49.3 \\
\hline \multicolumn{9}{|l|}{ Religion } \\
\hline Hindu & 1.7 & 14.3 & 33.5 & 50.5 & 11.4 & 23.2 & 33.0 & 32.4 \\
\hline Muslim & $\#$ & $\#$ & $\#$ & $\#$ & 16.4 & 35.1 & 25.6 & 22.9 \\
\hline Other ${ }^{2}$ & $\#$ & $\#$ & $\#$ & $\#$ & $(0.0)$ & $(14.8)$ & (33.3) & $(51.8)$ \\
\hline \multicolumn{9}{|l|}{ Caste } \\
\hline SC & 1.3 & 15.7 & 39.0 & 44.0 & 8.2 & 25.4 & 37.7 & 28.7 \\
\hline ST & 7.4 & 27.5 & 32.1 & 33.0 & 22.9 & 32.8 & 23.5 & 20.8 \\
\hline OBC & 0.0 & 7.1 & 34.2 & 58.8 & 11.8 & 24.9 & 33.3 & 29.9 \\
\hline General $^{3}$ & $(0.0)$ & (12.1) & $(26.0)$ & (61.9) & 3.5 & 14.6 & 32.1 & 49.9 \\
\hline
\end{tabular}


Table 3.2: (Cont'd)

\begin{tabular}{|c|c|c|c|c|c|c|c|c|}
\hline \multirow[b]{3}{*}{ Background characteristics } & \multicolumn{4}{|c|}{ Boys (\%) } & \multicolumn{4}{|c|}{ Girls (\%) } \\
\hline & \multicolumn{8}{|c|}{ Completed years of schooling } \\
\hline & None $^{1}$ & $1-7$ & $8-9$ & $10+$ & None $^{1}$ & $1-7$ & $8-9$ & $10+$ \\
\hline \multicolumn{9}{|l|}{ Worked in last 12 months } \\
\hline Yes & 2.7 & 41.6 & 26.3 & 29.3 & 19.0 & 43.1 & 20.5 & 17.4 \\
\hline No & 1.4 & 4.9 & 36.5 & 57.2 & 8.6 & 17.3 & 36.4 & 37.6 \\
\hline \multicolumn{9}{|l|}{ Wealth quintile } \\
\hline First & 2.9 & 19.8 & 43.9 & 33.4 & 22.3 & 36.7 & 25.3 & 15.7 \\
\hline Second & 3.1 & 15.3 & 29.9 & 51.6 & 12.9 & 30.2 & 31.3 & 25.6 \\
\hline Third & 0.0 & 11.8 & 28.2 & 60.1 & 10.6 & 19.9 & 37.3 & 32.2 \\
\hline Fourth & 0.0 & 9.1 & 27.9 & 63.0 & 2.3 & 19.5 & 36.7 & 41.5 \\
\hline Fifth & $\#$ & $\#$ & \# & \# & 2.2 & 5.3 & 33.1 & 59.4 \\
\hline Total & 1.7 & 13.9 & 34.0 & 50.4 & 11.3 & 23.9 & 32.3 & 32.4 \\
\hline
\end{tabular}

Note: Row totals may not equal 100\% due to missing cases or “don't know” responses. () Based on 25-49 unweighted cases. \# Percentage not shown, based on fewer than 25 unweighted cases. OBC: Other backward caste. SC: Scheduled caste. ST: Scheduled tribe. ${ }^{1}$ Includes those who are non-literate and literate with no formal schooling. ${ }^{2}$ Includes Christian, Buddhist, NeoBuddhist, Sikh, Jain, Jewish, Parsi/Zoroastrian, Sarana and no specified religion. ${ }^{3}$ Includes all those not belonging to SC, ST or OBC.

suggest that those belonging to general castes were considerably more likely than others and those belonging to scheduled tribes considerably less likely than others to have completed eight or more, and ten or more years of schooling. Educational attainment levels of those belonging to other backward castes were, for the most part, in between those of adolescents from general castes, and scheduled castes and tribes. These patterns were observed among both boys and girls, irrespective of rural-urban residence.

Educational attainment, both among boys and girls, was considerably greater among those who had not been engaged in paid work in the 12 months preceding the survey than among those who had been so involved (Table 3.2). Twenty-nine percent of boys and 25 percent of girls who had worked in the last 12 months compared to 61 percent of boys and 43 percent of girls who had not, had completed a high school education, for example. Similar patterns were observed in both rural and urban areas and among both boys and girls.

Finally, a positive association was observed between the economic status of adolescents' households, measured in wealth quintiles, and their educational attainment levels. For example, 34 percent of boys from households in the poorest (first) quintile had completed 10 or more years of schooling compared to 68 percent of those from households in the wealthiest (fifth) quintile. Among girls, disparities were wider: just 15 percent of girls from the poorest (first) quintile had completed 10 or more years of schooling compared to 67 percent of those from the wealthiest quintile (fifth). We note that gender differences were widest for those from the poorest quintile, decreased gradually among those from higher quintiles and were not evident among those from the wealthiest quintile. Ruralurban patterns are hard to discern, because of the small number of adolescents, particularly boys, falling into the wealthier quintiles in rural areas and poorer quintiles in urban areas. From what can be discerned, it is clear that patterns were similar for those residing in rural and urban areas, with the completion of a secondary education progressively more likely to be reported by boys and girls belonging to progressively wealthier households.

\subsection{School attendance}

Figure 3.1 presents schooling status at ages 12 and 15, representing periods before and after puberty was attained for many. Findings reconfirm that school attendance among surveyed adolescents in Rajasthan was far from universal even at age 12. Just 93 percent and 82 percent of boys and girls, respectively, were in school at age 12 in 2012 and fewer-85 percent and 69 percent-at age 15. Increases over time were however apparent, especially with regard to attendance at age 15 and among girls. Indeed, while 53 percent of all girls were in school at age 
15 in 2007, this percentage had increased to 69 by 2012. Increases were particularly evident among rural girls, among whom 64 percent were in school in 2012, compared to 47 percent in 2007. Notably, gender differences in percentages in school at each age and in both rural and urban areas were, for the most part, narrower in 2012 than in 2007.

Figures 3.2a to 3.2c show graphically, for the 2007 and 2012 cohorts, and the cumulative percentages of adolescents (all adolescents who had completed at least one year of schooling) who had completed each year of education from Class 2 to Class 15, using life table techniques. Findings show that completion rates are near universal for both boys and girls up to Class 7 , the final year of primary school at the time the survey was undertaken (that is, $98 \%$ of boys and 96\% of girls had completed Class 7). Thereafter, a steep decline in completion rates was observed among both boys and girls, such that just seven percent of boys and 12 percent of girls had completed a higher secondary education (Class 12). Declines in completion rates were particularly steep during the transitions from Class 8 to 9,9 to 10,10 to 11 , and 11 to 12 , and again, gender differences were mild (Figure 3.2a). Completion rates declined by 15 to 24 points per year over this period among boys, and by 14 to 25 points per year among girls.

Patterns were, by and large, similar for the two cohorts as well; however, considerably more boys and girls from the 2012 cohort had completed each class from Class 8 to 12 than had their counterparts from the cohort of 2007. For example, 46 percent and 48 percent of boys and girls had completed Class 10 in 2012 compared to 40 percent each in 2007.

With regard to rural and urban patterns of school completion (Figures 3.2b and 3.2c, respectively), findings from 2012 suggest that the rural disadvantage in terms of school completion was relatively mild for boys but substantial for girls. Among boys, hardly any rural-urban difference in completion rates was evident, except with regard to the completion of Class 9 , achieved by 71 percent of urban boys and 64 percent of their rural counterparts. Among girls, in contrast, ruralurban differences were wide after Class 7. For example, while 97 percent of urban girls and 95 percent of rural girls had completed Class 7 , the corresponding percentages of urban and rural girls who had completed Class 8 , Class 9 and Class 10 were 93 and 84,70 and 58 , and 55 and 43 , respectively. Changes over time among urban adolescents were negligible for the most
Figure 3.1: Percentage of adolescents who were in school at ages 12 and 15, according to residence, Rajasthan, 2007 and 2012

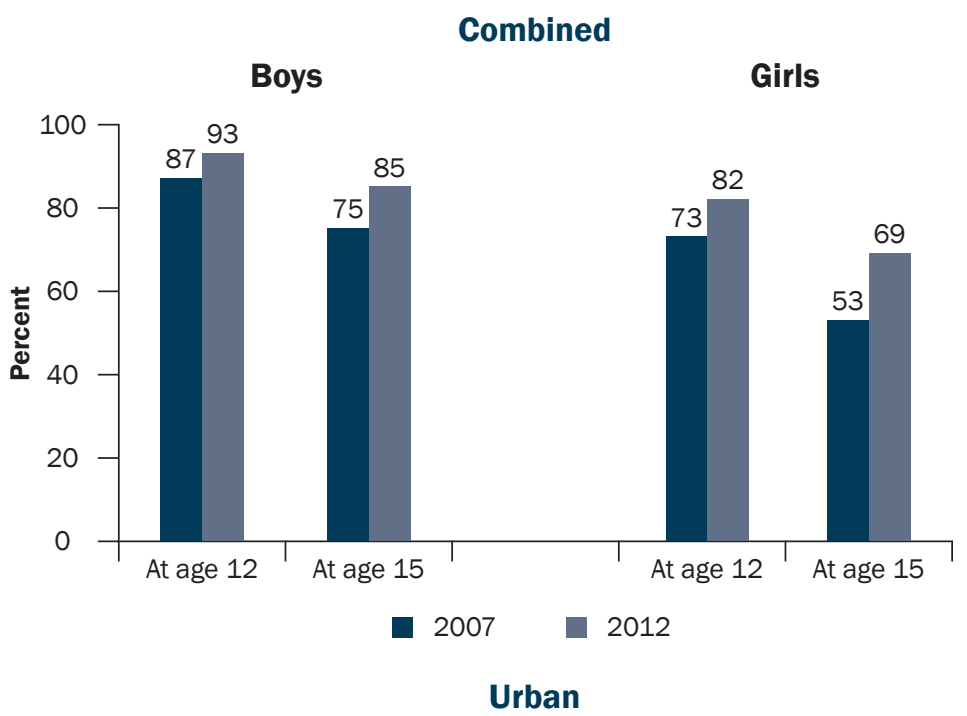

Boys

Girls

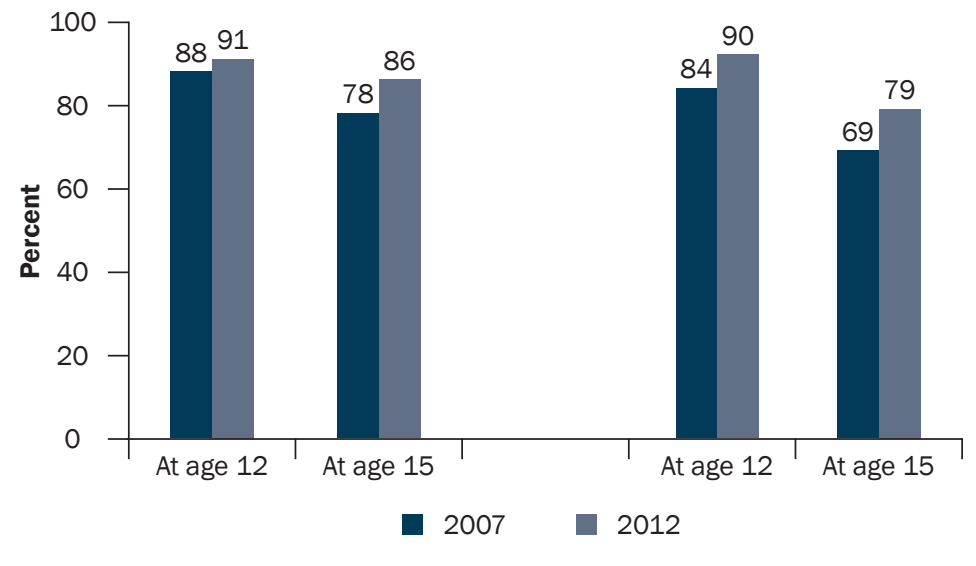

Rural

Boys

Girls

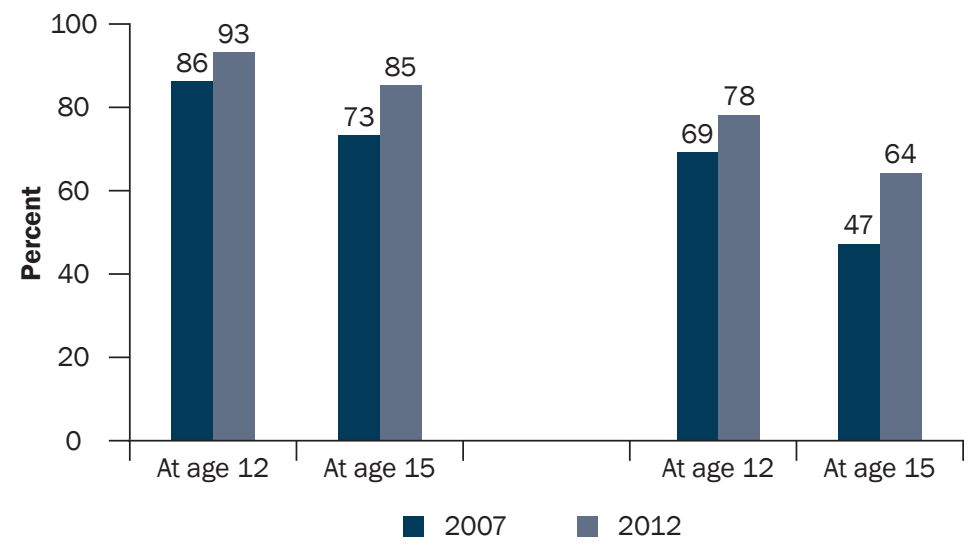


Figure 3.2a: Cumulative percentage of adolescents who had completed each year of education (Classes 1 to 15), Rajasthan (Combined), 2007 and 2012
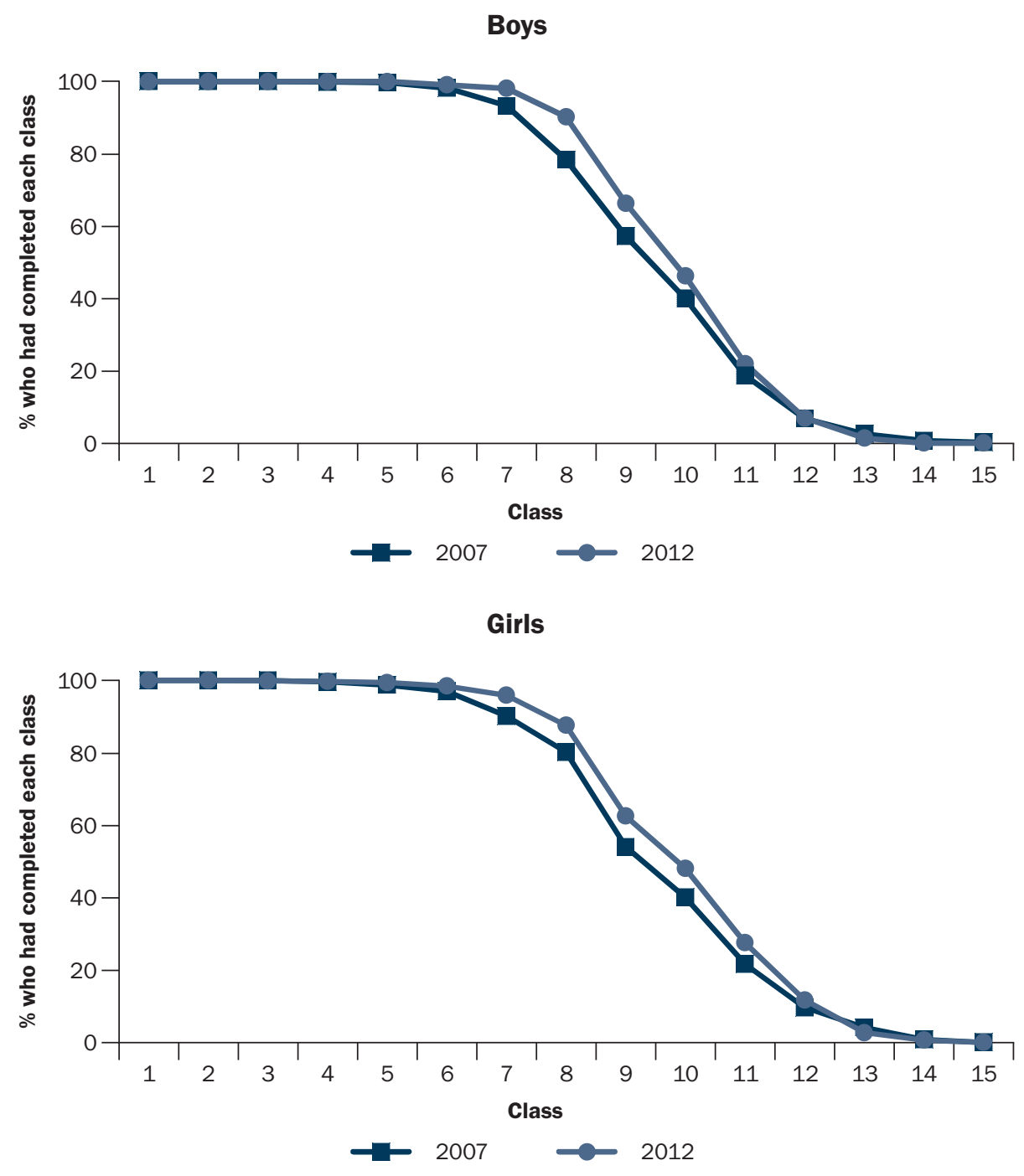

Figure 3.2b: Cumulative percentage of adolescents who had completed each year of education (Classes 1 to 15), Rajasthan (Urban), 2007 and 2012

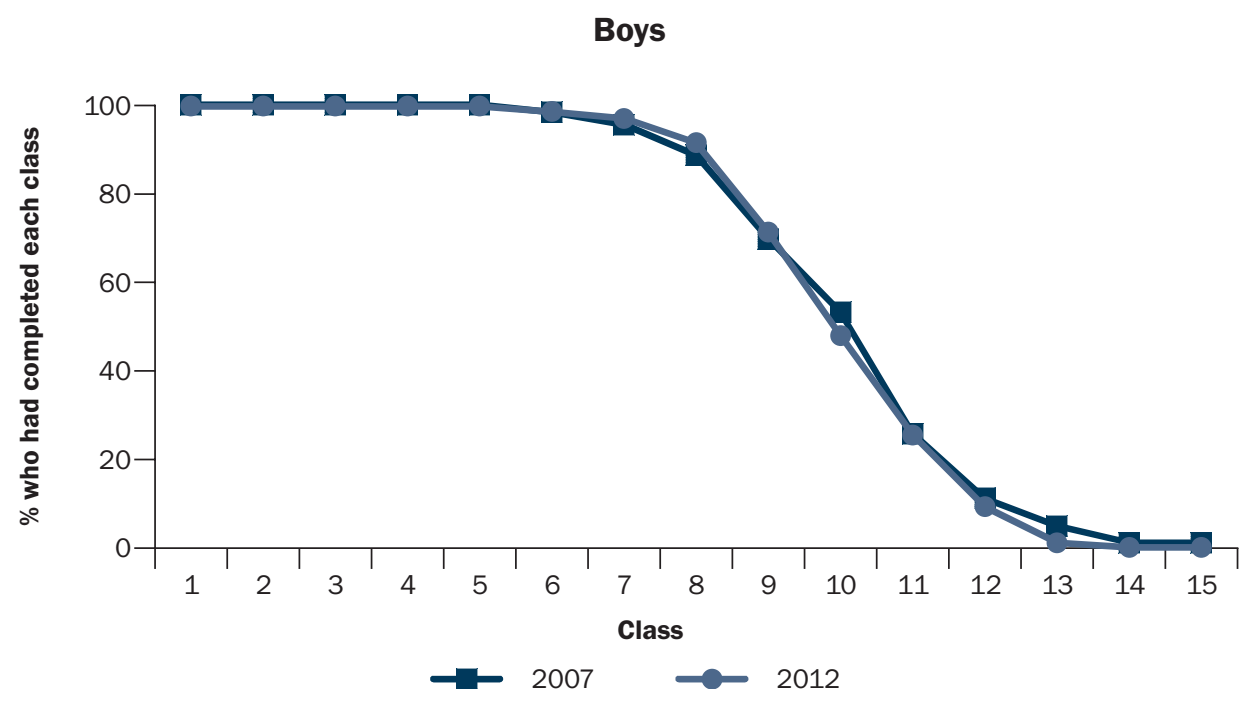




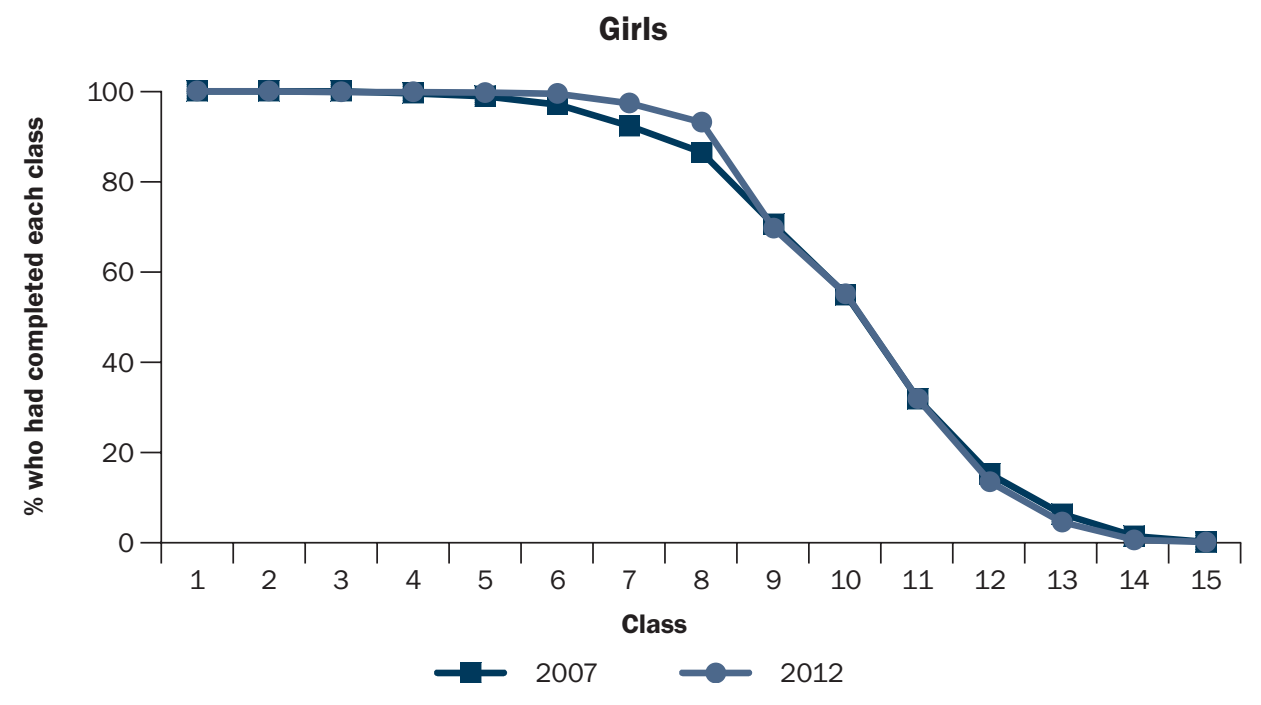

Figure 3.2c: Cumulative percentage of adolescents who had completed each year of education (Classes 1 to 15), Rajasthan (Rural), 2007 and 2012
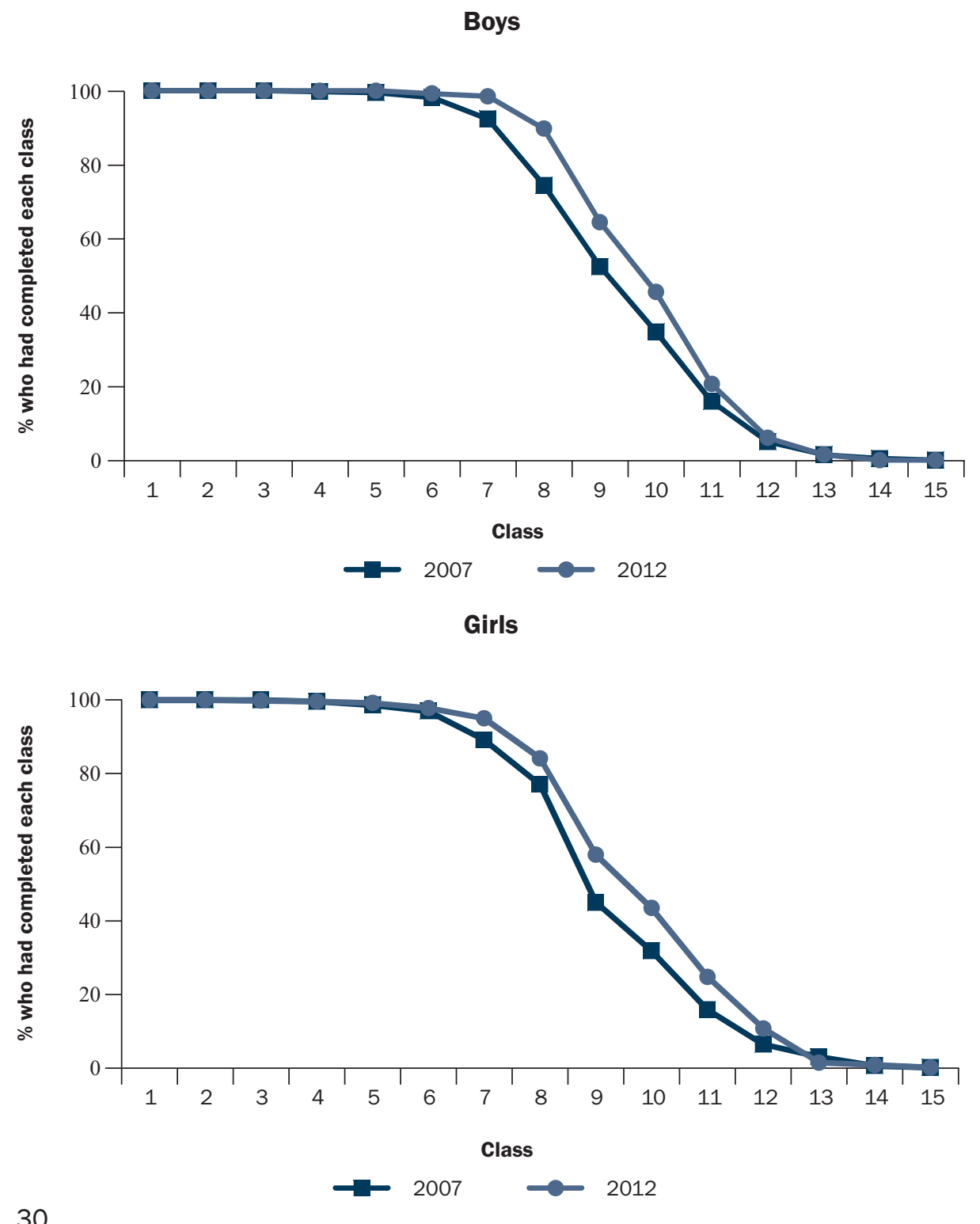
part; however, among rural adolescents, between 2007 and 2012, considerable increases in completion rates were observed among both boys and girls in Classes 8 to 12 .

\subsection{Reasons for school discontinuation}

Both surveys inquired about reasons for never going to school from all those who so reported, and reasons for discontinuing school from all those who had not completed Class 12. Overall, as shown earlier, few adolescents had never been to school, and very few who had completed Class 10 had discontinued their education before completing Class 12. Hence, we focus here on those who had gone to school but discontinued their education before completing Class 7 , and those who had completed at least seven years of education and had discontinued their education before completing Class 10.

Reasons for school discontinuation, as reported in Table 3.3 have been grouped into six categories: economic reasons (work on the family farm or business, wage-earning work, family poverty, that is, the family could not afford to keep the respondent in school); housework-related reasons (required for care of siblings or housework); attitude or perception-related reasons (adolescents' reports of parents' perceptions that it is unsafe to send children to school, and/or that education is not necessary, respondent's lack of interest in studies); school-related reasons (school located too far away, appropriate transport not available, poor quality of school facilities, no female teacher, poor quality of teaching, academic failure), and health-related reasons (health problems of respondent, illness or death of a family member).

As evident from Table 3.3 and Figures 3.3a and 3.3b, reasons for school discontinuation offered by adolescents in 2007 and 2012 varied considerably by the level at which education was discontinued as well as, by and large, by rural-urban residence of the respondent. Gender differences were also apparent.

Among those who had completed six or fewer years of schooling, attitudes and perceptions dominated reasons for school discontinuation for boys (58\%); notably, more than one-half of the boys (55\%) reported lack of interest in studies as a reason for discontinuing schooling. Many fewer (27\%) cited economic reasons, and just 6-11 percent reported such reasons as housework, and school-related or health-related reasons. A comparison with reasons for school discontinuation provided by boys in 2007 reveals two major changes vis-a-vis 2012: significantly fewer boys reported economic and housework-related reasons in 2012 than in 2007 for discontinuing their education (27\% compared to $53 \%$, and $5 \%$ compared to $32 \%$, respectively). Among girls, in contrast, leading reasons included both housework (35\%) and attitudes and perceptions (47\%). As in the case of boys, many fewer cited economic reasons (26\%), school-related reasons (22\%) or health reasons (12\%). Unlike boys, however, percentages of girls reporting different reasons for discontinuation in 2012 were more or less similar to corresponding percentages in 2007; the only exception was housework which fell from 45 percent in 2007 to 35 percent in 2012. Among individual reasons cited for school discontinuation in 2012, the leading reason for boys was their own lack of interest in studies, and for girls both housework demands and lack of interest. Other often-cited reasons as work for wages or work on the family farm or in the family business, the family's inability to cover the cost of schooling, or the attitude that education was unimportant were less frequently cited.

In 2012, patterns in the reported reasons offered by rural and urban boys for discontinuing school differed in a few ways (Table 3.3). While parental attitudes and perceptions were cited, boys' lack of interest in studies was the leading reason for school discontinuation in both rural and urban areas (54-59\%); economic reasons were less likely and school-related reasons more likely to be reported by boys in rural than in urban areas ( $24 \%$ versus $34 \%$, and $15 \%$ versus $0 \%$, respectively). Among girls, in contrast, by 2012, patterns in the reported reasons offered for school discontinuation in rural and urban areas were similar, differing mildly at best in a couple of instances. For example, housework, and attitudes and perceptions were more often described as reasons for school discontinuation among rural than urban girls (37\% versus $28 \%$ in the case of housework; $49 \%$ versus $40 \%$ in the case of attitudes and perceptions)

Reasons for discontinuing school in Classes 7-9 were largely similar, and gender differences were pronounced. The leading reason among boys continued to be related to attitudes and perceptions, cited by one-half of the boys (50\%) and largely relating to their own lack of interest in studies (43\%); a similar picture had emerged in 2007. At the same time, economic reasons were cited by 30 percent of all boys who had discontinued their education between Classes 7 and 9, a steep and significant decline from 2007, when more than one-half (55\%) had cited this reason. Schoolrelated reasons were cited by 29 percent, slightly more than in 2007 (22\%); school-related reasons almost entirely 


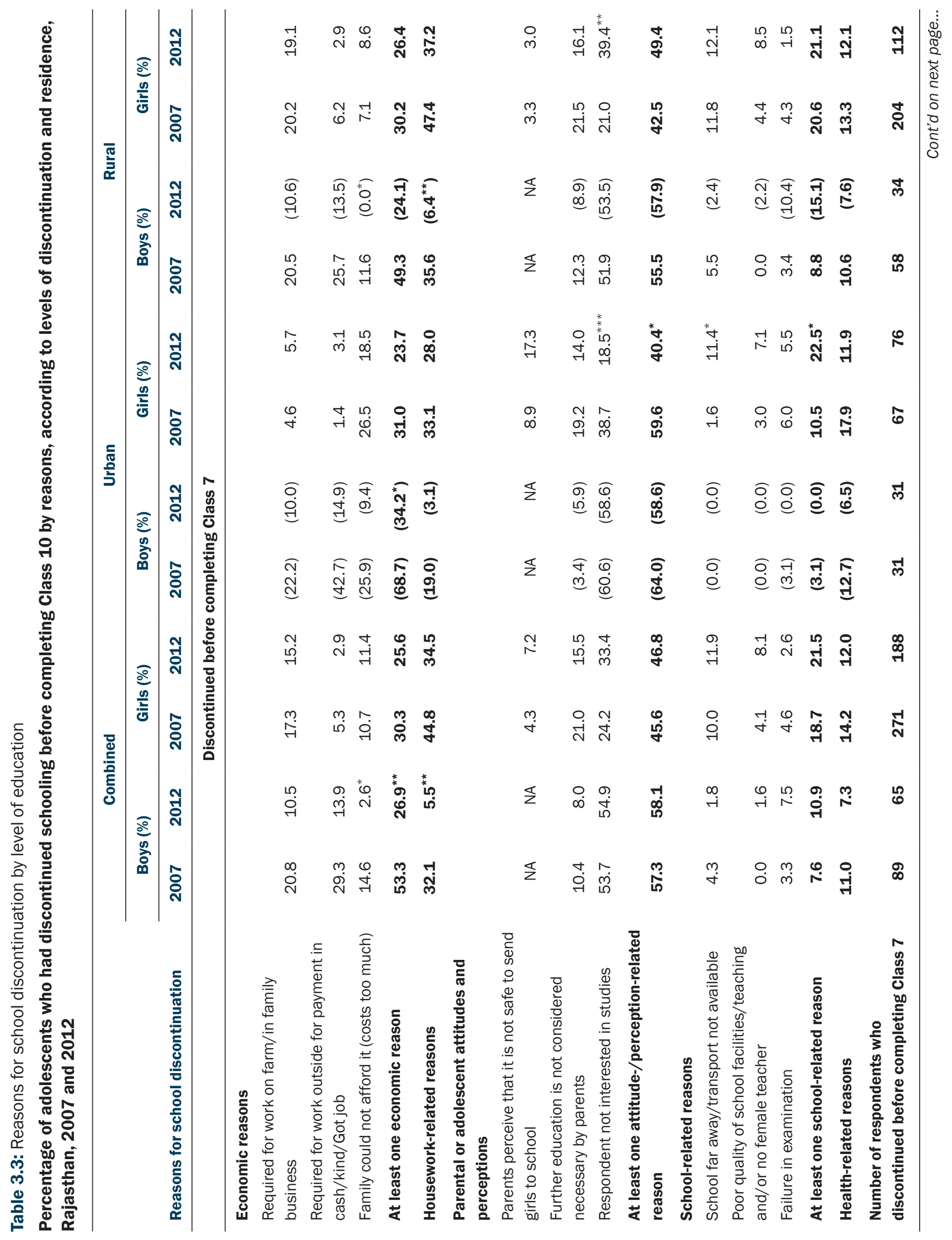




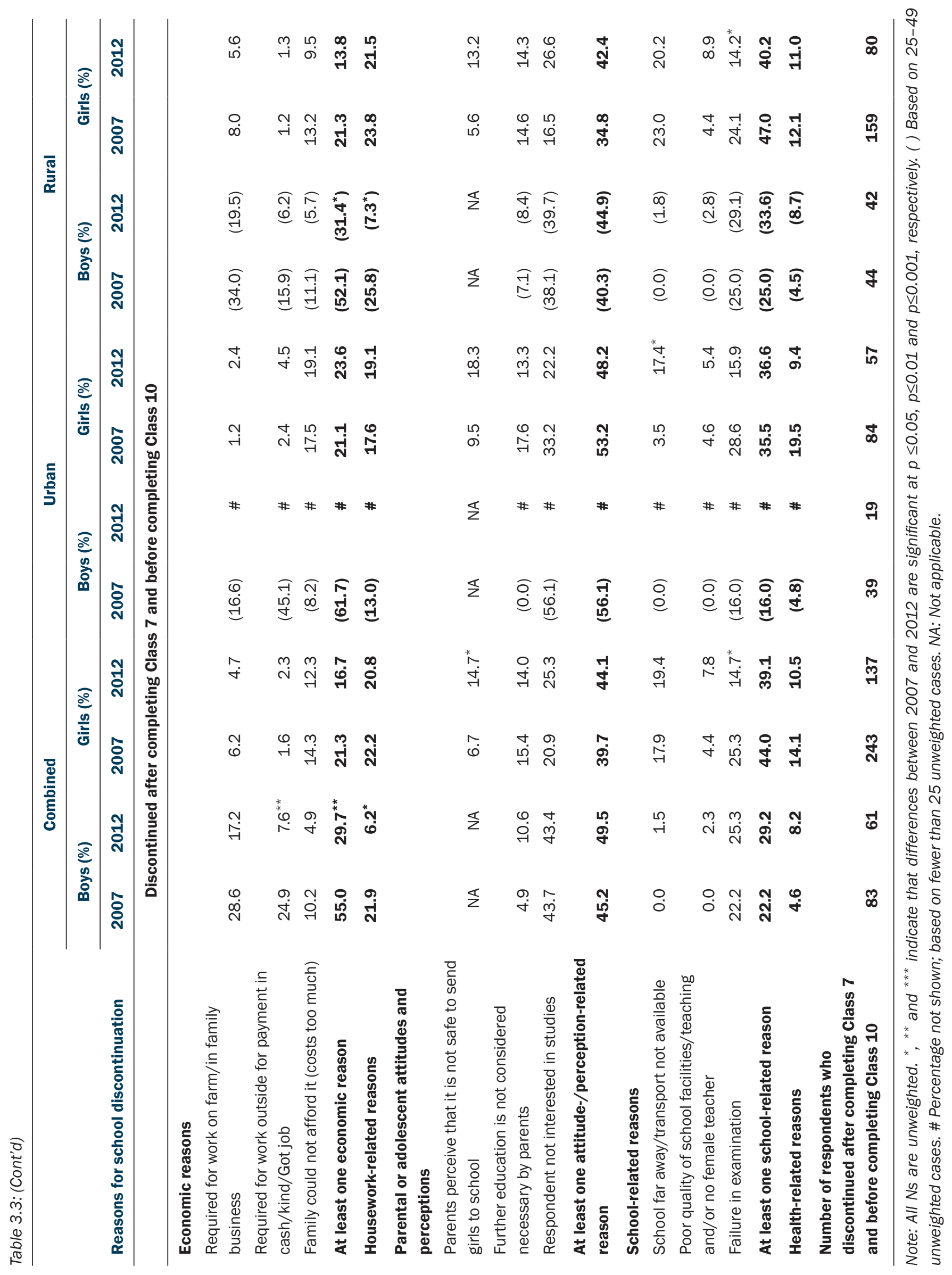


referred to academic failure (25\%). Notably, very few boys cited housework-related reasons in 2012 (6\%), a steep and significant decline since 2007 (22\%). Health-related reasons were rarely cited (8\% in 2012 and 5\% in 2007).

Among girls, in contrast, the leading reasons for discontinuing schooling between Classes 7 and 9 were both attitude- and perception-related and school-related (44\% and 39\%, respectively), with 25 percent citing lack of interest in studies, $14-15 \%$ citing parental concerns about safety or their perception that further education was unnecessary for girls, 19 percent citing distance to school and 15 percent citing academic failure, respectively, as specific reasons for discontinuation. Other key reasons cited were housework responsibilities (21\%) and economic reasons $(17 \%)$, largely parental inability to cover the cost of education (12\%). Health-related reasons were less frequently cited (11\%). For the most part, the percentages of girls citing this array of reasons were similar in 2007 as well. However, a significant increase was observed in percentages reporting safety concerns (from $7 \%$ to $15 \%$ ), and a significant decline in percentages reporting academic failure (from $25 \%$ to $15 \%$ ) as a reason for discontinuation.

Rural-urban differences in 2012 cannot be gauged for boys because of small numbers; differences were narrow, for the most part, for girls. For example, somewhat more urban than rural girls cited attitude- or perception-related reasons ( $48 \%$ versus $42 \%$ ) and economic reasons ( $24 \%$ versus $14 \%$ ), again largely related to the cost of education (19\% versus $10 \%)$; they were about as likely to report school-related reasons (37-40\%).

Figure 3.3a: Percentage of adolescent boys who had discontinued schooling by class when discontinued and reasons for discontinuation, Rajasthan, 2007 and 2012

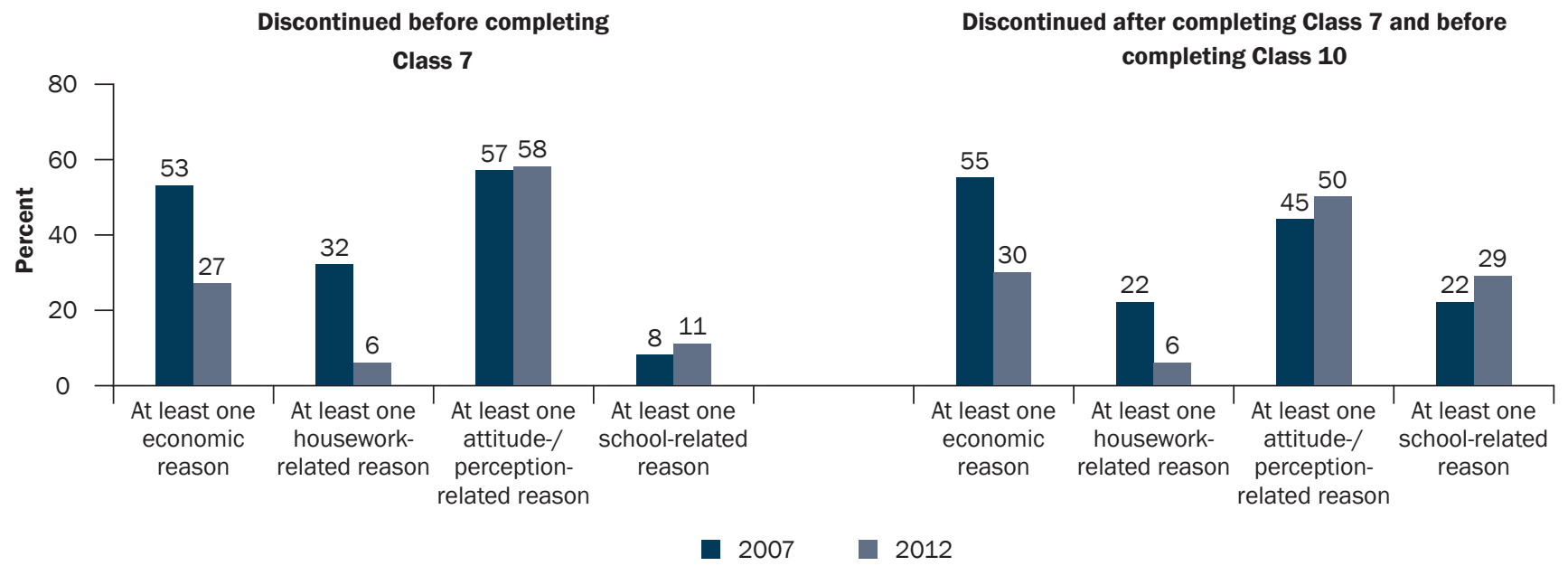

Figure 3.3b: Percentage of adolescent girls who had discontinued schooling by class when discontinued and reasons for discontinuation, Rajasthan, 2007 and 2012

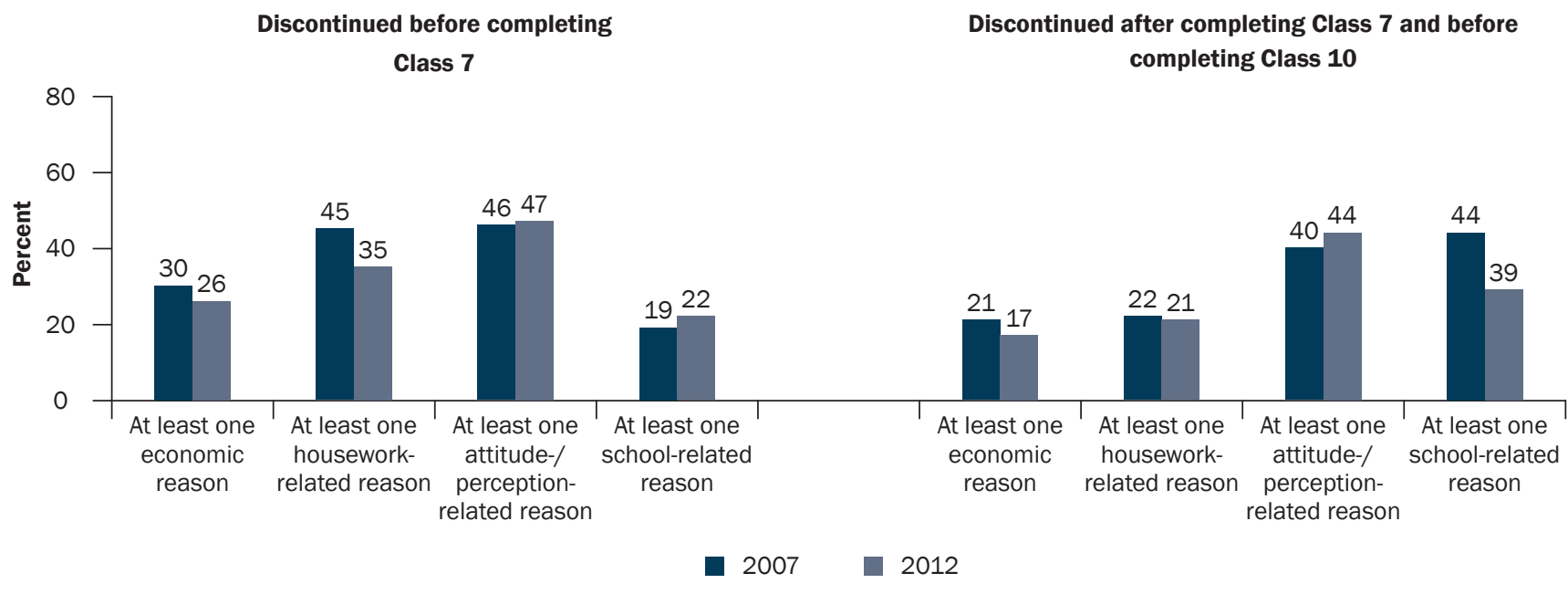


Table 3.3 also highlights huge gender disparities in reasons for school discontinuation. For example, lack of interest in studies was considerably more likely to be cited as a reason for school discontinuation among boys than girls, irrespective of the level at which discontinuation took place. In addition, among those who discontinued their education in Classes 7-9, academic failure was far more likely to be indicated by boys than girls, and distance to school by girls than boys. Housework responsibilities were more likely to be cited by girls than boys at each level. While economic reasons were, on the whole, more likely to be cited by boys than girls, specific economic reasons varied: wage labour was more likely to be cited by boys than girls, and parental inability to afford the cost of their education more likely to be cited by girls than boys.

\subsection{Summary}

While attainment of a high school education was far from universal among surveyed boys and girls in Rajasthan even in 2012, considerable improvements were observed in school enrolment rates, educational attainment rates and schooling status at the time of the interview, between adolescents in the 2012 and 2007 surveys.

Almost all adolescents had been to school in 2012. Indeed, just two percent of boys and eight percent of girls had never been enrolled in school, considerably fewer than in 2007 (8\% and 20\%). While rural-urban differences narrowed in 2012 compared to 2007, more girls in rural than in urban areas had never been to school among those aged 15-19 in 2012 (11\% versus 3\%).

Socio-demographic differentials were evident in 2012 in the educational attainment levels of surveyed boys and girls, measured with respect to completed years of schooling. Religion and caste-wise differences suggest that Hindu adolescents and those from general castes had attained higher levels of education than other adolescents. A strong positive association was observed between the economic status of adolescents' households, measured in wealth quintiles, and their educational attainment levels, for both boys and girls and in urban as well as in rural areas.

By 2012, school completion rates were near universal for both boys and girls up to Class 7 , that is, the final year of primary school, at the time the survey was undertaken. Thereafter, a steep decline in completion rates was observed among both boys and girls between Classes 8 and 12, during which completion rates declined by 15 to 24 points per year among boys, and by 14 to 25 points per year among girls. Patterns were, by and large, similar for the 2007 and 2012 cohorts; however, more boys and girls from the 2012 cohort had completed each class from Class 8 to 12 than had their counterparts from the cohort of 2007. Gender differences were milder in 2012 than in 2007. However, while the rural disadvantage was relatively mild for boys in 2012, it remained substantial for girls, among whom rural-urban differences were wide after Class 7 . Changes over time among urban adolescents were negligible for the most part; however, among rural adolescents, between 2007 and 2012, considerable increases in completion rates were observed among both boys and girls in Classes 8 to 12 .

While gender disparities persisted, striking increases were observed in percentages of adolescents who had completed high school between 2007 and 2012: from 38 to 53 among boys, and from 22 to 39 among girls. Even though increases were observed in percentages of adolescents in school at the time of the interview, between 2007 and 2012, gender disparities persisted: almost four in five boys compared to just three in five girls were still in school or college.

Among those who had ever been to school, several reasons were offered for discontinuation, and patterns differed somewhat by sex of the respondent and level at which schooling was discontinued. Among boys who had discontinued their education in Classes 1-6, for over one-half, reasons for discontinuation related to attitudes and perceptions, and largely lack of interest in studies; many fewer cited economic or school-related reasons. Among girls, leading reasons were both attitude- and perception-related (lack of interest in studies, as well as safety concerns and perceptions that education was unnecessary for girls among parents) as well as housework-related. Significant changes since 2007 included a decline in percentages of boys reporting economic and housework-related reasons; among girls, changes were not significant; however, we note that somewhat smaller percentages of girls reported housework-related reasons in 2012 than 2007.

In contrast, among those who had discontinued their education in Classes 7-9, attitude and perception-related reasons continued to dominate among reasons for school discontinuation among boys-cited by one-half of all boys; 43 percent had specifically cited lack of interest in studies. Economic reasons and school-related reasons were cited by over one-quarter each, notably academic failure was cited by as many as one-quarter. For girls, the 
leading issues were attitude- or perception-related factors as well as school-related factors, although about one-sixth reported economic reasons (largely the household's inability to cover the cost of their education) and one-fifth cited housework responsibilities. As shown for those who discontinued their education before Class 7 , significant changes since 2007 among boys reflected a decline in percentages reporting economic and housework-related reasons; and among girls, an increase in percentages reporting safety concerns, and a decline in percentages reporting academic failure as a reason for discontinuation.

Gender disparities in reasons for discontinuation were evident. Lack of interest in studies was considerably more likely to have been cited as a reason for school discontinuation among boys than girls, irrespective of the level at which discontinuation took place; among those who discontinued their education in Classes 7-9, academic failure was far more likely to have been indicated by boys, and distance to school by girls. Housework responsibilities were more likely to have been cited by girls than boys at each level. While economic reasons were, on the whole, more likely to have been cited by boys than girls, specific economic reasons varied: wage labour was more likely to be cited by boys than girls, and parental inability to afford the cost of their education more likely to have been cited by girls than boys. 


\section{Chapter 4 \\ Economic activity, skill acquisition and migration}

For many adolescents, the ages 15 to 19 mark the completion of secondary education and the discontinuation of education although increasing numbers do pursue a tertiary education during these ages. For many, these ages mark entry into the labour market and acquisition of professional and technical skills. For some, these years are associated with migrating away from their home village, including new living arrangements necessitated by outmigration. This chapter explores the economic activity of young people, their vocational skill-building experiences and preferences, and their migration and mobility experiences. It describes the experiences of adolescents in terms of economic activity, migration and mobility experiences, and exposure to and desire for vocational training. Where data permit, it also describes changes in these experiences among those aged 15-19 in 2012, compared to those aged $15-19$ in 2007.

\subsection{Economic activity}

During the survey, a number of questions were asked to assess the economic activity status of surveyed adolescents. Adolescents were asked whether they had ever worked for pay, whether they had worked for pay in the 12 months preceding the interview, whether they were seeking employment, and the number of months during which they had worked for pay or had sought work in the year preceding the interview.

Work profiles varied widely, as shown in Table 4.1. In total, 27 percent of boys interviewed in 2012 reported that they had been engaged in paid work at some point in their lives, almost identical to the percentage so reporting in 2007 (26\%). About as many girls as boys-26 percent-reported having ever participated in paid work, slightly more than in 2007 (21\%). As in 2007, rural-urban differences suggest that urban boys were about as likely to work for wages as rural boys (29\% versus $26 \%$ ), whereas urban girls were moderately less likely to do so than rural girls (22\% versus $28 \%)$.

Paid work was initiated in childhood or early adolescence, that is, before age 15, for about one in ten adolescentsmore girls than boys in 2012 (12\% versus 6\%). These percentages are more or less similar to those reported in 2007 among boys (10\%) and girls (11\%). Further, about twice as many rural as urban girls had initiated paid work before age 15 (13\% versus $7 \%$ in 2007; 14\% versus $8 \%$ in 2012). Corresponding rural-urban disparities among boys were mild at both times (10\% versus $11 \%$ in $2007 ; 5 \%$ versus $9 \%$ in 2012 ).

Percentages of surveyed adolescents reporting that they had worked for wages any time in the 12 months prior to the interview, also presented in Table 4.1, largely mirrored lifetime economic activity, with about as many boys as girls reporting paid work ( $25 \%$ and $23 \%$, respectively), and paid work about as likely to be reported by urban as rural boys (25\%), but by more rural than urban girls (26\% versus $18 \%)$.

Among adolescents who had worked for wages in the 12 months preceding the interview, work profiles, in terms of the number of months spent in paid work over the last year differed considerably between boys and girls, and patterns were, by and large, significantly different in 2012 and 2007 (Table 4.1). Working adolescents were, for example, significantly less likely in 2012 than in 2007 to have worked for the most part of the previous year (47\% versus $83 \%$ among boys; $23 \%$ versus $59 \%$ among girls), and conversely, significantly more likely to have worked for fewer than three months of the previous year (40\% versus $2 \%$ among boys; $56 \%$ versus $19 \%$ among girls). A similar pattern was observed when rural and urban adolescents were considered separately. However, ruralurban differences were apparent in 2012, with larger proportions of boys and girls in urban areas (58\% and 35\%, respectively) than their rural counterparts ( $42 \%$ and $19 \%$, respectively) reporting work for wages for most of the previous year.

Occupational distributions of adolescents engaged in remunerated work in the 12 months preceding the interview suggest considerable gender disparities. In 2012, among boys, most were engaged in unskilled non-agricultural labour (63\%) and skilled manual work (24\%), and very few were engaged in agriculture as cultivators or agricultural 
Table 4.1: Economic activity

Percentage of adolescents who ever worked and who worked in the last 12 months, and percent distribution of adolescents by duration of work and main occupation in the last $\mathbf{1 2}$ months, according to residence, Rajasthan, 2007 and 2012

\begin{tabular}{|c|c|c|c|c|}
\hline \multirow[b]{2}{*}{ Economic activity } & \multicolumn{2}{|c|}{ Boys (\%) } & \multicolumn{2}{|c|}{ Girls (\%) } \\
\hline & 2007 & 2012 & 2007 & 2012 \\
\hline \multicolumn{5}{|c|}{ Combined } \\
\hline Ever engaged in paid work & 26.3 & 26.6 & 21.0 & 25.6 \\
\hline Started working for pay before age 15 & 10.3 & $6.4^{* *}$ & 11.1 & 12.1 \\
\hline Engaged in paid work in last 12 months & 26.0 & 24.6 & 20.1 & 23.1 \\
\hline Number of respondents & 774 & 745 & 1,487 & 1,164 \\
\hline \multicolumn{5}{|l|}{ Duration of paid work in last 12 months } \\
\hline Most of the year ( 6 months or more) & 83.4 & 46.5 & 58.7 & 23.0 \\
\hline Part of the year ( $3-5$ months) & 14.4 & 13.3 & 21.2 & 18.4 \\
\hline Rarely (less than 3 months) & 2.2 & 40.1 & 19.3 & 55.6 \\
\hline Significance level & \multicolumn{2}{|c|}{ *** } & \multicolumn{2}{|c|}{$* * *$} \\
\hline \multicolumn{5}{|l|}{ Main occupation (paid work) } \\
\hline Cultivation & 2.7 & 2.7 & 0.8 & 0.4 \\
\hline Agricultural labour & 3.4 & 2.6 & 32.2 & 46.5 \\
\hline Administrative/Executive/Managerial/Clerical work & 1.7 & 5.6 & 4.4 & 7.4 \\
\hline Business & 3.4 & 1.8 & 0.8 & 0.4 \\
\hline Skilled manual labour/Machinery work & 22.1 & 23.5 & 21.8 & 21.5 \\
\hline Unskilled non-agricultural labour & 64.1 & 62.8 & 38.2 & 19.7 \\
\hline Other, including housewife & 2.1 & 1.0 & 1.4 & 2.8 \\
\hline Significance level & \multicolumn{2}{|c|}{-} & \multicolumn{2}{|c|}{ * } \\
\hline Number of respondents engaged in paid work in last 12 months & 202 & 190 & 283 & 260 \\
\hline \multicolumn{5}{|c|}{ Urban } \\
\hline Ever engaged in paid work & 28.6 & 28.5 & 14.0 & 21.8 \\
\hline Started working for pay before age 15 & 10.9 & 9.3 & 7.0 & 7.7 \\
\hline Engaged in paid work in last 12 months & 28.3 & 24.9 & 13.4 & 18.2 \\
\hline Number of respondents & 327 & 369 & 513 & 538 \\
\hline \multicolumn{5}{|l|}{ Duration of paid work in last 12 months } \\
\hline Most of the year ( 6 months or more) & 81.0 & 57.7 & 78.0 & 34.9 \\
\hline Part of the year ( $3-5$ months) & 15.9 & 14.4 & 10.3 & 22.5 \\
\hline Rarely (less than 3 months) & 3.1 & 27.9 & 11.7 & 41.2 \\
\hline Significance level & \multicolumn{2}{|c|}{$* * *$} & \multicolumn{2}{|c|}{$* * *$} \\
\hline
\end{tabular}




\begin{tabular}{|c|c|c|c|c|}
\hline \multirow[b]{2}{*}{ Economic activity } & \multicolumn{2}{|c|}{ Boys (\%) } & \multicolumn{2}{|c|}{ Girls (\%) } \\
\hline & 2007 & 2012 & 2007 & 2012 \\
\hline \multicolumn{5}{|l|}{ Main occupation (paid work) } \\
\hline Cultivation & 0.0 & 0.0 & 0.0 & 0.0 \\
\hline Agricultural labour & 0.0 & 0.0 & 3.0 & 8.0 \\
\hline Administrative/Executive/Managerial/Clerical work & 3.5 & 16.4 & 17.3 & 18.3 \\
\hline Business & 5.4 & 0.0 & 0.0 & 1.3 \\
\hline Skilled manual labour/Machinery work & 23.0 & 27.4 & 55.8 & 39.2 \\
\hline Unskilled non-agricultural labour & 65.9 & 52.6 & 18.1 & 21.7 \\
\hline Other, including housewife & 2.2 & 3.7 & 5.8 & 10.5 \\
\hline Significance level & \multicolumn{2}{|c|}{ * } & \multicolumn{2}{|c|}{-} \\
\hline Number of respondents engaged in paid work in last 12 months & 92 & 89 & 69 & 97 \\
\hline \multicolumn{5}{|l|}{ Rural } \\
\hline Ever engaged in paid work & 25.5 & 25.9 & 23.6 & 27.7 \\
\hline Started working for pay before age 15 & 10.1 & $5.3^{*}$ & 12.6 & 14.3 \\
\hline Engaged in paid work in last 12 months & 25.2 & 24.5 & 22.4 & 25.7 \\
\hline Number of respondents & 447 & 376 & 974 & 626 \\
\hline \multicolumn{5}{|l|}{ Duration of paid work in last 12 months } \\
\hline Most of the year (6 months or more) & 84.4 & 42.4 & 54.6 & 18.6 \\
\hline Part of the year (3-5 months) & 13.8 & 12.9 & 23.5 & 16.8 \\
\hline Rarely (less than 3 months) & 1.8 & 44.7 & 20.9 & 61.0 \\
\hline Significance level & \multicolumn{2}{|c|}{$* * *$} & \multicolumn{2}{|c|}{$* * *$} \\
\hline \multicolumn{5}{|l|}{ Main occupation (paid work) } \\
\hline Cultivation & 3.8 & 3.7 & 1.0 & 0.6 \\
\hline Agricultural labour & 4.8 & 3.6 & 38.5 & 60.9 \\
\hline Administrative/Executive/Managerial/Clerical work & 1.0 & 1.7 & 1.6 & 3.4 \\
\hline Business & 2.6 & 2.4 & 1.0 & 0.0 \\
\hline Skilled manual labour/Machinery work & 21.7 & 22.0 & 14.5 & 15.0 \\
\hline Unskilled non-agricultural labour & 63.3 & 66.6 & 42.5 & 19.0 \\
\hline Other, including housewife & 2.0 & 0.0 & 0.5 & 0.0 \\
\hline Significance level & \multicolumn{2}{|c|}{-} & \multicolumn{2}{|c|}{ * } \\
\hline Number of respondents engaged in paid work in last 12 months & 110 & 101 & 214 & 163 \\
\hline
\end{tabular}

Note: All Ns are unweighted. -, ${ }^{*},{ }^{* *}$ and ${ }^{* *}$ indicate that differences between 2007 and 2012 are not significant, significant at $p \leq 0.05, p \leq 0.01$ and $p \leq 0.001$, respectively. Column totals may not equal $100 \%$ due to missing cases or "don't know" responses.

labourers (just 5\%); this distribution was almost identical to the situation in 2007 (Table 4.1). Among girls in contrast, the leading occupation in 2012 was agricultural labour (47\%), followed by skilled manual work (22\%) and unskilled non-agricultural labour (20\%); while work in agricultural labour had increased, work in non-agricultural labour had declined over the five-year period.

As far as occupational distributions among surveyed adolescents engaged in remunerated work were concerned, in 2012, leading occupations among boys were unskilled non-agricultural and skilled manual labour, together reported by 80 percent and 89 percent of urban and rural boys, respectively, compared to 89 percent and 85 percent, respectively, in 2007. Surprisingly, relatively few boys, even in rural areas, reported agricultural occupations (7\%), 
probably attributed to small land holdings, and the fact that a considerable proportion of boys reported unpaid work on the family farm. Distributions in urban areas were significantly different in 2012 than 2007 in some important respects: considerably more boys were engaged in 2012 than 2007 in administrative, executive, managerial and clerical occupations (16\% versus $4 \%$ ), and correspondingly, fewer were engaged in unskilled non-agricultural labour (53\% versus $66 \%)$. Among girls, in 2012 , leading occupations in rural areas were agricultural, particularly agricultural labour (61\%), unskilled non-agricultural labour (19\%) and skilled manual labour (15\%); in contrast, leading occupations of girls in urban areas were skilled manual labour (39\%), unskilled non-agricultural labour (22\%), and administrative, executive, managerial and clerical occupations (18\%); distributions were similar, by and large, in 2007 , the only exception being the engagement of urban girls in skilled manual labour which had declined sharply between 2007 and 2012 (from 56\% to 39\%).

\subsection{Employment seeking}

Table 4.2 presents findings regarding the employment-seeking status of adolescents in both surveys. About onetenth of boys in both 2007 and 2012 (9\% and 11\%, respectively) were seeking employment at the time of the interview. In contrast, more girls in 2012 than 2007, reported doing so (6\% and 4\%, respectively). Rural-urban differences were negligible (11\% among both rural and urban boys; $6-7 \%$ among girls), but urban adolescents were significantly more likely to report seeking employment in 2012 than they were in 2007. In 2012, just three percent of boys and girls reported that they had been seeking work for six months or more.

Table 4.3 presents the socioeconomic and demographic characteristics of surveyed adolescents who were seeking employment in 2012, compared with those in the earlier survey. Findings show that older adolescents (those aged 18-19) were considerably more likely than their younger counterparts (those aged 15-17) to report that they were seeking work. Nineteen percent of boys and 12 percent of girls aged 18-19, compared to seven percent and five percent, respectively of those aged 15-17 were seeking work, and differentials were about as wide between those in rural and urban areas. Religion- and caste-wise differences among adolescent were not consistent, but Muslim and those from scheduled castes and tribes were, in general, more likely to report that they were seeking employment

Table 4.2: Employment seeking

Percentage of adolescents who were seeking employment at the time of the interview, according to residence, Rajasthan, 2007 and 2012

\begin{tabular}{lcccc}
\hline & \multicolumn{2}{c}{ Boys (\%) } & \multicolumn{2}{c}{ Girls (\%) } \\
\cline { 2 - 5 } Employment seeking status & $\mathbf{2 0 0 7}$ & $\mathbf{2 0 1 2}$ & $\mathbf{2 0 0 7}$ & $\mathbf{2 0 1 2}$ \\
\hline & Combined & & \\
\hline Currently seeking a job & 9.4 & 10.6 & 3.8 & $6.4^{*}$ \\
Seeking a job for 6 or more months & 2.6 & 3.3 & 0.9 & $2.5^{*}$ \\
Number of respondents & $\mathbf{7 7 4}$ & $\mathbf{7 4 5}$ & $\mathbf{1 , 4 8 7}$ & $\mathbf{1 , 1 6 4}$ \\
\hline & Urban & & & \\
\hline Currently seeking a job & 5.0 & $10.7^{*}$ & 2.5 & $6.1^{* *}$ \\
Seeking a job for 6 or more months & 1.6 & 2.1 & 0.4 & $1.9^{*}$ \\
Number of respondents & $\mathbf{3 2 7}$ & $\mathbf{3 6 9}$ & $\mathbf{5 1 3}$ & $\mathbf{5 3 8}$ \\
\hline & $\mathbf{R}$ & & & \\
\hline Currently seeking a job & 11.0 & 10.6 & 4.3 & 6.6 \\
Seeking a job for 6 or more months & 3.0 & 3.7 & 1.1 & $2.8^{*}$ \\
Number of respondents & $\mathbf{4 4 7}$ & $\mathbf{3 7 6}$ & $\mathbf{9 7 4}$ & $\mathbf{6 2 6}$ \\
\hline
\end{tabular}

Note: All Ns are unweighted. ${ }^{*}$ and ${ }^{* *}$ indicate that differences between 2007 and 2012 are significant at $p \leq 0.05$ and $p \leq 0.01$, respectively. 
than did adolescents from other religions and castes. So too, differentials by education suggest a generally inverse association, with an upturn among those who had completed Class 12. Findings also show a consistent and strong inverse association between household economic status and percentages of boys seeking work but, at best, a weak such association among girls. Rural and urban distributions were, by and large, similar.

Table 4.3: Employment seeking by selected background characteristics

Percentage of adolescents who were seeking employment at the time of the interview by selected background characteristics, according to residence, Rajasthan, 2012

\begin{tabular}{|c|c|c|c|c|c|c|}
\hline \multirow[b]{2}{*}{ Background characteristics } & \multicolumn{2}{|c|}{ Combined } & \multicolumn{2}{|c|}{ Urban } & \multicolumn{2}{|c|}{ Rural } \\
\hline & Boys (\%) & Girls (\%) & Boys (\%) & Girls (\%) & Boys (\%) & Girls (\%) \\
\hline \multicolumn{7}{|l|}{ Age (years) } \\
\hline $15-17$ & 6.6 & 4.6 & 5.7 & 3.6 & 6.9 & 5.1 \\
\hline $18-19$ & 19.0 & 11.6 & 20.2 & 12.7 & 18.5 & 11.0 \\
\hline \multicolumn{7}{|l|}{ Religion } \\
\hline Hindu & 10.6 & 6.4 & 10.6 & 5.7 & 10.5 & 6.7 \\
\hline Muslim & 13.7 & 6.9 & 11.8 & 8.5 & \# & 5.1 \\
\hline Other ${ }^{1}$ & $\#$ & (5.1) & $\#$ & $\#$ & $\#$ & (7.4) \\
\hline \multicolumn{7}{|l|}{ Caste } \\
\hline SC & 14.5 & 5.9 & 19.3 & 3.6 & 12.8 & 6.8 \\
\hline ST & 13.0 & 12.9 & \# & (4.9) & 13.8 & 14.9 \\
\hline $\mathrm{OBC}$ & 8.0 & 6.0 & 8.6 & 7.0 & 7.9 & 5.5 \\
\hline General $^{2}$ & 9.8 & 4.8 & 7.8 & 6.6 & $(13.1)$ & 3.2 \\
\hline \multicolumn{7}{|l|}{ Educational level (years) } \\
\hline None $^{3}$ & $\#$ & 4.9 & $\#$ & $\#$ & $\#$ & 4.8 \\
\hline $1-7$ & 28.2 & 10.0 & $(31.9)$ & 6.7 & 27.0 & 11.3 \\
\hline $8-9$ & 10.4 & 3.7 & 8.8 & 4.6 & 10.8 & 3.3 \\
\hline $10-11$ & 2.0 & 4.8 & 2.7 & 4.4 & 1.8 & 5.2 \\
\hline 12 and above & 12.7 & 9.7 & 10.4 & 9.5 & 13.8 & 9.9 \\
\hline \multicolumn{7}{|l|}{ Worked in last 12 months } \\
\hline Yes & 26.4 & 15.5 & 28.0 & 11.1 & 25.8 & 17.1 \\
\hline No & 5.5 & 3.7 & 4.9 & 5.0 & 5.7 & 2.9 \\
\hline \multicolumn{7}{|l|}{ Wealth quintile } \\
\hline First & 12.8 & 12.2 & $\#$ & $(10.0)$ & 12.3 & 12.4 \\
\hline Second & 13.7 & 5.9 & $(28.8)$ & 7.7 & 11.7 & 5.3 \\
\hline Third & 12.8 & 4.7 & (18.7) & 4.4 & 11.6 & 4.8 \\
\hline Fourth & 8.2 & 5.3 & 10.6 & 7.1 & 6.3 & 3.8 \\
\hline Fifth & 3.5 & 4.7 & 3.2 & 5.0 & $\#$ & 4.3 \\
\hline Total & 10.6 & 6.4 & 10.7 & 6.1 & 10.6 & 6.6 \\
\hline
\end{tabular}

Note: ( ) Based on 25-49 unweighted cases. \# Percentage not shown; based on fewer than 25 unweighted cases. OBC: Other backward caste. SC: Scheduled caste. ST: Scheduled tribe. ${ }^{1}$ Includes Christian, Buddhist/Neo-Buddhist, Sikh, Jain, Jewish, Parsi/ Zoroastrian, Sarana and no specified religion. ${ }^{2}$ Includes all those not belonging to SC, ST or OBC. ${ }^{3}$ Includes those who are nonliterate and literate with no formal schooling. 


\subsection{Economic activity and schooling status}

While the period of transition to adulthood is marked by discontinuation of schooling and entry into the labour market for many young people, some combine schooling and work and others are neither in school nor working. Data collected through the Life Event Calendar component of the Youth in India 2006-2007 study provided an opportunity to explore the pattern of these events (that is, studying, working for pay, both studying and working for wages, and neither studying nor working for wages) in young people's lives from the age of 12, and these are presented in Figures 4.1a and 4.1b.

Patterns were similar for boys and girls in both 2007 and 2012 in two key ways. As expected, the proportion of surveyed adolescents reporting school attendance declined steadily and those working for pay increased for both boys and girls at both times as they transitioned out of early into late adolescence. In other respects, patterns differed considerably.

At the same time, patterns varied widely over time for both boys and girls. Among boys, for example, in 2012, 93 percent were in school (a small minority of these were also engaged in paid work) at age 12, declining modestly to 85 percent by age 15 and more steeply to 65 percent by age 18. Corresponding proportions in 2007 were 87,75 and 52, suggesting a considerable increase in percentages studying in 2012 compared to 2007. Among girls, percentages in school at each age were considerably lower in both 2007 and 2012, but considerably larger proportions were studying in 2012 than in 2007: 82 percent, 69 percent and 58 percent at age 12, 15 and 18, respectively, in 2012, compared to 73 percent, 53 percent and 39 percent, in 2007. Percentages of adolescents who reported combining studying and paid work at any age were small, but increased over time (from 1-5\% among boys and 2-6\% among girls at each age from ages 12 to 19 in 2007, to 4-14\% and 6-13\%, respectively, in 2012).

Exit from school was accompanied by a rise in paid work participation over ages 12 to 19; however, changes over time were modest among both boys and girls. Among boys, engagement in paid work increased from seven percent at age 12 to 19 percent at age 15, and 54 percent by age 19 in 2012, compared to seven percent to 18 percent and 40 percent in 2007. Among girls, engagement in paid work increased from 11 percent at age 12 to 19 percent at age 15, and 24 percent at age 19, almost identical to corresponding percentages five years earlier $(9,17$ and 25 , respectively). Notably, far more adolescents were studying than working for wages at almost every age.

Gender differences were wide with regard to percentages of adolescents who were neither working for pay nor in school. Among boys, small proportions were neither working nor in school at any age at both times (4-9\% in 2012; $8-13 \%$ in 2007). Compared to boys, considerably larger percentages of girls reported neither working for pay nor being in school at both times and the percentages increased consistently from age 12 to age 19; however, fewer girls fell into this category in 2012 than in 2007. For example, by 2012, 13 percent of girls aged 12, 19 percent of those aged 15, and 30 percent of those aged 19 were neither working for pay nor attending school, compared to 21 percent, 32 percent and 33 percent, respectively, in 2007.

Figure 4.1a: Economic activity and schooling status at ages 12-19 among adolescent boys aged 15-19, by age, Rajasthan, 2007 and 2012
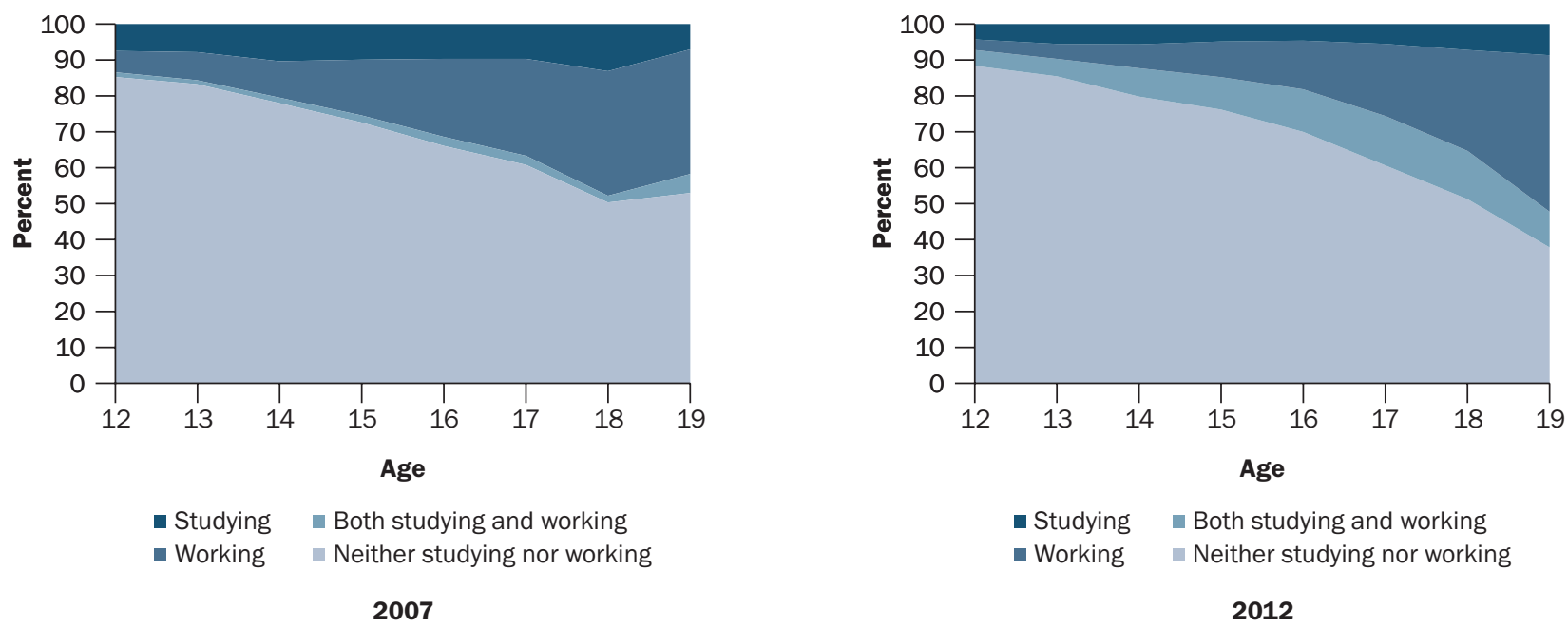
Figure 4.1b: Economic activity and schooling status at ages 12-19 among adolescent girls aged 15-19, by age, Rajasthan, 2007 and 2012
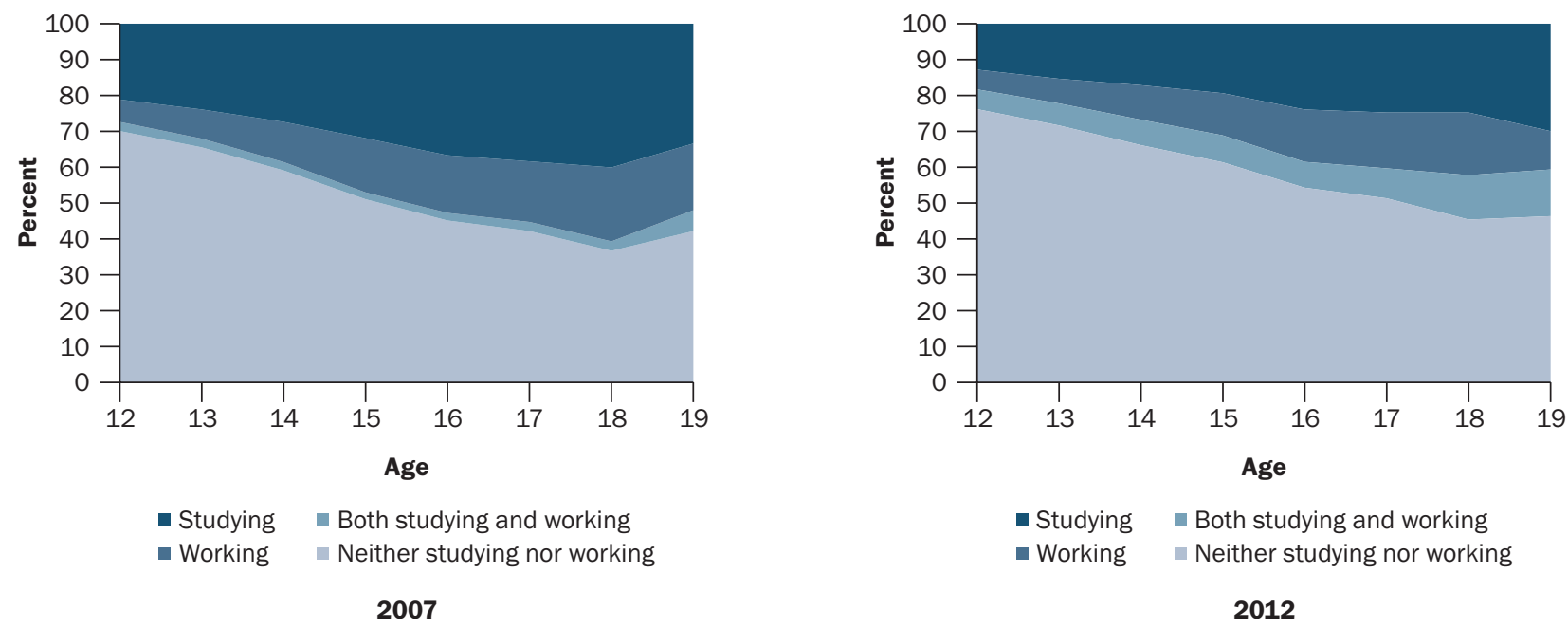

\subsection{Migration and mobility}

In 2012, questions were posed to surveyed adolescents about their migration histories: how long they had lived in their current village or urban area of residence, whether they had migrated to their current place of residence from some other place and their reason for migration. In order to assess mobility patterns, we also asked whether they had lived outside their village or urban area for work or education in the 12 months prior to the interview, the duration of their residence away from their home setting, and with whom they had co-resided during this period. Table 4.4 sums up these findings.

As seen in Table 4.4, Panel A, most adolescents, that is, 84 percent of boys and 89 percent of girls said that they had lived in their place of birth in 2012. Rural-urban differences were mild, but rural boys and girls were more likely than their urban counterparts to report so: 86 percent and 92 percent respectively, versus 80 percent and 84 percent, respectively. The timing of migration reveals some gender difference. Overall, about as many girls $(5 \%)$ reported that they had migrated during the five years preceding the interview as had done so earlier (6\%). Among boys, in contrast, more had migrated in the recent past (11\%) than earlier (5\%); this was particularly so among rural boys (11\% versus $3 \%$ ), but not observed among urban boys (10\% versus $11 \%$ ).

Among those reporting a migration experience, most adolescents had migrated with their parents. However, as many as 13 percent of boys and three percent of girls (and as many as 19\% of rural boys) reported migrating to their current place of residence for work-related reasons (not shown in table).

In order to capture adolescents' work- or education-related mobility, we asked all surveyed adolescents whether they had resided outside of their village or urban area for work or education in the 12 months preceding the interview. Findings are presented in Table 4.4, Panel B, and highlight wide gender differences. For example, ten percent of boys and two percent of girls reported to have lived away from their home setting in the 12 months preceding the interview. While rural-urban differences were negligible for girls (1-3\%), 12 percent of rural boys, compared with four percent of their urban counterparts so reported. Gender differences may be attributed to the finding observed earlier that boys were more likely than girls to be engaged in such activities as non-agricultural labour and skilled manual labour which entail mobility; they may also be attributed to the greater restrictions placed on the independent movement of girls than of boys.

While numbers were too small to gain further insight about girls, among boys, more than half (56\%) of those who had lived away from home had done so for three months or more in the previous year, and one-fifth (19\%) had lived away from home on two or more separate occasions. While living away from home, about one-half reported that they had lived away from family on these occasions, either on their own, in a hostel, or in a rented accommodation with colleagues and friends (not shown in table). 
Table 4.4: Migration and mobility experiences

Percentage of adolescents who had migrated to their current usual place of residence, and who had lived away from their usual residence for work or education in the $\mathbf{1 2}$ months preceding the interview, according to residence, Rajasthan, 2012

\begin{tabular}{|c|c|c|c|c|c|c|}
\hline \multirow{2}{*}{$\begin{array}{l}\text { Experiences of migrating } \\
\text { outside own village }\end{array}$} & \multicolumn{2}{|c|}{ Combined } & \multicolumn{2}{|c|}{ Urban } & \multicolumn{2}{|c|}{ Rural } \\
\hline & Boys (\%) & Girls (\%) & Boys (\%) & Girls (\%) & Boys (\%) & Girls (\%) \\
\hline \multicolumn{7}{|c|}{ Migration } \\
\hline \multicolumn{7}{|l|}{$\begin{array}{l}\text { Respondent had lived in his/her current place } \\
\text { of residence: }\end{array}$} \\
\hline Always/Since birth & 84.2 & 89.0 & 79.5 & 83.5 & 86.0 & 91.9 \\
\hline 5 or more years & 4.7 & 5.6 & 10.5 & 8.5 & 2.6 & 4.1 \\
\hline Less than 5 years & 11.0 & 5.4 & 9.9 & 8.0 & 11.4 & 4.0 \\
\hline Number of respondents & 745 & 1,164 & 369 & 538 & 376 & 626 \\
\hline \multicolumn{7}{|c|}{ Mobility } \\
\hline $\begin{array}{l}\text { Respondent had stayed outside his/her village/ } \\
\text { area for work or education in last } 12 \text { months }\end{array}$ & 10.0 & 2.2 & 3.5 & 1.4 & 12.4 & 2.6 \\
\hline Number of respondents & 745 & 1,164 & 369 & 538 & 376 & 626 \\
\hline $\begin{array}{l}\text { Stayed outside village/area for } 3 \text { months or } \\
\text { longer }\end{array}$ & 55.9 & \# & \# & \# & $(54.7)$ & $\#$ \\
\hline $\begin{array}{l}\text { Stayed outside village/area on more than one } \\
\text { separate occasion in last } 12 \text { months }\end{array}$ & 18.7 & $\#$ & $\#$ & $\#$ & $(18.3)$ & \# \\
\hline $\begin{array}{l}\text { Number of respondents who had stayed out of } \\
\text { their home village/area for work or education }\end{array}$ & 61 & 23 & 13 & 7 & 48 & 16 \\
\hline
\end{tabular}

Note: All Ns are unweighted. ( ) Based on 25-49 unweighted cases. \# Percentage not shown; based on fewer than 25 unweighted cases.

\subsection{Participation in vocational training programmes}

A number of vocational training opportunities are available to adolescents through government, non-government and private organisations. Our survey inquired whether respondents had attended any such programmes, and the kinds of programmes they would like to attend, if offered. Findings, presented in Table 4.5 and Figure 4.2, indicate that relatively few adolescents had undergone any vocational training even in 2012, but that while percentages of boys who had done so had increased significantly since 2007 (from 8\% to 15\%), those of girls remained similar to the percentages in 2007 ( $18 \%$ and 21\% in 2012 and 2007, respectively). Again, while significant increases were observed in percentages of both rural and urban boys who had attended vocational training programmes between 2007 and 2012, percentages of urban girls who had attended such programmes were similar at both times (36\% and $32 \%$, respectively) and declined significantly among rural girls (from $16 \%$ to $11 \%$ ). Urban-rural differences were evident: urban adolescents were more likely to have received training than their rural counterparts (24\% versus $12 \%$ among boys; $32 \%$ versus $11 \%$ among girls).

The pattern of training programmes to which adolescents were exposed in 2012 was quite different from that observed in 2007, and gender and rural-urban differences were apparent (Table 4.5). Among boys, exposure to computer skills training had increased significantly, from 54 percent in 2007 to 83 percent in 2012, while exposure to training in several other skills was limited and had declined significantly (auto mechanics or electrical work, from $24 \%$ to $2 \%$; driving, from $6 \%$ to $0 \%$; handicrafts, from $5 \%$ to $1 \%$ ). Girls in contrast, displayed a shift away from traditional to more modern skills, although the former continued to dominate. For example, percentages of girls 
reporting training in tailoring and handicrafts fell significantly, from 62 to 51, and from 39 to 14, respectively. In contrast, percentages reporting training in computer skills increased from 14 to 20 .

Training received by rural and urban adolescents followed the same pattern as among all surveyed adolescents in 2012 and in 2007. Even so, urban adolescents were far more likely than rural adolescents to report computer training, and, in the case of girls, beauty parlour skills. Conversely, urban girls were less likely than rural girls to report training in tailoring.

Table 4.5: Participation in vocational training programmes

Percentage of adolescents who ever attended a vocational training programme and type of programme attended, according to residence, Rajasthan, 2007 and 2012

\begin{tabular}{|c|c|c|c|c|}
\hline \multirow[b]{2}{*}{ Type of vocational training programme attended } & \multicolumn{2}{|c|}{ Boys (\%) } & \multicolumn{2}{|c|}{ Girls (\%) } \\
\hline & 2007 & 2012 & 2007 & 2012 \\
\hline \multicolumn{5}{|c|}{ Combined } \\
\hline Ever attended a vocational training programme & 7.5 & $15.2^{* * *}$ & 20.9 & 18.0 \\
\hline Number of respondents & 774 & 745 & 1,487 & 1,164 \\
\hline \multicolumn{5}{|l|}{ Type of vocational training programme attended } \\
\hline Tailoring & 1.2 & 1.3 & 61.9 & $50.7^{*}$ \\
\hline Auto mechanics/Electrical work & 24.5 & $2.1^{* * *}$ & 0.0 & 0.0 \\
\hline Driving & 5.5 & $0.0^{*}$ & 0.5 & 0.4 \\
\hline Plumbing/Masonry & 2.2 & 0.0 & 0.0 & 0.0 \\
\hline Poultry/Goat rearing & 0.0 & 0.0 & 0.0 & 0.0 \\
\hline Beauty parlour skills & 0.0 & 0.0 & 11.5 & 6.0 \\
\hline Nurse's aide & 2.3 & 0.0 & 0.0 & 0.0 \\
\hline Computer training & 54.4 & $83.1^{* * *}$ & 13.6 & 19.7 \\
\hline English language/Typing/Shorthand & 13.2 & 5.6 & 2.2 & 3.0 \\
\hline Handicrafts/Painting/Embroidery/Cooking & 5.4 & $0.5^{*}$ & 39.3 & $13.7^{* * *}$ \\
\hline \multicolumn{5}{|l|}{ Number of respondents who had ever attended any } \\
\hline vocational training programme & 70 & 131 & 335 & 240 \\
\hline \multicolumn{5}{|c|}{ Urban } \\
\hline Ever attended a vocational training programme & 15.5 & $24.2^{*}$ & 36.0 & 31.9 \\
\hline Number of respondents & 327 & 369 & 513 & 538 \\
\hline \multicolumn{5}{|l|}{ Type of vocational training programme attended } \\
\hline Tailoring & 2.1 & 0.0 & 46.7 & $37.4^{*}$ \\
\hline Auto mechanics/Electrical work & 23.1 & $1.2^{* * *}$ & 0.0 & 0.0 \\
\hline Driving & 1.9 & 0.0 & 1.2 & 0.6 \\
\hline Plumbing/Masonry & 0.0 & 0.0 & 0.0 & 0.0 \\
\hline Poultry/Goat rearing & 0.0 & 0.0 & 0.0 & 0.0 \\
\hline Beauty parlour skills & 0.0 & 0.0 & 19.4 & $9.8^{*}$ \\
\hline Nurse's aide & 0.0 & 0.0 & 0.0 & 0.0 \\
\hline Computer training & 66.2 & $90.2^{* * *}$ & 27.5 & 23.1 \\
\hline English language/Typing/Shorthand & 19.6 & $5.8^{*}$ & 4.8 & 4.9 \\
\hline Handicrafts/Painting/Embroidery/Cooking & 2.0 & 1.1 & 40.9 & $14.6^{* * *}$ \\
\hline \multicolumn{5}{|l|}{ Number of respondents who had ever attended any } \\
\hline vocational training programme & 50 & 90 & 184 & 172 \\
\hline
\end{tabular}


Table 4.5: (Cont'd)

\begin{tabular}{|c|c|c|c|c|}
\hline \multirow[b]{2}{*}{ Type of vocational training programme attended } & \multicolumn{2}{|c|}{ Boys (\%) } & \multicolumn{2}{|c|}{ Girls (\%) } \\
\hline & 2007 & 2012 & 2007 & 2012 \\
\hline \multicolumn{5}{|c|}{ Rural } \\
\hline Ever attended a vocational training programme & 4.5 & $11.9^{* *}$ & 15.5 & $10.6^{*}$ \\
\hline Number of respondents & 447 & 376 & 974 & 626 \\
\hline \multicolumn{5}{|l|}{ Type of vocational training programme attended } \\
\hline Tailoring & \# & $(2.3)$ & 74.6 & 71.7 \\
\hline Auto mechanics/Electrical work & \# & $(2.8)$ & 0.0 & 0.0 \\
\hline Driving & \# & $(0.0)$ & 0.0 & 0.0 \\
\hline Plumbing/Masonry & \# & $(0.0)$ & 0.0 & 0.0 \\
\hline Poultry/Goat rearing & \# & $(0.0)$ & 0.0 & 0.0 \\
\hline Beauty parlour skills & \# & $(0.0)$ & 4.9 & 0.0 \\
\hline Nurse's aide & \# & $(0.0)$ & 0.0 & 0.0 \\
\hline Computer training & \# & $(77.9)$ & 2.0 & $14.4^{* *}$ \\
\hline English language/Typing/Shorthand & \# & $(5.5)$ & 0.0 & 0.0 \\
\hline Handicrafts/Painting/Embroidery/Cooking & $\#$ & $(0.0)$ & 38.0 & $12.2^{* *}$ \\
\hline \multicolumn{5}{|l|}{ Number of respondents who had ever attended any } \\
\hline vocational training programme & 20 & 41 & 151 & 68 \\
\hline
\end{tabular}

Note: All Ns are unweighted. * , ${ }^{* *}$ and ${ }^{* * *}$ indicate that differences between 2007 and 2012 are significant at $p \leq 0.05, p \leq 0.01$ and $p \leq 0.001$, respectively. ( ) Based on 25-49 unweighted cases. \# Percentage not shown; based on fewer than 25 unweighted cases. Column totals may exceed $100 \%$ due to multiple responses.

In the 2012 survey, questions were also posed about the age at which vocational training was undertaken, whether the respondent had completed the course, received a certificate of completion or earned money by using the skill acquired through the training. Findings, presented in Table 4.6 along with corresponding findings of the 2007 survey, suggest that, on average, adolescents were aged 15-16 years when they joined a vocational training programme,

Table 4.6: Experience of exposure to vocational training

Percentage of adolescents who had attended at least one vocational training programme by their experience of training, according to residence, Rajasthan, 2007 and 2012

\begin{tabular}{|c|c|c|c|c|c|c|}
\hline \multirow[b]{2}{*}{ Exposure to vocational training programmes } & \multicolumn{2}{|c|}{ Combined } & \multicolumn{2}{|c|}{ Urban } & \multicolumn{2}{|c|}{ Rural } \\
\hline & Boys (\%) & Girls (\%) & Boys (\%) & Girls (\%) & Boys (\%) & Girls (\%) \\
\hline $\begin{array}{l}\text { Median age (in years) at first exposure to a vocational } \\
\text { training programme }\end{array}$ & 16.0 & 15.0 & 15.0 & 15.0 & $(16.0)$ & 15.0 \\
\hline Completed at least one vocational training programme & 55.7 & 55.3 & 67.1 & 61.3 & $(47.1)$ & 45.8 \\
\hline Completed all vocational training programmes attended & 53.3 & 48.6 & 61.5 & 52.1 & $(47.1)$ & 43.1 \\
\hline $\begin{array}{l}\text { Received a certificate for at least one vocational training } \\
\text { programme attended }\end{array}$ & 32.8 & 18.1 & 42.7 & 27.8 & $(25.4)$ & 2.7 \\
\hline $\begin{array}{l}\text { Earned money in the last } 12 \text { months from skill acquired } \\
\text { in one or more vocational training programmes }\end{array}$ & 3.6 & 16.9 & 4.4 & 18.1 & (3.1) & 14.9 \\
\hline $\begin{array}{l}\text { Number of respondents who had ever attended any } \\
\text { vocational training programme }\end{array}$ & 131 & 240 & 90 & 172 & 41 & 68 \\
\hline
\end{tabular}

Note: All Ns are unweighted. ( ) Based on 25-49 unweighted cases. Five respondents who attended more than three vocational training courses were asked about the three most important courses they had attended. 
with girls a year younger than boys (15 versus 16), and urban boys a year younger than their rural counterparts. Just over one-half of boys and girls who had attended any vocational training programme reported completing at least one such course (55-56\%) and similar percentages of both reported that they had completed all the courses in which they had enrolled (49-53\%). More adolescents in urban than rural areas reported completing at least one (61-67\% versus $46-$ $47 \%$ ) and all (52-62\% versus $43-47 \%$ ) training programmes that they had undertaken.

Also assessed were whether a certificate of completion of any course had been received and whether the respondent had earned any money from the skill learned. In general, findings suggest that many of the training programmes that the surveyed adolescents had attended were informal, not necessarily offering a certificate to those who had successfully completed the course, and few adolescents who had undergone training had used the skill acquired to earn money. For example, while 55-56 percent of adolescents who had participated in one or more courses had completed a course, just 33 percent of boys and even fewer-18 percent-girls had received a certificate for completing the course. Percentages who had received a course completion certificate were considerably lower among rural than urban boys (25\% versus $43 \%$ ) and girls (3\% versus $28 \%$ ). At the same time, just four percent of boys and far more-17 percent-girls had earned money from the skill acquired, with little rural-urban variation.

The kinds of training that the surveyed adolescents wished to take had changed considerably over the five-year inter-survey period, and also varied considerably by sex of the respondent and ruralurban residence. As seen in Table 4.7, while most boys expressed an interest in training on computer skills, percentages increased significantly, from 63 in 2007 to 78 in 2012; they were significantly less likely than five years earlier to express interest in such skills as driving (down from $7 \%$ to $3 \%$ ) and English language or secretarial skills (down from $21 \%$ to $9 \%$ ), and remained about as likely to express interest in auto mechanics or electrical work (20\% at both times). Among girls in contrast, preferences suggest a shift away from traditional to more modern skills, although the former continued to dominate. For example, percentages reporting a preference for training in tailoring and handicrafts fell significantly, from 83 to 72 , and from 32 to 14 , respectively. In contrast, percentages reporting
Figure 4.2: Percentage of adolescents who ever attended a vocational training programme and percentage who were interested in participating in such programmes, according to residence, Rajasthan, 2007 and 2012
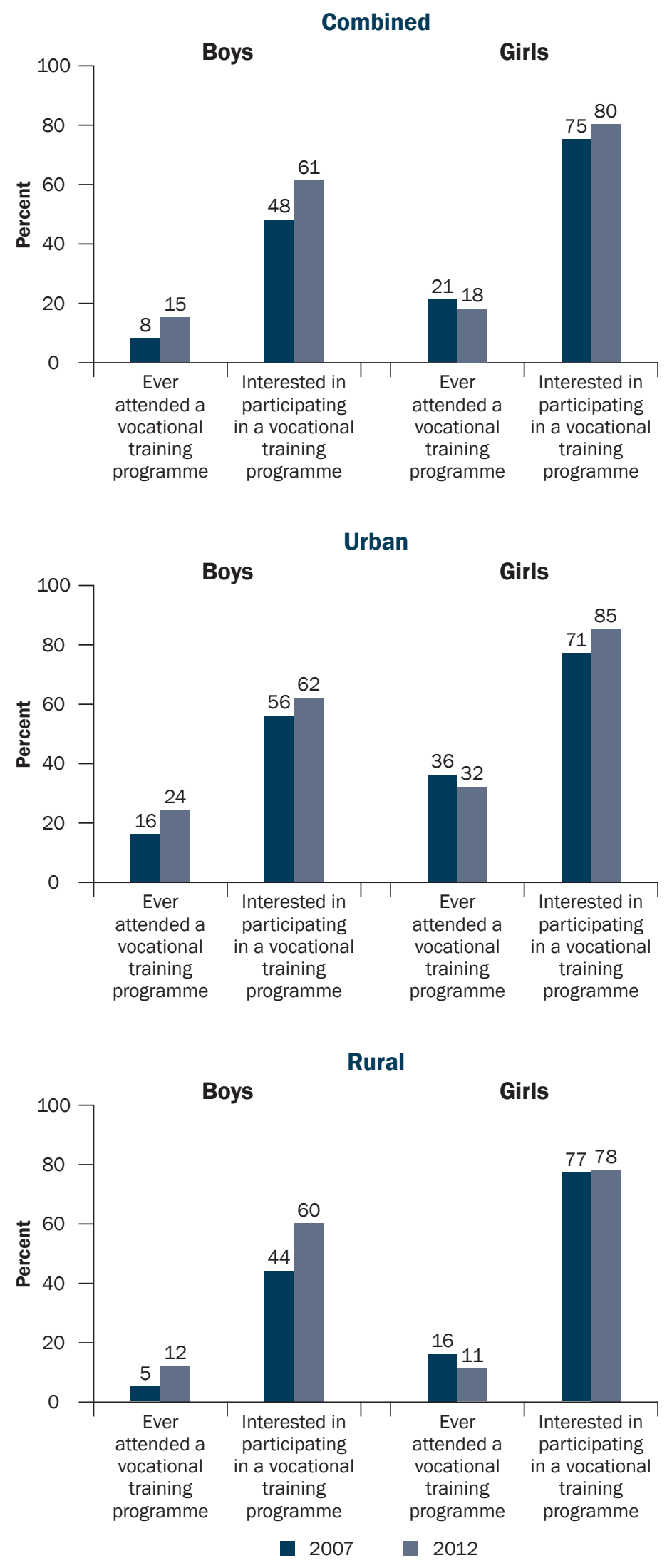
Table 4.7: Willingness of adolescents to participate in vocational training programmes

Percentage of adolescents interested in participating in vocational training programmes by type of programme, according to residence, Rajasthan, 2007 and 2012

\begin{tabular}{|c|c|c|c|c|}
\hline \multirow[b]{2}{*}{ Type of vocational training programme } & \multicolumn{2}{|c|}{ Boys (\%) } & \multicolumn{2}{|c|}{ Girls (\%) } \\
\hline & 2007 & 2012 & 2007 & 2012 \\
\hline \multicolumn{5}{|c|}{ Combined } \\
\hline Interested in participating in a vocational training programme & 47.6 & $60.5^{* * *}$ & 75.0 & $80.0^{*}$ \\
\hline Number of respondents & 774 & 745 & 1,487 & 1,164 \\
\hline \multicolumn{5}{|l|}{ Type of programme in which respondents wished to participate } \\
\hline Tailoring & 2.2 & 2.8 & 83.2 & $72.2^{* * *}$ \\
\hline Auto mechanics/Electrical work & 19.8 & 19.5 & 0.1 & 0.1 \\
\hline Driving & 7.4 & $3.0^{* *}$ & 0.3 & $2.0^{* * *}$ \\
\hline Plumbing/Masonry & 6.9 & 2.3 & 0.0 & 0.0 \\
\hline Poultry/Goat rearing & 0.2 & 0.0 & 0.0 & 0.0 \\
\hline Beauty parlour skills & 0.2 & 0.1 & 12.1 & $16.3^{*}$ \\
\hline Nurse's aide & 0.0 & 0.4 & 0.6 & 0.8 \\
\hline Computer training & 62.6 & $78.1^{* * *}$ & 19.2 & $30.6^{* * *}$ \\
\hline English language/Typing/Shorthand & 20.9 & $8.7^{* * *}$ & 6.7 & 5.5 \\
\hline Handicrafts/Painting/Embroidery/Cooking & 2.6 & 1.2 & 31.5 & $13.7^{* * *}$ \\
\hline Other $^{1}$ & 1.5 & $6.1^{* * *}$ & 0.6 & $17.9^{* * *}$ \\
\hline \multicolumn{4}{|l|}{ Number of respondents interested in participating in a vocational } & 941 \\
\hline \multicolumn{5}{|c|}{ Urban } \\
\hline Interested in participating in a vocational training programme & 56.4 & 61.7 & 70.6 & $84.8^{* * *}$ \\
\hline Number of respondents & 327 & 369 & 513 & 538 \\
\hline \multicolumn{5}{|l|}{ Type of programme in which respondents wished to participate } \\
\hline Tailoring & 1.6 & 1.3 & 61.9 & $52.6^{*}$ \\
\hline Auto mechanics/Electrical work & 19.7 & 17.3 & 0.3 & 0.3 \\
\hline Driving & 5.1 & 4.7 & 0.8 & 2.7 \\
\hline Plumbing/Masonry & 0.6 & 0.0 & 0.0 & 0.0 \\
\hline Poultry/Goat rearing & 0.6 & 0.0 & 0.0 & 0.0 \\
\hline Beauty parlour skills & 0.5 & 0.5 & 19.0 & 24.8 \\
\hline Nurse's aide & 0.0 & 0.0 & 0.3 & 0.7 \\
\hline Computer training & 68.0 & $78.7^{*}$ & 38.0 & 39.4 \\
\hline English language/Typing/Shorthand & 24.8 & $10.8^{* * *}$ & 13.7 & $9.0^{*}$ \\
\hline Handicrafts/Painting/Embroidery/Cooking & 2.1 & 1.6 & 33.6 & $17.0^{* * *}$ \\
\hline Other ${ }^{1}$ & 2.7 & $9.2^{* *}$ & 1.4 & $34.2^{* * *}$ \\
\hline \multicolumn{5}{|l|}{ Number of respondents interested in participating in a vocational } \\
\hline
\end{tabular}




\begin{tabular}{|c|c|c|c|c|}
\hline \multirow[b]{2}{*}{ Type of vocational training programme } & \multicolumn{2}{|c|}{ Boys (\%) } & \multicolumn{2}{|c|}{ Girls (\%) } \\
\hline & 2007 & 2012 & 2007 & 2012 \\
\hline \multicolumn{5}{|c|}{ Rural } \\
\hline Interested in participating in a vocational training programme & 44.3 & $60.0^{* *}$ & 76.6 & 77.5 \\
\hline Number of respondents & 447 & 376 & 974 & 626 \\
\hline \multicolumn{5}{|l|}{ Type of programme in which respondents wished to participate } \\
\hline Tailoring & 2.5 & 3.4 & 90.2 & $83.5^{* *}$ \\
\hline Auto mechanics/Electrical work & 19.9 & 20.3 & 0.0 & 0.0 \\
\hline Driving & 8.4 & $2.4^{* *}$ & 0.1 & $1.6^{*}$ \\
\hline Plumbing/Masonry & 9.8 & 3.2 & 0.0 & 0.0 \\
\hline Poultry/Goat rearing & 0.0 & 0.0 & 0.0 & 0.0 \\
\hline Beauty parlour skills & 0.0 & 0.0 & 9.8 & 11.5 \\
\hline Nurse's aide & 0.0 & 0.6 & 0.7 & 0.9 \\
\hline Computer training & 60.1 & $77.9^{* *}$ & 13.0 & $25.6^{* * *}$ \\
\hline English language/Typing/Shorthand & 19.2 & $7.9^{* * *}$ & 4.4 & 3.4 \\
\hline Handicrafts/Painting/Embroidery/Cooking & 2.9 & 1.1 & 30.8 & $11.7^{* * *}$ \\
\hline Other $^{1}$ & 1.0 & $5.0^{* * *}$ & 0.3 & $8.6^{* * *}$ \\
\hline \multicolumn{5}{|l|}{ Number of respondents interested in participating in a vocational } \\
\hline
\end{tabular}

Note: All Ns are unweighted. * , ** and ${ }^{* * *}$ indicate that differences between 2007 and 2012 are significant at $p \leq 0.05, p \leq 0.01$ and $p \leq 0.001$, respectively. Column totals may exceed $100 \%$ due to multiple responses. 1Includes programmes like performing arts, ICDS/Anganwadi, management etc.

a preference for training in computer skills increased from 19 to 31, as did those reporting a preference for beauty parlour training (from 12\% to 16\%). Patterns among rural and urban adolescents, and changes between 2007 and 2012, were similar to the overall situation.

Rural-urban differences were negligible for boys and considerable for girls. Indeed, as many rural as urban boys expressed a desire for training in computers (78-79\%). Among girls in contrast, rural-urban differences were evident, and the pattern in 2012 was quite different from that in 2007. Rural girls were significantly more likely than their urban counterparts to express an interest in tailoring ( $84 \%$ versus $53 \%$ ), and significantly less likely to express an interest in computer use (26\% versus $39 \%$ ), beauty parlour skills (12\% versus $25 \%)$, English language and secretarial skills (3\% versus $9 \%)$ and handicrafts (12\% versus $17 \%)$.

\subsection{Summary}

In 2012 and 2007, paid work participation in the 12-month period preceding the interview resembles lifetime work profiles. About one-quarter of surveyed boys $(27 \%)$ and girls $(26 \%)$ had at some time engaged in paid work, largely similar to the paid work reported in 2007 ( $26 \%$ and $21 \%$, respectively). While rural-urban differences were not observed among boys in 2012 (26\%-29\%), somewhat fewer urban than rural girls had been engaged in paid work (22\% versus $28 \%$ ). Paid work was initiated in childhood or early adolescence, that is, before age 15 , for about one in ten adolescents-more girls than boys in 2012 (12\% versus 6\%), and largely similar to percentages reported in 2007. What had changed dramatically was the time spent in wage work among adolescents who were so engaged in the year preceding the interview. Working adolescents were significantly less likely in 2012 than in 2007 to have worked for the most part of the year: 47 percent and 23 percent of boys and girls, respectively, had worked for most of the year compared to 83 percent and 59 percent, respectively, in 2007. In contrast, about one-tenth of boys (11\%) and fewer girls (6\%) were seeking employment at the time of the interview compared to nine percent and four percent in 2007. 
Occupational distributions of those engaged in remunerated work in the 12 months preceding the interview suggest considerable gender disparities. Among boys, most were engaged in unskilled non-agricultural labour (63\%) and skilled manual work (24\%) and, even in rural areas, very few were engaged in agriculture (5\%); this distribution was almost identical to the situation in 2007. Among girls in contrast, the leading occupation was agricultural labour (47\%), followed by skilled manual work (22\%) and unskilled non-agricultural labour (20\%).

Most surveyed adolescents, that is, 84 percent of boys and 89 percent of girls, resided in their place of birth in 2012, with slightly more rural than urban adolescents so reporting. More boys than girls reported that migration had taken place in the five years preceding the interview ( $11 \%$ versus $5 \%$, respectively), and most of those who so reported had migrated with their parents. With regard to adolescents' work- or education-related mobility, that is, residence outside of their village or urban area for work or education in the 12 months preceding the interview, ten percent of boys and two percent of girls had lived away from their home setting in the 12 months preceding the interview.

Relatively few adolescents in our survey had undergone any vocational training even in 2012, but while percentages of boys who had done so had increased since 2007 (from 8\% to 15\%), the corresponding percentages of girls remained similar to those in 2007 (23\% and 21\%, respectively). Urban adolescents were more likely to have received training than their rural counterparts. The pattern of training programmes to which adolescents were exposed in 2012 was quite different from that observed in 2007, and gender and rural-urban differences were apparent. Among boys, training had increasingly focused on computer skills and declined for all other skills for which programmes were offered. Among girls, there was a shift away from traditional (tailoring, handicrafts) to more modern skills (computer skills), although the former continued to dominate.

The characteristics of adolescents who received training suggest that they were, on average, aged 15-16 years when they joined a vocational training programme, with girls a year younger than boys (15 versus 16). Just over one-half (55-56\%) of those who had taken a vocational course reported completing it, just one-third of boys (33\%) and one-fifth of girls (18\%) reported having received a certificate for the course, and even fewer-four percent of boys and 17 percent of girls-had earned money from the skill they had acquired through the course in the 12 months preceding the interview.

Adolescents in our survey were clearly interested in acquiring skills that would generate employment; three-fifths of boys and four-fifths of girls reported interest in vocational skills training. The kinds of training that adolescents wished to take had changed considerably over the five-year period, suggesting a shift towards more modern skills. For example, boys continued to express interest in engaging in training on computer skills and auto mechanics or electrical work, and the preferences of girls also suggested a shift away from traditional (tailoring and handicrafts) to more modern skills such as computer use. 


\section{Chapter 5}

\section{Media exposure, mobile phone use and access to pornographic materials}

Media may play an important role in shaping the attitudes and behaviours of adolescents. Adolescents gain access to new information through a variety of sources, including print and visual media and, increasingly, the internet. Many are also exposed to pornography through these channels. This chapter highlights the exposure of adolescents who participated in our survey to various media sources, as well as the extent of their exposure to pornographic materials by way of books, magazines, films and the internet.

\subsection{Mass media exposure and mobile phone use}

The survey asked a number of questions regarding adolescents' use of mobile phones and exposure to mass media. With regard to mobile phone use, adolescents were asked whether they owned a mobile phone or could use a mobile phone owned by someone in the family. Questions relating to mass media exposure included whether and how frequently young people read newspapers, magazines and/or books; watched films or television programmes other than movies, and accessed the internet. Questions regarding exposure to print media and the internet were asked only to those who had attained at least five years of education, as this was considered a prerequisite for basic literacy and, thus, understanding of such materials. Adolescents were asked to rate the frequency of their exposure to each medium according to the categories "almost every day," "at least once a week," "at least once a month," "more rarely" and "never." In order to permit comparisons with 2007, these have been classified as "never," "sometimes" (at least once a week, once a month or more rarely) and "often" (almost every day).

Findings presented in Table 5.1 show that almost all surveyed adolescents had access to mobile phones by 2012 . Indeed, as many as 93 percent of boys and 89 percent of girls reported that they either owned a mobile phone or could use a mobile phone owned by someone in their family. While rural-urban differences were not evident for boys (92-94\%), more urban than rural girls reported access to a mobile phone (95\% versus $86 \%$ ).

Findings related to mass media exposure, presented in Table 5.1 and Figure 5.1, suggest that adolescents were exposed to a variety of media, that gender differences varied with the type of media in question, and that adolescents in 2012-both rural and urban-were significantly more likely than those in 2007 to have been exposed to various media.

The largest proportion of surveyed adolescents was exposed to television: equal percentages of boys and girls reported any exposure to television ( $90 \%$ of boys and $88 \%$ of girls), as well as frequent exposure to television (71-72\%). While any exposure to television remained about the same as in 2007 for boys (94\%), by 2012, it had increased considerably among girls from 72 percent to 88 percent. Frequent exposure to television, however, had increased considerably among both boys and girls between 2007 and 2012. Urban adolescents were more likely than their rural counterparts to report both any and frequent exposure to television.

Exposure to print materials (newspapers, magazines and/or books) among those with five or more years of education was reported by more boys than girls ( $91 \%$ versus $82 \%$ ), by and large, similar to the situation in 2007 (95\% and 81\%). However, frequent exposure was far more likely to be reported by adolescents in 2012 than 2007 (73\% versus 38\% among boys; $46 \%$ versus 30\% among girls), and considerably more likely to be reported by boys than girls in 2012 (73\% versus 46\%). Again, in 2012, urban adolescents were consistently more likely than their rural counterparts to report any and frequent exposure to the print media.

Finally, there has been a huge increase in internet access among adolescents with five or more years of education, especially among boys. While just five percent of boys and four percent of girls had accessed the internet in 2007, percentages had increased to 37 and 11, respectively, in 2012. Notably, in 2012, about one-fifth of boys (19\%) and one in 20 girls (6\%) reported frequent internet use. Rural-urban differences were also apparent. In addition, in 2012, 
Table 5.1: Mass media exposure and mobile phone access

Percent distribution of adolescents reporting access to mobile phones and exposure to various mass media by frequency of exposure, according to residence, Rajasthan, 2007 and 2012

\begin{tabular}{|c|c|c|c|c|}
\hline \multirow[b]{2}{*}{ Exposure by mode of communication } & \multicolumn{2}{|c|}{ Boys (\%) } & \multicolumn{2}{|c|}{ Girls (\%) } \\
\hline & 2007 & 2012 & 2007 & 2012 \\
\hline \multicolumn{5}{|c|}{ Combined } \\
\hline Access to mobile phones & na & 92.9 & na & 88.7 \\
\hline \multicolumn{5}{|l|}{ Frequency of watching television } \\
\hline Never & 5.8 & 9.9 & 28.3 & 11.7 \\
\hline Sometimes & 69.6 & 19.2 & 35.4 & 16.4 \\
\hline Often & 24.6 & 70.9 & 36.3 & 71.7 \\
\hline Significance level & \multicolumn{2}{|c|}{$* * *$} & \multicolumn{2}{|c|}{$* * *$} \\
\hline Number of respondents & 774 & 745 & 1,487 & 1,164 \\
\hline \multicolumn{5}{|l|}{ Frequency of reading newspapers/magazines/books ${ }^{1}$} \\
\hline Never & 5.0 & 8.7 & 18.7 & 18.0 \\
\hline Sometimes & 57.3 & 18.6 & 50.7 & 35.7 \\
\hline Often & 37.6 & 72.7 & 30.1 & 46.2 \\
\hline Significance level & \multicolumn{2}{|c|}{ *** } & \multicolumn{2}{|c|}{$* * *$} \\
\hline \multicolumn{5}{|l|}{ Frequency of accessing the internet ${ }^{1}$} \\
\hline Never & 94.6 & 62.9 & 95.5 & 88.5 \\
\hline Sometimes & 4.8 & 18.4 & 3.3 & 5.9 \\
\hline Often & 0.4 & 18.8 & 0.6 & 5.5 \\
\hline Significance level & \multicolumn{2}{|c|}{ *** } & \multicolumn{2}{|c|}{$* * *$} \\
\hline Number of respondents with 5 or more years of education & 691 & 704 & 1,108 & 1,006 \\
\hline \multicolumn{5}{|c|}{ Urban } \\
\hline Access to mobile phones & na & 94.1 & na & 94.5 \\
\hline \multicolumn{5}{|l|}{ Frequency of watching television } \\
\hline Never & 0.6 & 1.8 & 6.4 & 2.4 \\
\hline Sometimes & 47.6 & 6.3 & 26.5 & 6.1 \\
\hline Often & 51.8 & 91.9 & 67.0 & 91.5 \\
\hline Significance level & \multicolumn{2}{|c|}{$* * *$} & \multicolumn{2}{|c|}{$* * *$} \\
\hline Number of respondents & 327 & 369 & 513 & 538 \\
\hline \multicolumn{5}{|l|}{ Frequency of reading newspapers/magazines/books ${ }^{1}$} \\
\hline Never & 0.4 & 5.6 & 10.8 & 8.1 \\
\hline Sometimes & 39.0 & 12.3 & 44.4 & 25.3 \\
\hline Often & 60.6 & 82.2 & 43.8 & 66.6 \\
\hline Significance level & \multicolumn{2}{|c|}{$* * *$} & \multicolumn{2}{|c|}{ *** } \\
\hline \multicolumn{5}{|l|}{ Frequency of accessing the internet ${ }^{1}$} \\
\hline Never & 85.4 & 37.3 & 88.4 & 74.5 \\
\hline Sometimes & 13.3 & 27.3 & 9.4 & 12.4 \\
\hline Often & 1.4 & 35.4 & 1.3 & 13.1 \\
\hline Significance level & \multicolumn{2}{|c|}{ *** } & \multicolumn{2}{|c|}{ *** } \\
\hline Number of respondents with 5 or more years of education & 292 & 347 & 440 & 491 \\
\hline
\end{tabular}




\begin{tabular}{|c|c|c|c|c|}
\hline \multirow[b]{2}{*}{ Exposure by mode of communication } & \multicolumn{2}{|c|}{ Boys (\%) } & \multicolumn{2}{|c|}{ Girls (\%) } \\
\hline & 2007 & 2012 & 2007 & 2012 \\
\hline \multicolumn{5}{|c|}{ Rural } \\
\hline Access to mobile phones & na & 92.4 & na & 85.7 \\
\hline \multicolumn{5}{|l|}{ Frequency of watching television } \\
\hline Never & 7.8 & 12.9 & 36.2 & 16.6 \\
\hline Sometimes & 77.6 & 23.9 & 38.6 & 21.8 \\
\hline Often & 14.6 & 63.2 & 25.2 & 61.4 \\
\hline Significance level & \multicolumn{2}{|c|}{$* * *$} & \multicolumn{2}{|c|}{$* * *$} \\
\hline Number of respondents & 447 & 376 & 974 & 626 \\
\hline \multicolumn{5}{|l|}{ Frequency of reading newspapers/magazines/books ${ }^{1}$} \\
\hline Never & 6.6 & 9.8 & 22.3 & 23.8 \\
\hline Sometimes & 64.0 & 20.9 & 53.5 & 41.8 \\
\hline Often & 29.1 & 69.3 & 23.9 & 34.2 \\
\hline Significance level & \multicolumn{2}{|c|}{$* * *$} & \multicolumn{2}{|c|}{ ** } \\
\hline \multicolumn{5}{|l|}{ Frequency of accessing the internet ${ }^{1}$} \\
\hline Never & 98.1 & 72.1 & 98.7 & 96.7 \\
\hline Sometimes & 1.7 & 15.1 & 0.6 & 2.1 \\
\hline Often & 0.0 & 12.8 & 0.3 & 1.0 \\
\hline Significance level & \multicolumn{2}{|c|}{$* * *$} & \multicolumn{2}{|c|}{ * } \\
\hline Number of respondents with 5 or more years of education & 399 & 357 & 668 & 515 \\
\hline
\end{tabular}

Note: All Ns are unweighted. *, ${ }^{* *}$ and ${ }^{* * *}$ indicate that differences between 2007 and 2012 are significant at $p \leq 0.05, p \leq 0.01$ and $p \leq 0.001$, respectively. na: Not asked in 2007 survey. Column totals may not equal $100 \%$ due to missing cases. ${ }^{1}$ Question asked only of those respondents who had completed five or more years of education.

63 percent and 26 percent of urban boys and girls, respectively, had accessed the internet compared to 28 percent and three percent of their rural counterparts; likewise, 35 percent of boys and 13 percent of girls in urban areas had accessed the internet frequently compared to far fewer rural adolescents (13\% of boys and $1 \%$ of girls).

\subsection{Exposure to pornographic materials}

Adolescents were asked in both 2007 and 2012 whether they were exposed to-that is, had read or looked atpornographic materials by way of films, books and magazines, and the internet (for those who accessed the internet) and the frequency of such exposure. Table 5.2 presents findings from both surveys and shows that 48 percent of boys compared to eight percent of girls had watched "blue" or pornographic films in 2012 and 18 percent of boys and two percent of girls reported that they had done so sometimes or often. Indeed, percentages of adolescents exposed to pornographic materials had increased significantly between 2007 and 2012, both among girls (from 1\% to $8 \%$ ) and, more so, among boys (from $9 \%$ to $48 \%$ ). Differences by rural-urban residence, in 2012, were mild for girls (7-8\%) but suggest that more urban than rural boys had ever watched a pornographic film (54\% versus $46 \%$ ) and had done so sometimes or often (22\% versus $17 \%)$.

Exposure to pornographic books and magazines was reported by fewer boys $(22 \%)$ and about as many girls $(7-8 \%)$ as those exposed to pornographic films, representing an increase from 2007 (5\% and 1\% among boys and girls, respectively) with little variation by rural-urban residence (20-25\% among boys, 7-9\% among girls).

Of those with access to the internet, there was a significant increase in percentages exposed to pornographic materials. As many as 41 percent of boys and 18 percent of girls had accessed pornographic materials on the internet by 2012 compared to 12 percent and two percent, respectively, in 2007. Differences by rural-urban 
Figure 5.1: Percentage of adolescents exposed to television, print media and the internet, according to residence, Rajasthan, 2007 and 2012
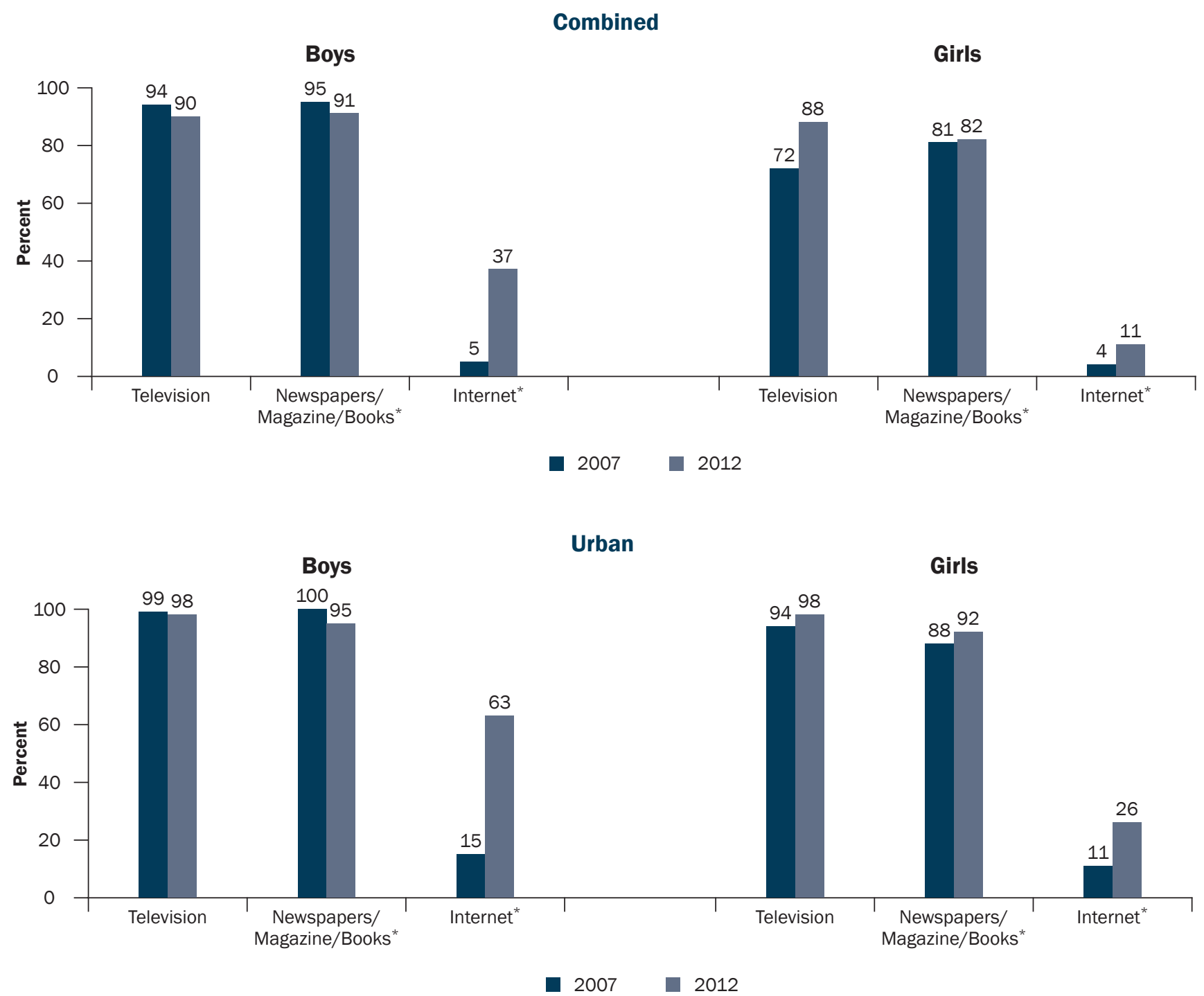

Rural

\section{Boys}

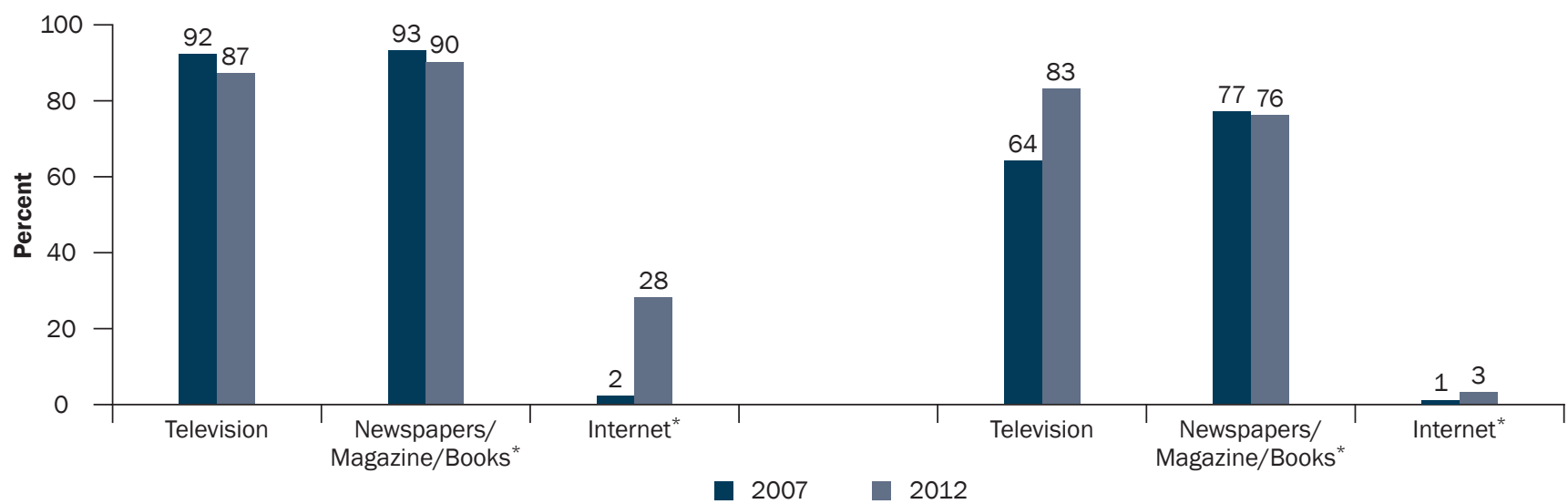

Note: *Question asked only of those respondents who had completed five or more years of education. 
residence were apparent in 2012 for boys, with 48 percent and 36 percent of those in urban and rural areas, respectively, reporting exposure to pornographic materials on the internet; a similar comparison is not possible for girls because of small numbers of rural girls who had accessed the internet.

Table 5.2: Exposure to pornographic materials

Percentage of adolescents exposed to pornographic materials, according to residence, Rajasthan, 2007 and 2012

\begin{tabular}{|c|c|c|c|c|}
\hline \multirow[b]{2}{*}{ Exposure to pornographic materials } & \multicolumn{2}{|c|}{ Boys (\%) } & \multicolumn{2}{|c|}{ Girls (\%) } \\
\hline & 2007 & 2012 & 2007 & 2012 \\
\hline \multicolumn{5}{|c|}{ Combined } \\
\hline \multicolumn{5}{|l|}{ Frequency of watching "blue"/pornographic films } \\
\hline Never & 91.2 & 51.9 & 99.5 & 92.3 \\
\hline Rarely & 4.4 & 30.0 & 0.5 & 5.7 \\
\hline Sometimes & 4.4 & 17.7 & 0.1 & 1.6 \\
\hline Often & 0.0 & 0.4 & 0.0 & 0.3 \\
\hline Significance level & \multicolumn{2}{|c|}{$* * *$} & \multicolumn{2}{|c|}{ *** } \\
\hline \multicolumn{5}{|c|}{ Frequency of reading/looking at pornographic books/magazines } \\
\hline Never & 95.0 & 78.4 & 99.4 & 92.5 \\
\hline Rarely & 3.0 & 18.0 & 0.3 & 5.5 \\
\hline Sometimes & 2.1 & 3.5 & 0.3 & 1.6 \\
\hline Often & 0.0 & 0.1 & 0.0 & 0.3 \\
\hline Significance level & \multicolumn{2}{|c|}{$* * *$} & \multicolumn{2}{|c|}{$* * *$} \\
\hline Number of respondents & 774 & 745 & 1,487 & 1,164 \\
\hline Ever accessed pornographic materials on the internet & 11.7 & $41.2^{* * *}$ & 2.0 & $17.5^{* *}$ \\
\hline Number of respondents who ever accessed the internet & 51 & 320 & 53 & 141 \\
\hline \multicolumn{5}{|c|}{ Urban } \\
\hline \multicolumn{5}{|l|}{ Frequency of watching "blue"/pornographic films } \\
\hline Never & 88.1 & 46.0 & 99.2 & 90.8 \\
\hline Rarely & 6.2 & 32.3 & 0.6 & 7.2 \\
\hline Sometimes & 5.7 & 21.3 & 0.2 & 1.5 \\
\hline Often & 0.0 & 0.5 & 0.0 & 0.5 \\
\hline Significance level & \multicolumn{2}{|c|}{$* * *$} & \multicolumn{2}{|c|}{$* * *$} \\
\hline \multicolumn{5}{|c|}{ Frequency of reading/looking at pornographic books/magazines } \\
\hline Never & 92.8 & 74.8 & 99.6 & 90.7 \\
\hline Rarely & 4.9 & 19.0 & 0.2 & 7.0 \\
\hline Sometimes & 2.3 & 5.8 & 0.2 & 2.0 \\
\hline Often & 0.0 & 0.3 & 0.0 & 0.3 \\
\hline Significance level & \multicolumn{2}{|c|}{ *** } & \multicolumn{2}{|c|}{$* * *$} \\
\hline Number of respondents & 327 & 369 & 513 & 538 \\
\hline Ever accessed pornographic materials on the internet & $(11.1)$ & $47.8^{* * *}$ & (2.3) & $17.2^{*}$ \\
\hline Number of respondents who ever accessed the internet & 44 & 221 & 47 & 125 \\
\hline
\end{tabular}


Table 5.2: (Cont'd)

\begin{tabular}{|c|c|c|c|c|}
\hline \multirow[b]{2}{*}{ Exposure to pornographic materials } & \multicolumn{2}{|c|}{ Boys (\%) } & \multicolumn{2}{|c|}{ Girls (\%) } \\
\hline & 2007 & 2012 & 2007 & 2012 \\
\hline \multicolumn{5}{|c|}{ Rural } \\
\hline \multicolumn{5}{|l|}{ Frequency of watching "blue"/pornographic films } \\
\hline Never & 92.3 & 54.1 & 99.6 & 93.0 \\
\hline Rarely & 3.8 & 29.1 & 0.4 & 5.0 \\
\hline Sometimes & 3.9 & 16.4 & 0.0 & 1.7 \\
\hline Often & 0.0 & 0.4 & 0.0 & 0.1 \\
\hline Significance level & \multicolumn{2}{|c|}{$* * *$} & \multicolumn{2}{|c|}{ *** } \\
\hline \multicolumn{5}{|c|}{ Frequency of reading/looking at pornographic books/magazines } \\
\hline Never & 95.8 & 79.6 & 99.3 & 93.5 \\
\hline Rarely & 2.3 & 17.7 & 0.3 & 4.6 \\
\hline Sometimes & 2.0 & 2.7 & 0.3 & 1.3 \\
\hline Often & 0.0 & 0.0 & 0.0 & 0.3 \\
\hline Significance level & \multicolumn{2}{|c|}{$* * *$} & \multicolumn{2}{|c|}{$* * *$} \\
\hline Number of respondents & 447 & 376 & 974 & 626 \\
\hline Ever accessed pornographic materials on the internet & \# & $35.8^{* * *}$ & \# & \# \\
\hline Number of respondents who ever accessed the internet & 7 & 99 & 6 & 16 \\
\hline
\end{tabular}

Note: All Ns are unweighted. *, ${ }^{* *}$ and ${ }^{* * *}$ indicate that differences between 2007 and 2012 are significant at $p \leq 0.05, p \leq 0.01$ and $p \leq 0.001$, respectively. ( ) Based on 25-49 unweighted cases. \# Percentage not shown; based on fewer than 25 unweighted cases. Column totals may not equal $100 \%$ due to missing cases.

\subsection{Summary}

Findings suggest that almost all the surveyed adolescents had access to mobile phones by 2012 . Indeed, as many as 93 percent of boys and 89 percent of girls reported that they either owned a mobile phone or could use a mobile phone owned by someone in their family. While rural-urban differences were negligible for boys, fewer rural than urban girls reported access to a mobile phone (86\% versus 95\%).

With regard to mass media exposure, large proportions of all surveyed adolescents in Rajasthan were exposed to television (88-90\%), and, among adolescents with five or more years of education, to newspapers, magazines and/or books ( $91 \%$ of boys and $82 \%$ of girls). Exposure to the internet, among those with five or more years of education, was reported by considerably fewer adolescents (37\% of boys and $11 \%$ of girls). At the same time, significant increases were observed in exposure to all three mass media among both girls and boys between 2007 and 2012. Most notably, internet access increased from five percent to 37 percent among boys and from four percent to 11 percent among girls. Gender differences were apparent, with boys typically more likely to be exposed to each mass communication medium than girls. Rural-urban differences persisted, with urban adolescents more likely to report frequent exposure to television and print media, and far more likely to have been exposed to the internet than their rural counterparts.

Findings also suggest that 48 percent of boys and eight percent of girls had watched pornographic films, and 22 percent of boys and seven percent of girls had accessed pornographic books and magazines. Differences by ruralurban residence were apparent in 2012 for boys, with 48 percent and 36 percent of those in urban and rural areas, respectively, reporting exposure to pornographic materials on the internet; a similar comparison is not possible for girls because of small numbers of rural girls who had accessed the internet. 


\section{Chapter 6 Growing up}

Several studies have highlighted the importance of close interaction with parents for the healthy development of young people (Laird et al., 2003; Marta, 1997; Sroufe, 1991). Yet others, including the Youth in India 2006-07 study, note that young people's interaction with parents is particularly limited when it comes to discussion of sensitive issues, for example, girl-boy relations or sexual and reproductive matters (Alexander et al., 2006a, 2006b; Lambert and Wood, 2005; Mehra, Savithri and Coutinho, 2002; Jejeebhoy and Santhya, 2011). In addition, as also observed in the Youth in India 2006-07 study, for many adolescents, the peer group is a central source of both information and support but, at the same time, a source of misinformation and pressure to adopt risky behaviours (International Institute for Population Sciences and Population Council, 2010; Bhuiya et al., 2003; Sachdev, 1998; UI Haque and Faizunnisa, 2003).

The 2012 study included several questions relating to these issues. This chapter focuses on adolescents' interaction with parents and peers. Specifically, it explores aspects of the family life of surveyed adolescents and their interaction with parents on various matters of importance to adolescents, as also the changes experienced in family life and interaction with parents among those aged 15-19 in the 2012 study compared to those aged 15-19 in the 2007 study. It also addresses peer networks and interaction, specifically, the size of same- and opposite-sex peer networks and peer activities in which respondents participated. Finally, the chapter discusses adolescents' access to support networks for discussing personal matters.

\subsection{Parental controls on adolescents' behaviours}

Parental attitudes towards adolescents' friendships and social activities were probed by asking the boys and girls who participated in the survey about whether their mother and father, respectively, would disapprove if they engaged in a series of activities, ranging from bringing a same-sex friend to their home to having a love marriage. Findings, presented in Table 6.1 along with those of the 2007 survey, suggest considerable variation in adolescents' perceptions by activity. What is clearly noticeable is that mothers and fathers were most likely to be perceived to disapprove of love marriages for their children, as reported by 91 percent of boys and 91-92 percent of girls, about the same as in 2007 (84-87\% and 91-93\%, respectively). Also noticeable is that adolescents perceived parents to be far more likely to disapprove of activities conducted with members of the opposite-sex than those conducted with same-sex individuals (also see Figure 6.1). For example, just eight percent of boys and three percent of girls reported that their mother or father would be angry if they brought same-sex friends home (compared to 9-11\% and 2-3\%, respectively in 2007). In contrast, 66-89 percent of boys and 82-88 percent of girls expected their father and mother to disapprove of activities such as bringing an opposite-sex friend home, talking to a person of the opposite-sex who did not belong to the family, and going to a mela (a fair) or a film with an opposite-sex individual, representing significant increases, especially among girls, between 2007 and 2012.

In other matters, considerable change was observed among the two cohorts of adolescents. For example, in 2012, 24 percent and 22 percent of girls reported that their father and mother, respectively, would disapprove of their joining a club or mandal compared with significantly more-about twice as many girls who reported so in 2007 (53\% and $48 \%$, respectively). Among boys, in contrast, there has been little change over time, with 29-33 percent reporting parental disapproval of boys joining a club in 2007 and 28 percent reporting so in 2012. Clearly, the wide gender differences observed in 2007 had narrowed considerably by 2012. Also showing a significant decline was the percentage of girls expecting disapproval from their father and mother, if they sought a job, from 21 percent to ten percent among fathers, and from 16 percent to ten percent among mothers; the question was posed only to boys in 2012, and just 3-4 percent of boys reported then that their parents would disapprove.

Table 6.1 further shows that in 2012, rural fathers and mothers were considerably more likely than urban fathers and mothers to disapprove of several of the activities about which we probed. For example, while 94-95 percent of rural boys and girls reported that their parents would disapprove of their having a love marriage, 83-86 percent of urban adolescents so reported. In the case of other opposite-sex activities, such as bringing an opposite-sex friend home, talking to a person of the opposite-sex who did not belong to the family, and going to a mela or a 
Table 6.1: Perceptions of parental reactions to selected activities

Percentage of adolescents who perceived that their parents would disapprove of them engaging in selected activities, according to residence, Rajasthan, 2007 and 2012

\begin{tabular}{|c|c|c|c|c|c|c|c|c|}
\hline \multirow[b]{3}{*}{ Perceptions of parental reactions } & \multicolumn{2}{|c|}{ Boys (\%) } & \multicolumn{2}{|c|}{ Girls (\%) } & \multicolumn{2}{|c|}{ Boys (\%) } & \multicolumn{2}{|c|}{ Girls (\%) } \\
\hline & \multicolumn{4}{|c|}{ Father } & \multicolumn{4}{|c|}{ Mother } \\
\hline & 2007 & 2012 & 2007 & 2012 & 2007 & 2012 & 2007 & 2012 \\
\hline \multicolumn{9}{|c|}{ Combined } \\
\hline \multicolumn{9}{|c|}{ Parent would disapprove if respondent: } \\
\hline Brought same-sex friends home & 11.1 & 8.1 & 3.3 & 3.3 & 9.3 & 7.8 & 2.0 & 2.9 \\
\hline Brought opposite-sex friends home & 78.8 & $88.3^{* * *}$ & 80.4 & $87.7^{* * *}$ & 78.6 & $89.0^{* * *}$ & 78.0 & $86.2^{* * *}$ \\
\hline $\begin{array}{l}\text { Talked to a person of the opposite-se } \\
\text { from outside the home }\end{array}$ & 66.5 & 65.8 & 81.7 & $86.0^{*}$ & 63.5 & 66.4 & 79.7 & $84.5^{* *}$ \\
\hline $\begin{array}{l}\text { Went to a mela/film with opposite-se } \\
\text { friends }\end{array}$ & 71.3 & 74.3 & 62.4 & $83.3^{* * *}$ & 65.5 & $74.9^{* *}$ & 60.9 & $81.5^{* * *}$ \\
\hline Joined a club or mandal & 32.6 & 27.8 & 52.8 & $23.7^{* * *}$ & 28.7 & 27.7 & 48.1 & $21.9^{* * *}$ \\
\hline Had a love marriage & 87.2 & 90.8 & 93.4 & 92.1 & 84.4 & $90.9^{* *}$ & 91.3 & 91.3 \\
\hline Found a job & na & 3.5 & 20.7 & $10.2^{* * *}$ & na & 2.5 & 16.4 & $9.5^{* * *}$ \\
\hline Number of respondents ${ }^{1}$ & 714 & 699 & 1,383 & 1,098 & 756 & 729 & 1,441 & 1,132 \\
\hline \multicolumn{9}{|c|}{ Urban } \\
\hline \multicolumn{9}{|c|}{ Parent would disapprove if respondent: } \\
\hline Brought same-sex friends home & 9.0 & 4.9 & 2.1 & 2.6 & 5.9 & 5.2 & 1.0 & 1.9 \\
\hline Brought opposite-sex friends home & 68.9 & $77.2^{*}$ & 71.2 & 77.1 & 71.1 & 78.2 & 69.9 & 75.4 \\
\hline $\begin{array}{l}\text { Talked to a person of the opposite-se } \\
\text { from outside the home }\end{array}$ & 61.0 & 50.9 & 71.8 & 75.0 & 60.0 & 52.0 & 69.1 & 73.3 \\
\hline $\begin{array}{l}\text { Went to a mela/film with opposite-se } \\
\text { friends }\end{array}$ & 66.4 & 59.3 & 54.5 & $75.7^{\star \star *}$ & 65.8 & 60.1 & 53.5 & $74.5^{* * *}$ \\
\hline Joined a club or mandal & 22.1 & 24.5 & 50.3 & $22.6^{* * *}$ & 22.1 & 24.7 & 45.6 & $20.1^{* * *}$ \\
\hline Had a love marriage & 85.6 & 83.0 & 90.8 & $86.4^{*}$ & 84.0 & 83.6 & 88.7 & $84.4^{*}$ \\
\hline Found a job & na & 3.2 & 19.3 & $11.9^{*}$ & na & 2.6 & 15.0 & 10.2 \\
\hline Number of respondents ${ }^{1}$ & 301 & 347 & 475 & 502 & 321 & 363 & 499 & 525 \\
\hline \multicolumn{9}{|c|}{ Rural } \\
\hline \multicolumn{9}{|c|}{ Parent would disapprove if respondent: } \\
\hline Brought same-sex friends home & 11.8 & 9.3 & 3.8 & 3.6 & 10.6 & 8.8 & 2.3 & 3.4 \\
\hline Brought opposite-sex friends home & 82.5 & $92.4^{* * *}$ & 83.7 & $93.2^{* * *}$ & 81.3 & $93.0^{* * *}$ & 81.0 & $92.0^{* * *}$ \\
\hline $\begin{array}{l}\text { Talked to a person of the opposite-se } \\
\text { from outside the home }\end{array}$ & 68.5 & 71.3 & 85.2 & $91.6^{* *}$ & 64.8 & 71.7 & 83.5 & $90.4^{* * *}$ \\
\hline $\begin{array}{l}\text { Went to a mela/film with opposite-se } \\
\text { friends }\end{array}$ & 73.1 & 79.8 & 65.2 & $87.2^{* * *}$ & 65.4 & $80.4^{* * *}$ & 63.6 & $85.3^{* * *}$ \\
\hline Joined a club or mandal & 36.5 & 29.0 & 53.7 & $24.2^{* * *}$ & 31.1 & 28.8 & 49.0 & $22.9^{* * *}$ \\
\hline Had a love marriage & 87.8 & $93.6^{*}$ & 94.3 & 95.0 & 84.5 & $93.6^{* * *}$ & 92.2 & 95.0 \\
\hline Found a job & na & 3.6 & 21.2 & $9.3^{* * *}$ & na & 2.5 & 16.9 & $9.1^{* *}$ \\
\hline Number of respondents ${ }^{1}$ & 413 & 352 & 908 & 596 & 435 & 366 & 942 & 607 \\
\hline
\end{tabular}

Note: All Ns are unweighted. *, ${ }^{* *}$ and ${ }^{* * *}$ indicate that differences between 2007 and 2012 are significant at $p \leq 0.05, p \leq 0.01$ and $p \leq 0.001$, respectively. na: Not asked in 2007 survey. ${ }^{1}$ Includes only those respondents whose father or mother, respectively, was alive at the time of the interview. 
film with an opposite-sex individual too, rural adolescents were much more likely than those from urban areas to report parental disapproval (71-93\% and $51-78 \%$ of rural and urban boys, respectively; $85-93 \%$ and $73-77 \%$ of rural and urban girls, respectively).

The study also sought information about the extent to which adolescents' family life was characterised by domestic violence between parents, that is, whether they had witnessed their father beating their mother or vice versa. Findings presented in Table 6.2 suggest that in both 2007 and 2012, less than one percent of the surveyed boys and girls had witnessed their mother beating their father. Considerably larger proportions-ten percent of boys and 17 percent of girls-reported ever witnessing their father beating their mother, somewhat similar to the situation reported by boys in 2007 , but significantly more than that reported by girls that year. Rural-urban differences were mild.

The adolescents were also asked whether one or both parents had ever beaten them since the age of 12. Findings, shown in Table 6.2, suggest that sizeable proportions of adolescents with at least one parent alive at the time of the interview reported being beaten by a parent at any time since the age of 12-19 percent of boys and 17 percent of girls so reported. Significantly fewer boys reported the experience of violence in 2012 than in 2007 (19\% versus 33\%); in contrast, significantly more girls reported such an experience in 2012 than in 2007 (17\% versus $11 \%$ ) such that, by 2012 , gender differences in percentages of adolescents reporting the experience of being beaten by their parents were negligible (19\% and 17\% among boys and girls, respectively). Rural-urban differences suggest that urban adolescents were more likely than their rural counterparts to have experienced such beatings in 2012 (24\% versus $17 \%$ among boys; $20 \%$ versus $15 \%$ among girls).
Figure 6.1: Percentage of adolescents reporting that their parents would disapprove if they brought same- and oppositesex friends home, Rajasthan, 2007 and 2012

Father would disapprove

Boys

Girls

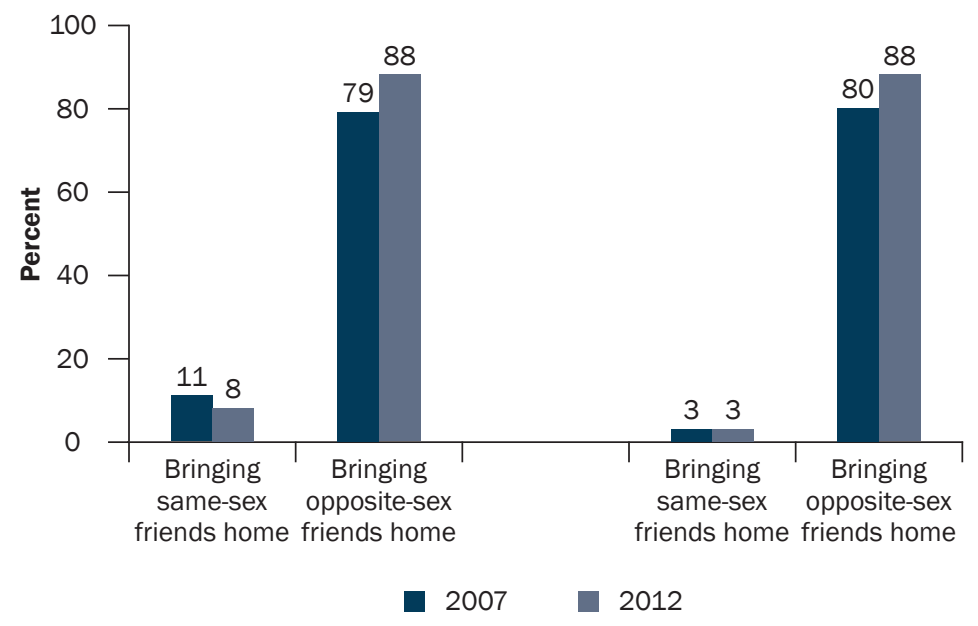

Mother would disapprove

Boys

Girls

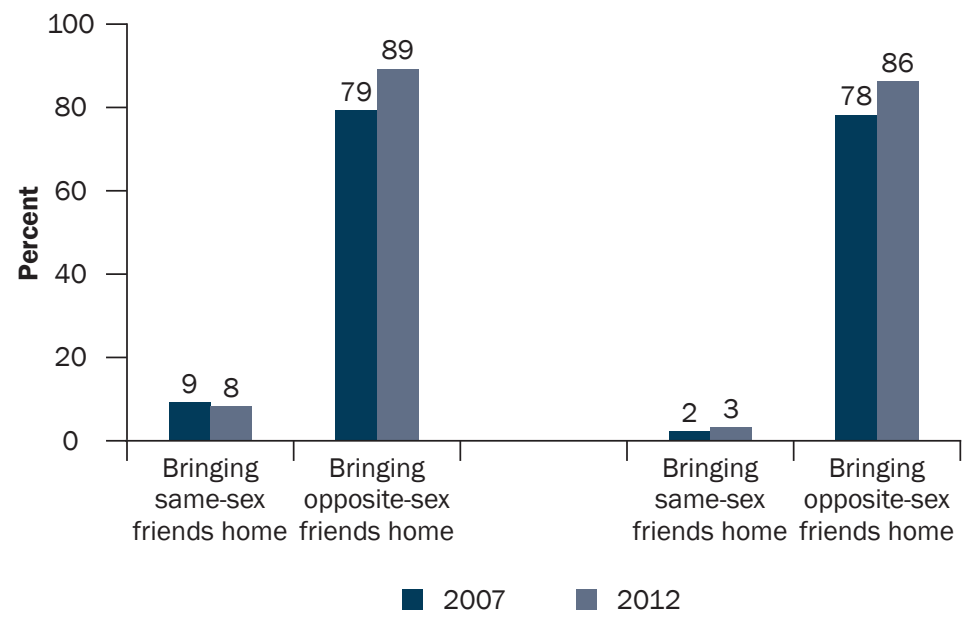

Note: Percentages were calculated only of those respondents who reported that their father or mother was alive at the time of the interview.

\subsection{Communication with parents}

Information regarding communication between adolescents and their parents on issues relevant to adolescentssuch as school performance, friendships, romantic relationships, being teased or bullied, reproductive processes and contraception-was elicited from all respondents reporting that their mother or father was alive at the time of the interview. Findings, presented in Table 6.3 and Figures $6.2 \mathrm{a}$ and $6.2 \mathrm{~b}$, reveal that communication on all topics was far from universal, and that while communication on non-sensitive matters such as education and friendships had increased significantly for both boys and girls between the 2007 and 2012 surveys, communication on sensitive sexual and reproductive health matters remained negligible at both times. 
Table 6.2: Experience of domestic violence

Percentage of adolescents reporting violence between parents and being beaten by parents, according to residence, Rajasthan, 2007 and 2012

\begin{tabular}{|c|c|c|c|c|}
\hline \multirow[b]{2}{*}{ Experience of domestic violence } & \multicolumn{2}{|c|}{ Boys (\%) } & \multicolumn{2}{|c|}{ Girls (\%) } \\
\hline & 2007 & 2012 & 2007 & 2012 \\
\hline \multicolumn{5}{|c|}{ Combined } \\
\hline Mother ever beat father & 0.9 & 0.3 & 0.6 & 0.8 \\
\hline Father ever beat mother & 11.7 & 9.6 & 12.3 & $16.7^{* *}$ \\
\hline Number of respondents with both parents alive & 701 & 685 & 1,346 & 1,071 \\
\hline Respondent beaten by father and/or mother since age 12 & 33.1 & $19.1^{* * *}$ & 10.5 & $16.7^{* *}$ \\
\hline Number of respondents with at least one parent alive & 769 & 743 & 1,478 & 1,159 \\
\hline \multicolumn{5}{|c|}{ Urban } \\
\hline Mother ever beat father & 0.0 & 0.6 & 0.2 & 1.2 \\
\hline Father ever beat mother & 8.4 & 8.8 & 8.2 & $15.5^{* *}$ \\
\hline Number of respondents with both parents alive & 297 & 342 & 465 & 491 \\
\hline Respondent beaten by father and/or mother since age 12 & 35.9 & $24.1^{* *}$ & 6.5 & $19.6^{* * *}$ \\
\hline Number of respondents with at least one parent alive & 325 & 368 & 509 & 536 \\
\hline \multicolumn{5}{|c|}{ Rural } \\
\hline Mother ever beat father & 1.2 & 0.2 & 0.8 & 0.6 \\
\hline Father ever beat mother & 13.0 & 9.9 & 13.8 & 17.4 \\
\hline Number of respondents with both parents alive & 404 & 343 & 881 & 580 \\
\hline Respondent beaten by father and/or mother since age 12 & 32.0 & $17.2^{* * *}$ & 11.9 & 15.1 \\
\hline Number of respondents with at least one parent alive & 444 & 375 & 969 & 623 \\
\hline
\end{tabular}

Note: All Ns are unweighted. ${ }^{* *}$ and ${ }^{* * *}$ indicate that differences between 2007 and 2012 are significant at $p \leq 0.01$ and $p \leq 0.001$, respectively. Domestic violence refers exclusively to physical violence.

By 2012, 77 percent of surveyed boys and 72 percent of surveyed girls had discussed their school performance with their father (Table 6.2 and Figures 6.2a), and 72 percent and 75 percent, respectively, had done so with their mother (Table 6.2 and Figures 6.2b). This represents, in each case, a significant increase over 2007, when just 50-71 percent of boys and girls had reported communication on school matters with a parent. Topics related to friendships were discussed with fathers by 46 percent and 25 percent of boys and girls, respectively, and with mothers, by 46 percent and 57 percent, respectively, highlighting that while boys were equally likely to have discussed friendships with their mother and father, girls were much more likely to have done so with their mother than with their father. As in the case of school performance, communication about friendships had increased significantly over the five-year period: from 27-28 percent to 46 percent among boys, with fathers and mothers alike, and among girls, from 18 percent to 25 percent with their father, and from 43 percent to 57 percent with their mother. As far as discussing being teased or bullied was concerned, while two percent of boys reported such a discussion with either parent, considerably more girls reported so, 31 percent with their mother and eight percent with their father, about the same as in 2007 (29\% and $7 \%$, respectively).

More sensitive issues were rarely discussed with either parent by the surveyed adolescents as seen from Table 6.2. For example, hardly any boy or girl had ever discussed romantic relationships with a parent (1-2\%). Very few boys had discussed romantic relationships with their mother or father at either time (1\%) (also see Figure 6.2a). In contrast, communication with a parent about romantic relationships was not only more prevalent among girls, but significant increases were recorded between 2007 and 2012, from 0.3 percent to two percent with their father, 
Table 6.3: Communication with parents

Percentage of adolescents who discussed selected matters with parents, according to residence, Rajasthan, 2007 and 2012

\begin{tabular}{|c|c|c|c|c|c|c|c|c|}
\hline \multirow{3}{*}{$\begin{array}{l}\text { Topics of parent-child } \\
\text { discussion }\end{array}$} & \multicolumn{2}{|c|}{ Boys (\%) } & \multicolumn{2}{|c|}{ Girls (\%) } & \multicolumn{2}{|c|}{ Boys (\%) } & \multicolumn{2}{|c|}{ Girls (\%) } \\
\hline & \multicolumn{4}{|c|}{ Father } & \multicolumn{4}{|c|}{ Mother } \\
\hline & 2007 & 2012 & 2007 & 2012 & 2007 & 2012 & 2007 & 2012 \\
\hline \multicolumn{9}{|c|}{ Combined } \\
\hline School performance & 70.7 & $77.2^{*}$ & 49.7 & $71.5^{\star * *}$ & 54.2 & $71.7^{\star \star *}$ & 49.8 & $75.0^{\star * *}$ \\
\hline Friendships & 28.0 & $46.4^{* * *}$ & 18.1 & $24.9^{* * *}$ & 26.8 & $46.1^{* * *}$ & 42.9 & $56.7^{* * *}$ \\
\hline Romantic relationships & 0.7 & 0.7 & 0.3 & $1.6^{* * *}$ & 0.9 & 0.9 & 2.8 & $10.3^{* * *}$ \\
\hline Being teased/bullied & 2.1 & 2.0 & 6.7 & 8.3 & 2.0 & 1.8 & 28.6 & 30.8 \\
\hline Reproductive processes & 0.0 & 0.1 & 0.1 & 0.1 & 0.0 & 0.1 & 1.2 & 2.2 \\
\hline Contraception & 0.0 & 0.0 & 0.0 & 0.1 & 0.0 & 0.0 & 0.7 & 1.4 \\
\hline Number of respondents ${ }^{1}$ & 714 & 699 & 1,383 & 1,098 & 756 & 729 & 1,441 & 1,132 \\
\hline \multicolumn{9}{|c|}{ Urban } \\
\hline School performance & 83.7 & 81.4 & 59.5 & $81.9^{* \star *}$ & 69.8 & 76.2 & 61.3 & $83.5^{* * *}$ \\
\hline Friendships & 43.6 & $53.3^{* *}$ & 24.6 & $35.6^{* * *}$ & 36.0 & $58.6^{* * *}$ & 50.8 & $67.7^{* * *}$ \\
\hline Romantic relationships & 1.4 & 1.2 & 0.4 & $3.7^{* * *}$ & 0.9 & 1.6 & 5.6 & $18.0^{* * *}$ \\
\hline Being teased/bullied & 2.6 & 2.6 & 7.9 & $12.3^{*}$ & 2.8 & 2.1 & 33.5 & $42.9^{*}$ \\
\hline Reproductive processes & 0.0 & 0.2 & 0.0 & 0.2 & 0.0 & 0.3 & 1.4 & $4.9^{* *}$ \\
\hline Contraception & 0.0 & 0.0 & 0.0 & 0.2 & 0.0 & 0.0 & 1.4 & $3.8^{*}$ \\
\hline Number of respondents ${ }^{1}$ & 301 & 347 & 475 & 502 & 321 & 363 & 499 & 525 \\
\hline \multicolumn{9}{|c|}{ Rural } \\
\hline School performance & 65.9 & $75.6^{*}$ & 46.2 & $66.2^{* * *}$ & 48.4 & $70.0^{* * *}$ & 45.7 & $70.5^{* * *}$ \\
\hline Friendships & 22.2 & $43.8^{* * *}$ & 15.8 & 19.4 & 23.4 & $41.5^{* * *}$ & 40.1 & $50.9^{* *}$ \\
\hline Romantic relationships & 0.4 & 0.5 & 0.2 & 0.5 & 0.9 & 0.6 & 1.8 & $6.3^{* * *}$ \\
\hline Being teased/bullied & 2.0 & 1.8 & 6.2 & 6.3 & 1.7 & 1.7 & 26.8 & 24.4 \\
\hline Reproductive processes & 0.0 & 0.0 & 0.1 & 0.0 & 0.0 & 0.0 & 1.2 & 0.8 \\
\hline Contraception & 0.0 & 0.0 & 0.0 & 0.0 & 0.0 & 0.0 & 0.4 & 0.2 \\
\hline Number of respondents ${ }^{1}$ & 413 & 352 & 908 & 596 & 435 & 366 & 942 & 607 \\
\hline
\end{tabular}

Note: All Ns are unweighted. *, ** and ${ }^{* * *}$ indicate that differences between 2007 and 2012 are significant at $p \leq 0.05, p \leq 0.01$ and $p \leq 0.001$, respectively. ${ }^{1}$ Includes only those respondents who reported that their father or mother was alive at the time of the interview.

and from three percent to ten percent with their mother (also see Figure 6.2b). Notably, hardly any adolescent had discussed reproductive processes or contraception with their father or mother ( $0 \%$ of boys, $1-2 \%$ of girls), about the same as in 2007 (0-1\%) (also see Figures 6.2a and 6.2b).

Rural-urban differences were evident in some respects (Table 6.2 and Figures 6.2a and 6.2b). While communication on school performance and friendships had increased considerably between 2007 and 2012 among both rural and urban adolescents, patterns remained similar, with more urban than rural adolescents reporting parent-child communication on these matters. Likewise, girls in urban areas remained more likely than their rural counterparts to discuss such topics with a parent as romantic relationships and being teased or bullied. Discussion of reproductive processes and contraception with a parent was extremely rare in both rural and urban areas, although in 2012, slightly more girls in urban than rural areas had discussed these topics with their mother (4-5\% versus $0-1 \%$ ). 
Figure 6.2a: Percentage of adolescents who discussed various matters with their fathers, according to residence, Rajasthan, 2007 and 2012

\section{Combined}

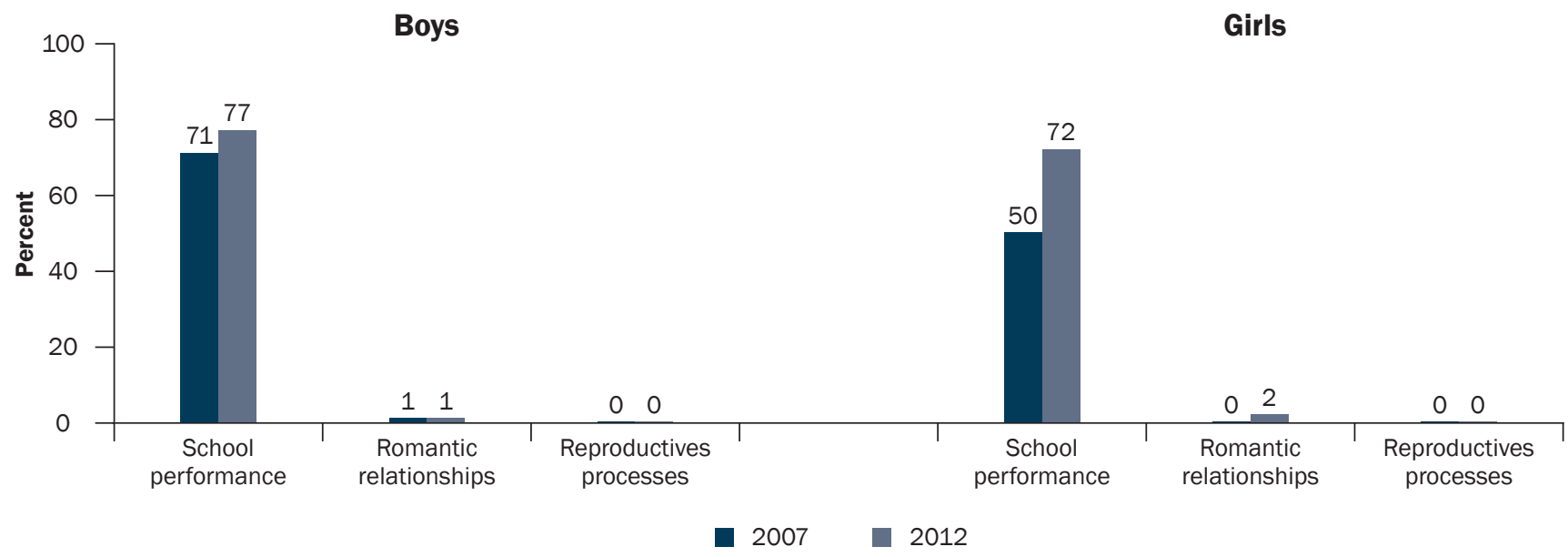

\section{Urban}

Boys

Girls

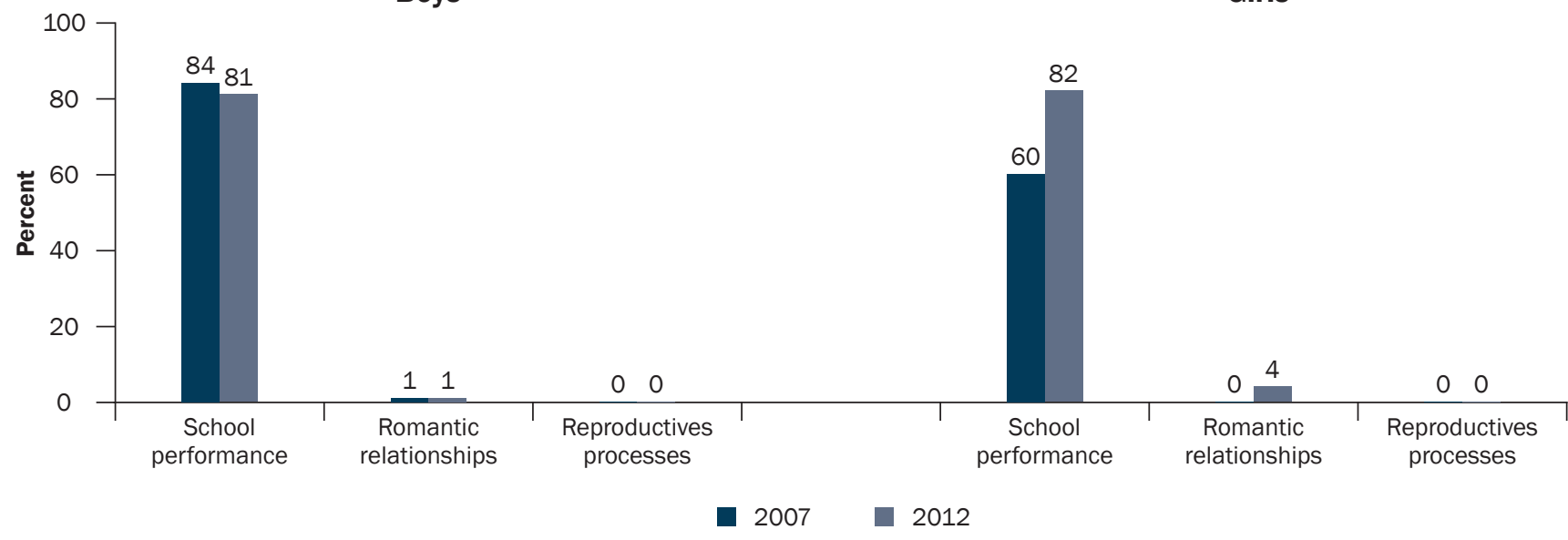

Rural

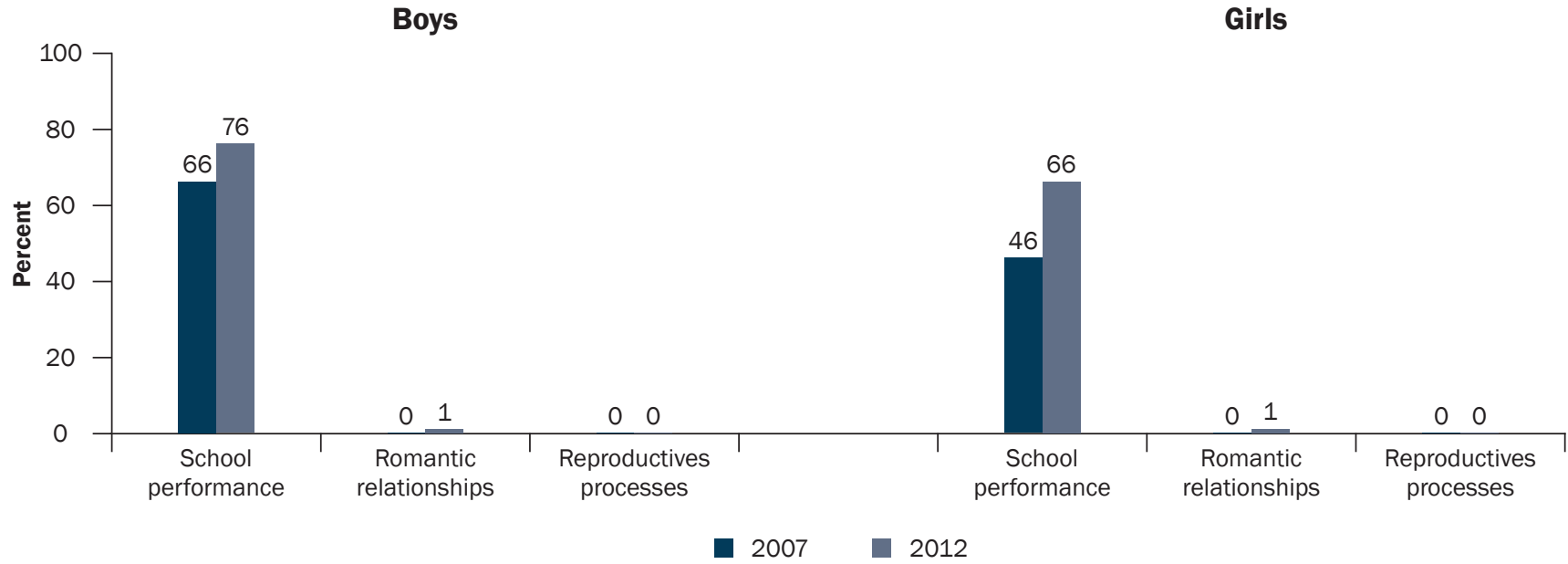

Note: Percentages were calculated only of those respondents who reported that their father was alive at the time of the interview. 
Figure 6.2b: Percentage of adolescents who discussed various matters with their mothers, according to residence, Rajasthan, 2007 and 2012

\section{Combined}

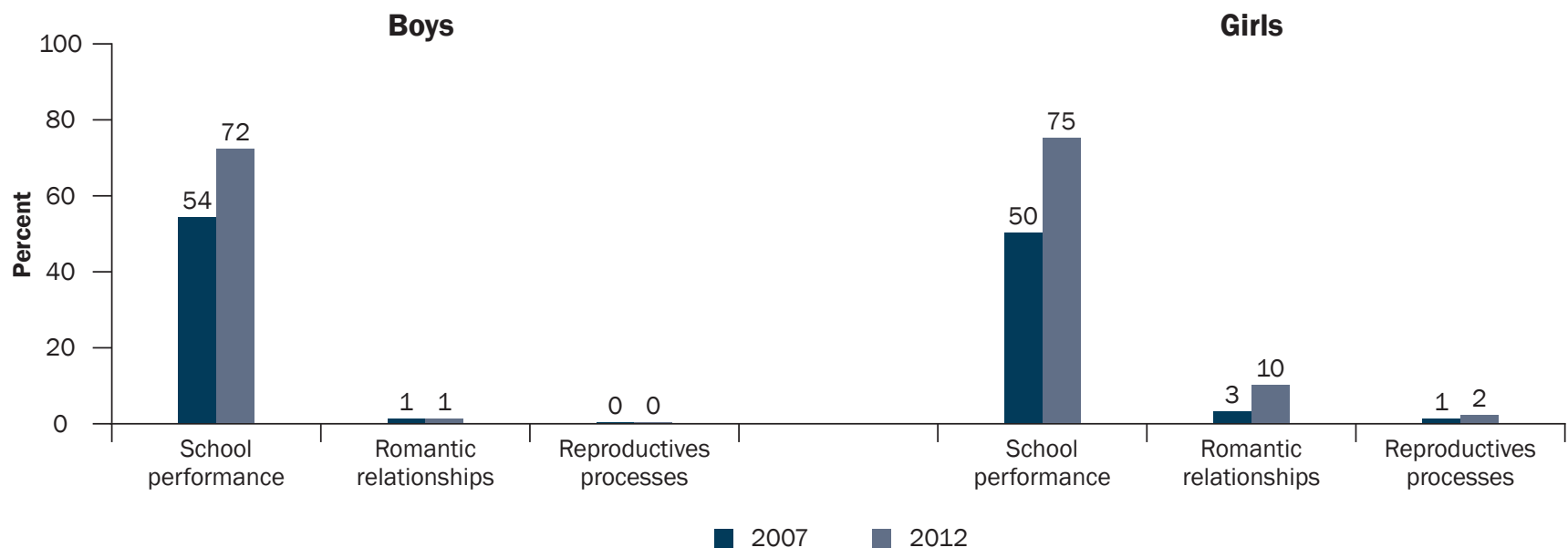

\section{Urban}

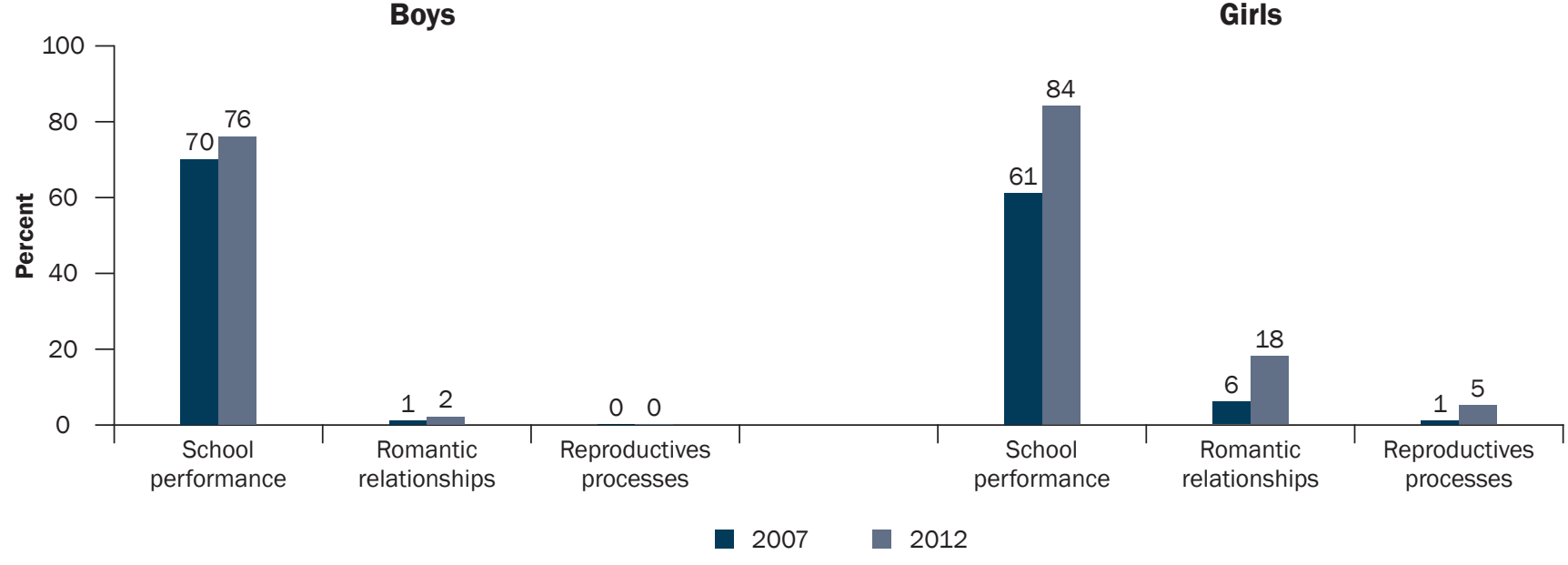

Rural

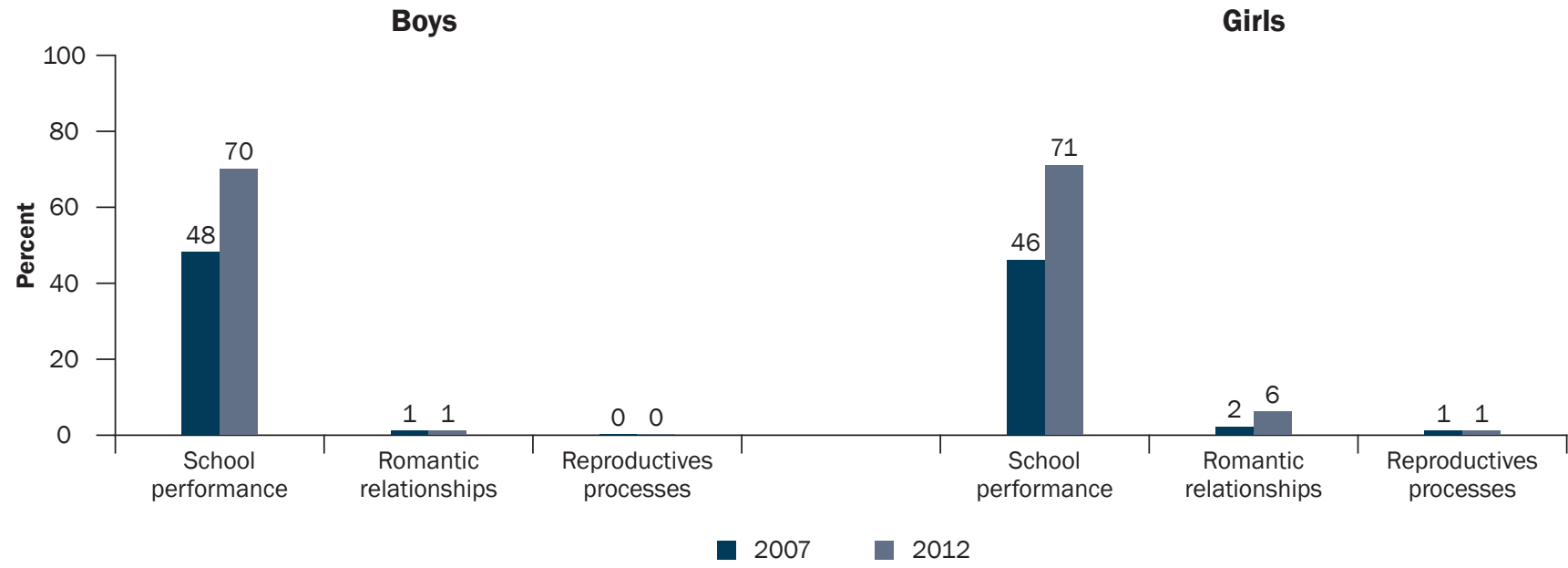

Note: Percentages were calculated only of those respondents who reported that their mother was alive at the time of the interview. 


\subsection{Communication with parents about marriage-related plans and adolescents' involvement in marriage-related decisions}

Information regarding communication with parents (or guardians) about marriage-related planning was elicited from all respondents; further, information regarding adolescents' own involvement in these plans was elicited from those for whom marriage-related planning had commenced by the time of the interview. Findings presented in Table 6.4 reveal that in 2012, marriage-related planning had commenced for more than two in five girls (44\%) and just one in six boys (17\%). Rural-urban differences were considerable, with 47 percent of rural girls and 20 percent of rural boys reporting that planning for their marriage had already begun, compared to 38 percent and nine percent, respectively, of urban girls and boys. At the same time, few adolescents (just 10-11\%) reported that they had been asked about the age at which they would like to marry; rural-urban differences in this regard were negligible.

Adolescents who reported that planning for their marriage was in progress, were asked when such discussion had started; whether a potential spouse had been proposed and if so, how many; whether the marriage had been fixed, and whether the partner was of the respondent's own choice or of his or her parents' choice. As shown in Table 6.4, findings confirm that marriage-related planning had started early, particularly among girls: for example, 22 percent of girls versus nine percent of boys reported that such planning had begun before they attained age 15. Ruralurban differences were wide for girls, with one-quarter of rural girls (25\%) compared to 15 percent of their urban

Table 6.4: Communication with parents about marriage-related plans and adolescents' involvement in marriagerelated decisions

Percentage of adolescents for whom marriage-related planning had commenced, and adolescents' own involvement in spouse selection, according to residence, Rajasthan, 2012

\begin{tabular}{|c|c|c|c|c|c|c|}
\hline \multirow[b]{2}{*}{ Discussion about marriage } & \multicolumn{2}{|c|}{ Combined } & \multicolumn{2}{|c|}{ Urban } & \multicolumn{2}{|c|}{ Rural } \\
\hline & Boys (\%) & Girls (\%) & Boys (\%) & Girls (\%) & Boys (\%) & Girls (\%) \\
\hline Parents asked respondent when he/she would like to marry & 9.6 & 11.3 & 8.5 & 14.0 & 10.0 & 9.9 \\
\hline Parents initiated discussion on marriage & 17.4 & 43.6 & 9.1 & 37.5 & 20.4 & 46.8 \\
\hline Number of respondents & 745 & 1,164 & 369 & 538 & 376 & 626 \\
\hline Discussion on marriage initiated before age 15 & 8.5 & 22.1 & $(5.8)$ & 14.5 & 8.9 & 25.3 \\
\hline \multicolumn{7}{|l|}{$\begin{array}{l}\text { Number of respondents whose parents had initiated } \\
\text { discussion on marriage and who recalled their age when }\end{array}$} \\
\hline such discussion was initiated & 110 & 476 & 32 & 193 & 78 & 283 \\
\hline Boy/girl had ever been proposed for respondent & 50.5 & 55.1 & $(44.1)$ & 59.3 & 51.6 & 53.3 \\
\hline \multicolumn{7}{|l|}{ Number of respondents whose parents had initiated } \\
\hline Three or more boys/girls had been proposed for respondent & 27.1 & 32.7 & \# & 35.2 & $(26.0)$ & 31.5 \\
\hline \multicolumn{7}{|l|}{ Number of respondents to whom a boy/girl had been } \\
\hline Respondent got engaged or marriage has been fixed & 4.3 & 14.5 & 1.8 & 10.5 & 5.2 & 16.6 \\
\hline Number of respondents & 745 & 1,164 & 369 & 538 & 376 & 626 \\
\hline \multicolumn{7}{|l|}{ Choice of partner: } \\
\hline Respondent's own choice & $(7.7)$ & 3.5 & $\#$ & 2.3 & \# & 3.9 \\
\hline Parents' choice & $(92.3)$ & 96.5 & \# & 97.7 & \# & 96.1 \\
\hline $\begin{array}{l}\text { Number of respondents who got engaged or whose } \\
\text { marriage has been fixed }\end{array}$ & 25 & 164 & 6 & 57 & 19 & 107 \\
\hline
\end{tabular}

Note: All Ns are unweighted. () Based on 25-49 unweighted cases. \# Percentage not shown; based on fewer than 25 unweighted cases. 
counterparts reporting that planning had commenced by the time they were 15; corresponding differences were narrow for boys ( $9 \%$ versus $6 \%)$.

Table 6.4 also shows that more than one-half of all boys and girls ( $51 \%$ and $55 \%$, respectively) for whom marriagerelated discussion was in progress reported that at least one potential spouse had been proposed for themsomewhat more rural than urban boys ( $52 \%$ versus $44 \%$ ), and somewhat more urban than rural girls (59\% versus $53 \%)$ so reported. Overall, 27 percent and 33 percent of these boys and girls, respectively, for whom marriagerelated discussion was in progress reported that three or more potential spouses had been proposed for them.

Further, as many as 15 percent of all girls and four percent of all boys reported that they were already engaged to be married or that their marriage had already been fixed. Somewhat more rural than urban adolescents so reported: 17 percent versus 11 percent among girls, and five percent versus two percent among boys. Overwhelmingly, among those whose marriage had already been fixed, the choice of the partner was made by the parents and excluded the adolescent: 97 percent of girls, with little rural-urban variation, and 92 percent of the boys.

\subsection{Peer networks and interaction}

In order to assess the size of peer networks, the study probed surveyed adolescents about the number of close same-sex friends they had, and whether they had opposite-sex friends. Table 6.5 presents findings on the size of peer networks; we note that the questions posed were slightly different in 2007 and 2012 (in 2007 we asked about any friends and, among these, about close friends, while in 2012, we asked about close friends directly). With regard to same-sex peer networks, boys reported an average of two close friends in 2012, as in 2007. Girls, in contrast, reported an average of just one close friend in 2012, compared to two in 2007, and as many as 19 percent reported not having a single close friend in 2012. Urban boys had an average of one more close same-sex friend than rural boys ( 3 versus 2) at both times; among girls, rural and urban girls reported the same number of close friends in 2012 (one friend) and 2007 (two friends). Further, among boys in 2012, 15 percent reported five or more close same-sex friends, with considerably larger percentages of those in urban than rural areas so reporting (24 versus 12). Among girls in contrast, very few, just two percent, reported five or more close friends, and rural-urban differences were negligible; notably, however, significantly more girls had so reported in 2007 (rural: 14\%; urban: 15\%).

Table 6.5: Size of peer networks

Percent distribution of adolescents by number of same- and opposite-sex friends, according to residence, Rajasthan, 2007 and 2012

\begin{tabular}{|c|c|c|c|c|}
\hline \multirow[b]{2}{*}{ Number of friends } & \multicolumn{2}{|c|}{ Boys (\%) } & \multicolumn{2}{|c|}{ Girls (\%) } \\
\hline & 2007 & 2012 & 2007 & 2012 \\
\hline \multicolumn{5}{|c|}{ Combined } \\
\hline \multicolumn{5}{|l|}{ Number of same-sex friends } \\
\hline None & 2.6 & 3.6 & 4.1 & 18.5 \\
\hline 1 & 15.2 & 23.0 & 24.4 & 45.3 \\
\hline 2 & 34.8 & 31.2 & 31.4 & 24.0 \\
\hline 3 & 20.4 & 15.6 & 15.4 & 8.0 \\
\hline 4 & 9.4 & 11.3 & 10.3 & 2.6 \\
\hline 5 or more & 17.6 & 15.1 & 14.4 & 1.6 \\
\hline Significance level & \multicolumn{2}{|c|}{ * } & \multicolumn{2}{|c|}{$* * *$} \\
\hline Median number of same-sex friends & 2.0 & 2.0 & 2.0 & 1.0 \\
\hline At least one opposite-sex friend (\%) & 14.6 & $27.1^{* * *}$ & 10.9 & $23.2^{* \star *}$ \\
\hline Number of respondents & 774 & 745 & 1,487 & 1,164 \\
\hline
\end{tabular}


Table 6.5: (Cont'd)

\begin{tabular}{|c|c|c|c|c|}
\hline \multirow[b]{2}{*}{ Number of friends } & \multicolumn{2}{|c|}{ Boys (\%) } & \multicolumn{2}{|c|}{ Girls (\%) } \\
\hline & 2007 & 2012 & 2007 & 2012 \\
\hline \multicolumn{5}{|c|}{ Urban } \\
\hline \multicolumn{5}{|l|}{ Number of same-sex friends } \\
\hline None & 0.9 & 2.5 & 5.7 & 17.5 \\
\hline 1 & 12.1 & 15.2 & 24.5 & 48.1 \\
\hline 2 & 33.3 & 28.0 & 34.0 & 22.3 \\
\hline 3 & 22.4 & 17.3 & 10.7 & 8.2 \\
\hline 4 & 8.5 & 12.9 & 9.8 & 1.9 \\
\hline 5 or more & 22.8 & 24.2 & 15.4 & 2.0 \\
\hline Significance level & \multicolumn{2}{|c|}{-} & \multicolumn{2}{|c|}{$* * *$} \\
\hline Median number of same-sex friends & 3.0 & 3.0 & 2.0 & 1.0 \\
\hline At least one opposite-sex friend (\%) & 19.9 & 35.2 & 14.3 & 29.8 \\
\hline Number of respondents & 327 & 369 & 513 & 538 \\
\hline \multicolumn{5}{|c|}{ Rural } \\
\hline \multicolumn{5}{|l|}{ Number of same-sex friends } \\
\hline None & 3.2 & 4.1 & 3.6 & 19.1 \\
\hline 1 & 16.4 & 25.9 & 24.3 & 43.8 \\
\hline 2 & 35.4 & 32.4 & 30.4 & 24.9 \\
\hline 3 & 19.7 & 15.0 & 17.1 & 7.9 \\
\hline 4 & 9.7 & 10.7 & 10.5 & 2.9 \\
\hline 5 or more & 15.6 & 11.7 & 14.1 & 1.4 \\
\hline Significance level & \multicolumn{2}{|c|}{-} & \multicolumn{2}{|c|}{$* * *$} \\
\hline Median number of same-sex friends & 2.0 & 2.0 & 2.0 & 1.0 \\
\hline At least one opposite-sex friend (\%) & 12.7 & $24.2^{* * *}$ & 9.7 & $19.7^{* * *}$ \\
\hline Number of respondents & 447 & 376 & 974 & 626 \\
\hline
\end{tabular}

Note: All Ns are unweighted. -, ${ }^{*}$ and ${ }^{* \star *}$ indicate that differences between 2007 and 2012 are not significant, and significant at $p \leq 0.05$ and $p \leq 0.001$, respectively. Column totals may not equal $100 \%$ due to missing cases.

The study also probed whether surveyed adolescents had opposite-sex friends. Opposite-sex peer networks were reported by smaller proportions of young people (Table 6.5). Gender differences were relatively narrow, with 27 percent of boys and 23 percent of girls reporting at least one opposite-sex friend. Rural-urban differences were wider, with urban boys and girls more likely than their rural counterparts to report an opposite-sex friend (35\% and $30 \%$ of urban boys and girls, respectively, compared to $24 \%$ and $20 \%$ of their counterparts in rural areas). Wider than gender and rural-urban differences was the change in opposite-sex peer networks over the five-year period: while 15 percent of boys and 11 percent of girls had reported an opposite-sex friend in 2007, significantly more-27 percent of boys and 23 percent of girls-had done so in 2012 (see Figure 6.3).

\subsection{Support networks}

The study also asked respondents about the individual with whom they would most likely discuss two personal matters, namely, taking a job and boy-girl relationships. Findings, reported in Table 6.6 along with corresponding findings of the 2007 survey, indicate that the person with whom adolescents would most likely discuss personal matters varied considerably by type of topic. With regard to taking a job, both boys and girls were most likely to confide in their father (59\% and 47\%, respectively), similar to percentages reported in 2007 (53\% and 47\%, respectively). A considerable proportion of girls and somewhat fewer boys also reported that they would confide 
Figure 6.3: Percentage of adolescents reporting at least one opposite-sex friend, according to residence, Rajasthan, 2007 and 2012

$\begin{array}{lll}\text { Combined Urban } & \text { Rural }\end{array}$

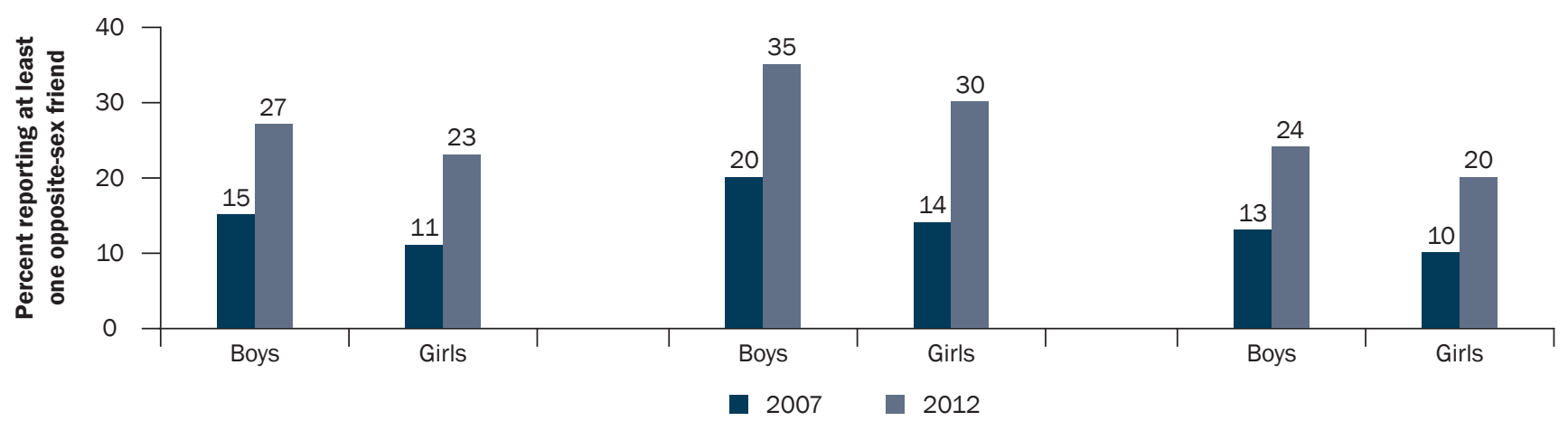

in their mother ( $41 \%$ and $16 \%$, respectively, in 2012 , compared to $36 \%$ and $13 \%$, respectively, in 2007 ). Notably, far fewer adolescents reported in 2012 than in 2007 that they had no one to confide in about seeking a job (from $10-14 \%$ in 2007 to less than $1 \%$ in 2012).

The picture changes considerably with adolescents' responses about the individual with whom they would most likely confide with regard to boy-girl matters (Table 6.6). As in 2007, adolescents in 2012 were most likely to report that they would confide in a peer: 87 percent of boys (up from 69\% in 2007) and 52 percent of girls (almost identical to 2007 when $49 \%$ so reported). While two percent or fewer boys reported they would confide in either parent, a sibling or other person, a few girls-12 percent and 15 percent, respectively, reported that they would confide in their mother or a sibling. Again, notably, percentages reporting that they would not confide in anyone declined considerably between 2007 and 2012: from 31 percent to ten percent among boys, and from 27 percent to 15 percent among girls.

Table 6.6 also shows that patterns in rural and urban settings remained fairly similar, with a few notable exceptions among girls. For example, rural girls were more likely than their urban counterparts to confide in their father about taking a job (50\% versus $41 \%$ ), but were less likely than their urban counterparts to confide in their mother or sibling on boy-girl matters (11\% and $13 \%$, respectively, in rural areas, versus $15 \%$ and $20 \%$, respectively, in urban areas).

Table 6.6: Leading confidante on personal matters

Percent distribution of adolescents by person with whom they were most likely to discuss selected personal matters, according to topic and residence, Rajasthan, 2007 and 2012

\begin{tabular}{|c|c|c|c|c|c|c|c|c|}
\hline \multirow[b]{3}{*}{ Leading confidante } & \multicolumn{2}{|c|}{ Boys (\%) } & \multicolumn{2}{|c|}{ Girls (\%) } & \multicolumn{2}{|c|}{ Boys (\%) } & \multicolumn{2}{|c|}{ Girls (\%) } \\
\hline & \multicolumn{4}{|c|}{ Taking a job } & \multicolumn{4}{|c|}{ Boy-girl relationships } \\
\hline & 2007 & 2012 & 2007 & 2012 & 2007 & 2012 & 2007 & 2012 \\
\hline \multicolumn{9}{|c|}{ Combined } \\
\hline Mother & 12.9 & 16.0 & 36.4 & 40.6 & 0.0 & 0.3 & 10.2 & 12.2 \\
\hline Father & 53.4 & 59.4 & 46.7 & 47.2 & 0.2 & 0.1 & 0.2 & 0.1 \\
\hline Sibling & 3.3 & 10.0 & 4.6 & 6.7 & 0.0 & 1.6 & 8.4 & 15.2 \\
\hline Friend & 12.1 & 8.3 & 0.1 & 1.1 & 68.9 & 87.4 & 49.3 & 51.7 \\
\hline HCP/Locally influential person/Teacher & 1.8 & 2.3 & 0.2 & 0.1 & 0.0 & 0.0 & 0.3 & 0.0 \\
\hline Other & 2.9 & 3.9 & 2.3 & 3.9 & 0.3 & 0.4 & 4.6 & 5.8 \\
\hline None & 13.5 & 0.2 & 9.7 & 0.5 & 30.7 & 10.2 & 27.0 & 15.1 \\
\hline Significance level & \multicolumn{2}{|c|}{$* * *$} & \multicolumn{2}{|c|}{$* * *$} & \multicolumn{2}{|c|}{$* * *$} & \multicolumn{2}{|c|}{$* * *$} \\
\hline Number of respondents & 774 & 745 & 1,487 & 1,164 & 774 & 745 & 1,487 & 1,164 \\
\hline
\end{tabular}


Table 6.6: (Cont'd)

\begin{tabular}{|c|c|c|c|c|c|c|c|c|}
\hline \multirow[b]{3}{*}{ Leading confidante } & \multicolumn{2}{|c|}{ Boys (\%) } & \multicolumn{2}{|c|}{ Girls (\%) } & \multicolumn{2}{|c|}{ Boys (\%) } & \multicolumn{2}{|c|}{ Girls (\%) } \\
\hline & \multicolumn{4}{|c|}{ Taking a job } & \multicolumn{4}{|c|}{ Boy-girl relationships } \\
\hline & 2007 & 2012 & 2007 & 2012 & 2007 & 2012 & 2007 & 2012 \\
\hline \multicolumn{9}{|c|}{ Urban } \\
\hline Mother & 14.7 & 19.0 & 37.4 & 42.6 & 0.0 & 1.2 & 10.3 & 15.4 \\
\hline Father & 54.7 & 56.4 & 48.2 & 41.0 & 0.0 & 0.5 & 0.0 & 0.2 \\
\hline Sibling & 2.9 & 8.4 & 5.3 & 9.4 & 0.0 & 2.6 & 9.2 & 19.6 \\
\hline Friend & 12.0 & 8.7 & 0.2 & 2.2 & 74.3 & 84.5 & 47.4 & 48.5 \\
\hline HCP/Locally influential person/Teacher & 1.8 & 1.1 & 0.2 & 0.2 & 0.0 & 0.0 & 0.4 & 0.0 \\
\hline Other & 3.6 & 5.7 & 2.3 & 4.4 & 0.3 & 1.4 & 4.8 & 5.3 \\
\hline None & 10.4 & 0.6 & 6.5 & 0.3 & 25.4 & 9.7 & 27.8 & 11.0 \\
\hline Significance level & \multicolumn{2}{|c|}{$* * *$} & \multicolumn{2}{|c|}{$* * *$} & \multicolumn{2}{|c|}{$* * *$} & \multicolumn{2}{|c|}{$* * *$} \\
\hline Number of respondents & 327 & 369 & 513 & 538 & 327 & 369 & 513 & 538 \\
\hline \multicolumn{9}{|c|}{ Rural } \\
\hline Mother & 12.3 & 14.9 & 36.1 & 39.6 & 0.0 & 0.0 & 10.1 & 10.5 \\
\hline Father & 52.9 & 60.5 & 46.1 & 50.4 & 0.2 & 0.0 & 0.3 & 0.0 \\
\hline Sibling & 3.4 & 10.5 & 4.4 & 5.3 & 0.0 & 1.2 & 8.2 & 12.9 \\
\hline Friend & 12.2 & 8.2 & 0.1 & 0.5 & 66.9 & 88.4 & 50.0 & 53.4 \\
\hline HCP/Locally influential person/Teacher & 1.8 & 2.7 & 0.2 & 0.0 & 0.0 & 0.0 & 0.2 & 0.0 \\
\hline Other & 2.7 & 3.2 & 2.3 & 3.6 & 0.2 & 0.0 & 4.5 & 6.0 \\
\hline None & 14.7 & 0.0 & 10.8 & 0.6 & 32.7 & 10.4 & 26.7 & 17.2 \\
\hline Significance level & \multicolumn{2}{|c|}{$* * *$} & \multicolumn{2}{|c|}{$* * *$} & \multicolumn{2}{|c|}{$* * *$} & \multicolumn{2}{|c|}{ ** } \\
\hline Number of respondents & 447 & 376 & 974 & 626 & 447 & 376 & 974 & 626 \\
\hline
\end{tabular}

Note: All Ns are unweighted. ${ }^{* *}$ and ${ }^{* * *}$ indicate that differences between 2007 and 2012 are significant at $p \leq 0.01$ and $p \leq 0.001$, respectively. Column totals may not equal $100 \%$ due to missing cases. HCP: Health care provider.

\subsection{Summary}

Study findings presented in this chapter suggest that parents controlled both boys' and girls' social interactions, particularly those involving members of the opposite sex. For example, over 90 percent of adolescents expected parental disapproval if they had a love marriage, and 66-89 percent of boys and 82-88 percent of girls expected parental disapproval if they brought an opposite-sex friend home, talked to a person of the opposite-sex who did not belong to the family or went to a mela or a film with an opposite-sex individual. Notably, while changes over the inter-survey period were, by and large, insignificant among boys, percentages of girls perceiving disapproval about activities with boys had increased significantly between 2007 and 2012. In contrast, girls were significantly less likely in 2012 than in 2007 to report that their parents would disapprove of their joining a club or mandal, or taking a job. In both surveys, rural adolescents were considerably more likely than their urban counterparts to expect parental disapproval for activities relating to the opposite-sex.

Young people's family lives were marked by violence, both experienced and witnessed. About one in ten boys and one in six girls had observed their father beating their mother. Many respondents reported experiencing a beating by a parent during adolescence; one-fifth of boys and one-sixth of girls reported such experiences, representing a significant decline from 2007 among boys and a significant increase among girls, with urban boys and girls somewhat more likely than their rural counterparts to so report. 
Findings regarding communication of surveyed adolescents with their parents on issues relevant to adolescentssuch as school performance, friendships, being teased or bullied, romantic relationships and reproductive processes-reiterate that such communication was far from universal at both times. Indeed, sensitive topics, such as romantic relationships, reproduction and contraception were rarely discussed with either parent. However, on non-sensitive issues such as school performance and friendships, communication with mothers and fathers had increased significantly among both boys and girls, suggesting some increase in overall communication between parents and children over the five-year period. While girls were significantly more likely to have discussed romantic relationships with their father and mother in 2012 compared to 2007, we note that percentages were, overall, small at both times.

Marriage-related planning had already commenced for more than two in five girls and one in six boys; in rural areas, almost one-half of all girls and one-fifth of all boys so reported in 2012. Findings confirm that marriage-related planning started early, particularly among girls: for example, 22 percent of girls compared to nine percent of boys reported that such planning had begun before they attained age 15. More than one-half of all girls and boys for whom marriage-related planning was in progress, reported that at least one potential spouse had been proposed for them, and one-third of all girls and one-quarter of all boys reported that three or more potential spouses had already been proposed for them.

As many as 15 percent of girls and four percent of boys in 2012-somewhat more rural than urban-were already engaged to be married or reported that their marriage had already been fixed. For well over 90 percent of these adolescents, the choice of the partner was made by the parents and excluded the adolescent.

That parent-child communication was restricted was also evident from responses to questions probing the most likely confidante on one non-sensitive topic, that is, taking a job, and one sensitive topic, that is, boy-girl relationships. Parents, particularly fathers, were mentioned as leading confidantes on the topic of taking a job, but were rarely cited as leading confidantes on the more sensitive matter of boy-girl relationships. Notably, far fewer adolescents in 2012 than 2007 reported that they had no one in whom to confide on these two matters.

In contrast, growing up was associated with close peer networks, especially among boys. For example, while almost all boys reported having some close same-sex friends, almost one-fifth of the girls reported having no such friends. In 2012, girls reported an average of one close same-sex friend, down from two in 2007; boys reported an average of two in both 2012 and 2007 That same-sex peer networks were wider among boys than girls is evident from the finding that 15 percent of boys had five or more friends, compared to just two percent of girls. Opposite-sex peer networks were less common but reported by about one-quarter of boys and girls, reflecting significant increases over the 2007 to 2012 period (from 15\% to 27\% among boys, and from 11\% to 23\% among girls). Indeed, findings suggest that adolescents derived an important measure of support from their peer networks on personal matters: friends were, by far, the leading confidante on boy-girl relationships for both boys and girls. 


\section{Chapter 7 \\ Agency and gender role attitudes}

Evidence on agency and gender role attitudes among adolescents in India suggests that girls, and even some boys, have limited agency in terms of decision-making on matters affecting their own lives, freedom of movement and access to resources. Gender role attitudes, similarly, tend to be traditional, assigning greater value to boys than girls (International Institute for Population Sciences and Population Council, 2010). This chapter discusses findings on agency and gender role attitudes of the adolescents who participated in this study.

\subsection{Decision-making}

In order to assess adolescents' involvement in decision-making, the study asked all respondents about their involvement in decisions related to spending one's own money. If the adolescents reported that they were involved in decision-making on this issue, they were asked whether they participated in the decision entirely on their own or jointly with other family members.

Findings are presented in Table 7.1 and Figure 7.1 along with corresponding findings of the 2007 survey. Over the five-year period, there was a significant increase among both boys and girls, and those from rural and urban areas, in percentages reporting that they made independent decisions about spending money. Among boys, 79 percent reported that they made independent decisions about spending money compared to 69 percent five years earlier.

Table 7.1: Decision-making

Percent distribution of adolescents by participation in decision-making on spending money, according to residence, Rajasthan, 2007 and 2012

\begin{tabular}{|c|c|c|c|c|}
\hline \multirow[b]{2}{*}{ Decision-making on spending money } & \multicolumn{2}{|c|}{ Boys (\%) } & \multicolumn{2}{|c|}{ Girls (\%) } \\
\hline & 2007 & 2012 & 2007 & 2012 \\
\hline \multicolumn{5}{|c|}{ Combined } \\
\hline Respondent only & 69.4 & 79.4 & 34.1 & 58.5 \\
\hline Jointly with others & 13.1 & 4.8 & 36.4 & 13.6 \\
\hline Others only & 17.5 & 15.8 & 29.5 & 27.8 \\
\hline Significance level & \multicolumn{2}{|c|}{$* *$} & \multicolumn{2}{|c|}{ *** } \\
\hline Number of respondents & 774 & 745 & 1,487 & 1,164 \\
\hline \multicolumn{5}{|c|}{ Urban } \\
\hline Respondent only & 66.1 & 83.1 & 41.2 & 73.4 \\
\hline Jointly with others & 12.8 & 5.6 & 31.9 & 7.8 \\
\hline Others only & 21.1 & 11.3 & 26.9 & 18.8 \\
\hline Significance level & \multicolumn{2}{|c|}{ ** } & \multicolumn{2}{|c|}{$* * *$} \\
\hline Number of respondents & 327 & 369 & 513 & 538 \\
\hline \multicolumn{5}{|c|}{ Rural } \\
\hline Respondent only & 70.6 & 78.0 & 31.5 & 50.7 \\
\hline Jointly with others & 13.2 & 4.4 & 38.0 & 16.7 \\
\hline Others only & 16.2 & 17.5 & 30.4 & 32.5 \\
\hline Significance level & \multicolumn{2}{|c|}{ * } & \multicolumn{2}{|c|}{$* * *$} \\
\hline Number of respondents & 447 & 376 & 974 & 626 \\
\hline
\end{tabular}

Note: All Ns are unweighted. * , ${ }^{* *}$ and ${ }^{* * *}$ indicate that differences between 2007 and 2012 are significant at $p \leq 0.05, p \leq 0.01$ and $p \leq 0.001$, respectively. Column totals may not equal $100 \%$ due to missing cases. 
Among girls, the increase was steeper, from 34 percent in 2007 to 59 percent in 2012. Gender disparities have thus narrowed over the five-year period, although more boys than girls made independent decisions even in 2012. There was, conversely, a decline over time, in percentages reporting that it was other family members who made such decisions together with the adolescent (from 13\% to $5 \%$ among boys; from $36 \%$ to $14 \%$ among girls). Interestingly, virtually identical percentages were reported in 2007 and 2012 that decisions on spending their money were made by others alone, without involving the adolescent (by $16-18 \%$ of boys; $28-30 \%$ of girls). Rural-urban differences were modest among boys at both times, but urban girls were considerably more likely than those in rural areas to be involved in decisions related to spending their own money, and differences had widened in 2012 compared to 2007 (73\% versus $51 \%$ in 2012 , and $41 \%$ versus $32 \%$ in 2007 ).

Figure 7.1: Percent distribution of adolescents by participation in decision-making on spending money, Rajasthan, 2007 and 2012

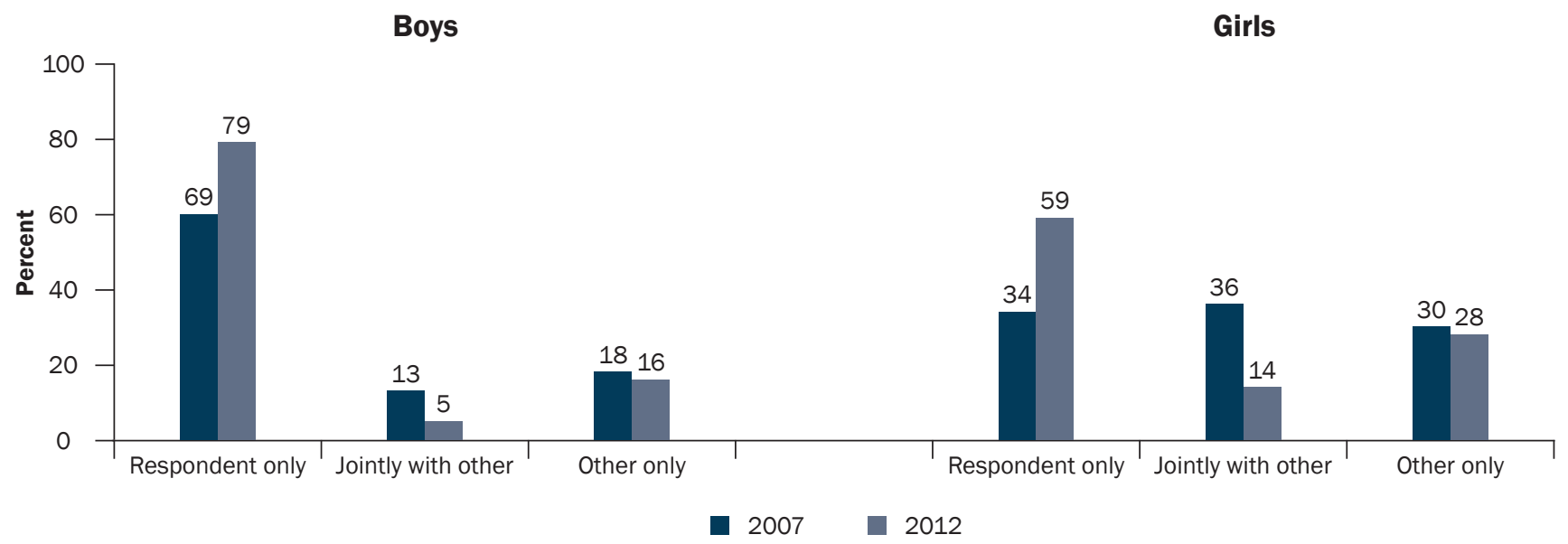

Table 7.2 presents the percentage of adolescents in 2012 who reported that they independently made decisions on spending money by selected background characteristics. Findings reveal that independent decision-making on spending money was indeed higher among older than younger adolescents, irrespective of sex or rural-urban residence. Differences by religion and caste were negligible among boys (79\% of Hindu and Muslim boys alike; $77-84 \%$ across different caste groups); among girls, decision-making varied from 57 percent among Hindus to 63 percent among Muslims and 71 percent among those from other religions, and from 53-54 percent among those belonging to scheduled castes and tribes to $65 \%$ among those belonging to general castes. Religion- and caste-wise differences among adolescents in rural and urban areas were, however, negligible.

Independent decision-making increased consistently with level of education, but increases were wider among girls than among boys (Table 7.2). Among girls, for example, in 2012, 75 percent of those with 12 or more years of schooling decided independently on spending money, compared with just 31 percent of girls without any formal education and 50 percent of those with 1-7 years of education; among boys, 88 percent of those with 12 or more years of education compared to 76 percent of those with 1-7 years of education reported decision-making about spending money. Interestingly, the least educated boys were about as likely as the most educated girls to report independent decision-making on spending money. Rural-urban patterns show, in both rural and urban areas, a strong positive association between education and decision-making for girls and a milder positive association for boys.

Table 7.2 further shows that in 2012, independent decision-making on spending money was unrelated with economic activity (wage work in the last 12 months) for all boys and girls, as well as for those in rural and urban areas. It was, however, positively associated with household economic status. 
Table 7.2: Decision-making autonomy by selected background characteristics

Percentage of adolescents who independently made decisions on spending money by selected background characteristics, according to residence, Rajasthan, 2012

\begin{tabular}{|c|c|c|c|c|c|c|}
\hline \multirow[b]{2}{*}{ Background characteristics } & \multicolumn{2}{|c|}{ Combined } & \multicolumn{2}{|c|}{ Urban } & \multicolumn{2}{|c|}{ Rural } \\
\hline & Boys (\%) & Girls (\%) & Boys (\%) & Girls (\%) & Boys (\%) & Girls (\%) \\
\hline \multicolumn{7}{|l|}{ Age (years) } \\
\hline $15-17$ & 76.8 & 54.8 & 82.5 & 70.8 & 74.8 & 46.8 \\
\hline $18-19$ & 84.9 & 69.2 & 84.2 & 80.0 & 85.1 & 62.7 \\
\hline \multicolumn{7}{|l|}{ Religion } \\
\hline Hindu & 79.3 & 57.1 & 83.1 & 72.2 & 78.1 & 50.3 \\
\hline Muslim & 79.2 & 62.9 & 83.7 & 74.9 & \# & 48.2 \\
\hline Other $^{1}$ & $\#$ & $(70.5)$ & \# & $\#$ & $\#$ & $(63.0)$ \\
\hline \multicolumn{7}{|l|}{ Caste } \\
\hline SC & 79.8 & 52.6 & 90.6 & 64.2 & 76.2 & 47.6 \\
\hline ST & 84.2 & 53.6 & \# & $(77.6)$ & 83.3 & 47.6 \\
\hline OBC & 78.6 & 59.3 & 77.0 & 74.8 & 79.0 & 51.2 \\
\hline General $^{2}$ & 76.6 & 65.3 & 84.0 & 75.4 & $(64.9)$ & 56.7 \\
\hline \multicolumn{7}{|l|}{ Educational level (years) } \\
\hline None $^{3}$ & \# & 31.2 & \# & \# & \# & 28.6 \\
\hline $1-7$ & 75.8 & 49.9 & $(79.0)$ & 63.1 & 74.8 & 44.5 \\
\hline $8-9$ & 78.0 & 55.7 & 79.8 & 69.2 & 77.5 & 49.5 \\
\hline $10-11$ & 77.3 & 69.2 & 84.7 & 77.7 & 74.3 & 63.1 \\
\hline 12 and above & 88.2 & 74.6 & 84.4 & 83.8 & 90.0 & 65.4 \\
\hline \multicolumn{7}{|l|}{ Worked in last 12 months } \\
\hline Yes & 78.6 & 56.2 & 82.0 & 69.9 & 77.4 & 51.1 \\
\hline No & 79.6 & 59.2 & 83.5 & 74.2 & 78.2 & 50.5 \\
\hline \multicolumn{7}{|l|}{ Wealth quintile } \\
\hline First & 72.7 & 36.2 & \# & (47.1) & 72.5 & 34.9 \\
\hline Second & 75.5 & 52.8 & $(72.0)$ & 59.3 & 76.0 & 50.6 \\
\hline Third & 82.5 & 56.4 & $(82.9)$ & 69.3 & 82.4 & 51.6 \\
\hline Fourth & 79.8 & 63.0 & 83.7 & 75.4 & 76.7 & 53.1 \\
\hline Fifth & 89.8 & 78.2 & 85.7 & 82.3 & $\#$ & 72.6 \\
\hline Total & 79.4 & 58.5 & 83.1 & 73.4 & 78.0 & 50.7 \\
\hline
\end{tabular}

Note: ( ) Based on 25-49 unweighted cases. \# Percentage not shown; based on fewer than 25 unweighted cases. OBC: Other backward caste. SC: Scheduled caste. ST: Scheduled tribe. ${ }^{1}$ Includes Christian, Buddhist, Neo-Buddhist, Sikh, Jain, Jewish, Parsi/ Zoroastrian, Sarana and no specified religion. ${ }^{2}$ Includes all those not belonging to SC, ST or OBC. ${ }^{3}$ Includes those who are nonliterate and literate with no formal schooling. 
As in the case of its association with education, in 2012, differentials in independent decision-making on spending money were narrow for boys but wide for girls: among boys, 90 percent of those in the richest (fifth) quintile compared to 73 percent in the poorest (first) quintile made such independent decisions; among girls, in contrast, corresponding percentages were 78 and 36. This pattern was observed irrespective of rural-urban residence, although among boys, differences were less consistent and narrower. Notably, boys from households in the poorest (first) quintile were almost as likely to report independent decision-making as were girls in the wealthiest quintile.

\subsection{Freedom of movement}

Freedom of movement was measured by a number of questions relating to whether the respondent was permitted to visit places within and outside the village (rural) or neighbourhood (urban) unescorted, only if accompanied by someone else, or was not permitted to visit the place at all. Places within the village or neighbourhood included a shop/market, the home of a friend/relative and a health facility. With regard to freedom of movement within the village or neighbourhood, a summary measure was created that assessed percentages of surveyed boys and girls who were free to visit all three places within the village or neighbourhood (shop or market, a friend and a health facility). In contrast, freedom of movement outside the village or neighbourhood was measured by a single indicator, namely the percentages free to visit the home of a friend outside the village.

Findings presented in Table 7.3 and Figure 7.2 for the surveys conducted at both times, confirm that freedom of movement even within the village or neighbourhood was not universal, and the mobility of girls was far more limited than that of boys. For example, in 2012, findings suggest that 79-82 percent of girls could go unescorted to a shop or market or to visit a friend within the village or neighbourhood compared with almost all (99-100\%) boys. In both cases, there was a modest increase in girls' freedom of movement (from $71-78 \%$ in 2007 to $79-82 \%$ in 2012). Many fewer adolescents were permitted to visit a health facility unescorted, and again, gender differences are evident, overall 75 percent of boys and 31 percent of girls reported that they were permitted to do so unescorted; again, while percentages so reporting remained virtually unchanged between 2007 and 2012 for boys (73-75\%), they increased considerably for girls (from $17 \%$ to $31 \%$ ). On the whole, in 2012, three-quarters (75\%) of boys were free to visit all three locations within the village, up marginally, from 70 percent in 2007 . While considerably fewer girls than boys reported such freedom of movement, improvements over the inter-survey period for girls was significant; for example, fewer than one-third (30\%) of girls had freedom of movement to visit all three locations within the village in 2012, up from just 16\% in 2007.

Freedom to visit places outside the village or neighbourhood, that is, to visit a friend outside the village or neighbourhood unescorted was more restricted than mobility within the village. Girls' mobility was particularly limited: in 2012, only 23 percent of girls compared with 78 percent of boys were allowed to visit a friend outside the village unescorted (Table 7.3). Overall, percentages reporting such freedom of movement fell modestly for boys (from $85 \%$ to $78 \%$ ) and increased modestly among girls (from $19 \%$ to $23 \%$ ).

Rural-urban differentials with respect to freedom of movement were muted among boys but were striking among girls. Among girls, those in rural areas were consistently less likely than their urban counterparts to be permitted to visit any location within or outside their village or neighbourhood unescorted. Differences were more pronounced with regard to visiting a friend outside the village than any place inside the village or neighbourhood. For example, in 2012, 77-80 percent of rural girls, compared to 83-87 percent of their urban counterparts, were permitted to make unescorted visits to a shop or market, or a friend or relative within the village; and 28 percent and 37 percent of rural and urban girls, respectively, were permitted to visit a village health facility unescorted. Overall, 27 percent of rural girls and 37 percent of urban girls were permitted to visit all three places within the village or neighbourhood unescorted, significantly more than in 2007 (13\% and 25\% in rural and urban areas, respectively). Rural-urban differences were much wider in the case of freedom to visit a friend outside the village or neighbourhood: only 14 percent of rural girls, compared to 40 percent of their urban counterparts, were permitted to do so. While freedom to visit a friend or relative outside the village or neighbourhood remained similar at both times for boys and for rural girls, freedom of movement had increased significantly for urban girls (from $29 \%$ to $40 \%$ ). 
Table 7.3: Freedom of movement

Percent distribution of adolescents by extent of freedom to visit selected locations within or outside village/ neighbourhood, according to residence, Rajasthan, 2007 and 2012

\begin{tabular}{|c|c|c|c|c|c|c|c|c|c|c|c|c|}
\hline \multirow[b]{3}{*}{ Mobility indicators } & \multicolumn{4}{|c|}{ Combined } & \multicolumn{4}{|c|}{ Urban } & \multicolumn{4}{|c|}{ Rural } \\
\hline & \multicolumn{2}{|c|}{ Boys (\%) } & \multicolumn{2}{|c|}{ Girls (\%) } & \multicolumn{2}{|c|}{ Boys (\%) } & \multicolumn{2}{|c|}{ Girls (\%) } & \multicolumn{2}{|c|}{ Boys (\%) } & \multicolumn{2}{|c|}{ Girls (\%) } \\
\hline & 2007 & 2012 & 2007 & 2012 & 2007 & 2012 & 2007 & 2012 & 2007 & 2012 & 2007 & 2012 \\
\hline \multicolumn{13}{|l|}{ Permitted to: } \\
\hline \multicolumn{13}{|l|}{$\begin{array}{l}\text { Visit shop/market within } \\
\text { village/neighbourhood }\end{array}$} \\
\hline Alone & 99.6 & 99.8 & 78.4 & 82.2 & 99.1 & 100.0 & 80.9 & 87.1 & 99.8 & 99.7 & 77.5 & 79.7 \\
\hline Only with someone else & 0.4 & 0.2 & 20.6 & 17.2 & 0.9 & 0.0 & 18.5 & 12.9 & 0.2 & 0.3 & 21.3 & 19.4 \\
\hline Not allowed & 0.0 & 0.0 & 1.0 & 0.5 & 0.0 & 0.0 & 0.6 & 0.0 & 0.0 & 0.0 & 1.2 & 0.8 \\
\hline Significance level & \multicolumn{2}{|c|}{-} & \multicolumn{2}{|c|}{-} & \multicolumn{2}{|c|}{-} & \multicolumn{2}{|c|}{ * } & \multicolumn{2}{|c|}{-} & \multicolumn{2}{|c|}{-} \\
\hline \multicolumn{13}{|l|}{$\begin{array}{l}\text { Visit friend/relative } \\
\text { inside village/ } \\
\text { neighbourhood }\end{array}$} \\
\hline Alone & 91.4 & 98.7 & 71.0 & 78.9 & 91.4 & 98.3 & 71.6 & 82.7 & 91.5 & 98.8 & 70.8 & 76.9 \\
\hline Only with someone else & 8.2 & 1.1 & 28.4 & 20.9 & 8.6 & 1.7 & 27.8 & 17.1 & 8.1 & 0.8 & 28.6 & 22.9 \\
\hline Not allowed & 0.3 & 0.2 & 0.6 & 0.1 & 0.0 & 0.0 & 0.6 & 0.1 & 0.4 & 0.3 & 0.6 & 0.1 \\
\hline Significance level & \multicolumn{2}{|c|}{$* * *$} & \multicolumn{2}{|c|}{ ** } & \multicolumn{2}{|c|}{ ** } & \multicolumn{2}{|c|}{$* *$} & \multicolumn{2}{|c|}{$* * *$} & \multicolumn{2}{|c|}{-} \\
\hline \multicolumn{13}{|l|}{$\begin{array}{l}\text { Visit health facility inside } \\
\text { village/neighbourhood }\end{array}$} \\
\hline Alone & 72.5 & 75.2 & 16.5 & 31.0 & 75.3 & 74.8 & 25.4 & 37.4 & 71.4 & 75.4 & 13.3 & 27.7 \\
\hline Only with someone else & 27.0 & 24.8 & 80.6 & 68.7 & 24.0 & 25.2 & 71.3 & 62.4 & 28.2 & 24.6 & 84.0 & 71.9 \\
\hline Not allowed & 0.5 & 0.0 & 2.9 & 0.2 & 0.7 & 0.0 & 3.3 & 0.2 & 0.4 & 0.0 & 2.7 & 0.2 \\
\hline Significance level & \multicolumn{2}{|c|}{-} & \multicolumn{2}{|c|}{$* * *$} & & - & & *** & & - & & $* * *$ \\
\hline Summary measure: & & & & & & & & & & & & \\
\hline $\begin{array}{l}\text { Permitted to visit all } \\
\text { three places inside } \\
\text { village/neighbourhood }\end{array}$ & & & & & & & & & & & & \\
\hline alone & 70.7 & 75.0 & 15.9 & 30.1 & 73.9 & 74.5 & 25.0 & 36.8 & 69.5 & 75.1 & 12.6 & 26.6 \\
\hline Significance level & & - & & *** & & - & & ** & & - & & $* * *$ \\
\hline $\begin{array}{l}\text { Visit friend/relative } \\
\text { outside village/ } \\
\text { neighbourhood }\end{array}$ & & & & & & & & & & & & \\
\hline Alone & 85.1 & 78.1 & 19.3 & 23.0 & 84.1 & 81.6 & 28.9 & 40.4 & 85.5 & 76.9 & 15.9 & 13.8 \\
\hline Only with someone else & 14.6 & 19.5 & 76.7 & 75.9 & 15.6 & 16.5 & 67.3 & 59.0 & 14.3 & 20.7 & 80.0 & 84.8 \\
\hline Not allowed & 0.2 & 2.3 & 4.0 & 1.0 & 0.3 & 1.9 & 3.9 & 0.6 & 0.2 & 2.5 & 4.1 & 1.3 \\
\hline Significance level & & ** & & *** & & - & & $* *$ & & $* *$ & & ** \\
\hline Number of respondents & 774 & 745 & 1,487 & 1,164 & 327 & 369 & 513 & 538 & 447 & 376 & 974 & 626 \\
\hline
\end{tabular}

Note: All Ns are unweighted. - , *, ${ }^{* *}$ and ${ }^{* * *}$ indicate that differences between 2007 and 2012 are not significant, and significant at $p \leq 0.05, p \leq 0.01$ and $p \leq 0.001$, respectively. Column totals may not equal $100 \%$ due to missing cases. 
Figure 7.2: Percentage of adolescents allowed to visit selected places within and outside the village/neighbourhood unescorted, Rajasthan, 2007 and 2012

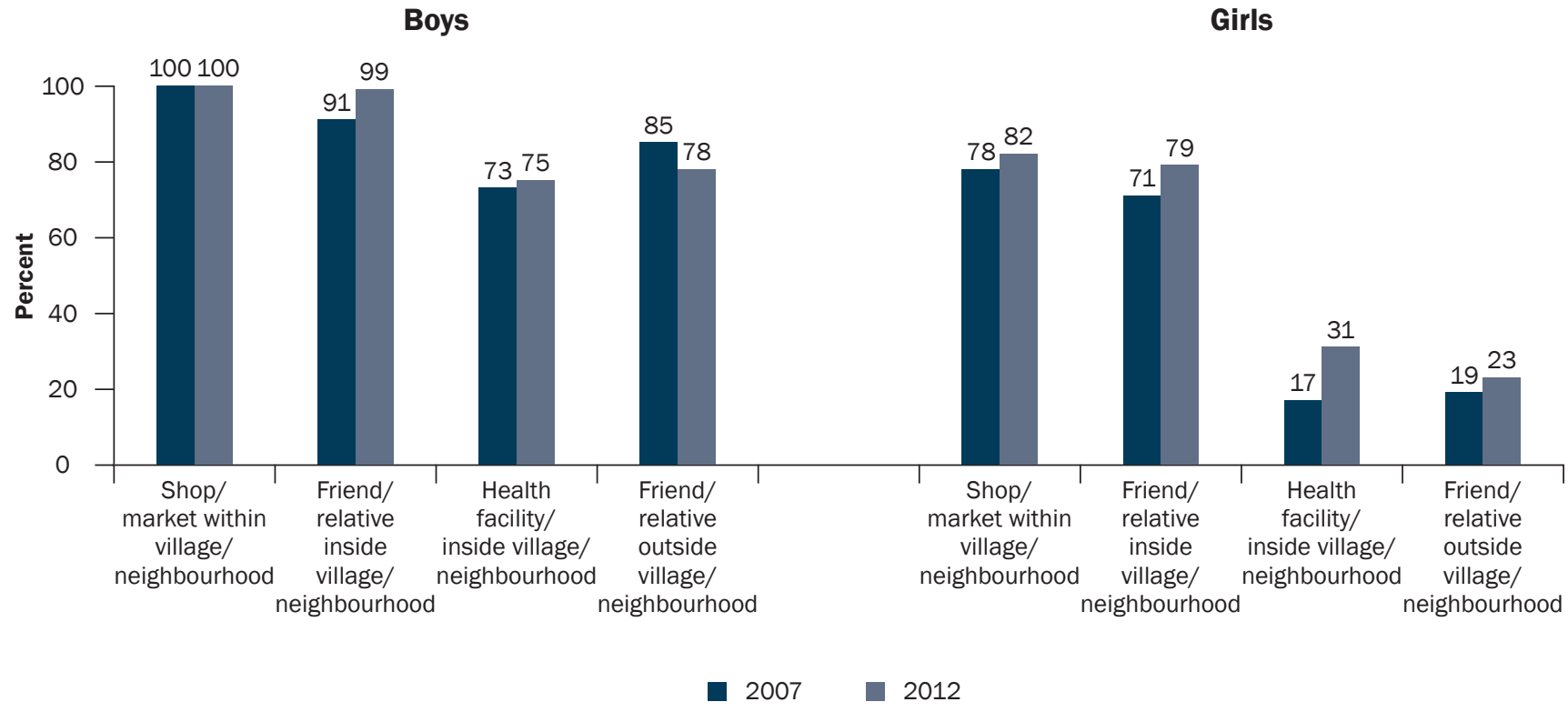

Table 7.4 presents the summary measure of freedom of movement of rural and urban adolescent boys and girls, in 2012, within the village (freedom to visit a shop/market, a friend and a health centre unescorted) and outside the village or neighbourhood (freedom to visit a friend) by selected socio-economic and demographic characteristics. In general, socio-demographic differentials in freedom of movement were evident, more so among girls than boys. Among boys, more older than younger boys (aged 18-19 versus 15-17) reported freedom of movement both inside ( $86 \%$ versus $70 \%$ ) and outside ( $90 \%$ versus $72 \%$ ) the village or neighbourhood. So too did better educated and economically better off boys: For example, 87 percent of boys with 12 or more years of education compared with 74 percent of those with 1-7 years of education reported freedom of movement inside the village, and 93 percent and 81 percent, respectively, reported freedom to visit a friend outside the village. Likewise, while $80-86$ percent of boys in the wealthiest quintile reported freedom of movement both inside and outside the village, 65-67 percent of those in the poorest wealth quintile so reported. Working boys were more likely than other boys to report the freedom to visit a friend within the village ( $81 \%$ versus $73 \%$ ) as well as outside the village ( $87 \%$ versus $75 \%)$. Other differentials were mild: Hindu boys were more likely than Muslim boys to report freedom to move within the village, but about as likely to report the freedom to visit a friend outside the village. Caste wise differences were modest in both instances. These associations were observed, by and large, among both rural and urban boys.

Among girls, in contrast, socio-demographic differentials were wide for each indicator of mobility, except work status. Girls' freedom to visit locations inside and outside the village or neighbourhood increased with age, educational attainment and household economic status. For example, while 53 percent and 51 percent of girls who had completed 12 or more years of education reported freedom of movement inside and outside the village, respectively, just 11 percent and eight percent, respectively, of their uneducated counterparts so reported. Differences by religion suggest that Muslim girls were less likely than Hindu girls or those from other religions to report freedom of movement within the village ( $17 \%$ versus $32 \%$ and $43 \%$, respectively); both Hindu and Muslim girls were far more likely than those belonging to other religions to report freedom of movement outside their village or urban neighbourhood (21-23\% versus 39\%). Caste-wise differences show that girls belonging to general castes displayed greater freedom to visit places within and outside the village or urban neighbourhood than those belonging to socially excluded castes. Finally, a positive association was observed between wealth quintiles and mobility; for example, girls in the wealthiest (fifth) quintile consistently reported greater mobility than those from the poorest (first) quintile, both with regard to freedom to visit locations inside (46\% versus $18 \%$ ) and outside (40\% versus $11 \%$ ) the village or urban neighbourhood. These associations were observed, by and large, among both rural and urban girls. 
Table 7.4: Freedom of movement by selected background characteristics

Percentage of adolescents who could visit various places within and outside their home setting unescorted, by selected background characteristics, according to residence, Rajasthan, 2007 and 2012

\begin{tabular}{|c|c|c|c|c|}
\hline \multirow[b]{2}{*}{ Background characteristics } & Boys (\%) & Girls (\%) & Boys (\%) & Girls (\%) \\
\hline & \multicolumn{2}{|c|}{$\begin{array}{c}\text { Within } \\
\text { village/neighbourhood }\end{array}$} & \multicolumn{2}{|c|}{$\begin{array}{c}\text { Outside } \\
\text { village/neighbourhood }\end{array}$} \\
\hline \multicolumn{5}{|c|}{ Combined } \\
\hline \multicolumn{5}{|l|}{ Age (years) } \\
\hline $15-17$ & 69.8 & 28.3 & 72.3 & 20.1 \\
\hline $18-19$ & 85.8 & 35.4 & 90.4 & 31.5 \\
\hline \multicolumn{5}{|l|}{ Religion } \\
\hline Hindu & 75.5 & 31.6 & 78.2 & 22.5 \\
\hline Muslim & 65.7 & 16.9 & 74.7 & 20.7 \\
\hline Other $^{1}$ & $\#$ & $(43.2)$ & $\#$ & $(38.8)$ \\
\hline \multicolumn{5}{|l|}{ Caste } \\
\hline SC & 73.7 & 26.6 & 74.6 & 16.0 \\
\hline ST & 73.0 & 19.1 & 74.1 & 18.8 \\
\hline $\mathrm{OBC}$ & 75.2 & 29.3 & 79.7 & 22.6 \\
\hline General $^{2}$ & 77.1 & 40.4 & 82.1 & 31.4 \\
\hline \multicolumn{5}{|l|}{ Educational level (years) } \\
\hline None $^{3}$ & $\#$ & 11.1 & $\#$ & 7.8 \\
\hline $1-7$ & 74.3 & 19.7 & 80.6 & 9.3 \\
\hline $8-9$ & 67.7 & 23.6 & 66.6 & 13.4 \\
\hline $10-11$ & 76.4 & 40.3 & 80.6 & 34.9 \\
\hline 12 and above & 87.0 & 52.5 & 92.6 & 51.3 \\
\hline \multicolumn{5}{|l|}{ Worked in last 12 months } \\
\hline Yes & 80.5 & 29.4 & 86.9 & 22.3 \\
\hline No & 73.2 & 30.3 & 75.3 & 23.2 \\
\hline \multicolumn{5}{|l|}{ Wealth quintile } \\
\hline First & 64.8 & 18.2 & 67.3 & 11.2 \\
\hline Second & 72.9 & 20.5 & 81.0 & 11.6 \\
\hline Third & 80.5 & 31.2 & 77.5 & 18.8 \\
\hline Fourth & 79.1 & 30.7 & 81.2 & 28.5 \\
\hline Fifth & 80.0 & 45.5 & 86.4 & 39.9 \\
\hline Total & 75.0 & 30.1 & 78.1 & 23.0 \\
\hline \multicolumn{5}{|c|}{ Urban } \\
\hline \multicolumn{5}{|l|}{ Age (years) } \\
\hline $15-17$ & 67.4 & 33.4 & 74.3 & 35.4 \\
\hline $18-19$ & 88.2 & 45.9 & 95.4 & 53.6 \\
\hline \multicolumn{5}{|l|}{ Religion } \\
\hline Hindu & 75.6 & 40.9 & 81.6 & 42.2 \\
\hline Muslim & 67.5 & 18.1 & 82.0 & 28.1 \\
\hline Other $^{1}$ & $\#$ & $\#$ & $\#$ & $\#$ \\
\hline
\end{tabular}


Table 7.4: (Cont'd)

\begin{tabular}{|c|c|c|c|c|}
\hline \multirow[b]{2}{*}{ Background characteristics } & Boys (\%) & Girls (\%) & Boys (\%) & Girls (\%) \\
\hline & \multicolumn{2}{|c|}{$\begin{array}{c}\text { Within } \\
\text { village/neighbourhood }\end{array}$} & \multicolumn{2}{|c|}{$\begin{array}{c}\text { Outside } \\
\text { village/neighbourhood }\end{array}$} \\
\hline \multicolumn{5}{|l|}{ Caste } \\
\hline SC & 79.5 & 24.7 & 80.1 & 30.5 \\
\hline ST & $\#$ & $(41.2)$ & $\#$ & $(30.4)$ \\
\hline OBC & 64.0 & 34.1 & 78.0 & 37.3 \\
\hline General $^{2}$ & 79.4 & 46.3 & 85.7 & 51.9 \\
\hline \multicolumn{5}{|l|}{ Educational level (years) } \\
\hline None $^{3}$ & $\#$ & \# & $\#$ & \# \\
\hline $1-7$ & $(72.1)$ & 13.5 & $(87.3)$ & 15.2 \\
\hline $8-9$ & 63.2 & 29.4 & 70.0 & 24.7 \\
\hline $10-11$ & 75.8 & 48.4 & 78.4 & 50.2 \\
\hline 12 and above & 86.3 & 53.1 & 96.5 & 69.6 \\
\hline \multicolumn{5}{|l|}{ Worked in last 12 months } \\
\hline Yes & 80.4 & 36.0 & 88.4 & 46.3 \\
\hline No & 72.6 & 37.0 & 79.3 & 39.1 \\
\hline \multicolumn{5}{|l|}{ Wealth quintile } \\
\hline First & \# & $(27.6)$ & \# & $(34.8)$ \\
\hline Second & $(73.5)$ & 19.6 & $(75.2)$ & 15.7 \\
\hline Third & $(72.1)$ & 35.1 & $(74.0)$ & 31.7 \\
\hline Fourth & 74.9 & 39.0 & 80.2 & 47.0 \\
\hline Fifth & 73.7 & 43.4 & 86.9 & 49.1 \\
\hline Total & 74.5 & 36.8 & 81.6 & 40.4 \\
\hline \multicolumn{5}{|c|}{ Rural } \\
\hline \multicolumn{5}{|l|}{ Age (years) } \\
\hline $15-17$ & 70.7 & 25.8 & 71.6 & 12.4 \\
\hline $18-19$ & 84.8 & 29.0 & 88.3 & 18.2 \\
\hline \multicolumn{5}{|l|}{ Religion } \\
\hline Hindu & 75.5 & 27.4 & 77.1 & 13.6 \\
\hline Muslim & $\#$ & 15.5 & \# & 11.7 \\
\hline Other $^{1}$ & \# & (33.4) & \# & $(22.2)$ \\
\hline \multicolumn{5}{|l|}{ Caste } \\
\hline SC & 71.8 & 27.4 & 72.7 & 9.6 \\
\hline ST & 71.4 & 13.7 & 74.1 & 15.9 \\
\hline $\mathrm{OBC}$ & 78.3 & 26.8 & 80.2 & 15.1 \\
\hline General $^{2}$ & (73.6) & 35.4 & $(76.3)$ & 13.9 \\
\hline \multicolumn{5}{|l|}{ Educational level (years) } \\
\hline None $^{3}$ & $\#$ & 10.6 & $\#$ & 5.3 \\
\hline $1-7$ & 75.1 & 22.2 & 78.3 & 7.0 \\
\hline $8-9$ & 69.0 & 20.9 & 65.7 & 8.2 \\
\hline $10-11$ & 76.6 & 34.5 & 81.5 & 23.8 \\
\hline 12 and above & 87.3 & 51.9 & 90.7 & 33.2 \\
\hline
\end{tabular}




\begin{tabular}{|c|c|c|c|c|}
\hline \multirow[b]{2}{*}{ Background characteristics } & Boys (\%) & Girls (\%) & Boys (\%) & Girls (\%) \\
\hline & \multicolumn{2}{|c|}{$\begin{array}{c}\text { Within } \\
\text { village/neighbourhood }\end{array}$} & \multicolumn{2}{|c|}{$\begin{array}{c}\text { Outside } \\
\text { village/neighbourhood }\end{array}$} \\
\hline \multicolumn{5}{|l|}{ Worked in last 12 months } \\
\hline Yes & 80.6 & 26.9 & 86.3 & 13.3 \\
\hline No & 73.4 & 26.4 & 73.8 & 14.0 \\
\hline \multicolumn{5}{|l|}{ Wealth quintile } \\
\hline First & 63.5 & 17.1 & 66.9 & 8.5 \\
\hline Second & 72.8 & 20.8 & 81.8 & 10.2 \\
\hline Third & 82.3 & 29.7 & 78.2 & 13.9 \\
\hline Fourth & 82.5 & 24.0 & 81.9 & 13.7 \\
\hline Fifth & 95.7 & 48.4 & \# & 27.3 \\
\hline Total & 75.1 & 26.6 & 76.9 & 13.8 \\
\hline
\end{tabular}

Note: ( ) Based on 25-49 unweighted cases. \# Percentage not shown; based on fewer than 25 unweighted cases. OBC: Other backward caste. SC: Scheduled caste. ST: Scheduled tribe. ${ }^{1}$ Includes Christian, Buddhist, Neo-Buddhist, Sikh, Jain, Jewish, Parsi/ Zoroastrian, Sarana and no specified religion. ${ }^{2}$ Includes all those not belonging to SC, ST or OBC. ${ }^{3}$ Includes those who are nonliterate and literate with no formal schooling.

\subsection{Access to money}

In order to understand access to financial resources among surveyed adolescents, information was obtained on whether they had any savings, whether they owned an account in a bank or a post office, and if so, whether they operated the account themselves. Questions were posed in a somewhat different way in 2012 than in 2007 (for example, we probed separately about school-related savings accounts and other accounts in 2012 but not in 2007); hence these results are not entirely comparable. Results are presented in Table 7.5.

As far as savings behaviour is concerned, significantly more adolescents in 2012 than in 2007 reported having some savings (21\% versus $11 \%$ of boys; $42 \%$ versus $32 \%$ of girls), and as in 2007 , savings were reported by far more girls than boys in 2012 (42\% versus 21\%). Moreover, more urban than rural adolescents reported some savings in 2012: 30 percent versus 17 percent among boys, and 56 percent versus 35 percent among girls.

In 2012, many adolescents owned an account in a bank or post office: as many as 27 percent of boys and girls alike. However, gender differences were apparent in the kind of account owned. For example, relatively similar percentages of girls and boys-19 percent and 15 percent, respectively-reported owning a school account, that is, an account specially opened by the school in which scholarship and related money is directly deposited and which must be used for specific, school-based purposes only. In contrast, boys were considerably more likely than girls to own a personal account in a bank or post office, that is, an account opened for them by their family: 26 percent of boys and 18 percent of girls so reported. While percentages reported for 2007 and 2012 are not wholly comparable, it is clear that there has been a huge increase in percentages of adolescents owning accounts over the inter-survey period. Rural-urban differences were apparent as well, with urban adolescents considerably more likely than their rural counterparts to own a bank account (31\% versus 26\% among boys, and 32\% versus $25 \%$ among girls).

With regard to the operation of the account, comparisons over time suggest some decline among boys (from $90 \%$ to $80 \%$ ) and a significant increase among girls (from 19\% to 56\%). As evident from these percentages, gender differences were apparent, although considerably narrowed as compared to 2007. Rural-urban differences in 2012 were negligible for boys (79-80\%) and modest for girls, with more rural than urban girls operating their accounts independently (60\% versus $52 \%)$. 
Table 7.5: Access to money

Percentage of adolescents who reported having any savings, owning an account in a bank or post office and operating the account themselves, according to residence, Rajasthan, 2007 and 2012

\begin{tabular}{|c|c|c|c|c|}
\hline \multirow[b]{2}{*}{ Saving behaviour } & \multicolumn{2}{|c|}{ Boys (\%) } & \multicolumn{2}{|c|}{ Girls (\%) } \\
\hline & 2007 & 2012 & 2007 & 2012 \\
\hline \multicolumn{5}{|c|}{ Combined } \\
\hline Has savings from any source & 11.1 & $20.7^{* * *}$ & 31.5 & $41.9^{* * *}$ \\
\hline Owns an account in a bank/post office & 4.8 & $27.3^{* * *}$ & 9.7 & $27.3^{* * *}$ \\
\hline Owns an account in a bank/post office opened by school & na & 15.1 & na & 18.7 \\
\hline Has an account personally in a bank/post office & 4.5 & $26.1^{* * *}$ & 8.4 & $17.5^{* * *}$ \\
\hline Has an account jointly in a bank/post office & 0.3 & 0.1 & 1.2 & 1.4 \\
\hline Number of respondents & 774 & 745 & 1,487 & 1,164 \\
\hline Operates bank/post office account on own & $(89.7)$ & 79.5 & 18.8 & $56.2^{* * *}$ \\
\hline Number of respondents with an account & 41 & 205 & 150 & 227 \\
\hline \multicolumn{5}{|c|}{ Urban } \\
\hline Has savings from any source & 20.8 & $29.8^{*}$ & 42.2 & $55.9^{* * *}$ \\
\hline Owns an account in a bank/post office & 7.9 & $31.1^{* * *}$ & 13.6 & $32.2^{* * *}$ \\
\hline Owns an account in a bank/post office opened by school & na & 12.7 & na & 18.1 \\
\hline Has an account personally in a bank/post office & 7.2 & $29.4^{* * *}$ & 11.7 & $22.4^{* *}$ \\
\hline Has an account jointly in a bank/post office & 0.7 & 0.5 & 1.9 & 2.5 \\
\hline Number of respondents & 327 & 369 & 513 & 538 \\
\hline Operates bank/post office account on own & $(92.1)$ & 78.5 & 16.9 & $51.7^{* * *}$ \\
\hline Number of respondents with an account & 25 & 112 & 70 & 131 \\
\hline \multicolumn{5}{|c|}{ Rural } \\
\hline Has savings from any source & 7.5 & $17.4^{* * *}$ & 27.6 & 34.6 \\
\hline Owns an account in a bank/post office & 3.6 & $26.0^{* * *}$ & 8.3 & $24.7^{* * *}$ \\
\hline Owns an account in a bank/post office opened by school & na & 15.9 & na & 19.0 \\
\hline Has an account personally in a bank/post office & 3.4 & $24.8^{* * *}$ & 7.3 & $15.0^{* * *}$ \\
\hline Has an account jointly in a bank/post office & 0.2 & 0.0 & 1.0 & 0.8 \\
\hline Number of respondents & 447 & 376 & 974 & 626 \\
\hline Operates bank/post office account on own & \# & 79.9 & 19.9 & $60.0^{* * *}$ \\
\hline Number of respondents with an account & 16 & 93 & 80 & 96 \\
\hline
\end{tabular}

Note: All Ns are unweighted. *, ** and ${ }^{* * *}$ indicate that differences between 2007 and 2012 are significant at $p \leq 0.05, p \leq 0.01$ and $p \leq 0.001$, respectively. na: Not asked in 2007 survey. ( ) Based on 25-49 unweighted cases. \# Percentage not shown; based on fewer than 25 unweighted cases.

\subsection{Gender role attitudes}

In order to understand gender role attitudes, adolescents in 2012 were asked a range of questions reflecting gender role attitudes; four of these had also been asked in 2007, namely the relative importance attached to educating boys versus girls, the role of husbands as main decision-makers with regard to spending money, girls' participation in decisions about their own marriage, and a woman's need to take permission from her husband for engaging in any activity. Other attitudes, that were probed only in 2012, related to boy-girl relations, marital roles, and sex and contraception. Findings, presented in Table 7.6, suggest a mixed scenario. 
Table 7.6: Gender role attitudes

Percentage of adolescents by attitudes towards gender roles, according to residence, Rajasthan, 2007 and 2012

\begin{tabular}{|c|c|c|c|c|}
\hline \multirow[b]{2}{*}{ Gender role attitudes } & \multicolumn{2}{|c|}{ Boys (\%) } & \multicolumn{2}{|c|}{ Girls (\%) } \\
\hline & 2007 & 2012 & 2007 & 2012 \\
\hline \multicolumn{5}{|l|}{ Combined } \\
\hline Disagree that educating boys is more important than educating girls & 65.6 & $86.9^{* * *}$ & 80.4 & $92.4^{* * *}$ \\
\hline Agree that girls should be allowed to decide when they want to marry & 51.8 & $59.6^{*}$ & 75.3 & 74.7 \\
\hline $\begin{array}{l}\text { Disagree that a woman should obtain her husband's permission for most } \\
\text { things }\end{array}$ & 22.3 & $16.2^{*}$ & 33.0 & $38.5^{\star *}$ \\
\hline Disagree that the husband alone/mainly should decide how to spend money & 52.4 & 55.2 & 52.3 & $77.2^{* * *}$ \\
\hline $\begin{array}{l}\text { Disagree that since girls have to get married, they should not be sent for } \\
\text { higher education }\end{array}$ & na & 72.8 & na & 78.3 \\
\hline Disagree that it is wrong for a girl to have male friends & na & 56.1 & na & 60.5 \\
\hline Disagree that girls like to be teased by boys & na & 84.5 & na & 94.8 \\
\hline Disagree that it is necessary to give dowry & na & 77.9 & na & 74.1 \\
\hline Disagree that a woman should not earn more than her husband & na & 76.9 & na & 84.4 \\
\hline $\begin{array}{l}\text { Disagree that giving the kids a bath and feeding the kids are the mother's } \\
\text { responsibility }\end{array}$ & na & 73.4 & na & 65.8 \\
\hline Disagree that it is a woman's responsibility to avoid getting pregnant & na & 77.5 & na & 74.9 \\
\hline Disagree that it is the man who should decide whether to use a condom & & & & \\
\hline or not & na & 60.5 & na & 41.7 \\
\hline Disagree that a man needs other women even if things with his wife are fine & na & 89.1 & na & 95.5 \\
\hline Number of respondents & 774 & 745 & 1,487 & 1,164 \\
\hline \multicolumn{5}{|l|}{ Urban } \\
\hline Disagree that educating boys is more important than educating girls & 77.4 & $89.5^{* *}$ & 87.8 & $97.6^{\star \star *}$ \\
\hline Agree that girls should be allowed to decide when they want to marry & 59.0 & $70.5^{* *}$ & 80.2 & 83.1 \\
\hline $\begin{array}{l}\text { Disagree that a woman should obtain her husband's permission for most } \\
\text { things }\end{array}$ & 27.1 & 23.6 & 42.7 & $55.2^{* * *}$ \\
\hline Disagree that the husband alone/mainly should decide how to spend money & 56.7 & 66.3 & 60.4 & $85.6^{* * *}$ \\
\hline $\begin{array}{l}\text { Disagree that since girls have to get married, they should not be sent for } \\
\text { higher education }\end{array}$ & na & 77.4 & na & 89.2 \\
\hline Disagree that it is wrong for a girl to have male friends & na & 75.5 & na & 75.9 \\
\hline Disagree that girls like to be teased by boys & na & 86.9 & na & 96.6 \\
\hline Disagree that it is necessary to give dowry & na & 85.7 & na & 86.1 \\
\hline Disagree that a woman should not earn more than her husband & na & 81.7 & na & 89.3 \\
\hline $\begin{array}{l}\text { Disagree that giving the kids a bath and feeding the kids are the mother's } \\
\text { responsibility }\end{array}$ & na & 84.1 & na & 80.8 \\
\hline Disagree that it is a woman's responsibility to avoid getting pregnant & na & 81.3 & na & 85.6 \\
\hline $\begin{array}{l}\text { Disagree that it is the man who should decide whether to use a condom } \\
\text { or not }\end{array}$ & na & 66.3 & na & 53.3 \\
\hline Disagree that a man needs other women even if things with his wife are fine & na & 90.4 & na & 96.0 \\
\hline Number of respondents & 327 & 369 & 513 & 538 \\
\hline
\end{tabular}




\begin{tabular}{|c|c|c|c|c|}
\hline \multirow[b]{2}{*}{ Gender role attitudes } & \multicolumn{2}{|c|}{ Boys (\%) } & \multicolumn{2}{|c|}{ Girls (\%) } \\
\hline & 2007 & 2012 & 2007 & 2012 \\
\hline \multicolumn{5}{|l|}{ Rural } \\
\hline Disagree that educating boys is more important than educating girls & 61.3 & $86.0^{* * *}$ & 77.8 & $89.6^{* * *}$ \\
\hline Agree that girls should be allowed to decide when they want to marry & 49.1 & 55.6 & 73.5 & 70.2 \\
\hline $\begin{array}{l}\text { Disagree that a woman should obtain her husband's permission for most } \\
\text { things }\end{array}$ & 20.5 & 13.4 & 29.5 & 29.7 \\
\hline Disagree that the husband alone/mainly should decide how to spend money & 50.8 & 51.1 & 49.4 & $72.8^{* * *}$ \\
\hline $\begin{array}{l}\text { Disagree that since girls have to get married, they should not be sent for } \\
\text { higher education }\end{array}$ & na & 71.1 & na & 72.6 \\
\hline Disagree that it is wrong for a girl to have male friends & na & 49.0 & na & 52.4 \\
\hline Disagree that girls like to be teased by boys & na & 83.6 & na & 93.9 \\
\hline Disagree that it is necessary to give dowry & na & 75.1 & na & 67.8 \\
\hline Disagree that a woman should not earn more than her husband & na & 75.1 & na & 81.9 \\
\hline $\begin{array}{l}\text { Disagree that giving the kids a bath and feeding the kids are the mother's } \\
\text { responsibility }\end{array}$ & na & 69.5 & na & 57.9 \\
\hline Disagree that it is a woman's responsibility to avoid getting pregnant & na & 76.2 & na & 69.2 \\
\hline $\begin{array}{l}\text { Disagree that it is the man who should decide whether to use a condom } \\
\text { or not }\end{array}$ & na & 58.4 & na & 35.6 \\
\hline Disagree that a man needs other women even if things with his wife are fine & na & 88.6 & na & 95.2 \\
\hline Number of respondents & 447 & 376 & 974 & 626 \\
\hline
\end{tabular}

Note: All Ns are unweighted. * ${ }^{* *}$ and ${ }^{* * *}$ indicate that differences between 2007 and 2012 are significant at $p \leq 0.05, p \leq 0.01$ and $p \leq 0.001$, respectively. na: Not asked in 2007 survey.

From the four statements for which findings are available for both surveys, it is apparent that gender role attitudes have indeed become more egalitarian among both boys and girls, although the expression of egalitarian attitudes is still far from universal. For example, significantly more boys and girls in 2012 than 2007 disagreed that educating boys is more important than educating girls (87\% versus $66 \%$ among boys; $92 \%$ versus $80 \%$ among girls); significantly more girls disagreed with the statement that a woman should obtain her husband's permission for most things (39\% versus 33\%) and that the husband alone/mainly should decide how to spend money (77\% versus 52\%) (Table 7.6 and Figure 7.3). While significantly more boys in 2012 than in 2007 agreed that girls should be allowed to decide when they want to marry (60\% versus $52 \%)$, significantly fewer discarded the notion that a woman should obtain her husband's permission for most things (16\% versus $22 \%$ ).

Other attitudes were probed only in 2012. With regard to attitudes about the roles of women and girls, three-quarters or more of surveyed adolescents rejected the view that girls like to be teased by boys ( $85 \%$ and $95 \%$ of boys and girls, respectively), that it is necessary to give a dowry (78\% and $74 \%$ of boys and girls, respectively), girls should not receive higher education because they will get married ( $73 \%$ and $78 \%$ of boys and girls, respectively), or that a woman should not earn more than her husband ( $77 \%$ and $84 \%$ of boys and girls respectively); somewhat fewer rejected the view that caring for children is the mother's responsibility ( $73 \%$ and $66 \%$ of boys and girls respectively).

With regard to boy-girl relations, and sex and reproductive health matters, responses were mixed. Almost all surveyed adolescents rejected the view that a man needs other women even if he has a good marital life (89-96\%), and three-quarters that it is a woman's responsibility to avoid pregnancy (75-78\%). Many fewer rejected the view that it is wrong for a girl to have male friends (56-61\%), and that it is the man who should decide whether to use a condom or not ( $61 \%$ of boys and $42 \%$ of girls).

Differences by rural-urban residence indicate that urban adolescents were more likely than their rural counterparts to express gender egalitarian attitudes in relation to almost all the issues studied. Variations in reporting of egalitarian attitudes by issue are highlighted in Figure 7.3. 
Figure 7.3: Percentage of adolescents who expressed egalitarian gender role attitudes on selected issues, Rajasthan, 2007 and 2012

Boys

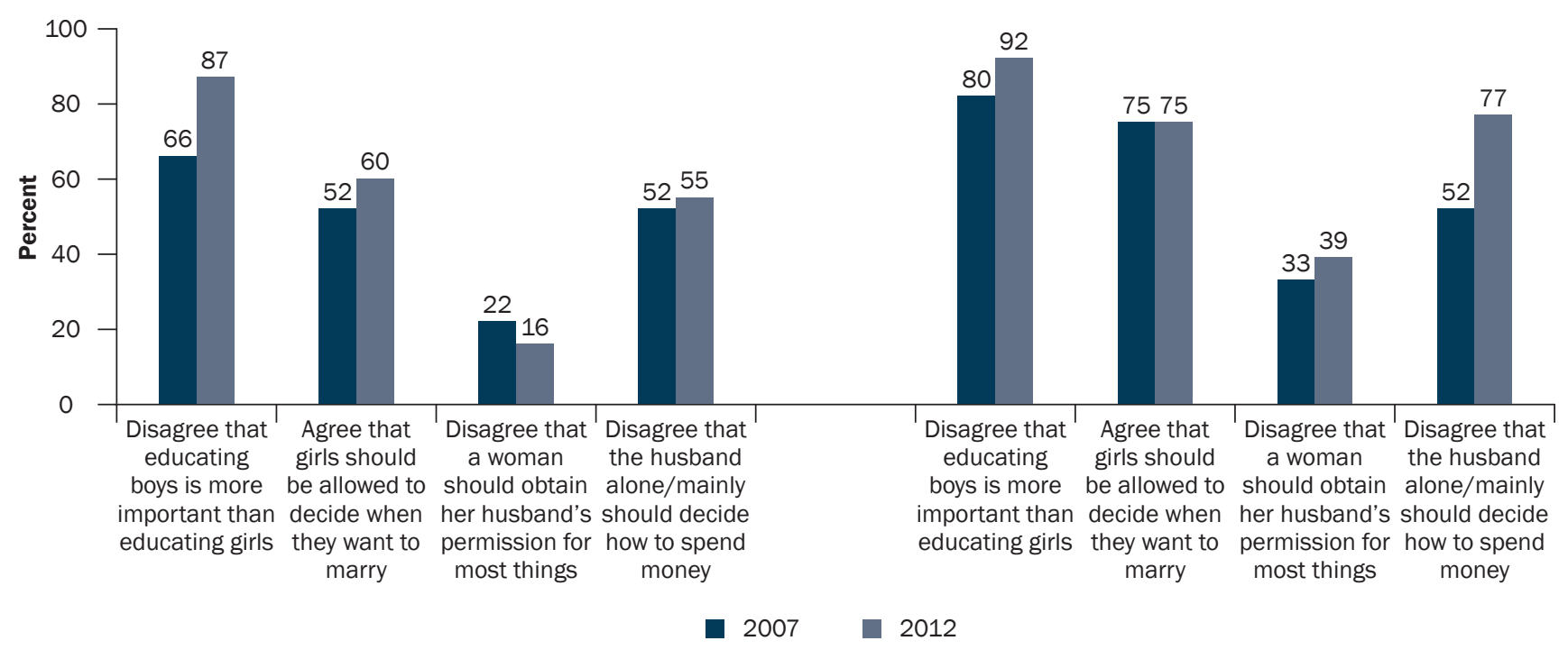

\subsection{Attitudes towards wife beating}

Adolescents were asked a number of questions to gauge the extent to which beating one's wife was perceived to be an acceptable behaviour. Young people were asked whether wife beating was justified in four situations, including refusal to have sex with the husband. Findings, presented in Table 7.7 and Figure 7.4 for both surveys, show that in most instances, significantly more adolescents in 2012 than in 2007 rejected the acceptability of wife beating. However, increases were more consistently observed among girls than boys, and girls were hugely more likely to reject the acceptability of wife beating than were boys in almost every situation probed. Of the four situations posed, boys, irrespective of rural-urban residence, were most likely to reject the acceptability of wife beating if the wife disagreed with her husband's opinion (76\%, up from $65 \%$ in 2007 ) or refused to have sex with him (75\%, up from $72 \%)$; they were somewhat less likely to find wife beating unacceptable if the wife went out without informing her husband $(62 \%$, down from $65 \%$ in 2007 ) or if the husband suspected that his wife had been unfaithful (52\%, up from 47\%). Far more girls than boys perceived wife beating to be unjustifiable, and percentages perceiving so were considerably higher in 2012 than in 2007: in 2012, as many as 87 percent found wife beating unacceptable if the wife goes out without telling her husband, disagrees with her husband's opinion or refuses to have sexual relations with him, and 83 percent if the husband suspects his wife of being unfaithful, representing increases from 69 percent, 74 percent, 76 percent and 78 percent, respectively, in 2007.

A summary measure, that is, the percentage of adolescents who rejected the acceptability of violence in all four situations confirms that attitudes about the acceptability of wife beating have become more egalitarian among girls, among whom percentages who rejected the acceptability of wife beating increased significantly from 57 to 74 . Among boys, in contrast, percentages remained identical in 2007 and 2012 (41-42\%). The already considerable gender disparity observed in 2007 had clearly widened considerably by 2012 .

Differences by rural-urban setting suggest that urban adolescents were more likely than their rural counterparts to reject the acceptability of wife beating in every situation (Table 7.7). Further, changes over time were, for the most part, considerable, in both rural and urban areas, with one exception: percentages rejecting wife beating actually declined somewhat among rural boys (from $41 \%$ to $34 \%$ ).

Finally, two attitudes-about whether there are times when a woman deserves to be beaten, and that a woman should tolerate violence to keep her family together-were probed only in 2012. Findings show wide gender disparities. Just 45-48 percent of boys rejected views about the acceptability of marital violence and the need 
for women to tolerate violence to keep the family together. In contrast, far more girls rejected these views about violence ( $81 \%$ and $71 \%$, respectively). Again, more urban than rural adolescents showed egalitarian attitudes in these matters.

Table 7.7: Attitudes towards wife beating

Percent distribution of adolescents by attitudes towards wife beating in selected situations, according to residence, Rajasthan, 2007 and 2012

\begin{tabular}{|c|c|c|c|c|}
\hline \multirow[b]{2}{*}{ Attitudes towards wife beating } & \multicolumn{2}{|c|}{ Boys (\%) } & \multicolumn{2}{|c|}{ Girls (\%) } \\
\hline & 2007 & 2012 & 2007 & 2012 \\
\hline \multicolumn{5}{|l|}{ Combined } \\
\hline \multicolumn{5}{|l|}{ Wife beating is not justified if } \\
\hline Husband suspects wife has been unfaithful & 47.0 & $51.6^{* * *}$ & 77.5 & $82.9^{* * *}$ \\
\hline Wife goes out without telling husband & 65.2 & $61.7^{* * *}$ & 68.5 & $86.6^{* * *}$ \\
\hline Wife disagrees with husband's opinion & 65.4 & $76.1^{* * *}$ & 73.5 & $87.3^{* * *}$ \\
\hline Wife refuses to have sexual relations with husband & 71.7 & $75.4^{* * *}$ & 76.0 & $86.9^{* * *}$ \\
\hline Wife beating is not justified in all four situations & 42.4 & 41.0 & 57.1 & $73.7^{* * *}$ \\
\hline Disagree that there are times when a woman deserves to be beaten & na & 45.2 & na & 81.0 \\
\hline Disagree that a woman should tolerate violence to keep her family together & na & 48.0 & na & 71.4 \\
\hline Number of respondents & 774 & 745 & 1,487 & 1,164 \\
\hline \multicolumn{5}{|l|}{ Urban } \\
\hline \multicolumn{5}{|l|}{ Wife beating is not justified if } \\
\hline Husband suspects wife has been unfaithful & 49.3 & $67.7^{* * *}$ & 89.6 & $93.3^{*}$ \\
\hline Wife goes out without telling husband & 65.0 & $82.5^{* * *}$ & 80.9 & $94.5^{* * *}$ \\
\hline Wife disagrees with husband's opinion & 68.8 & $89.8^{* * *}$ & 84.4 & $95.2^{* * *}$ \\
\hline Wife refuses to have sexual relations with husband & 69.8 & $84.2^{* * *}$ & 87.4 & $93.7^{*}$ \\
\hline Wife beating is not justified in all four situations & 45.4 & $59.9^{*}$ & 71.5 & $88.0^{* * *}$ \\
\hline Disagree that there are times when a woman deserves to be beaten & na & 63.3 & na & 90.8 \\
\hline Disagree that a woman should tolerate violence to keep her family together & na & 58.4 & na & 83.9 \\
\hline Number of respondents & 327 & 369 & 513 & 538 \\
\hline \multicolumn{5}{|l|}{ Rural } \\
\hline \multicolumn{5}{|l|}{ Wife beating is not justified if } \\
\hline Husband suspects wife has been unfaithful & 46.1 & $45.6^{* * *}$ & 73.1 & $77.4^{* *}$ \\
\hline Wife goes out without telling husband & 65.3 & $54.1^{* * *}$ & 64.0 & $82.4^{* * *}$ \\
\hline Wife disagrees with husband's opinion & 64.2 & $71.1^{* * *}$ & 69.6 & $83.2^{* * *}$ \\
\hline Wife refuses to have sexual relations with husband & 72.3 & $72.2^{* * *}$ & 71.9 & $83.2^{* * *}$ \\
\hline Wife beating is not justified in all four situations & 41.3 & 34.0 & 52.0 & $66.1^{* * *}$ \\
\hline Disagree that there are times when a woman deserves to be beaten & na & 38.6 & na & 75.9 \\
\hline Disagree that a woman should tolerate violence to keep her family together & na & 44.1 & na & 64.9 \\
\hline Number of respondents & 447 & 376 & 974 & 626 \\
\hline
\end{tabular}

Note: All Ns are unweighted. *, ** and ${ }^{* \star}$ indicate that differences between 2007 and 2012 are significant at $p \leq 0.05, p \leq 0.01$ and $p \leq 0.001$, respectively. na: Not asked in 2007 survey. 
Figure 7.4: Percentage of adolescents who believed that wife beating is not justified in selected situations, Rajasthan, 2007 and 2012

Boys

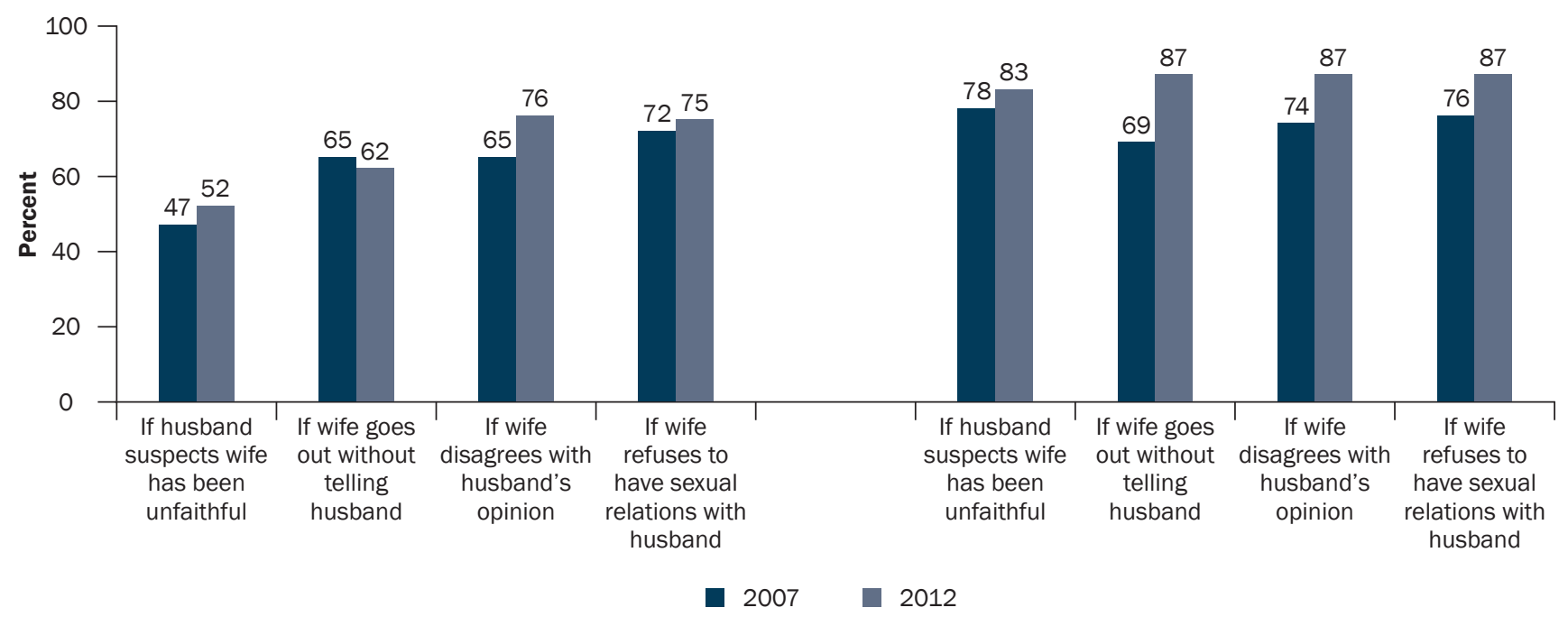

\subsection{Summary}

Findings clearly highlight girls' limited agency, but suggest that there has indeed been an increase in agency between cohorts in 2007 and 2012. For example, while just one-third of girls reported making independent decisions on spending money that they had in 2007 , this percentage had increased to almost three-fifths by 2012. Likewise, freedom of movement even within the village or neighbourhood was not universal among girls, and in this case, the increase between 2007 and 2012 was moderate; while 79-82 percent of girls had the freedom to visit a shop or a friend within their own village or neighbourhood unescorted in 2012, 71-78 percent had so reported in 2007. Likewise, percentages of girls permitted to visit a health centre in the village or neighbourhood unescorted increased from 17 to 31. Overall, while just 16 percent of girls had been permitted to visit all three locations within the village unescorted in 2007 , this percentage had increased to 30 by 2012. Freedom to visit a friend or relative outside the village or neighbourhood unescorted was particularly restricted for girls; just 23 percent reported such freedom of movement, slightly more than in 2007 (19\%). Access to and control over financial resources had increased considerably by 2012, and while still far from universal, improvements over 2007 were apparent; by 2012, more than two in five girls reported some savings, more than one-quarter owned a bank or post office savings account, and of these, more than one-half operated it themselves.

While boys were not as disadvantaged as girls, findings indicate that many boys were also not able to exercise agency in their everyday lives. For example, only 79 percent of boys reported independent decision-making. Boys had considerable freedom of movement, yet 22 percent were not permitted to visit a friend or relative outside their village or neighbourhood unescorted. Compared to the experience of girls, changes in agency were not pronounced among boys in 2012 compared to those in 2007. Access to and control over financial resources among boys suggest that by 2012, one-fifth reported some savings, more than one-quarter owned a bank or post office savings account, and of these, four in five operated it themselves.

Indeed, there continues to be a striking gender divide in the various dimensions of adolescents' agency explored in the survey. For example, even the least educated boys were more likely than the most educated girls to have made money-related decisions independently, and boys belonging to the poorest wealth quintile were almost as likely as girls in the wealthiest quintile to so report. Likewise, although girls were more likely than boys to have money saved ( $42 \%$ and $21 \%$, respectively), they were as likely as boys to own a bank or post office savings account (27\%), and less likely than them to operate these accounts themselves (56\% versus $80 \%$ of those who had an account). 
Gender role attitudes have become more egalitarian among both boys and girls, although many adolescents, particularly boys, continue to express inegalitarian attitudes. Indeed, even the perception that educating boys is no more important than educating girls was not universally expressed by 2012, although increases since 2007 were apparent ( $87 \%$ versus $66 \%$ among boys; $92 \%$ versus $80 \%$ among girls). Just $56-61$ percent believed that there is nothing wrong in a girl having male friends. On many attitudes however, girls were more likely than boys to express egalitarian attitudes: for example, 77 percent of girls compared to 55 percent of boys disagreed that only the husband should decide about how to spend money, and 39 percent compared to 16 percent, respectively, believed that a woman should obtain her husband's permission for most things.

Attitudes towards wife beating highlight that boys are far more likely than girls to justify violence against women and girls, and that shifts towards more egalitarian attitudes towards violence are far more spectacular among girls than among boys. About two in five boys and three-quarters of girls rejected the notion that wife beating is justifiable in a variety of situations ranging from if a woman disagrees with her husband's opinion to if a husband suspects his wife of being unfaithful. While significantly more girls in 2012 than 2007 rejected the acceptability of wife beating, among boys, shifts were observed only among those in urban areas. 


\section{Chapter 8}

\section{Awareness of sexual and reproductive health matters}

A considerable body of research has highlighted relatively low levels of awareness regarding selected sexual and reproductive health issues in both the general and adolescent populations. The Rajasthan Adolescents and Youth Study 2012 sought to explore awareness, among adolescents, of a wide range of issues relating to sex, pregnancy, contraception and STIs, including HIV/AIDS, as well as knowledge of laws governing the age at marriage and abortion. Where possible, further questions were posed to assess the extent of in-depth awareness of these matters. Along with the results of adolescents' responses to questions on these issues, this chapter presents findings on communication about and sources of information for sexual and reproductive health matters, as well as adolescents' perceptions and experiences of family life or sexuality education.

\subsection{Awareness of sex and pregnancy, contraception, STIs and HIV/AIDS}

In this section, we present evidence of the extent to which surveyed adolescents were aware of or held misconceptions about various issues related to sex and pregnancy, contraception, STIs and HIV/AIDS.

\subsubsection{Sex and pregnancy}

In order to assess young people's knowledge about sex and pregnancy, the current study asked adolescents whether they agreed or disagreed with two statements: (a) a woman can get pregnant at first sex; and (b) a woman is most likely to get pregnant if she has sex half-way between her periods. Given the serious situation with regard to genderbiased sex selection in India, we also asked adolescents whether it is possible to do a medical test to know the sex of the foetus.

Findings, presented in Table 8.1 and Figure 8.1, clearly suggest that awareness of sex-and pregnancy-related matters was limited even in 2012, but had increased, for the most part, between 2007 and 2012. Almost one-half of both boys and girls (46\%) were aware that a woman can get pregnant at first sex, reflecting a significant increase in awareness since 2007 (when 21\% of boys and 23\% of girls reported correct awareness). Significant increases were also observed among both boys and girls in awareness that women are most likely to become pregnant if they engage in sexual relations mid-cycle: from 11 percent in 2007 to 51 percent in 2012 among boys and, likewise, from 14 percent to 38 percent, among girls. Differences between rural and urban respondents were modest, especially for boys.

Awareness of the sex determination test had also increased significantly over the inter-survey period; thus, in 2012, about four in five surveyed adolescents ( $83 \%$ of boys; $84 \%$ of girls) were aware that medical tests are available through which the sex of the foetus can be detected, a significant increase since 2007 when 53 percent and 69 percent of boys and girls, respectively, had so reported. Differences between rural and urban adolescents were pronounced in 2007, with considerably larger percentages of urban than rural adolescents reporting awareness of sex determination tests ( $64 \%$ versus $48 \%$, respectively, among boys; $84 \%$ versus $64 \%$, respectively, among girls). By 2012 , these differences had narrowed considerably among girls (92\% versus $80 \%$ ) and virtually disappeared among boys ( $85 \%$ versus $81 \%)$.

In order to examine overall knowledge regarding sex and pregnancy, a summary measure was computed that assessed the percentage of surveyed adolescents who were aware of all of these three matters. The findings, also presented in Table 8.1, show a significant increase in awareness levels over time: while just 4-5 percent of boys and girls had correct knowledge of all three issues in 2007, percentages had increased to 38 among boys and 29 among girls by 2012. Rural-urban differences were negligible in 2007; by 2012, however, girls in urban areas were far more likely than their rural counterparts to report correct knowledge of all three issues (37\% versus $25 \%$ ); among boys, differences were narrower (41\% versus 37\%). 
Table 8.1: Awareness of sex- and pregnancy-related matters

Percentage of adolescents by awareness of sex- and pregnancy-related matters, according to residence, Rajasthan, 2007 and 2012

\begin{tabular}{|c|c|c|c|c|}
\hline \multirow[b]{2}{*}{ Awareness of sex and pregnancy matters } & \multicolumn{2}{|c|}{ Boys (\%) } & \multicolumn{2}{|c|}{ Girls (\%) } \\
\hline & 2007 & 2012 & 2007 & 2012 \\
\hline \multicolumn{5}{|c|}{ Combined } \\
\hline A woman can get pregnant at first sex & 20.6 & $46.4^{* * *}$ & 23.3 & $45.5^{* * *}$ \\
\hline $\begin{array}{l}\text { A woman is most likely to get pregnant if she has sex half-way } \\
\text { between her periods }\end{array}$ & 10.8 & $50.5^{* * *}$ & 13.9 & $37.6^{* * *}$ \\
\hline It is possible to do a medical test to know the sex of a foetus & 52.6 & $82.5^{* * *}$ & 68.9 & $84.4^{* * *}$ \\
\hline Respondent has correct knowledge of all of the above & 3.5 & $37.9^{* * *}$ & 5.2 & $29.3^{* * *}$ \\
\hline Number of respondents & 774 & 745 & 1,487 & 1,164 \\
\hline \multicolumn{5}{|c|}{ Urban } \\
\hline A woman can get pregnant at first sex & 27.3 & $49.8^{* * *}$ & 26.6 & $48.7^{* * *}$ \\
\hline $\begin{array}{l}\text { A woman is most likely to get pregnant if she has sex half-way } \\
\text { between her periods }\end{array}$ & 10.6 & $52.0^{* * *}$ & 16.4 & $43.2^{\star \star *}$ \\
\hline It is possible to do a medical test to know the sex of a foetus & 64.0 & $85.4^{* * *}$ & 83.9 & $92.1^{* * *}$ \\
\hline Respondent has correct knowledge of all of the above & 2.5 & $40.6^{* * *}$ & 7.4 & $37.2^{* \star *}$ \\
\hline Number of respondents & 327 & 369 & 513 & 538 \\
\hline \multicolumn{5}{|c|}{ Rural } \\
\hline A woman can get pregnant at first sex & 18.1 & $45.2^{* * *}$ & 22.1 & $43.8^{* *}$ \\
\hline $\begin{array}{l}\text { A woman is most likely to get pregnant if she has sex half-way } \\
\text { between her periods }\end{array}$ & 10.9 & $50.0^{* * *}$ & 13.1 & $34.7^{* * *}$ \\
\hline It is possible to do a medical test to know the sex of a foetus & 48.4 & $81.4^{* * *}$ & 63.5 & $80.4^{* * *}$ \\
\hline Respondent has correct knowledge of all of the above & 3.9 & $36.9^{* * *}$ & 4.4 & $25.1^{* *}$ \\
\hline Number of respondents & 447 & 376 & 974 & 626 \\
\hline
\end{tabular}

Note: All Ns are unweighted. ${ }^{* *}$ indicates that the difference between 2007 and 2012 is significant at $p \leq 0.001$.

Figure 8.1: Percentage of adolescents reporting awareness of selected sex- and pregnancy-related matters, Rajasthan, 2007 and 2012

Boys Girls

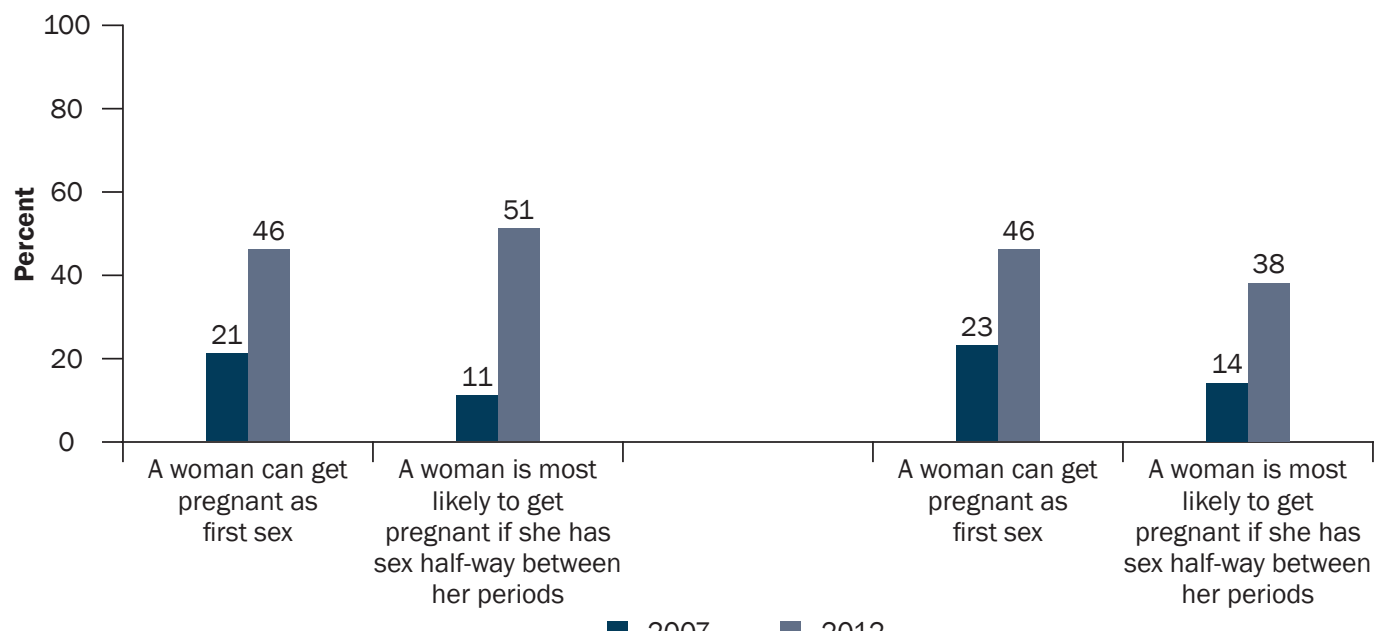




\subsubsection{Socio-demographic differentials in awareness of sex- and pregnancy-related matters}

Socio-demographic differentials in awareness in 2012, measured with respect to the percentage of surveyed adolescents aware of the three issues relating to sex and pregnancy discussed above, are presented in Table 8.2. Findings show that better educated and economically better off adolescents tended to report higher levels of awareness than others. For example, 51 percent of boys and 42 percent of girls with 12 or more years of education reported correct knowledge about all three matters, compared to seven percent among the least educated boys and eight percent among girls who had never been to school. Differences in awareness by age, religion, caste and work status were less consistent. For example, older girls, particularly those from rural areas, were more likely to report awareness than their younger counterparts, but differences were not observed among boys. More Muslim than

Table 8.2: Awareness of sex- and pregnancy-related matters by selected background characteristics

Percentage of adolescents who had correct knowledge of specific sex- and pregnancy-related matters by selected background characteristics, according to residence, Rajasthan, 2012

\begin{tabular}{|c|c|c|c|c|c|c|}
\hline \multirow[b]{2}{*}{ Background characteristics } & \multicolumn{2}{|c|}{ Combined } & \multicolumn{2}{|c|}{ Urban } & \multicolumn{2}{|c|}{ Rural } \\
\hline & Boys (\%) & Girls (\%) & Boys (\%) & Girls (\%) & Boys (\%) & Girls (\%) \\
\hline \multicolumn{7}{|l|}{ Age (years) } \\
\hline $15-17$ & 36.9 & 27.5 & 40.9 & 36.4 & 35.5 & 23.0 \\
\hline $18-19$ & 39.9 & 34.5 & 40.1 & 39.2 & 39.8 & 31.6 \\
\hline \multicolumn{7}{|l|}{ Religion } \\
\hline Hindu & 37.2 & 30.6 & 40.1 & 38.6 & 36.3 & 26.9 \\
\hline Muslim & 46.7 & 21.7 & 44.3 & 31.2 & \# & 10.1 \\
\hline Other ${ }^{1}$ & \# & $(28.8)$ & $\#$ & $\#$ & \# & $(22.2)$ \\
\hline \multicolumn{7}{|l|}{ Caste } \\
\hline SC & 32.3 & 28.8 & 24.0 & 31.0 & 35.2 & 27.8 \\
\hline ST & 30.3 & 25.4 & \# & (34.8) & 29.2 & 23.1 \\
\hline OBC & 42.9 & 28.5 & 47.7 & 40.6 & 41.6 & 22.3 \\
\hline General $^{2}$ & 40.6 & 33.1 & 44.4 & 35.9 & (34.5) & 30.8 \\
\hline \multicolumn{7}{|l|}{ Educational level (years) } \\
\hline None $^{3}$ & \# & 8.3 & \# & \# & \# & 8.0 \\
\hline $1-7$ & 7.4 & 17.3 & $(13.2)$ & 22.0 & 5.5 & 15.4 \\
\hline $8-9$ & 29.0 & 25.8 & 28.3 & 28.9 & 29.2 & 24.3 \\
\hline $10-11$ & 52.9 & 44.2 & 53.1 & 53.8 & 52.9 & 37.3 \\
\hline 12 and above & 51.3 & 42.0 & 53.9 & 42.3 & 50.0 & 41.7 \\
\hline \multicolumn{7}{|l|}{ Worked in last 12 months } \\
\hline Yes & 30.3 & 27.7 & 28.0 & 40.6 & 31.2 & 22.8 \\
\hline No & 40.4 & 29.7 & 44.8 & 36.4 & 38.7 & 25.9 \\
\hline \multicolumn{7}{|l|}{ Wealth quintile } \\
\hline First & 32.2 & 19.6 & \# & $(24.8)$ & 32.6 & 19.0 \\
\hline Second & 36.5 & 24.5 & $(21.3)$ & 26.1 & 38.5 & 24.0 \\
\hline Third & 38.1 & 27.4 & $(25.2)$ & 36.9 & 40.8 & 23.8 \\
\hline Fourth & 37.7 & 30.1 & 38.3 & 34.2 & 37.1 & 26.7 \\
\hline Fifth & 47.8 & 41.4 & 52.9 & 44.9 & $\#$ & 36.5 \\
\hline Total & 37.9 & 29.3 & 40.6 & 37.2 & 36.9 & 25.1 \\
\hline
\end{tabular}

Note: ( ) Based on 25-49 unweighted cases. \# Percentage not shown; based on fewer than 25 unweighted cases. OBC: Other backward caste. SC: Scheduled caste. ST: Scheduled tribe. ${ }^{1}$ Includes Christian, Buddhist, Neo-Buddhist, Sikh, Jain, Jewish, Parsi/ Zoroastrian, Sarana and no specified religion. ${ }^{2}$ Includes all those not belonging to SC, ST or OBC. ${ }^{3}$ Includes those who are nonliterate and literate with no formal schooling. 
Hindu boys reported awareness of all three issues (47\% versus 37\%), but fewer Muslim than Hindu girls so reported (22\% versus $31 \%$ ). Girls from general castes were somewhat more likely to report awareness of all three matters than were those from other castes; among boys, those from general and other backward castes were more likely than those from scheduled castes and tribes to so report. Finally, boys who were working for wages at the time of the interview were less likely to report awareness than those who were not working, perhaps because the latter were in school; no such difference was observed among girls. By and large, similar patterns were observed in rural and urban areas.

\subsubsection{Awareness of contraceptive methods}

Our study explored adolescents' awareness of contraceptive methods in several ways. First, surveyed adolescents were asked to list all the contraceptive methods about which they had heard, following which the interviewers gave them a brief description of a variety of non-terminal contraceptive methods not mentioned spontaneously, and inquired whether the respondent had heard of each; and second, further questioning probed for specific knowledge regarding the use of specific contraceptive methods. Table 8.3 presents percentages of adolescents reporting awareness-spontaneously or on prompting-of condoms, oral contraceptives, emergency contraceptive pills, the intrauterine contraceptive device (IUCD) and such traditional methods as withdrawal and periodic abstinence. Also presented are percentages of respondents reporting correct specific knowledge of the four modern methods mentioned above.

Panel A of Table 8.3 presents percentages of adolescents reporting awareness of selected contraceptive methods appropriate for young people. Findings show that in 2012, the vast majority of adolescents reported awareness (spontaneous or prompted) of at least one modern non-terminal contraceptive method. Awareness increased significantly over the inter-survey period among boys (from $89 \%$ in 2007 to $94 \%$ in 2012) but not for girls (79\% and

Table 8.3: Awareness of contraceptive methods

Percentage of adolescents who reported awareness and correct specific knowledge of various contraceptive methods, according to residence, Rajasthan, 2007 and 2012

\begin{tabular}{|c|c|c|c|c|}
\hline \multirow{2}{*}{$\begin{array}{l}\text { Awareness and correct knowledge of } \\
\text { contraceptive methods }\end{array}$} & \multicolumn{2}{|c|}{ Boys (\%) } & \multicolumn{2}{|c|}{ Girls (\%) } \\
\hline & 2007 & 2012 & 2007 & 2012 \\
\hline \multicolumn{5}{|c|}{ A. Awareness } \\
\hline \multicolumn{5}{|c|}{ Combined } \\
\hline Any modern non-terminal method ${ }^{1}$ & 88.8 & 93.5 & 78.8 & 80.8 \\
\hline Oral pills & 50.9 & $65.2^{* * *}$ & 74.6 & 74.3 \\
\hline Emergency contraceptive pills & 1.9 & $49.1^{* * *}$ & 3.6 & $39.8^{* * *}$ \\
\hline Condom & 88.4 & 92.2 & 64.9 & 64.4 \\
\hline IUCD & 19.3 & $60.0^{* * *}$ & 28.4 & $35.4^{* *}$ \\
\hline Any traditional method & 0.9 & $11.3^{* * *}$ & 1.4 & $9.8^{* * *}$ \\
\hline Number of respondents & 774 & 745 & 1,487 & 1,164 \\
\hline \multicolumn{5}{|c|}{ Urban } \\
\hline Any modern non-terminal method ${ }^{1}$ & 96.1 & 95.9 & 94.0 & 89.1 \\
\hline Oral pills & 65.1 & $74.2^{*}$ & 89.7 & $82.0^{* * *}$ \\
\hline Emergency contraceptive pills & 5.0 & $58.8^{* * *}$ & 9.3 & $56.3^{* * *}$ \\
\hline Condom & 96.1 & 95.4 & 86.3 & $74.7^{* * *}$ \\
\hline IUCD & 26.4 & $46.4^{* * *}$ & 42.0 & 45.9 \\
\hline Any traditional method & 1.6 & $13.5^{* * *}$ & 1.8 & $11.3^{* * *}$ \\
\hline Number of respondents & 327 & 369 & 513 & 538 \\
\hline
\end{tabular}


Table 8.3: (Cont'd)

\begin{tabular}{|c|c|c|c|c|}
\hline \multirow{2}{*}{$\begin{array}{l}\text { Awareness and correct knowledge of } \\
\text { contraceptive methods }\end{array}$} & \multicolumn{2}{|c|}{ Boys (\%) } & \multicolumn{2}{|c|}{ Girls (\%) } \\
\hline & 2007 & 2012 & 2007 & 2012 \\
\hline \multicolumn{5}{|c|}{ Rural } \\
\hline Any modern non-terminal method ${ }^{1}$ & 86.1 & $91.3^{*}$ & 73.3 & 76.4 \\
\hline Oral pills & 45.6 & $61.9^{* * *}$ & 69.2 & 70.2 \\
\hline Emergency contraceptive pills & 0.7 & $45.5^{\star * *}$ & 1.5 & $31.1^{* * *}$ \\
\hline Condom & 85.6 & 91.0 & 57.2 & 59.0 \\
\hline IUCD & 16.6 & $37.7^{* \star *}$ & 23.5 & $29.8^{*}$ \\
\hline Any traditional method & 0.7 & $10.5^{* * *}$ & 1.2 & $9.1^{* * *}$ \\
\hline Number of respondents & 447 & 376 & 974 & 626 \\
\hline
\end{tabular}

\begin{tabular}{|c|c|c|c|c|}
\hline \multicolumn{5}{|c|}{ B. Correct specific knowledge ${ }^{2}$} \\
\hline & Comb & & & \\
\hline At least one non-terminal method listed below & 74.6 & 79.4 & 36.3 & 35.1 \\
\hline Oral pills & 16.7 & $40.0^{* * *}$ & 30.1 & $25.9^{*}$ \\
\hline Emergency contraceptive pills & 0.6 & $41.6^{* * *}$ & 1.9 & $23.9^{* * *}$ \\
\hline Condom & 74.4 & 78.7 & 21.0 & $29.7^{* \star *}$ \\
\hline Number of respondents & 774 & 745 & 1,487 & 1,164 \\
\hline \multicolumn{5}{|c|}{ Urban } \\
\hline At least one non-terminal method listed below & 79.1 & 80.6 & 55.2 & $48.6^{*}$ \\
\hline Oral pills & 20.2 & $43.2^{* * *}$ & 47.3 & $35.5^{* * *}$ \\
\hline Emergency contraceptive pills & 1.0 & $49.4^{* * *}$ & 5.3 & $37.2^{* * *}$ \\
\hline Condom & 78.8 & 79.5 & 32.0 & $40.9^{* *}$ \\
\hline Number of respondents & 327 & 369 & 513 & 538 \\
\hline \multicolumn{5}{|c|}{ Rural } \\
\hline At least one non-terminal method listed below & 73.0 & 78.9 & 29.5 & 28.0 \\
\hline Oral pills & 15.4 & $38.8^{* * *}$ & 23.9 & 20.9 \\
\hline Emergency contraceptive pills & 0.5 & $38.8^{* * *}$ & 0.6 & $16.9^{* * *}$ \\
\hline Condom & 72.8 & 78.4 & 17.0 & $23.8^{* *}$ \\
\hline Number of respondents & 447 & 376 & 974 & 626 \\
\hline
\end{tabular}

Note: All Ns are unweighted. *, ${ }^{* *}$ and ${ }^{* * *}$ indicate that differences between 2007 and 2012 are significant at $p \leq 0.05, p \leq 0.01$ and $p \leq 0.001$, respectively. ${ }^{1}$ Includes oral pills, emergency contraceptive pills, condoms, IUCDs, implants, injectables and vaginal methods. ${ }^{2}$ Correct specific knowledge was assessed for oral pills, emergency contraceptive pills and condoms. The following questions were asked (correct answers in brackets)-Oral pills: How often should a woman take pills? [Daily/Weekly]; Emergency contraceptive pills: How soon after sexual intercourse should these pills be taken? [Within 72 hours]; Condoms: For how many acts of sexual intercourse can one condom be used? [One].

81\%, in 2007 and 2012, respectively). Rural-urban differences were apparent, with urban adolescents more likely to report awareness of any modern non-terminal method of contraception than were their rural counterparts.

In 2012, the most widely known non-terminal methods among surveyed adolescents were condoms and oral contraceptive pills. However, gender differences were wide, with more boys than girls reporting awareness of condoms (92\% versus 64\%) and IUCDs (60\% versus 35\%) in 2012, and fewer boys than girls aware of oral contraceptive pills (65\% versus $74 \%$ ). Fewer still were aware of emergency contraceptive pills (49\% of boys and $40 \%$ 
of girls) than other non-terminal methods. Compared to awareness of modern methods, awareness of traditional methods was reported by very few adolescents-just 10-11 percent of boys and girls.

Significant increases in awareness over time in several contraceptive methods were also observed. For example, awareness of emergency contraceptive pills increased significantly among both boys and girls, from 2-4 percent of adolescents in 2007 to 40-49 percent by 2012, reflecting perhaps the aggressive advertising of this method in the intervening period. Likewise, awareness of the IUCD increased from 19 percent and 28 percent among boys and girls, respectively, in 2007, to 60 percent and 35 percent, respectively, by 2012. Awareness of oral contraceptive pills increased among boys (51\% to $65 \%$ ) but remained unchanged among girls (74-75\%). Finally, while small, percentages reporting awareness of traditional methods increased considerably among both boys and girls (from $1 \%$ in 2007 to $10-11 \%$ in 2012 ).

Rural-urban differences were also apparent, with urban adolescents more likely than their rural counterparts to report awareness of most contraceptive methods, and increases over time were observed among adolescents from both rural and urban areas.

In order to assess the extent to which adolescents had correct specific knowledge of contraceptive methods, and had not just heard of various methods, the study inquired, among adolescents reporting awareness of the method, whether they were aware of the frequency with which oral contraceptives must be consumed (daily or weekly), the number of sex acts for which one condom could be used (one), and the number of hours following sex that emergency contraceptive pills could be consumed (within 72 hours). Panel B of Table 8.3 presents percentages of adolescents reporting correct specific knowledge of these three methods. Findings suggest that such in-depth awareness of even one method was not universal; just 79 percent of boys and far fewer girls-35 percent-reported correct specific knowledge of at least one of the three methods about which probing questions were asked. Among boys, four-fifths were aware in-depth about condoms, and two-fifths (40-42\%) about oral contraceptives and emergency contraceptives; moreover, while this knowledge had increased significantly since 2007 (from $17 \%$ to $40 \%$, and from $1 \%$ to $42 \%$, for oral and emergency contraceptive pills; respectively); in-depth awareness of condoms, had increased only mildly (from $74 \%$ to $79 \%$ ) (See also Figure 8.2 ).

Among girls too, correct specific knowledge of these contraceptive methods had increased significantly over time. Notably, far more girls in 2012 than in 2007 reported such in-depth awareness of emergency contraceptive pills (24\% versus $2 \%$ ) and condoms (30\% versus $21 \%$ ); however, somewhat fewer reported in-depth awareness of oral contraceptive pills in 2012 than in 2007 (26\% versus 30\%).

Differentials in correct specific knowledge of contraceptive methods by rural-urban residence were evident among girls but not among boys. Girls in urban areas were more likely than their rural counterparts to report correct specific knowledge of almost every method, both in 2012 and in 2007. Rural-urban differences were negligible, in contrast, at both times for boys.

Figure 8.2: Percentage of adolescents who reported correct specific knowledge of oral pills, emergency contraceptive pills and condoms, Rajasthan, 2007 and 2012

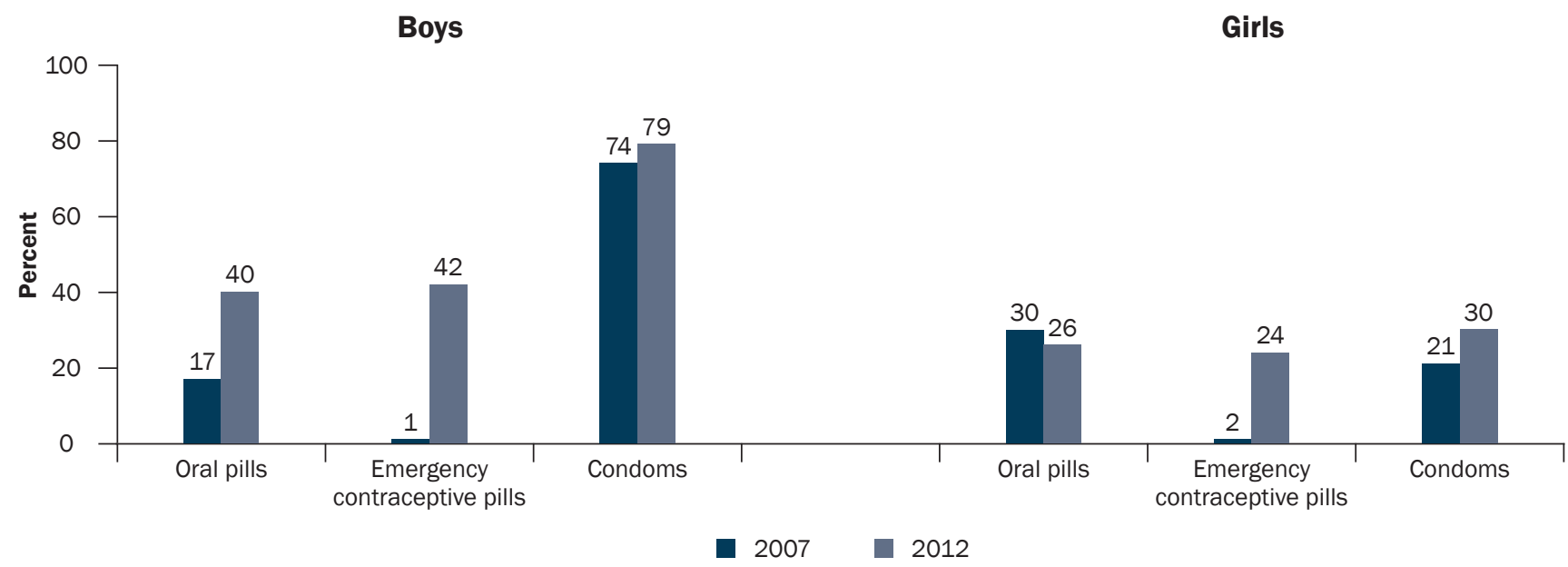




\subsubsection{Condom-related perceptions}

Among adolescents who reported awareness of condoms, the 2012 study probed perceptions regarding two specific aspects of this method, namely, whether condoms can slip off a man and disappear inside a woman's body and whether condoms reduce sexual pleasure. Findings, presented in Table 8.4, show that in 2012, just 44 percent of boys and 23 percent of girls were aware that condoms cannot disappear inside a woman's body; considerably more than corresponding percentages in 2007 (22\% and 15\%, respectively). Fewer-just 21 percent and 14 percent of boys and girls, respectively, felt that condoms do not reduce sexual pleasure, almost identical to percentages observed in 2007 (22 and 14, respectively). Notably, even in 2012, 50-60 percent of boys and 69-76 percent of girls reported that they were unsure about these issues. Rural-urban differences were negligible.

Table 8.4: Perceptions of selected issues related to condom use

Percent distribution of adolescents by their perceptions of condom use, according to residence, Rajasthan, 2007 and 2012

\begin{tabular}{|c|c|c|c|c|}
\hline \multirow[b]{2}{*}{ Perceptions of condom use } & \multicolumn{2}{|c|}{ Boys (\%) } & \multicolumn{2}{|c|}{ Girls (\%) } \\
\hline & 2007 & 2012 & 2007 & 2012 \\
\hline \multicolumn{5}{|c|}{ Combined } \\
\hline \multicolumn{5}{|l|}{ Condoms reduce sexual pleasure } \\
\hline Agree & 5.4 & 19.6 & 1.3 & 10.4 \\
\hline Disagree & 22.2 & 20.9 & 14.3 & 14.0 \\
\hline Don't know/ Can't say & 72.4 & 59.5 & 84.1 & 75.6 \\
\hline Significance level & \multicolumn{2}{|c|}{ *** } & \multicolumn{2}{|c|}{$* * *$} \\
\hline \multicolumn{5}{|c|}{ Condoms can slip off a man and disappear inside a woman's body } \\
\hline Agree & 1.0 & 6.1 & 1.1 & 7.4 \\
\hline Disagree & 21.5 & 43.5 & 14.6 & 23.2 \\
\hline Don't know/ Can't say & 77.5 & 50.4 & 84.0 & 69.4 \\
\hline Significance level & \multicolumn{2}{|c|}{$* * *$} & \multicolumn{2}{|c|}{ *** } \\
\hline Number of respondents aware of condoms & 697 & 691 & 1,001 & 744 \\
\hline \multicolumn{5}{|c|}{ Urban } \\
\hline \multicolumn{5}{|l|}{ Condoms reduce sexual pleasure } \\
\hline Agree & 6.6 & 13.8 & 0.2 & 11.0 \\
\hline Disagree & 23.6 & 22.6 & 15.0 & 10.2 \\
\hline Don't know/ Can't say & 69.8 & 63.7 & 84.8 & 78.8 \\
\hline Significance level & \multicolumn{2}{|c|}{ * } & \multicolumn{2}{|c|}{ *** } \\
\hline \multicolumn{5}{|c|}{ Condoms can slip off a man and disappear inside a woman's body } \\
\hline Agree & 1.6 & 4.6 & 1.2 & 7.3 \\
\hline Disagree & 21.5 & 42.9 & 12.9 & 21.9 \\
\hline Don't know/ Can't say & 76.9 & 52.5 & 85.9 & 70.8 \\
\hline Significance level & \multicolumn{2}{|c|}{$* * *$} & \multicolumn{2}{|c|}{ *** } \\
\hline Number of respondents aware of condoms & 314 & 352 & 442 & 393 \\
\hline
\end{tabular}


Table 8.4: (Cont'd)

\begin{tabular}{|c|c|c|c|c|}
\hline \multirow[b]{2}{*}{ Perceptions of condom use } & \multicolumn{2}{|c|}{ Boys (\%) } & \multicolumn{2}{|c|}{ Girls (\%) } \\
\hline & 2007 & 2012 & 2007 & 2012 \\
\hline \multicolumn{5}{|c|}{ Rural } \\
\hline \multicolumn{5}{|l|}{ Condoms reduce sexual pleasure } \\
\hline Agree & 4.9 & 21.8 & 1.9 & 10.0 \\
\hline Disagree & 21.7 & 20.3 & 14.0 & 16.7 \\
\hline Don't know/ Can't say & 73.4 & 57.9 & 83.8 & 73.4 \\
\hline Significance level & \multicolumn{2}{|c|}{$* * *$} & \multicolumn{2}{|c|}{$* * *$} \\
\hline \multicolumn{5}{|c|}{ Condoms can slip off a man and disappear inside a woman's body } \\
\hline Agree & 0.8 & 6.7 & 1.1 & 7.4 \\
\hline Disagree & 21.5 & 43.8 & 15.6 & 24.1 \\
\hline Don't know/ Can’t say & 77.8 & 49.6 & 83.0 & 68.5 \\
\hline Significance level & \multicolumn{2}{|c|}{$* * *$} & \multicolumn{2}{|c|}{$* * *$} \\
\hline Number of respondents aware of condoms & 383 & 339 & 559 & 351 \\
\hline
\end{tabular}

Note: All Ns are unweighted. * and ${ }^{* * *}$ indicate that differences between 2007 and 2012 are significant at $p \leq 0.05$ and $p \leq 0.001$, respectively. Column totals may not equal $100 \%$ due to missing cases.

\subsubsection{Awareness of sexually transmitted infections (STIs) and HIV/AIDS}

The study inquired whether adolescents had ever heard of infections that were transmitted through sexual contact. Findings, presented in Table 8.5, suggest that surveyed adolescents had limited awareness of STIs other than HIV/ AIDS. Indeed, in 2012, just 30 percent of boys and 15 percent of girls had heard about such STIs. Awareness of STIs had increased significantly among boys between 2007 and 2012 (from 7\% to 30\%) but remained virtually unchanged among girls (15-17\%). Differences by rural-urban residence were evident, with more urban than rural adolescents having heard about STIs (36\% versus $27 \%$ among boys; $20 \%$ versus $12 \%$ among girls). Even these percentages obscure major limitations in understanding: indeed, a look at the percentages of adolescents who were aware of STIs and could name at least one symptom of infection, suggests overall, an extremely limited in-depth awareness: in 2012, just 22 percent of boys and five percent of girls had both heard of STIs and could name at least one symptom of infection, suggesting an increase overall in the percentage of boys who could identify at least one symptom of infection (from $7 \%$ in 2007), but a decline, correspondingly among girls (from 11\% in 2007).

Questions exploring young people's awareness of HIV/AIDS were adapted from those used in the NFHS (International Institute for Population Sciences and Macro International, 2007b). Findings, presented in Table 8.5, show that in 2012, 88 percent of surveyed boys compared to 62 percent of surveyed girls had heard of HIV/AIDS. Gender differences were apparent in both urban and rural areas, and urban respondents were considerably more likely than their rural counterparts to report awareness of HIV/AIDS (94\% versus $85 \%$ among boys, and $79 \%$ versus $53 \%$ among girls). As far as changes over the two cohorts are concerned, awareness levels among boys remained similar at both times, and in both urban and rural areas (85-88\% for all boys, and 94-97\% and 80-85\% among those in urban and rural areas, respectively). Among girls, there appears to have been a slight decline in percentages who had ever heard of HIV/AIDS during the five-year period: from 66 percent to 62 percent for all girls, from 58 percent to 53 percent among rural girls, and from 87 percent to significantly fewer (79\%) among those in urban areas.

Among adolescents who reported awareness of HIV/AIDS, knowledge of specific aspects of the disease was by no means complete. Among boys, awareness levels had increased significantly on four of six matters concerning HIV/AIDS (for example, between 2007 and 2012, percentages aware that one can reduce the chances of contracting HIV by staying faithful to a single partner increased from 84 to 93, and by consistent use of condoms, from 80 to 91) (Table 8.5). Among girls, there was a significant increase in awareness levels of all six matters over the five-year period: the importance of being faithful to a single partner (from $72 \%$ to $81 \%$ ), the importance of consistent condom 
Table 8.5: Awareness of STIs and HIV/AIDS

Percentage of adolescents who had heard of and had specific knowledge about STIs and HIV/AIDS, according to residence, Rajasthan, 2007 and 2012

\begin{tabular}{|c|c|c|c|c|}
\hline \multirow[b]{2}{*}{ Awareness of STIs and HIV/AIDS } & \multicolumn{2}{|c|}{ Boys (\%) } & \multicolumn{2}{|c|}{ Girls (\%) } \\
\hline & 2007 & 2012 & 2007 & 2012 \\
\hline \multicolumn{5}{|c|}{ Combined } \\
\hline Heard about STIs ${ }^{1}$ & 7.4 & $29.6^{* * *}$ & 16.8 & 14.7 \\
\hline Had heard of and could identify at least one symptom of STIs & 7.3 & $21.6^{* * *}$ & 10.8 & $5.0^{* * *}$ \\
\hline Heard about HIV/AIDS & 84.7 & 87.5 & 65.8 & 61.7 \\
\hline Number of respondents & 774 & 745 & 1,487 & 1,164 \\
\hline \multicolumn{5}{|l|}{$\begin{array}{l}\text { Of respondents who had heard about HIV/AIDS, those } \\
\text { reporting that: }\end{array}$} \\
\hline $\begin{array}{l}\text { One can reduce one's chances of getting HIV infection by } \\
\text { having a single sexual partner }\end{array}$ & 83.6 & $92.9^{* * *}$ & 72.1 & $81.4^{* \star}$ \\
\hline $\begin{array}{l}\text { One can reduce one's chances of getting HIV infection by } \\
\text { consistent use of condoms }\end{array}$ & 80.0 & $91.2^{* * *}$ & 55.9 & $76.7^{* * *}$ \\
\hline One cannot get HIV through mosquito bites & 80.1 & $90.2^{* * *}$ & 61.3 & $86.5^{* * *}$ \\
\hline $\begin{array}{l}\text { One cannot get HIV by sharing food with an HIV-positive } \\
\text { person }\end{array}$ & 86.6 & 87.5 & 76.3 & $85.9^{* * *}$ \\
\hline One cannot get HIV by hugging an HIV-positive person & 83.5 & 88.5 & 77.3 & $88.1^{* * *}$ \\
\hline $\begin{array}{l}\text { One cannot tell if a person is HIV-positive by just looking at } \\
\text { him/her }\end{array}$ & 87.2 & $95.5^{* * *}$ & 86.5 & $98.0^{* * *}$ \\
\hline Number of respondents who had heard about HIV/AIDS & 676 & 663 & 1,013 & 745 \\
\hline Comprehensive knowledge of HIV/AIDS & 46.4 & $70.0^{* * *}$ & 21.0 & $44.8^{* * *}$ \\
\hline Number of respondents & 774 & 745 & 1,487 & 1,164 \\
\hline \multicolumn{5}{|c|}{ Urban } \\
\hline Heard about STIs ${ }^{1}$ & 11.6 & $35.9^{* * *}$ & 21.3 & 19.7 \\
\hline Had heard of and could identify at least one symptom of STIS & 11.3 & $22.6^{* * *}$ & 13.0 & $6.1^{* *}$ \\
\hline Heard about HIV/AIDS & 96.6 & 93.5 & 86.6 & $78.6^{* *}$ \\
\hline Number of respondents & 327 & 369 & 513 & 538 \\
\hline \multicolumn{5}{|l|}{$\begin{array}{l}\text { Of respondents who had heard about HIV/AIDS, those } \\
\text { reporting that: }\end{array}$} \\
\hline $\begin{array}{l}\text { One can reduce one's chances of getting HIV infection by } \\
\text { having a single sexual partner }\end{array}$ & 84.9 & $93.7^{* *}$ & 78.0 & 83.9 \\
\hline $\begin{array}{l}\text { One can reduce one's chances of getting HIV infection by } \\
\text { consistent use of condoms }\end{array}$ & 83.3 & $91.9^{* *}$ & 61.3 & $80.4^{* * *}$ \\
\hline One cannot get HIV through mosquito bites & 84.0 & $91.7^{*}$ & 72.4 & $89.7^{* * *}$ \\
\hline $\begin{array}{l}\text { One cannot get HIV by sharing food with an HIV-positive } \\
\text { person }\end{array}$ & 88.4 & 92.9 & 87.4 & 90.7 \\
\hline One cannot get HIV by hugging an HIV-positive person & 86.2 & $92.8^{*}$ & 86.0 & 91.2 \\
\hline $\begin{array}{l}\text { One cannot tell if a person is HIV-positive by just looking at } \\
\text { him/her }\end{array}$ & 91.8 & $97.0^{*}$ & 87.3 & $98.9^{* * *}$ \\
\hline Number of respondents who had heard about HIV/AIDS & 316 & 345 & 444 & 417 \\
\hline Comprehensive knowledge of HIV/AIDS & 59.2 & $76.7^{* * *}$ & 36.3 & $59.5^{* * *}$ \\
\hline Number of respondents & 327 & 369 & 513 & 538 \\
\hline
\end{tabular}


Table 8.5: (Cont'd)

\begin{tabular}{|c|c|c|c|c|}
\hline \multirow[b]{2}{*}{ Awareness of STIs and HIV/AIDS } & \multicolumn{2}{|c|}{ Boys (\%) } & \multicolumn{2}{|c|}{ Girls (\%) } \\
\hline & 2007 & 2012 & 2007 & 2012 \\
\hline \multicolumn{5}{|c|}{ Rural } \\
\hline Heard about STIs ${ }^{1}$ & 5.9 & $27.3^{* \star *}$ & 15.2 & 12.1 \\
\hline Had heard of and could identify at least one symptom of STIs & 5.9 & $21.3^{* * *}$ & 10.0 & $4.4^{* * *}$ \\
\hline Heard about HIV/AIDS & 80.3 & 85.3 & 58.4 & 52.8 \\
\hline Number of respondents & 447 & 376 & 974 & 626 \\
\hline \multicolumn{5}{|l|}{$\begin{array}{l}\text { Of respondents who had heard about HIV/AIDS, those } \\
\text { reporting that: }\end{array}$} \\
\hline $\begin{array}{l}\text { One can reduce one's chances of getting HIV infection by } \\
\text { having a single sexual partner }\end{array}$ & 83.0 & $92.6^{* *}$ & 69.0 & $79.5^{*}$ \\
\hline $\begin{array}{l}\text { One can reduce one's chances of getting HIV infection by } \\
\text { consistent use of condoms }\end{array}$ & 78.5 & $90.9^{* *}$ & 53.1 & $73.8^{* * *}$ \\
\hline One cannot get HIV through mosquito bites & 78.4 & $89.6^{* *}$ & 55.4 & $83.9^{* * *}$ \\
\hline $\begin{array}{l}\text { One cannot get HIV by sharing food with an HIV-positive } \\
\text { person }\end{array}$ & 85.8 & 85.4 & 70.4 & $82.2^{* * *}$ \\
\hline One cannot get HIV by hugging an HIV-positive person & 82.4 & 86.8 & 72.8 & $85.6^{* * *}$ \\
\hline $\begin{array}{l}\text { One cannot tell if a person is HIV-positive by just looking at } \\
\mathrm{him} / \mathrm{her}\end{array}$ & 85.2 & $94.9^{* * *}$ & 86.0 & $97.2^{* * *}$ \\
\hline Number of respondents who had heard about HIV/AIDS & 360 & 318 & 569 & 328 \\
\hline Comprehensive knowledge of HIV/AIDS & 41.7 & $67.5^{* * *}$ & 15.5 & $37.0^{* * *}$ \\
\hline Number of respondents & 447 & 376 & 974 & 626 \\
\hline
\end{tabular}

Note: All Ns are unweighted. ${ }^{*},{ }^{* *}$ and ${ }^{* * *}$ indicate that differences between 2007 and 2012 are significant at $p \leq 0.05, p \leq 0.01$ and $p \leq 0.001$, respectively. ${ }^{1}$ Other than HIV.

use (from $56 \%$ to $77 \%$ ), that one cannot get AIDS by sharing food with an infected person (from $76 \%$ to $86 \%$ ), that one cannot get AIDS from mosquito bites (from $61 \%$ to $87 \%$ ), that one cannot get AIDS by hugging an HIV-positive person (from $73 \%$ to $86 \%$ ) and that one cannot tell if a person is HIV-positive by just looking at the person (from $87 \%$ to $98 \%$ ). Rural-urban differences were typically narrow for boys, but among girls, more of those from urban than rural areas reported awareness of each matter.

Comprehensive knowledge of HIV/AIDS was defined as knowledge of two ways of preventing HIV infection (specifically, condom use and single partner relations), rejection of common misconceptions about HIV transmission (namely, that HIV can be transmitted through mosquito bites, or sharing food or hugging an infected person) and awareness that one cannot tell by looking at a person whether he or she has HIV. Findings, presented in Table 8.5, confirm that comprehensive knowledge levels of HIV had indeed increased significantly over time, from 46 percent to 70 percent among boys, and from 21 percent to 45 percent among girls. Even so, comprehensive knowledge levels of HIV/AIDS among girls in 2012 had reached those achieved by boys five years earlier, highlighting wide gender differences in HIV/AIDS awareness.

Rural-urban differences were observed, with urban adolescents more likely to report comprehensive HIV/AIDS knowledge than rural adolescents ( $77 \%$ and $60 \%$ of boys and girls, respectively, in urban settings, compared to $68 \%$ and $37 \%$, respectively, in rural settings). Notably, significant increases in comprehensive HIV/AIDS knowledge levels were observed over time in both urban and rural areas.

Table 8.6 presents levels of comprehensive knowledge of HIV/AIDS by background characteristics of adolescents in 2012. Findings suggest that comprehensive knowledge of HIV/AIDS was consistently greater among older, better educated and economically better off adolescents than others. For example, 91 percent of boys and 85 percent of girls who had completed Class 12 had comprehensive HIV/AIDS knowledge compared to just 19 percent and 
Table 8.6: Comprehensive knowledge of HIV/AIDS by selected background characteristics

Percentage of adolescents who had comprehensive knowledge of HIV/AIDS by selected background characteristics, according to residence, Rajasthan, 2012

\begin{tabular}{|c|c|c|c|c|c|c|}
\hline \multirow[b]{2}{*}{ Background characteristics } & \multicolumn{2}{|c|}{ Combined } & \multicolumn{2}{|c|}{ Urban } & \multicolumn{2}{|c|}{ Rural } \\
\hline & Boys (\%) & Girls (\%) & Boys (\%) & Girls (\%) & Boys (\%) & Girls (\%) \\
\hline \multicolumn{7}{|l|}{ Age (years) } \\
\hline $15-17$ & 70.7 & 40.3 & 74.1 & 55.5 & 69.6 & 32.7 \\
\hline $18-19$ & 68.4 & 57.8 & 81.6 & 69.8 & 63.1 & 50.6 \\
\hline \multicolumn{7}{|l|}{ Religion } \\
\hline Hindu & 69.6 & 45.8 & 76.7 & 64.8 & 67.4 & 37.2 \\
\hline Muslim & 72.7 & 31.6 & 76.5 & 37.2 & $\#$ & 24.8 \\
\hline Other ${ }^{1}$ & $\#$ & $(66.4)$ & $\#$ & $\#$ & $\#$ & $(59.3)$ \\
\hline \multicolumn{7}{|l|}{ Caste } \\
\hline SC & 59.7 & 43.4 & 58.8 & 57.4 & 60.0 & 37.2 \\
\hline ST & 56.2 & 22.1 & $\#$ & $(49.2)$ & 54.7 & 15.5 \\
\hline $\mathrm{OBC}$ & 78.7 & 42.6 & 86.0 & 57.4 & 76.7 & 35.0 \\
\hline General $^{2}$ & 75.0 & 60.5 & 80.1 & 65.4 & $(66.9)$ & 56.4 \\
\hline \multicolumn{7}{|l|}{ Educational level (years) } \\
\hline None $^{3}$ & $\#$ & 0.9 & $\#$ & $\#$ & $\#$ & 1.0 \\
\hline $1-7$ & 18.6 & 7.8 & $(31.4)$ & 5.7 & 14.3 & 8.6 \\
\hline $8-9$ & 63.8 & 39.2 & 70.5 & 53.0 & 62.0 & 32.9 \\
\hline $10-11$ & 88.7 & 75.8 & 89.7 & 82.8 & 88.2 & 70.7 \\
\hline 12 and above & 90.9 & 85.2 & 96.3 & 89.0 & 88.3 & 81.5 \\
\hline \multicolumn{7}{|l|}{ Worked in last 12 months } \\
\hline Yes & 50.3 & 33.8 & 56.7 & 46.2 & 47.9 & 29.1 \\
\hline No & 76.4 & 48.1 & 83.3 & 62.4 & 73.9 & 39.7 \\
\hline \multicolumn{7}{|l|}{ Wealth quintile } \\
\hline First & 58.1 & 16.6 & $\#$ & $(14.3)$ & 59.1 & 16.9 \\
\hline Second & 63.6 & 32.6 & $(55.1)$ & 40.9 & 64.7 & 29.7 \\
\hline Third & 72.2 & 42.4 & $(70.6)$ & 47.6 & 72.5 & 40.4 \\
\hline Fourth & 77.1 & 55.5 & 76.6 & 62.1 & 77.5 & 50.3 \\
\hline Fifth & 84.1 & 69.0 & 86.7 & 75.3 & $\#$ & 60.3 \\
\hline Total & 70.0 & 44.8 & 76.7 & 59.5 & 67.5 & 37.0 \\
\hline
\end{tabular}

Note: ( ) Based on 25-49 unweighted cases. \# Percentage not shown; based on fewer than 25 unweighted cases. OBC: Other backward caste. SC: Scheduled caste. ST: Scheduled tribe. ${ }^{1}$ Includes Christian, Buddhist, Neo-Buddhist, Sikh, Jain, Jewish, Parsi/ Zoroastrian, Sarana and no specified religion. ${ }^{2}$ Includes all those not belonging to SC, ST or OBC. ${ }^{3}$ Includes those who are nonliterate and literate with no formal schooling.

eight percent of boys and girls, respectively, with 1-7 years of education. Comprehensive knowledge of HIV/AIDS increased from 58 percent among boys in the poorest (first) wealth quintile to 84 percent among those in the wealthiest (fifth) quintile, and from 17 percent to 69 percent, respectively, among girls. It was also consistently greater among non-working than working adolescents ( $76 \%$ versus $48 \%$ among boys, and $48 \%$ versus $34 \%$ among girls) perhaps because many of those who were not working were in school or college and, therefore, more likely to be exposed to HIV-related information. Differentials by religion were negligible among boys; comprehensive knowledge of HIV/AIDS was lower, however, among Muslim than Hindu girls, particularly those in urban areas. Caste-wise differences suggest that among boys, those belonging to general and other backward castes were more 
likely than those from scheduled castes and tribes to report comprehensive HIV/AIDS knowledge (75-79\% versus 56-60\%). Among girls, those from general castes were most likely (61\%) and those from scheduled tribes least likely (22\%) to so report. Differences in comprehensive HIV/AIDS knowledge by age group were negligible for boys (68-71\%), but older girls were more likely to report awareness than their younger counterparts (58\% versus $40 \%$ ). Socio-demographic differences among rural and urban adolescents more or less mirrored the patterns observed for the combined sample.

A comparison of awareness and comprehensive knowledge of HIV/AIDS and of other STIs, presented in Figure 8.4, shows that awareness of STIs other than HIV among adolescents was far more limited than awareness of HIV/AIDS.

Figure 8.3: Percentage of adolescents by awareness of HIV/AIDS, comprehensive knowledge about HIV/AIDS and awareness of STIs, Rajasthan, 2012

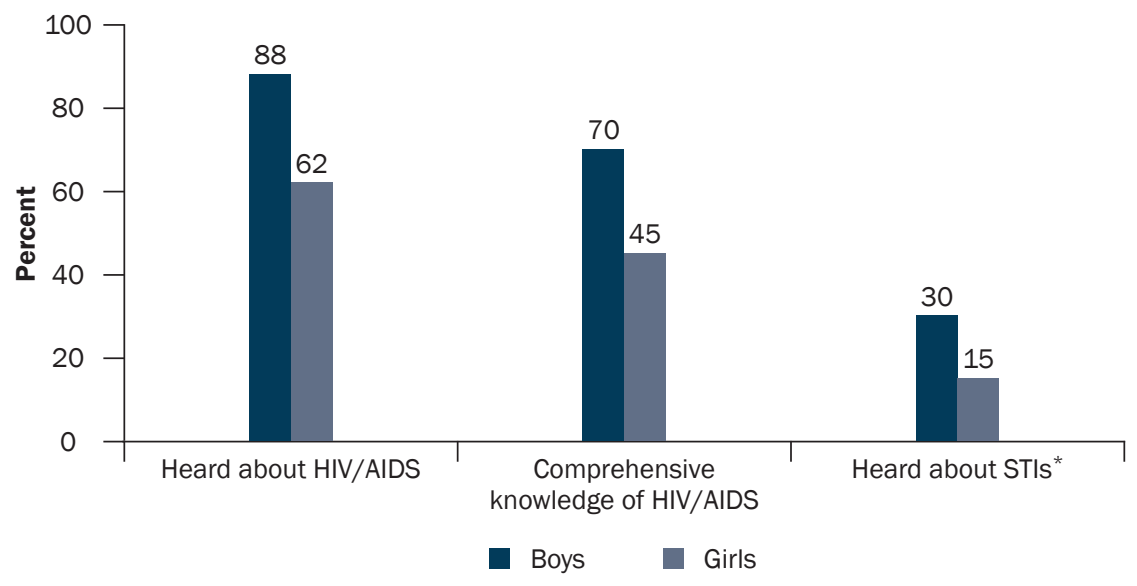

Note: *Other than HIV.

\subsection{Knowledge of legal issues related to marriage and abortion}

The study collected information on whether adolescents were aware of the existence of laws relating to the legal minimum age at marriage for males and females in India and probed specific knowledge of these laws. Findings are presented in Table 8.7 and suggest that even in 2012, awareness of the correct legal minimum age at marriage for females, and especially for males, was not universally known. Awareness had, however, increased significantly, among adolescents during the five-year, inter-survey period. For example, in 2012, 90-93 percent of boys and 78-85 percent of girls were aware that 21 and 18 are the respective legal minimum ages at marriage for boys and girls in India, compared to 81-86 percent and 65-76 percent, respectively, in 2007. Similarly, significant increases were observed in the case of rural adolescents, but not among their urban counterparts.

Rural-urban differences were mild among boys, with rural boys about as likely to report awareness as their urban counterparts (92-94\% versus 86-92\%), but among girls, those in urban areas were better informed about the correct legal minimum age at marriage than were those in rural areas ( $85 \%$ versus $74 \%$, respectively, reported the correct legal minimum age at marriage for boys; $91 \%$ versus $81 \%$, reported the correct legal minimum age at marriage for girls).

The present study also sought to understand adolescents' awareness of the legal situation with regard to sex selection. In order to gauge their awareness, we asked whether it is legal for a woman to terminate her pregnancy if the foetus is female but the couple wants a son. Findings are presented in Table 8.7.

Far more boys than girls reported awareness that sex-selective abortion is illegal, and the change over time was significant among both boys and girls. For example, in 2012, 90 percent of boys were aware that sex-selective abortion is illegal; this compared with 44 percent in 2007. Among girls, in contrast, 72 percent were aware that sexselective abortion is illegal, up from 65 percent in 2007. Significant changes over time were observed among urban and rural adolescents as well. 
Table 8.7: Knowledge of legal issues concerning age at marriage and sex selection

Percentage of adolescents who had correct knowledge of the legal minimum age at marriage in India and legality of sex-selective abortion, according to residence, Rajasthan, 2007 and 2012

\begin{tabular}{|c|c|c|c|c|}
\hline \multirow{2}{*}{$\begin{array}{l}\text { Knowledge of specific legal issues about marriage and } \\
\text { abortion }\end{array}$} & \multicolumn{2}{|c|}{ Boys (\%) } & \multicolumn{2}{|c|}{ Girls (\%) } \\
\hline & 2007 & 2012 & 2007 & 2012 \\
\hline \multicolumn{5}{|c|}{ Combined } \\
\hline \multicolumn{5}{|l|}{ Aware of correct legal age at marriage for: } \\
\hline Boys & 80.8 & $90.2^{* * *}$ & 65.4 & $77.9^{* * *}$ \\
\hline Girls & 86.2 & $93.4^{* *}$ & 75.9 & $84.5^{* * *}$ \\
\hline Know that it is illegal for couples to have sex-selective abortion & 44.1 & $89.5^{* * *}$ & 64.6 & $71.5^{* \star *}$ \\
\hline Number of respondents & 774 & 745 & 1,487 & 1,164 \\
\hline \multicolumn{5}{|c|}{ Urban } \\
\hline \multicolumn{5}{|l|}{ Aware of correct legal age at marriage for: } \\
\hline Boys & 85.8 & 85.9 & 80.2 & $85.1^{*}$ \\
\hline Girls & 90.6 & 92.1 & 88.6 & 91.3 \\
\hline Know that it is illegal for couples to have sex-selective abortion & 45.5 & $92.0^{* * *}$ & 72.7 & $83.3^{* * *}$ \\
\hline Number of respondents & 327 & 369 & 513 & 538 \\
\hline \multicolumn{5}{|c|}{ Rural } \\
\hline \multicolumn{5}{|l|}{ Aware of correct legal age at marriage for: } \\
\hline Boys & 78.9 & $91.8^{* \star *}$ & 60.1 & $74.2^{* * *}$ \\
\hline Girls & 84.6 & $93.8^{* *}$ & 71.3 & $81.0^{* * *}$ \\
\hline Know that it is illegal for couples to have sex-selective abortion & 43.6 & $88.6^{* * *}$ & 61.6 & $65.3^{* *}$ \\
\hline Number of respondents & 447 & 376 & 974 & 626 \\
\hline
\end{tabular}

Rural-urban differences were narrow among boys at both times-44-46 percent in 2007 and 89-92 percent in 2012. Among girls, however, rural-urban differences were evident and became wider over time. Whereas in 2007 , 73 percent of urban girls and 62 percent of rural girls were aware that sex-selective abortion is illegal, by 2012, differences had widened to 83 percent and 65 percent, respectively.

\subsection{Sources of information on sex and reproduction}

This study further questioned the respondents about their sources of information on sexual matters. Findings, presented in Table 8.8, suggest that almost all the boys and girls had received information on sex and reproduction from some source or the other. Indeed, unlike in 2007, when one-third of surveyed boys and three-fifths of surveyed girls had reported that they had never received any information on sexual matters, by 2012, 95 percent of both had received such information from one or more sources. Differences by rural-urban residence were negligible. Much of this increase may be attributed to the greater openness among the young about discussing these matters, the longer duration of schooling for them and the greater likelihood of school-and college-based sexuality education programmes; however, the possibility that some of this reported increase in the span of five years may have been the result of differences in interviewing techniques must be acknowledged. 
Table 8.8: Sources of information on sexual matters

Percentage of adolescents by sources of information on sexual matters, according to residence, Rajasthan, 2007 and 2012

\begin{tabular}{|c|c|c|c|c|}
\hline \multirow{2}{*}{$\begin{array}{l}\text { Source of information on sexual } \\
\text { matters }\end{array}$} & \multicolumn{2}{|c|}{ Boys (\%) } & \multicolumn{2}{|c|}{ Girls (\%) } \\
\hline & 2007 & 2012 & 2007 & 2012 \\
\hline \multicolumn{5}{|c|}{ Combined } \\
\hline Never received any information & 34.2 & $4.6^{* * *}$ & 60.1 & $4.8^{* * *}$ \\
\hline A family member & 0.7 & 0.8 & 4.3 & $49.8^{* * *}$ \\
\hline Partner & 0.0 & 0.0 & 0.0 & 0.2 \\
\hline Friend/Neighbour & 36.7 & $82.2^{* * *}$ & 7.4 & $54.0^{* * *}$ \\
\hline Teacher/School & 3.0 & $59.1^{* *}$ & 4.7 & $48.4^{* * *}$ \\
\hline Health care provider & 0.9 & 4.7 & 0.4 & 1.2 \\
\hline Mass media ${ }^{1}$ & 21.0 & $55.9^{* * \star}$ & 8.3 & $61.7^{* * *}$ \\
\hline Youth/Mahila mandal/NGO worker & 0.2 & 0.3 & 0.2 & 0.3 \\
\hline Poster/Billboard & 1.5 & $7.6^{* * *}$ & 0.4 & $4.2^{* * *}$ \\
\hline Other ${ }^{2}$ & 0.0 & $0.8^{*}$ & 0.0 & $2.2^{* * *}$ \\
\hline Don't remember & 15.1 & $0.0^{* * *}$ & 19.6 & $0.4^{* * *}$ \\
\hline Number of respondents & 774 & 745 & 1,487 & 1,164 \\
\hline \multicolumn{5}{|c|}{ Urban } \\
\hline Never received any information & 24.0 & $4.1^{* * *}$ & 62.6 & $2.5^{* * *}$ \\
\hline A family member & 0.0 & $2.3^{* *}$ & 5.2 & $49.7^{* * *}$ \\
\hline Partner & 0.0 & 0.0 & 0.0 & 0.0 \\
\hline Friend/Neighbour & 40.3 & $78.5^{* * *}$ & 5.2 & $49.5^{* * *}$ \\
\hline Teacher/School & 3.3 & $63.9^{* * *}$ & 5.7 & $63.1^{* * *}$ \\
\hline Health care provider & 0.9 & 2.7 & 0.2 & 1.3 \\
\hline Mass media ${ }^{1}$ & 37.0 & $70.5^{* * *}$ & 11.5 & $80.6^{* * *}$ \\
\hline Youth/Mahila mandal/NGO worker & 0.0 & 0.5 & 0.4 & 0.5 \\
\hline Poster/Billboard & 3.2 & $11.0^{* * *}$ & 0.6 & $5.1^{* *}$ \\
\hline Other ${ }^{2}$ & 0.0 & 0.6 & 0.0 & $2.1^{* *}$ \\
\hline Don't remember & 11.5 & $0.0^{* * *}$ & 16.0 & $0.0^{* * *}$ \\
\hline Number of respondents & 327 & 369 & 513 & 538 \\
\hline \multicolumn{5}{|c|}{ Rural } \\
\hline Never received any information & 38.0 & $4.8^{* * *}$ & 59.2 & $6.0^{* * *}$ \\
\hline A family member & 1.0 & 0.3 & 4.0 & $49.8^{* * *}$ \\
\hline Partner & 0.0 & 0.0 & 0.0 & 0.3 \\
\hline Friend/Neighbour & 35.4 & $83.6^{* * *}$ & 8.2 & $56.3^{* * *}$ \\
\hline Teacher/School & 2.9 & $57.3^{* * *}$ & 4.3 & $40.6^{* * *}$ \\
\hline Health care provider & 0.9 & $5.5^{* *}$ & 0.4 & 1.1 \\
\hline Mass media ${ }^{1}$ & 15.1 & $50.5^{* * *}$ & 7.1 & $51.8^{* * *}$ \\
\hline Youth/Mahila mandal/NGO worker & 0.2 & 0.3 & 0.1 & 0.2 \\
\hline Poster/Billboard & 0.9 & $6.3^{* * *}$ & 0.4 & $3.7^{* * *}$ \\
\hline Other ${ }^{2}$ & 0.0 & $0.9^{*}$ & 0.0 & $2.3^{* * *}$ \\
\hline Don't remember & 16.5 & $0.0^{* * *}$ & 20.9 & $0.7^{* * *}$ \\
\hline Number of respondents & 447 & 376 & 974 & 626 \\
\hline
\end{tabular}

Note: All Ns are unweighted. *, ** and ${ }^{* *}$ indicate that differences between 2007 and 2012 are significant at $p \leq 0.05, p \leq 0.01$ and $p \leq 0.001$, respectively. Column totals may exceed $100 \%$ due to multiple responses. ${ }^{1}$ Includes newspapers, books/magazines, radio/television and the internet. ${ }^{2}$ Includes Anganwadi Worker, ASHA etc. 
Leading sources of information on sex and reproduction were somewhat different among boys and girls (Table 8.8). Among boys, by far, the leading source of information in 2012, was friends and neighbours (82\%), followed by teachers (59\%) and the media (56\%). Among girls, four key sources of information were reported: the media (62\%), friends and neighbours (54\%), family members (50\%) and teachers (48\%). Between 2007 and 2012, these sources of information showed huge increases among both boys and girls: for example, in 2007, friends and neighbours constituted a source of information for just 37 percent of boys and seven percent of girls, and teachers for 3-5\% of boys and girls. Notably, while girls were far more likely in 2012 than in 2007 to obtain information from a family member ( $50 \%$ compared to $4 \%$ ), hardly any boys, at both times, reported receiving information from a family member ( $1 \%$ at both times). Very few boys and girls ( $0-8 \%$ of boys and $0-4 \%$ of girls) cited billboards and posters, health care providers, or adolescents' or women's groups or NGO workers as a source of information on sex and reproduction.

Rural-urban differentials were evident. Urban adolescents were more likely than their rural counterparts to obtain their information about sexual matters from the media ( $71 \%$ versus $51 \%$ among boys; $81 \%$ versus $52 \%$ among girls) and from teachers (64\% versus $57 \%$ among boys; $63 \%$ versus $41 \%$ among girls). They were, in contrast, somewhat less likely than their rural counterparts to cite friends and neighbours as their main source of information (79\% versus $84 \%$ boys, and $50 \%$ versus $56 \%$ girls).

\subsection{Experience of family life or sexuality education}

In the present study, we also asked adolescents whether they had received formal family life or sexuality education and if so, the source of this education, the age at which they received this information, and whether they had been taught about such matters as modes of HIV transmission and ways of preventing HIV/AIDS, as well as menstruation, pregnancy and boy-girl relationships.

Table 8.9 presents findings for 2012. Corresponding with the huge increase between 2007 and 2012 in percentages of adolescents reporting teachers as a source of information on sexual matters, there has been a huge increase in percentages of adolescents reporting exposure to family life or sexuality education: from one percent to 62 percent among boys, and from four percent to 50 percent among girls (not shown for 2007 in table). Almost all (99\%) of those who had received such education had acquired it in the school or college setting rather than through special programmes sponsored by the government or NGOs (not shown in table). Rural-urban differentials in percentages who had received family life or sexuality education were narrow among boys (66\% urban versus $60 \%$ rural) but wide among girls (65\% urban versus $42 \%$ rural).

The majority of adolescents who had received sexuality education reported having received it for the first time at ages $13-14$ ( $56 \%$ and $51 \%$ of boys and girls, respectively), corresponding with Class 9 , the class in which the first year of the national Adolescence Education Programme is taught (those in Class 9 are typically aged 14-15). Some 33 percent of boys and 27 percent of girls had received this education at ages 15 or older, corresponding with Class 11 , the second class in which the national programme is taught.

In 2012, we also probed about the family life or sexuality education topics covered. Gender differences were apparent. Among boys, for example, almost all those who had received sexuality education recalled being informed about HIV transmission and prevention (97-98\%). In contrast, 53-58 percent reported exposure to such topics as pregnancy and boy-girl relationships, and just 19\% had been informed about nocturnal emission. Among girls, in contrast, the large majority of those who had received such education (84\%) reported that they had been taught about menstruation; HIV-related topics had also been addressed (75-78\%), while fewer had received information on pregnancy and boy-girl relationships ( $40 \%$ and $25 \%$, respectively). Boys were consistently more likely than girls to report exposure to almost all comparable topics. Notably, while rural-urban differences were not seen among boys, urban girls were consistently more likely than their rural counterparts to report exposure to each topic about which we probed.

Findings suggest that sexuality education was not comprehensive. Indeed, just 15-18 percent of adolescents reported that sexuality education had encompassed all the five topics about which we probed. While rural-urban differences were negligible for boys (14-15\%), far more urban than rural girls had received information on all five topics ( $25 \%$ versus $13 \%)$. 
Table 8.9: Experiences of family life or sexuality education

Percentage of adolescents by experiences of family life or sexuality education, according to residence, Rajasthan, 2007 and 2012

\begin{tabular}{lcccccc}
\hline & \multicolumn{2}{c}{ Combined } & \multicolumn{2}{c}{ Urban } & \multicolumn{2}{c}{ Rural } \\
Family life/sexuality education received & Boys (\%) & Girls (\%) & Boys (\%) & Girls (\%) & Boys (\%) & Girls (\%) \\
\hline Received formal family life/sexuality education & 61.5 & 50.0 & 66.0 & 64.9 & 59.9 & 42.1 \\
Number of respondents & $\mathbf{7 4 5}$ & $\mathbf{1 , 1 6 4}$ & $\mathbf{3 6 9}$ & $\mathbf{5 3 8}$ & $\mathbf{3 7 6}$ & $\mathbf{6 2 6}$ \\
Age when family life/sexuality education was received & & & & & & \\
(years) & & & & & & \\
10-12 & 10.8 & 22.2 & 14.3 & 18.2 & 9.4 & 25.4 \\
13-14 & 56.2 & 51.2 & 52.3 & 51.4 & 57.8 & 51.0 \\
15-19 & 32.9 & 26.6 & 33.4 & 30.4 & 32.8 & 23.6 \\
Trainer/teacher talked about: & & & & & & \\
Different modes of HIV transmission & 97.6 & 78.1 & 95.5 & 83.2 & 98.5 & 74.0 \\
Different ways of preventing HIV infection & 97.0 & 75.0 & 95.1 & 79.8 & 97.8 & 71.2 \\
Nocturnal emission (swapnadosh)/menstruation & 19.1 & 84.0 & 19.7 & 88.1 & 18.8 & 80.6 \\
How a woman gets pregnant & 53.1 & 39.7 & 52.9 & 44.6 & 53.2 & 35.8 \\
Relationships between boys and girls & 57.6 & 24.8 & 53.8 & 31.7 & 59.1 & 19.3 \\
Talked about all of the above & $\mathbf{1 4 . 7}$ & $\mathbf{1 8 . 1}$ & $\mathbf{1 3 . 9}$ & $\mathbf{2 4 . 9}$ & $\mathbf{1 5 . 1}$ & $\mathbf{1 2 . 6}$ \\
Number of respondents who received family life/ & & & & & & \\
sexuality education & $\mathbf{4 6 6}$ & $\mathbf{6 0 4}$ & $\mathbf{2 4 5}$ & $\mathbf{3 4 3}$ & $\mathbf{2 2 1}$ & $\mathbf{2 6 1}$ \\
\hline
\end{tabular}

Note: All Ns are unweighted.

\subsection{Summary}

Findings presented in this chapter suggest that even in 2012, awareness levels among adolescents about various sexual and reproductive matters-how pregnancy occurs, contraception, HIV and safe sex practices, and abortionrelated matters-was mixed. At the same time, they underscore the impressive increases in awareness that have taken place over time among successive cohorts of adolescents.

In 2012, for example, fewer than one-half of surveyed boys and girls were aware that a woman can get pregnant at first sex (46\%) or that they are most likely to become pregnant mid-cycle (51\% of boys; $28 \%$ of girls), yet $83-84$ percent were aware that it is possible to detect the sex of the foetus; overall, just 38 percent of boys and 29 percent of girls were aware of all the three sex- and pregnancy-related matters explored. While the vast majority of adolescents had heard of at least one modern contraceptive method (90-93\%), girls were typically less well informed than boys about particular methods well suited to adolescents (condoms and emergency contraception, for example), and correct specific awareness of even one method (out of condoms, oral contraceptive pills, emergency contraception) was reported by 79 percent of boys, and far fewer, $37 \%$ of girls. Moreover, even among those aware of condoms, misperceptions about its use were widespread, particularly among girls. Awareness of STIs was particularly limited, and again, girls fared far worse than boys: just 30 percent of boys and 15 percent of girls had heard of diseases spread through sexual contact (aside from HIV/AIDS) and just 22 percent of boys and five percent of girls could also name at least one such infection. While larger proportions of adolescents had heard about HIV/AIDS, comprehensive knowledge of HIV/AIDS was reported by fewer and gender differences were wide, with girls faring far worse than boys ( $62 \%$ versus $88 \%$ had heard about HIV/AIDS; $45 \%$ versus $70 \%$ had comprehensive HIV/AIDS knowledge).

A key issue of relevance to adolescents, namely, knowledge about the legal minimum age at marriage was also not universal: 90-93 percent of boys and 78-85 percent of girls were aware that 21 and 18 are the legal minimum age at marriage for boys and girls, respectively. Boys were also more aware than girls that sex selection is not a 
legal ground for pregnancy termination: 90 percent of boys and 72 percent of girls were aware that sex-selective abortion is illegal. Findings of considerable gender differences in awareness of the law as well as in comprehensive awareness/knowledge about sex and pregnancy, contraception and HIV/AIDS raise concern about the vulnerability of girls, in particular.

At the same time, impressive increases had taken place in the awareness levels of surveyed adolescents between 2007 and 2012. For example, correct knowledge of sex- and pregnancy-related matters increased from just 4-5 percent among boys and girls in 2007 to 38 percent among boys and 29 percent among girls by 2012. In-depth awareness about various contraceptive methods had also increased impressively: in-depth awareness of emergency contraception increased from 1-2 percent in 2007 to 42 percent among boys and 24 percent among girls; in-depth awareness of oral contraceptive pills increased from 17 percent to 40 percent among boys, but no such change was observed among girls, and conversely, in-depth awareness of condoms increased from 21 percent to 30 percent among girls but did not change much among boys. Likewise, improvements were observed in awareness of the legal minimum age at marriage for males and females, and the fact that sex-selective abortion is not legally permitted.

By 2012, almost all surveyed boys and girls had received information on sex and reproduction from various sources; indeed, unlike in 2007 when one-third of the boys and three-fifths of the girls had reported that they had never received any information on sexual matters, by 2012, 95 percent of both had received such information from one or more sources. As in 2007, such less reliable sources of information as friends and relatives and the media were reported by large proportions of boys (82\% and 56\%, respectively) and girls (54\% and 62\%, respectively) in 2012. Notably, while girls were far more likely in 2012 than in 2007 to obtain information from a family member (50\% compared to 4\%), hardly any boys, at both times, reported receiving information from a family member (1\% at both times). Notwithstanding the government's Adolescent Reproductive and Sexual Health programme, in 2012, just five percent of surveyed boys and one percent of surveyed girls had obtained information from a health care provider, or from health-related messages displayed on billboards and posters (4-8\%).

One of the most significant findings with regard to sources of information about sexual matters is the huge increase between 2007 and 2012 in percentages of surveyed adolescents who reported that they had obtained their information from teachers and schools: from 37 percent to 82 percent among boys, and from seven percent to 54 percent among girls. Corresponding with this huge increase, there has been a considerable increase in percentages of adolescents reporting exposure to family life or sexuality education: from one percent to 62 percent among boys, and from four percent to 50 percent among girls. Almost all (99\%) of those who received such education had obtained it in the school or college setting rather than through special programmes sponsored by the government or NGOs. In 2012, the majority of adolescents who had received sexuality education reported having received it for the first time at ages 13-14 (56\% and 51\% of boys and girls, respectively), corresponding to the age at which adolescents are in Class 9, that is, when the first year of the Adolescence Education Programme is delivered. Gender differences were apparent with regard to the topics covered. For example, topics related to HIV transmission and prevention were reported by almost all boys who received such education, compared to about three-quarters of all girls. Pregnancy-related information and information about boy-girl relationships was imparted to more than one-half of all boys, compared to two-fifths and one-quarter of all girls, respectively. Physical maturation issues-menstruation for girls and nocturnal emission for boys-were, in contrast, far more likely to have been imparted to girls than boys (84\% versus 19\%). The limited quality of the programmes to which surveyed adolescents had been exposed is evident from the findings, suggesting that just 15-18 percent of adolescents who attended these programmes had received information about all the key topics that we probed (physical maturation, boy-girl relationships, pregnancy and HIV/AIDS). 


\section{Chapter 9 \\ Romantic and sexual relationships}

The Youth in India; Situation and Needs 2006-07 study established, for the first time at sub-national level, that among youth aged 15-24, some 15 percent of boys and four percent of girls had experienced pre-marital sex; in Rajasthan, corresponding percentages were 15 percent and two percent. The study also noted considerable premarital interaction and romantic relations between boys and girls. Findings highlighted that despite socio-cultural taboos, youth in India do find opportunities to mix and form romantic relationships, and to engage in pre-marital sex with a range of partners and in a variety of situations, findings also observed in other small studies (Abraham, 2001; 2002; Abraham and Kumar, 1999; Alexander et al., 2006a; 2006b; Awasthi, Nichter and Pande, 2000). The Adolescents and Youth survey in 2012, probed, in a largely similar way as in the 2007 survey, the extent of unmarried adolescents' romantic experiences and sexual experiences, including those within romantic partnerships and other situations. As in 2007 , aside from direct questioning regarding sexual experiences through face-to-face interviews, anonymous reporting of the respondents' own experiences using a sealed envelope was also employed. This chapter describes findings relating to the romantic and sexual relationships of the surveyed adolescents.

\subsection{Questionnaire module on romantic and sexual relationships}

The questionnaire module on premarital romantic and sexual relationships that was developed for the 2007 survey is described in detail elsewhere (International Institute for Population Sciences and Population Council, 2010). In the 2012 survey, the same module was used with a few modifications.

In order to assess romantic relationships, adolescents were asked questions on whether or not they had ever had a boyfriend or girlfriend (culturally appropriately phrased); whether they had "proposed" to anyone of the opposite sex or someone of the opposite sex had "proposed" to them and the "proposal" was accepted, and whether they had spent time alone and secretly with an opposite-sex person. Adolescents who reported any of the above experiences were considered to have experienced a romantic relationship. We note that our definition of romantic relationships precluded the possibility of reporting same-sex romantic relationships.

In order to assess sexual relationships, we probed separately for relationships with different partners. All respondents who had reported a romantic partner were then probed regarding the nature of the relationship and the extent of physical contact experienced in the relationship. Questions relating to physical intimacy were posed on a continuum, starting with hand-holding and extending to sexual relations. Thus, the instrument sought to ask potentially sensitive or embarrassing questions in a gradual way, thereby also enabling the interviewer to build rapport with the respondent. Detailed questions concerning the nature of the relationship were asked with reference to the first romantic partner as well as the most recent, if more than one was reported. For each relationship, moreover, questions were asked about the age at initiation; condom use at first and last sex, and consistent condom use, and the extent to which first sex was consensual or forced.

Sexual relations in other situations and with other partners, including with sex workers and older married girls or women (for boys), casual sex, and forced and exchange sex were also probed. In each case, those who reported such relationships were asked to indicate their age the first time such a relationship was experienced, as also condom use at first, last, and all sexual encounters with the partner.

Additionally, recognising the reluctance of youth to disclose sexual experiences in a survey situation, at the conclusion of the interview, all unmarried respondents were given two blank cards, containing questions on any sexual experience and experience/perpetration of forced sex. Both girls and boys were asked: "Have you ever had sex with anyone?" In addition, girls were asked "Has anybody ever forced you to have sex with him?" and boys were asked "Have you ever forced anyone to have sex with you?" All respondents were asked to mark each card with a " $\sqrt{ }$ " or a " $X$," depending on their experience, place the cards in an envelope, seal it and return it to the interviewer. Respondents were informed that the envelope would not be opened in the field, and that only the principal investigators would be able to link the information provided in the envelope with what was provided in the main body 
of the questionnaire. We note that in 2007 , only one question - "Have you ever had sex with anyone?" - was posed anonymously.

In addition, efforts were made to ensure that adolescents were comfortable revealing sensitive behaviours. The interviewers were young and trained to build rapport, discuss sensitive experiences in empathetic and matter-of-fact ways and generally make the respondents feel comfortable about the topics to be discussed during the interview. As far as possible, interviews were held at times and places that assured the respondent maximum confidentiality. In cases in which family members attempted to participate in or overhear the interview, another interviewer was called upon to conduct an informal discussion or interview with other family members so as to ensure privacy for the respondent's interview. Nevertheless, we acknowledge that ensuring privacy may have been a problem, especially in low-income urban settings characterised by cramped housing conditions, or that some adolescents may not have felt entirely at ease despite the extensive efforts made to ensure confidentiality. We thus acknowledge that romantic and sexual experiences may have been under-reported in the survey, notably by girls, and suggest that the percentages presented here may be interpreted as conservative estimates.

\subsection{Romantic relationships}

In this section, we present findings on the prevalence of opposite-sex romantic relationships among adolescents and a profile of those who engaged in such relationships. The section also describes parent and peer awareness of romantic relationships, and the extent of physical contact experienced in these relationships.

\subsubsection{Prevalence of romantic relationships}

Despite the fact that pre-marital boy-girl interaction and romantic relationships are typically discouraged in Rajasthan, opportunities to form romantic relationships did exist for some adolescents, irrespective of rural-urban residence or sex. As boy-girl relationships are typically formed through making and accepting "proposals", our questionnaire inquired whether the respondents had made or received a proposal and had accepted it, whether the respondent had met a boy alone and secretly, and more directly, whether the respondent had a boyfriend or girlfriend. As mentioned earlier, respondents responding positively to any of these three questions were considered to have had a romantic relationship.

As shown in Table 9.1, in 2012, several adolescents-23 percent of boys and 38 percent of girls-had either made a romantic "proposal" to an opposite-sex individual or had received such a "proposal". Huge and significant increases in the experience of romantic relationships were evident among boys and girls between 2007 and 2012, for example, while in 2007 , just ten percent of boys and 22 percent of girls had reported making or receiving a romantic "proposal"; in 2012, corresponding percentages showed significant increases-23 and 38, respectively (also see Figure 9.1). Very few girls reported "proposing" to a boy at both times (1\%, not shown in table); among boys, however, almost as many reported making a "proposal" as receiving one at both times (5-6\% in 2007 and 13-15\% in 2012, respectively) (not shown in table), suggesting the possibility that boys may have exaggerated the extent to which girls had approached them with expressions of affection, or girls may have concealed behaviour that may be considered socially unacceptable, that is, "proposing" to a boy. That more girls than boys had made or received such a "proposal" may be attributed to the fact that male partners are typically older than female partners and, as a result, more girls than boys in the lower age bounds of our sample would have been eligible, in practice, to have made or received a "proposal".

As in 2007, in 2012, rural-urban differences in experiences in initiating romantic relationships were negligible among boys, but among girls, larger percentages of those in urban areas compared to their rural counterparts had made or received a "proposal" (44\% versus 34\%).

Compared to those who had made or received "proposals", fewer adolescents, particularly girls, reported the acceptance of such a "proposal". One-fifth of all boys and almost one-fifth of all girls reported that they had accepted a "proposal" or that their own "proposal" had been accepted, an increase from 7-8 percent of adolescents in 2007 (Table 9.1). Somewhat fewer (19\% and 14\% of boys and girls, respectively) reported that they had met an opposite-sex individual secretly, up from seven percent of adolescents in 2007. Rural-urban differences, again, were negligible. Increases over time in both indicators were significant for both girls and boys. 
Table 9.1: Romantic relationships

Percentage of adolescents reporting a romantic relationship by relationship characteristics, according to residence, Rajasthan, 2007 and 2012

\begin{tabular}{|c|c|c|c|c|}
\hline \multirow[b]{2}{*}{ Characteristics of romantic relationships } & \multicolumn{2}{|c|}{ Boys (\%) } & \multicolumn{2}{|c|}{ Girls (\%) } \\
\hline & 2007 & 2012 & 2007 & 2012 \\
\hline \multicolumn{5}{|c|}{ Combined } \\
\hline \multicolumn{5}{|l|}{ "Proposals" made/received and accepted } \\
\hline Made or received a "proposal" & 9.5 & $22.6^{* * *}$ & 21.9 & $37.6^{* * *}$ \\
\hline Accepted a "proposal”/“proposal” was accepted & 7.8 & $19.9^{* * *}$ & 7.1 & $18.0^{* * *}$ \\
\hline \multicolumn{5}{|l|}{ Secret meetings with an opposite-sex individual } \\
\hline Met secretly with opposite sex individual & 6.9 & $18.5^{* * *}$ & 6.5 & $14.2^{* * *}$ \\
\hline \multicolumn{5}{|c|}{$\begin{array}{l}\text { Reported romantic relationship in one of the above or in } \\
\text { direct question }{ }^{1}\end{array}$} \\
\hline Reported a romantic partner & 7.8 & $20.0^{* * *}$ & 7.4 & $18.4^{* * *}$ \\
\hline Reported more than one romantic partner & 1.2 & $7.1^{* * *}$ & 0.1 & $1.1^{* *}$ \\
\hline Number of respondents & 774 & 745 & 1,487 & 1,164 \\
\hline \multicolumn{5}{|c|}{ Urban } \\
\hline \multicolumn{5}{|l|}{ "Proposals" made/received and accepted } \\
\hline Made or received a "proposal" & 8.6 & $24.4^{* * *}$ & 26.8 & $44.0^{* * *}$ \\
\hline Accepted a "proposal”/“proposal” was accepted & 7.3 & $19.8^{* * *}$ & 7.5 & $16.0^{* * *}$ \\
\hline \multicolumn{5}{|l|}{ Secret meetings with an opposite-sex individual } \\
\hline Met secretly with opposite sex individual & 5.9 & $18.2^{* * *}$ & 6.2 & $12.8^{* *}$ \\
\hline \multicolumn{5}{|c|}{$\begin{array}{l}\text { Reported romantic relationship in one of the above or in } \\
\text { direct question }{ }^{1}\end{array}$} \\
\hline Reported a romantic partner & 7.3 & $20.1^{* * *}$ & 7.5 & $16.4^{* * *}$ \\
\hline Reported more than one romantic partner & 1.5 & $8.0^{* * *}$ & 0.2 & 1.3 \\
\hline Number of respondents & 327 & 369 & 513 & 538 \\
\hline \multicolumn{5}{|c|}{ Rural } \\
\hline \multicolumn{5}{|l|}{ "Proposals" made/received and accepted } \\
\hline Made or received a "proposal" & 9.8 & $22.0^{* * *}$ & 20.1 & $34.2^{* * *}$ \\
\hline Accepted a "proposal”/“proposal” was accepted & 8.0 & $20.0^{* * *}$ & 7.0 & $19.1^{* * *}$ \\
\hline \multicolumn{5}{|l|}{ Secret meetings with an opposite-sex individual } \\
\hline Met secretly with opposite sex individual & 7.3 & $18.6^{* * *}$ & 6.6 & $15.0^{* * *}$ \\
\hline \multicolumn{5}{|c|}{$\begin{array}{l}\text { Reported romantic relationship in one of the above or in } \\
\text { direct question }{ }^{1}\end{array}$} \\
\hline Reported a romantic partner & 8.0 & $20.0^{* * *}$ & 7.4 & $19.4^{* * *}$ \\
\hline Reported more than one romantic partner & 1.2 & $6.7^{* * *}$ & 0.1 & $1.0^{*}$ \\
\hline Number of respondents & 447 & 376 & 974 & 626 \\
\hline
\end{tabular}

Note: All Ns are unweighted. *, ${ }^{* *}$ and ${ }^{* * *}$ indicate that differences between 2007 and 2012 are significant at $p \leq 0.05, p \leq 0.01$ and $p \leq 0.001$, respectively. ${ }^{1}$ Respondents were asked whether or not they had ever had a boyfriend/girlfriend. 
Figure 9.1: Percentage of adolescents who had made or received a "proposal" for forming a romantic partnership and percentage who had an opposite-sex romantic partner, Rajasthan, 2007 and 2012

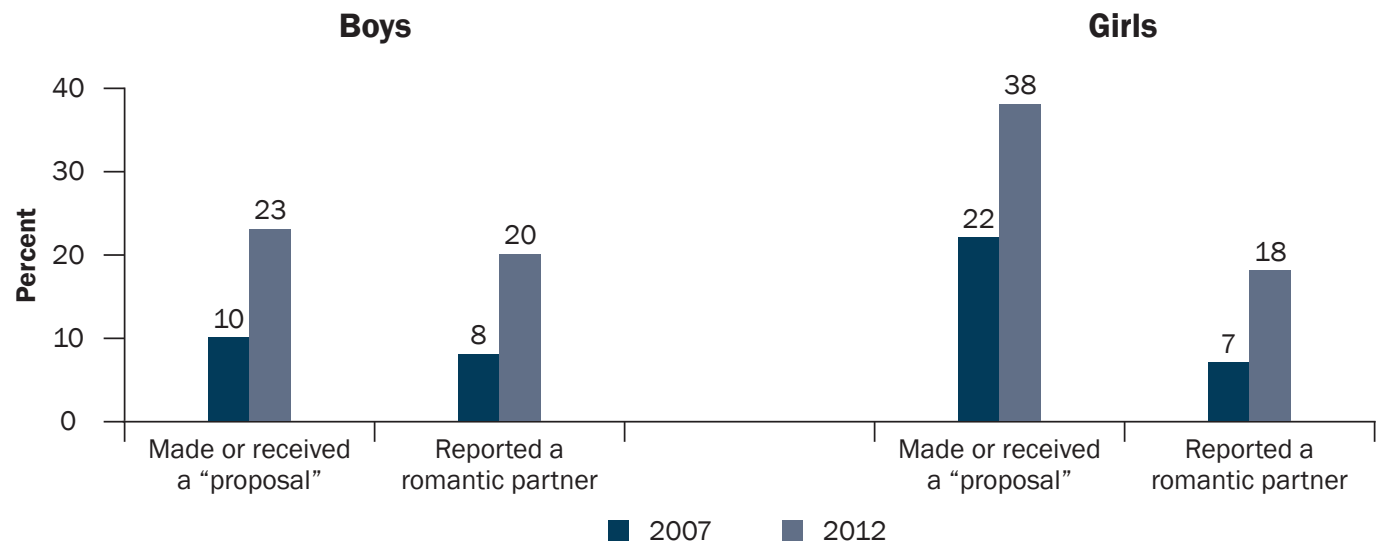

In total, in response to the direct or indirect questions, 20 percent of boys and 18 percent of girls acknowledged the experience of a romantic partnership in 2012, a large and significant increase over 2007 when just eight percent of boys and seven percent of girls had so reported. There was also a significant increase in the percentage of boys reporting more than a single romantic partner, from one percent in 2007 to seven percent in 2012; very few girls so reported (0.1\% and 1\% in 2007 and 2012, respectively). Rural-urban differences were negligible at both times for boys; among girls, slightly more of those from rural than urban areas reported a romantic partner in 2012 (19\% versus $16 \%$ ).

Table 9.2 presents the percentage of surveyed adolescents reporting romantic relationships by background characteristics in the 2012 survey. We note that such characteristics as work status and household economic status reflect the situation of adolescents at the time of the interview, and not necessarily at the time when romantic relationships were formed. As seen in Table 9.2, age profiles indicate a positive association between age and the formation of romantic relationships: from 15 percent and 17 percent among boys and girls aged 15-17, respectively, to 30 percent and 22 percent among those aged 18-19, respectively. Among boys, differentials by religion were negligible, but somewhat fewer boys from general castes than other castes reported a romantic relationship. Among girls, Hindu girls were more likely than Muslim girls (20\% versus 11\%), and those from scheduled tribes most likely and those belonging to other backward castes and general caste groups least likely (39\% versus 14\%) to report a romantic relationship. By and large, similar patterns were observed among adolescents in rural and urban areas.

Associations between work status, schooling and household economic status and the formation of romantic relationships varied. Working adolescents were consistently more likely to have experienced a romantic relationship than their non-working counterparts (31\% versus 16\% among boys; $28 \%$ versus 16\% among girls), and this pattern was evident among both rural and urban adolescents. Associations with educational attainment levels were not as consistent. For example, the percentage of boys who reported a romantic partner increased from 21 percent among those with 1-7 years of education to 30 percent among those who had completed 12 or more years of schooling, with those with some education less likely than both extreme groups to report a romantic relationship (17-18\%); this pattern was observed among boys in rural and urban areas as well. Among girls, education was unrelated with the experience of a romantic relationship (17-20\% irrespective of level of education attained). Patterns differed considerably for rural and urban girls: in rural areas, girls with 12 or more years of education were considerably less likely than those who had attained fewer years of education to report a romantic relationship (13\% versus 20-21\%), while in urban areas, they were somewhat more likely to report a romantic relationship than were lesser educated girls $(21 \%$ versus $13-18 \%)$.

Differentials by household economic status were also somewhat inconsistent. For boys, the association between household economic status and the experience of a romantic relationship was J-shaped, that is, percentages reporting such a relationship fell from 17 percent among the poorest (first quintile) to 14 percent among the second, and then increased to 25 percent among the richest two quintiles (fourth and fifth). Among girls, in contrast, an 
inverse association was observed (from 22-23 percent among those in the poorest two (first and second) quintiles to 15-17 percent in the richest three quintiles (third, fourth and fifth). Among boys, the J-shaped relationship was noted in rural areas, and a more or less positive relationship was observed in urban areas. Among girls, in contrast, a positive association was observed in urban areas (with 10-11\% of those in the poorer quintiles (second and third) and 19-21 percent of those in the richest (fourth and fifth) quintiles reporting a romantic relationship; the opposite was observed in rural areas, with 23-27 percent of those in the poorest quintiles (first and second) compared to 11-15 percent of those in the richest (fourth and fifth), reporting the experience of a romantic relationship.

Table 9.2: Prevalence of romantic relationships by selected background characteristics

Percentage of adolescents reporting a romantic relationship by selected background characteristics, according to residence, Rajasthan, 2012

\begin{tabular}{|c|c|c|c|c|c|c|}
\hline \multirow[b]{2}{*}{ Background characteristics } & \multicolumn{2}{|c|}{ Combined } & \multicolumn{2}{|c|}{ Urban } & \multicolumn{2}{|c|}{ Rural } \\
\hline & Boys (\%) & Girls (\%) & Boys (\%) & Girls (\%) & Boys (\%) & Girls (\%) \\
\hline \multicolumn{7}{|l|}{ Age (years) } \\
\hline $15-17$ & 15.3 & 17.1 & 14.8 & 14.8 & 15.4 & 18.2 \\
\hline $18-19$ & 30.0 & 22.2 & 30.1 & 20.5 & 29.9 & 23.2 \\
\hline \multicolumn{7}{|l|}{ Religion } \\
\hline Hindu & 20.3 & 19.7 & 21.6 & 17.8 & 19.9 & 20.6 \\
\hline Muslim & 18.7 & 11.3 & 13.4 & 12.9 & $\#$ & 9.2 \\
\hline Other ${ }^{1}$ & $\#$ & $(15.7)$ & $\#$ & $\#$ & $\#$ & $(18.5)$ \\
\hline \multicolumn{7}{|l|}{ Caste } \\
\hline SC & 22.5 & 22.4 & 25.0 & 19.3 & 21.7 & 23.8 \\
\hline ST & 22.0 & 39.4 & \# & $(35.2)$ & 21.7 & 40.4 \\
\hline $\mathrm{OBC}$ & 19.6 & 13.8 & 15.4 & 13.7 & 20.8 & 13.9 \\
\hline General $^{2}$ & 15.9 & 13.5 & 20.4 & 14.7 & (8.8) & 12.6 \\
\hline \multicolumn{7}{|l|}{ Educational level (years) } \\
\hline None $^{3}$ & \# & 18.2 & \# & $\#$ & $\#$ & 19.5 \\
\hline $1-7$ & 21.4 & 19.6 & $(28.2)$ & 18.4 & 19.1 & 20.1 \\
\hline $8-9$ & 16.8 & 18.1 & 16.4 & 13.1 & 16.9 & 20.4 \\
\hline $10-11$ & 18.1 & 18.5 & 15.2 & 15.1 & 19.2 & 20.9 \\
\hline 12 and above & 29.5 & 17.2 & 28.0 & 21.4 & 30.3 & 13.1 \\
\hline \multicolumn{7}{|l|}{ Worked in last 12 months } \\
\hline Yes & 31.1 & 27.7 & 32.6 & 24.6 & 30.6 & 28.9 \\
\hline No & 16.4 & 15.6 & 15.9 & 14.5 & 16.6 & 16.2 \\
\hline \multicolumn{7}{|l|}{ Wealth quintile } \\
\hline First & 16.8 & 21.9 & $\#$ & $(12.8)$ & 16.9 & 23.0 \\
\hline Second & 13.9 & 22.9 & (9.6) & 11.2 & 14.4 & 26.9 \\
\hline Third & 21.6 & 15.8 & $(19.4)$ & 9.6 & 22.1 & 18.1 \\
\hline Fourth & 25.3 & 15.2 & 22.1 & 20.8 & 27.9 & 10.7 \\
\hline Fifth & 24.6 & 17.0 & 21.6 & 18.5 & $\#$ & 15.0 \\
\hline Total & 20.0 & 18.4 & 20.1 & 16.4 & 20.0 & 19.4 \\
\hline
\end{tabular}

Note: ( ) Based on 25-49 unweighted cases. \# Percentage not shown; based on fewer than 25 unweighted cases. OBC: Other backward caste. SC: Scheduled caste. ST: Scheduled tribe. ${ }^{1}$ Includes Christian, Buddhist, Neo-Buddhist, Sikh, Jain, Jewish, Parsi/ Zoroastrian, Sarana and no specified religion. ${ }^{2}$ Includes all those not belonging to SC, ST or OBC. ${ }^{3}$ Includes those who are nonliterate and literate with no formal schooling. 


\subsubsection{Characteristics of romantic relationships}

Selected characteristics of reported romantic relationships of surveyed adolescents are presented in Table 9.3; in cases in which more than one romantic partner was reported, only information relating to the respondent's first romantic relationship was included. Age at initiation of romantic relationships was measured by the age at which adolescents first spent time alone with their partner.

Findings indicate that relationships were initiated at a young age for considerably large proportions of surveyed adolescents who had experienced romantic relationships. Indeed, 57 percent of boys and 63 percent of girls reported that they had spent time alone with their first romantic partner at age 15 or below. This represents a considerable increase since 2007 when 45 percent of boys and 47 percent of girls so reported. In 2012, moreover, about as many boys in rural as in urban areas had initiated a romantic relationship at age 15 or below (57\% and $54 \%$ respectively); many more rural than urban girls had done so (69\% versus 51\%). Further, the median age of respondents when they first spent time alone with their romantic partner was 15, irrespective of sex and rural-urban residence and, with the exception of rural areas where it remained unchanged at 15 years over the five-year period, it fell by one year among boys and girls on the whole, as well as among those in urban areas.

Table 9.3: Characteristics of romantic relationships and partners

Percentage of adolescents reporting a romantic relationship by own and partner's age at initiation of relationship, according to residence, Rajasthan, 2007 and 2012

\begin{tabular}{|c|c|c|c|c|}
\hline \multirow[b]{2}{*}{ Age at initiation of romantic relationship ${ }^{1}$} & \multicolumn{2}{|c|}{ Boys (\%) } & \multicolumn{2}{|c|}{ Girls (\%) } \\
\hline & 2007 & 2012 & 2007 & 2012 \\
\hline \multicolumn{5}{|c|}{ Combined } \\
\hline \multicolumn{5}{|l|}{ Age when respondent first spent time alone with partner (years) } \\
\hline 15 or below & 45.3 & 56.5 & 47.2 & $63.2^{* *}$ \\
\hline Median age when respondent first spent time alone with partner & 16.0 & 15.0 & 16.0 & 15.0 \\
\hline \multicolumn{5}{|l|}{ Age of partner } \\
\hline Younger than respondent & 22.9 & 35.0 & 0.0 & 0.7 \\
\hline Same age as respondent & 47.6 & 59.0 & 8.1 & 10.9 \\
\hline Older than respondent & 16.2 & 6.0 & 74.5 & 77.4 \\
\hline Don't remember & 13.3 & 0.0 & 17.5 & 11.0 \\
\hline Significance level & \multicolumn{2}{|c|}{$* * *$} & \multicolumn{2}{|c|}{-} \\
\hline Number of respondents reporting a romantic relationship & 60 & 151 & 109 & 214 \\
\hline \multicolumn{5}{|c|}{ Urban } \\
\hline \multicolumn{5}{|l|}{ Age when respondent first spent time alone with partner (years) } \\
\hline 15 or below & $(28.2)$ & $53.9^{*}$ & $(31.9)$ & 50.9 \\
\hline Median age when respondent first spent time alone with partner & $(16.0)$ & 15.0 & $(16.0)$ & 15.0 \\
\hline \multicolumn{5}{|l|}{ Age of partner } \\
\hline Younger than respondent & $(23.1)$ & 40.5 & $(0.0)$ & 0.9 \\
\hline Same age as respondent & $(44.0)$ & 52.3 & $(2.7)$ & 10.5 \\
\hline Older than respondent & $(16.6)$ & 7.2 & $(84.3)$ & 85.3 \\
\hline Don't remember & $(16.3)$ & 0.0 & $(13.0)$ & 3.4 \\
\hline Significance level & \multicolumn{2}{|c|}{ * } & \multicolumn{2}{|c|}{-} \\
\hline Number of respondents reporting a romantic relationship & 25 & 74 & 38 & 87 \\
\hline
\end{tabular}




\begin{tabular}{|c|c|c|c|c|}
\hline \multirow[b]{2}{*}{ Age at initiation of romantic relationship ${ }^{1}$} & \multicolumn{2}{|c|}{ Boys (\%) } & \multicolumn{2}{|c|}{ Girls (\%) } \\
\hline & 2007 & 2012 & 2007 & 2012 \\
\hline \multicolumn{5}{|c|}{ Rural } \\
\hline \multicolumn{5}{|l|}{ Age when respondent first spent time alone with partner (years) } \\
\hline 15 or below & $(51.1)$ & 57.4 & 52.8 & $68.6^{*}$ \\
\hline Median age when respondent first spent time alone with partner & $(15.0)$ & 15.0 & 15.0 & 15.0 \\
\hline \multicolumn{5}{|l|}{ Age of partner } \\
\hline Younger than respondent & $(22.8)$ & 33.0 & 0.0 & 0.6 \\
\hline Same age as respondent & $(48.9)$ & 61.5 & 10.0 & 11.1 \\
\hline Older than respondent & $(16.1)$ & 5.5 & 70.9 & 73.9 \\
\hline Don't remember & $(12.2)$ & 0.0 & 19.1 & 14.3 \\
\hline Significance level & \multicolumn{2}{|c|}{ ** } & \multicolumn{2}{|c|}{-} \\
\hline Number of respondents reporting a romantic relationship & 35 & 77 & 71 & 127 \\
\hline
\end{tabular}

Note: All Ns are unweighted. -, * , ** and ${ }^{* *}$ indicate that differences between 2007 and 2012 are not significant, and significant at $p \leq 0.05, p \leq 0.01$ and $p \leq 0.001$, respectively. () Based on 25-49 unweighted cases. ${ }^{1}$ Age of respondent's first romantic partner, if more than one romantic partner reported.

Information on the relative ages of reported partners in 2012 suggests that male partners were either the same age as or older than their female partners. For example, 59 percent of boys reported a female partner who was the same age as them, and 35 percent reported one who was younger than they were. In contrast, just 11 percent of girls reported a male partner of the same age, and 77 percent reported a male partner who was older than they were. By and large, a similar pattern was evident for 2007; however, we note that over time, percentages of boys reporting a relationship with an older girl (or woman) fell from 16 to 6. Rural-urban differences were not observed in 2012 , except that more urban than rural girls reported that their partner at initiation of a romantic relationship was older than them (85\% versus $74 \%)$.

At both times, most adolescents reporting a romantic relationship said that their friends were aware of their relationship, while few reported that their parents were. For example, in 2012, 79 percent of boys and 91 percent of girls reported that their friends were aware of their relationship, similar to the situation in 2007 (79-83\% reported peer awareness). In contrast, in 2012, just 11 percent of boys and girls reported that their parents/guardian were aware of their relationship, also similar to the percentages reported in 2007 (8-13\%), (Figure 9.2).

Figure 9.2: Among adolescents reporting a romantic relationship, percentages who reported peer and parental awareness of their first romantic relationship, Rajasthan, 2007 and 2012

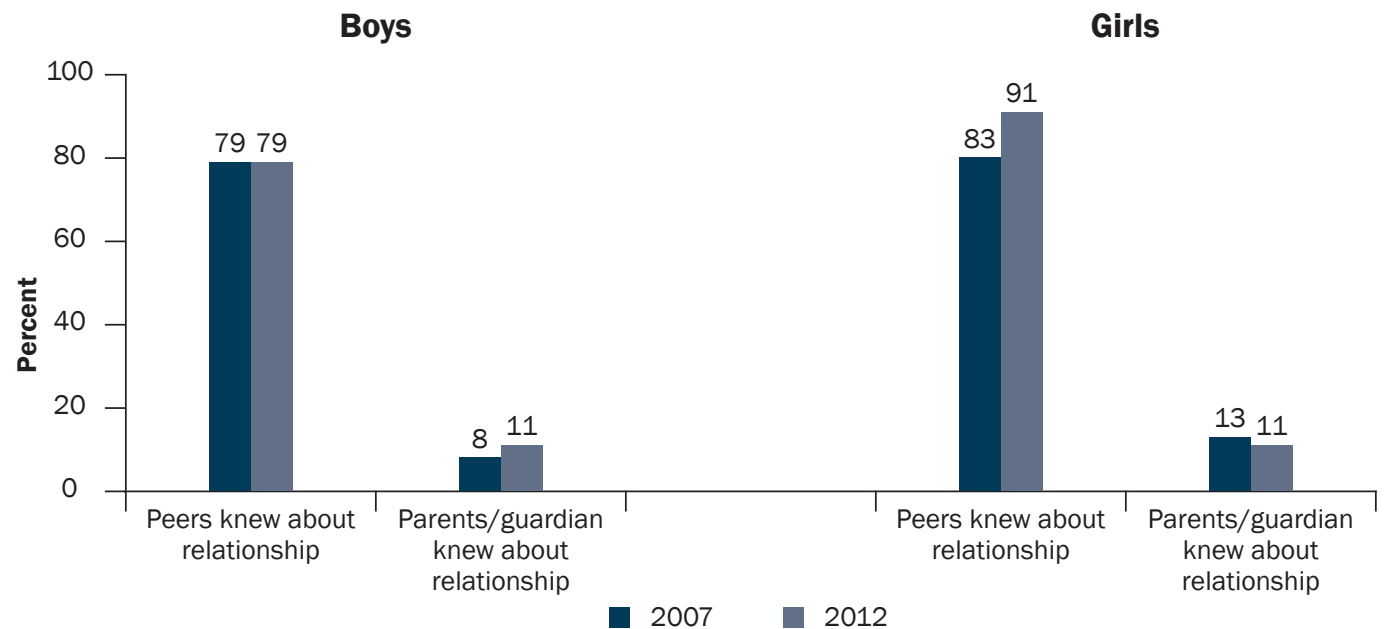




\subsubsection{Physical intimacy and sex with a romantic partner}

Respondents who reported a romantic relationship were asked whether they had engaged in a number of intimate behaviours with their romantic partner. These ranged from behaviours reflecting minimal physical intimacy (handholding, hugging) to those reflecting increased physical intimacy (kissing on the lips) and finally, engaging in sexual relations. Findings, presented in Table 9.4 and Figure 9.3, refer to adolescents' experiences of physical intimacy with their first and/or most recent romantic partner, if more than one partner was reported

As expected, while the large majority of surveyed adolescents had held hands with a romantic partner (88\% of boys and $77 \%$ of girls), consistently fewer reported progressively more intimate behaviours in 2012 , such as hugging their romantic partner ( $77 \%$ of boys and $70 \%$ of girls), kissing their romantic partner on the lips ( $72 \%$ and $65 \%$, of boys and girls, respectively) and engaging in sexual relations with their partner (53\% and $41 \%$, of boys and girls, respectively). Among boys, while similar percentages reported handholding, hugging and kissing in 2012 and 2007 , somewhat more reported engaging in sexual relations with a romantic partner in 2012 than in $2007: 53$ percent versus to 45 percent. Among girls, in contrast, significant increases were observed between 2007 and 2012 in respect of each behaviour; for example, handholding was reported by 77 percent of girls in 2012, compared to 64 percent in 2007; hugging by 70 percent versus 43 percent, kissing by 65 percent versus 30 percent, and sexual relations by 41 percent versus 16 percent.

Table 9.4: Physical intimacy and sexual experiences in romantic relationships

Percentage of adolescents reporting a romantic relationship by experiences of physical intimacy and sex with their partner, according to residence, Rajasthan, 2007 and 2012

\begin{tabular}{|c|c|c|c|c|}
\hline \multirow[b]{2}{*}{ Physical intimacy ${ }^{1}$} & \multicolumn{2}{|c|}{ Boys (\%) } & \multicolumn{2}{|c|}{ Girls (\%) } \\
\hline & 2007 & 2012 & 2007 & 2012 \\
\hline \multicolumn{5}{|c|}{ Combined } \\
\hline Ever held hands & 91.5 & 87.9 & 64.1 & $76.7^{*}$ \\
\hline Ever hugged & 75.4 & 77.2 & 43.0 & $69.5^{* * *}$ \\
\hline Ever kissed & 71.3 & 71.8 & 29.5 & $65.3^{* * *}$ \\
\hline Ever had sexual relations & 44.5 & 52.5 & 15.6 & $40.7^{* * *}$ \\
\hline Number of respondents reporting a romantic relationship & 60 & 151 & 109 & 214 \\
\hline \multicolumn{5}{|c|}{ Urban } \\
\hline Ever held hands & (83.7) & 83.1 & $(73.9)$ & 72.6 \\
\hline Ever hugged & (71.5) & 70.7 & $(44.9)$ & 60.0 \\
\hline Ever kissed & $(72.1)$ & 66.1 & $(29.3)$ & $53.6^{*}$ \\
\hline Ever had sexual relations & $(34.5)$ & 29.7 & $(13.7)$ & 19.5 \\
\hline Number of respondents reporting a romantic relationship & 25 & 74 & 38 & 87 \\
\hline \multicolumn{5}{|c|}{ Rural } \\
\hline Ever held hands & $(94.1)$ & 89.7 & 60.6 & $78.5^{* *}$ \\
\hline Ever hugged & $(76.7)$ & 79.6 & 42.3 & $73.7^{* * *}$ \\
\hline Ever kissed & $(71.0)$ & 73.9 & 29.6 & $70.5^{* * *}$ \\
\hline Ever had sexual relations & $(47.9)$ & 61.0 & 16.3 & $50.0^{* * *}$ \\
\hline Number of respondents reporting a romantic relationship & 35 & 77 & 71 & 127 \\
\hline
\end{tabular}

Note: All Ns are unweighted. * ${ }^{* *}$ and ${ }^{* * *}$ indicate that differences between 2007 and 2012 are significant at $p \leq 0.05, p \leq 0.01$ and $p \leq 0.001$, respectively. ( ) Based on 25-49 unweighted cases. ${ }^{1}$ Data on ever held hands, ever hugged and ever kissed pertain to the first or most recent/last partner, if more than one partner was reported. Data on sexual relations pertain not only to the first or most recent/last partner, but also to other romantic partners, if more than two romantic partners were reported. 
As such, there has been a notable narrowing of gender differences over time. Differences in percentages of boys and girls reporting handholding narrowed from a 27-point difference in 2007 to an 11-point difference in 2012; kissing their romantic partner narrowed from a 42-point to a 7-point difference; and having sexual relations with their romantic partner, from a 29 - to a 12 -point difference.

Rural-urban differences were consistently observed. In 2012, boys in rural settings were considerably more likely than their urban counterparts to report each behaviour and far more likely to report that they had sexual relations with their partner (61\% versus 30\%) than their urban counterparts. Girls in rural areas were moderately more likely than those in urban areas to report handholding (79\% versus $73 \%)$, but considerably more likely to report hugging ( $74 \%$ versus $60 \%$ ), kissing ( $71 \%$ versus $54 \%$ ) and especially, engaging in sex (50\% versus $20 \%$ ). That adolescents in rural areas were more likely than those in urban areas to report sex with a romantic partner may be attributed to the greater opportunities for privacy in rural than in urban areas.

In short, findings confirm that romantic relationships among adolescents almost always included some form of physical intimacy at both times. They also confirm that there has been a systematic increase in sexual relations among adolescents in a romantic relationship over the five-year period between 2007 and 2012, and that gender differences have declined, suggesting perhaps both that more boys and girls were engaging in romantic relations with partners closer in age to themselves, and that adolescents, notably girls, may have become more likely than earlier to report reliably about the activities in which they engaged with their romantic partners.

Figure 9.3: Percentage of adolescents reporting experiences of physical intimacy and sex with a romantic partner, Rajasthan, 2007 and 2012

\section{Boys}

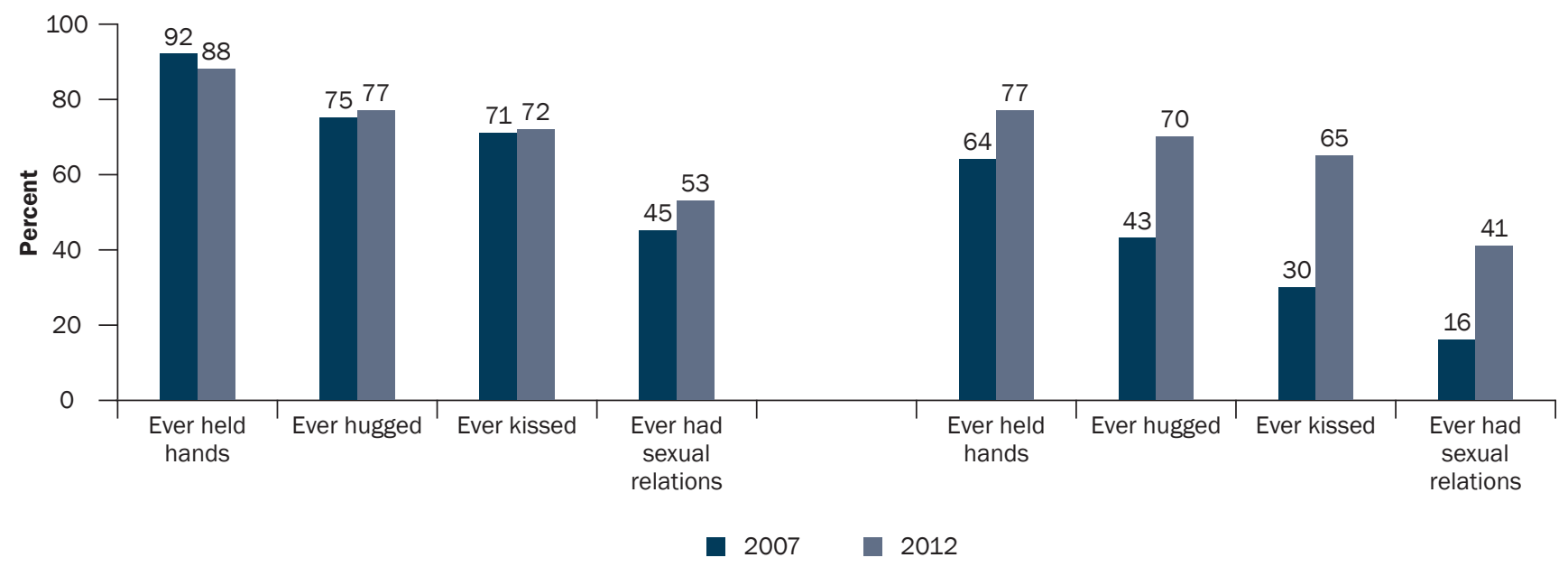

\subsubsection{Characteristics of sexual experiences within romantic relationships}

The 2012 study asked all respondents reporting sex with a romantic partner about condom and contraceptive use at first and subsequent sexual encounters with a romantic sexual partner, and the consensual nature of first sex. Findings are presented in Table 9.5. Given the small numbers of adolescent respondents, particularly girls, reporting sexual experiences in the 2007 survey, we have not presented percentages reporting these experiences in 2007 in Table 9.5; for similar reasons, we are unable to present percentages of rural and urban respondents reporting these experiences in 2012. For illustrative purposes, however, we compare below findings on contraceptive use and the consensual nature of sex with a romantic partner reported by 15-19 year old boys and by 15-24 year-old unmarried young women in 2007 (International Institute for Population Sciences and Population Council, 2009).

As seen in Table 9.5, contraceptive use in a romantic relationship was limited among adolescents in 2012. Surprisingly, contraceptive use at first sex with a romantic partner was reported by more girls than boys: 37 percent versus 29 percent. Consistent contraceptive use in 2012 was more limited, with just one-quarter of boys and girls 
alike (24-25\%) so reporting. While numbers are small, percentages do suggest a mild increase in condom use at first sex and consistent condom use from 2007 among boys (18\% in each case); while corresponding information for girls is unavailable because of small numbers in 2007, some 15 percent of young women aged 15-24 in 2007 had reported contraceptive use at first sex and in all sexual encounters, suggesting that increases had likely taken place among girls as well (International Institute for Population Sciences and Population Council, 2009).

Condom use was correspondingly limited. In 2012, just 23-24 percent of boys and girls had used a condom during their first sexual encounter with a romantic partner, and 21-22 percent reported consistent condom use (Table 9.5). Among boys, this represented an increase from 2007 when just 18 percent of boys had reported condom use at initiation as well as consistent condom use. It likely also suggests an increase among girls; while not entirely comparable; nine percent of young women aged 15-24 had reported condom use at initiation and always thereafter in 2007 (IIPS and Population Council, 2009).

Table 9.5: Characteristics of sexual experiences within romantic relationships

Percentage of adolescents reporting sexual experiences with an opposite-sex romantic partner by contraceptive use and consensuality of first and subsequent sexual encounters with the partner, Rajasthan, 2012

\begin{tabular}{lcc}
\hline Characteristics of sexual experiences $^{\mathbf{1}}$ & Boys (\%) & Girls (\%) \\
\hline Contraceptive use & & 36.9 \\
Practised contraception at first sex & 28.9 & 24.8 \\
Practised contraception in all sexual encounters ${ }^{2}$ & 24.1 & \\
Condom use & 24.2 & 23.0 \\
Used condom at first sex & 21.0 & 22.3 \\
Used condoms in all sexual encounters & \\
Consensuality of first sex & & $63.8^{*}$ \\
Male partner forced & 19.4 & $\mathbf{8 4}$ \\
\hline Number reporting sex with an opposite-sex romantic partner & $\mathbf{6 8}$ & \\
\hline
\end{tabular}

Note: All Ns are unweighted. ${ }^{*}$ indicates that the difference between 2007 and 2012 is significant at $p \leq 0.05 .{ }^{1}$ In-depth probing of sexual experiences was restricted to respondents' first or most recent/last romantic partner. Therefore, if a respondent reported his/her first sexual experience as occurring with a romantic partner other than the first or the most recent, then age, consensuality and other characteristics at first sex were unknown. ${ }^{2}$ In 2012, data were missing for two boys who reported sexual experiences with a romantic partner other than the first or most recent/last partner.

As far as consensuality of first sex is concerned, huge gender differences were reported. As seen in Table 9.5, almost two-thirds of girls (64\%) reported that their first experience of sex with a romantic partner was forced by the boyfriend. In contrast, while considerable, many fewer boys-19 percent-reported that they had forced their girlfriend to have sex. While numbers in 2007 are small, findings suggest a considerable increase in the percentage of boys admitting that they had forced their girlfriend to engage in sexual relations (from $5 \%$ in 2007). While not entirely comparable, we note that in 2007, 17 percent of young women aged 15-24 reported forced first sex perpetrated by their boyfriend (International Institute for Population Sciences and Population Council, 2009); we infer from this finding that experience of forced sex in a romantic relationship has likely increased for girls.

\subsection{Non-consensual sexual experiences}

The 2012 questionnaire also probed the extent to which adolescents had experienced such non-consensual sexual experiences as verbal harassment of a sexual nature, being forced to watch a pornographic film, non-consensual sexual touch or forced sex. In addition, boys were asked whether they had ever verbally harassed a girl, forced a girl to watch a pornographic film (only in 2012) or perpetrated non-consensual sexual touch or forced sex on a girl or woman. We acknowledge that forced sex is an extremely sensitive issue and hence, very likely to have been underreported. As such, although the study inquired about forced sex at both times through face-to-face interviews, in 
2012, it supplemented questions in the face-to-face format with a single question using an anonymous format, that is, via the sealed envelope. As mentioned earlier, girls were asked whether they had ever experienced forced sex and boys were asked whether they had ever perpetrated forced sex. Findings on all of these non-consensual sexual experiences are presented in Table 9.6.

To assess verbal harassment, we asked adolescent boys and girls whether anyone had ever made dirty comments or gestures to them, and, in the case of boys, whether they had ever made dirty comments or gestures to a girl or woman. Verbal harassment was experienced by three-fifths of all girls (59\%) and not a single boy in 2012 compared to 12 percent and one percent, respectively, in 2007. Significant increases of similar magnitude were observed over time among girls in urban and rural areas as well (from $14 \%$ to $68 \%$ in urban areas; from $11 \%$ to $54 \%$ in rural areas). Conversely, significantly more boys in 2012 than 2007 reported verbally harassing a girl or woman: 27 percent versus 14 percent. As in the case of girls' experiences, a similar pattern prevailed among those in urban and rural areas as well (from $18 \%$ to $29 \%$ in urban areas; from $13 \%$ to $26 \%$ in rural areas).

In 2012 (but not in 2007), adolescents were asked whether anyone had forced them to watch pornographic films, and, in the case of boys, whether they had forced someone to watch a pornographic film. Notably, more boys than girls so reported ( $8 \%$ versus $2 \%$ ), and this pattern prevailed in urban ( $7 \%$ versus $2 \%$ ) and rural ( $9 \%$ versus $2 \%$ ) areas. In contrast, just one percent of boys reported that they had forced someone to watch a pornographic film, with no urban-rural difference.

Non-consensual sexual touch was measured by questions that probed whether the respondent had ever been a victim of unwanted hugging or kissing in a sexual way, whether someone had touched their private parts without consent or had forced them to touch the perpetrator's private parts, and finally, whether someone had attempted to have sex with the respondent against her/his will using physical force or threats. Boys were also asked an additional question about whether they had ever perpetrated any of these acts. The findings presented is Table 9.6, indicate that among boys, 0-1 percent reported the experience of unwanted hugging or kissing in a sexual way, touching of their private parts without consent, being forced to touch a perpetrator's private parts, and finally, any attempt to have sex with the respondent against his will using physical force or threats. At the same time, four percent reported that they had hugged, kissed or touched a girl without her consent. Reports of boys as victims and perpetrators of forced touch were about the same as in 2007. In contrast, three percent of girls reported that someone had hugged or kissed them forcibly and nine percent reported that someone had forcibly touched their private parts or forced them to touch the perpetrator's private parts, reflecting a modest but significant increase from 2007 in the former (from 1\%), and a reduction (from 12\%) in the latter; two percent reported the experience of attempted forced sex. Patterns in urban and rural areas were similar to those observed for all adolescents in 2012. Further, urban-rural differences were, for the most part, negligible among boys and girls; however, girls in urban areas were more likely than their rural counterparts to report unwanted touch of private parts (13\% versus $8 \%$ ).

Questions on forced sex were posed in two ways: via a specific question on first sex with a romantic opposite-sex partner and a more general question about any forced sex with any partner. Measured in this way, not a single boy reported the experience of forced sex; however, five percent of girls had experienced forced sex, representing a significant increase over 2007 when just 0.2 percent had admitted a forced sex experience. Although increases were observed in urban and rural areas, urban-rural differences were marked in 2012, with rural girls considerably more likely than urban girls to have experienced forced sex ( $7 \%$ versus $1 \%)$. As far as the perpetration of forced sex is concerned, in the face-to-face interview, three percent of boys admitted that they had forced a girl or woman to have sex against her will, an increase from 0.2 percent in 2007; percentages were almost identical in urban and rural areas at both times.

Giving adolescents the opportunity in 2012 to report forced sex anonymously did indeed result in more girls reporting the experience of forced sex and more boys reporting its perpetration as compared with face-to-face responses. Indeed, six percent of girls reported in the anonymous format that they had experienced forced sex (compared to $5 \%$ in the face-to-face interview). As many as five percent of boys reported the perpetration of forced sex in the anonymous format compared to three percent in the face-to-face format. Combining responses in both formats, a total of nine percent of girls reported a forced sexual encounter, and a total of seven percent of boys reported forcing a girl or woman to engage in sex against her will. Forced sexual experiences were more likely to be reported by rural than urban girls (11\% versus $5 \%$ ), but rural-urban differences were not observed in boys' reporting of perpetration of forced sex. 
Table 9.6: Non-consensual sexual experiences

Percentage of adolescents reporting various non-consensual sexual experiences, according to residence, Rajasthan, 2007 and 2012

\begin{tabular}{|c|c|c|c|c|}
\hline \multirow[b]{2}{*}{ Non-consensual sexual experiences } & \multicolumn{2}{|c|}{ Boys (\%) } & \multicolumn{2}{|c|}{ Girls (\%) } \\
\hline & 2007 & 2012 & 2007 & 2012 \\
\hline \multicolumn{5}{|c|}{ Combined } \\
\hline \multicolumn{5}{|l|}{ Respondent (girl) ever experienced the following: } \\
\hline Someone made dirty comments or gestures to her & 1.1 & $0.0^{* *}$ & 11.9 & $59.0^{* * *}$ \\
\hline Someone forced her to watch porn & na & 8.1 & na & 2.0 \\
\hline Someone hugged or kissed her forcibly & 0.7 & 1.4 & 1.2 & $2.8^{*}$ \\
\hline Someone touched/made to touch her private parts forcibly & 1.1 & 1.0 & 12.0 & 9.3 \\
\hline Someone attempted to have sex with her & 0.0 & 0.0 & 0.5 & $1.8^{*}$ \\
\hline $\begin{array}{l}\text { Someone (including romantic partner) forced her to have } \\
\text { sex (as reported in face-to-face interview) }\end{array}$ & 0.0 & 0.0 & 0.2 & $4.9^{* * *}$ \\
\hline $\begin{array}{l}\text { Someone (including romantic partner) forced her to have } \\
\text { sex (as reported in sealed envelope anonymously) }\end{array}$ & na & 0.0 & na & $6.1^{* * *}$ \\
\hline $\begin{array}{l}\text { Any experience of forced sex (as reported through either of } \\
\text { these two techniques) }\end{array}$ & NA & 0.0 & NA & 9.0 \\
\hline \multicolumn{5}{|l|}{ Respondent (boy) ever perpetrated the following: } \\
\hline Made dirty comments/gestures at girls/women & 14.1 & $27.0^{* \star *}$ & NA & NA \\
\hline Forced girl/woman to watch porn & 0.0 & $1.2^{*}$ & NA & NA \\
\hline Hugged/kissed/touched private parts of a girl/woman forcibly & 4.3 & 3.7 & NA & NA \\
\hline Attempted to have sex with a girl/woman & 0.0 & 0.7 & NA & NA \\
\hline $\begin{array}{l}\text { Forced a girl/woman (including girlfriend) to have sex (as } \\
\text { reported in face-to-face interview) }\end{array}$ & 0.2 & $2.9^{* * *}$ & NA & NA \\
\hline $\begin{array}{l}\text { Forced a girl/woman (including girlfriend) to have sex (as } \\
\text { reported in sealed envelope anonymously) }\end{array}$ & na & 5.0 & na & NA \\
\hline $\begin{array}{l}\text { Any perpetration of forced sex (as reported through either of } \\
\text { these two techniques) }\end{array}$ & NA & 7.2 & NA & NA \\
\hline Number of respondents & 774 & 745 & 1,487 & 1,164 \\
\hline \multicolumn{5}{|c|}{ Urban } \\
\hline \multicolumn{5}{|l|}{ Respondent (girl) ever experienced the following: } \\
\hline Someone made dirty comments or gestures to her & 0.0 & 0.0 & 13.5 & $67.8^{* * *}$ \\
\hline Someone forced her to watch porn & na & 7.3 & na & 2.1 \\
\hline Someone hugged or kissed her forcibly & 0.0 & $2.5^{*}$ & 0.4 & $3.0^{* * *}$ \\
\hline Someone touched/made to touch private parts forcibly & 0.0 & 1.7 & 13.5 & 12.8 \\
\hline Someone attempted to have sex with her & 0.0 & 0.0 & 0.2 & $1.5^{*}$ \\
\hline $\begin{array}{l}\text { Someone (including romantic partner) forced her to have } \\
\text { sex (as reported in face-to-face interview) }\end{array}$ & 0.0 & 0.0 & 0.0 & $1.3^{*}$ \\
\hline $\begin{array}{l}\text { Someone (romantic partner) forced her to have sex (as } \\
\text { reported in sealed envelope anonymously) }\end{array}$ & na & 0.0 & na & $4.2^{* * *}$ \\
\hline $\begin{array}{l}\text { Any experience of forced sex (as reported through either of } \\
\text { these two techniques) }\end{array}$ & NA & 0.0 & NA & 5.3 \\
\hline
\end{tabular}




\begin{tabular}{|c|c|c|c|c|}
\hline \multirow[b]{2}{*}{ Non-consensual sexual experiences } & \multicolumn{2}{|c|}{ Boys (\%) } & \multicolumn{2}{|c|}{ Girls (\%) } \\
\hline & 2007 & 2012 & 2007 & 2012 \\
\hline \multicolumn{5}{|l|}{ Respondent (boy) ever perpetrated the following: } \\
\hline Made dirty comments/gestures at girls/women & 18.1 & $29.0^{* *}$ & NA & NA \\
\hline Forced girl/woman to watch porn & 0.0 & $1.0^{*}$ & NA & NA \\
\hline Hugged/kissed/touched private parts of a girl/woman forcibly & 4.9 & 4.1 & NA & NA \\
\hline Attempted to have sex with a girl/woman & 0.0 & 1.2 & NA & NA \\
\hline $\begin{array}{l}\text { Forced a girl/woman (including girlfriend) to have sex (as } \\
\text { reported in face-to-face interview) }\end{array}$ & 0.3 & $2.5^{*}$ & NA & NA \\
\hline $\begin{array}{l}\text { Forced a girl/woman (including girlfriend) to have sex (as } \\
\text { reported in sealed envelope anonymously) }\end{array}$ & na & 4.9 & na & NA \\
\hline $\begin{array}{l}\text { Any perpetration of forced sex (as reported through either of } \\
\text { these two techniques) }\end{array}$ & NA & 6.8 & NA & NA \\
\hline Number of respondents & 327 & 369 & 513 & 538 \\
\hline
\end{tabular}

\section{Respondent (girl) ever experienced the following:}

Someone made dirty comments or gestures to her

Someone forced her to watch porn

Someone hugged or kissed her forcibly

\begin{tabular}{|c|c|c|c|}
\hline 1.6 & $0.0^{* *}$ & 11.3 & $54.4^{* * *}$ \\
\hline na & 8.5 & na & 1.9 \\
\hline 1.0 & 1.0 & 1.5 & 2.7 \\
\hline 1.6 & 0.7 & 11.4 & $7.5^{*}$ \\
\hline 0.0 & 0.0 & 0.6 & 1.9 \\
\hline 0.0 & 0.0 & 0.3 & $6.9^{* * *}$ \\
\hline na & 0.0 & na & $7.2^{* * *}$ \\
\hline NA & 0.0 & NA & 10.9 \\
\hline 12.7 & $26.2^{* * *}$ & NA & NA \\
\hline 0.0 & $1.2^{*}$ & NA & NA \\
\hline 4.1 & 3.6 & NA & NA \\
\hline 0.0 & 0.6 & NA & NA \\
\hline 0.2 & $3.0^{* *}$ & NA & NA \\
\hline na & 5.1 & na & NA \\
\hline 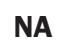 & 7.3 & NA & NA \\
\hline & 376 & 974 & 626 \\
\hline
\end{tabular}

Someone touched/made to touch private parts forcibly

Someone attempted to have sex with her

Someone (including romantic partner) forced her to have sex (as reported in face-to-face interview)

Someone (including romantic partner) forced her to have sex (as reported in sealed envelope anonymously)

Any experience of forced sex (as reported through either of these two techniques)

Respondent (boy) ever perpetrated the following:

Made dirty comments/gestures at girls/women

Forced girl/woman to watch porn

Hugged/kissed/touched private parts of a girl/woman forcibly

Attempted to have sex with a girl/woman

Forced a girl/woman (including girlfriend) to have sex (as reported in face-to-face interview)

Forced a girl/woman (including girlfriend) to have sex (as reported in sealed envelope anonymously)

Any perpetration of forced sex (as reported through either of these two techniques)

Number of respondents

626

Note: All Ns are unweighted. *, ${ }^{* *}$ and ${ }^{* *}$ indicate that differences between 2007 and 2012 are significant at $p \leq 0.05, p \leq 0.01$ and $p \leq 0.001$, respectively. na: Not asked in 2007 survey. NA: Not applicable. 
Table 9.7 presents percentages of surveyed adolescents reporting the experience (girls) and perpetration (boys) of forced sex in 2012, by selected socio-demographic characteristics. As indicated earlier, such background characteristics as work status and household economic status reflect the situation of adolescents at the time of interview, and not necessarily at the time when the non-consensual incident took place.

With regard to girls' experience of forced sex, findings suggest that older girls, Hindu girls, and girls from scheduled castes and especially scheduled tribes were more likely than other girls to report the experience of forced sex. Notably, as many as 26 percent of girls from scheduled tribes and ten percent of those from scheduled castes had experienced forced sex, compared to five percent of those from general castes. Findings also confirm that poorly educated girls and girls from poor households are more likely than better educated and better off girls to experience forced sex: while 15 percent of uneducated girls and 12-15 percent of girls from the poorest quintiles (first and second) had experienced forced sex, just 3-4 percent of those who had completed Class 12 or were from the wealthiest households (fifth quintile) had so experienced. Finally, working girls were somewhat more likely to have experienced forced sex than other girls (12\% versus $8 \%)$.

Table 9.7: Perpetration and experience of forced sex

\section{Percentage of adolescents reporting perpetration (boys) and forced sexual experience (girls) by selected} background characteristics, Rajasthan, 2012

\begin{tabular}{|c|c|c|}
\hline Background characteristics & Boys (\%) & Girls (\%) \\
\hline \multicolumn{3}{|l|}{ Age (years) } \\
\hline $15-17$ & 3.9 & 8.5 \\
\hline $18-19$ & 14.1 & 10.6 \\
\hline \multicolumn{3}{|l|}{ Religion } \\
\hline Hindu & 7.4 & 10.3 \\
\hline Muslim & 5.4 & 2.7 \\
\hline Other ${ }^{1}$ & $\#$ & (3.9) \\
\hline \multicolumn{3}{|l|}{ Caste } \\
\hline SC & 10.2 & 10.0 \\
\hline ST & 6.1 & 25.9 \\
\hline $\mathrm{OBC}$ & 7.1 & 6.5 \\
\hline General $^{2}$ & 3.7 & 4.6 \\
\hline \multicolumn{3}{|l|}{ Educational level (years) } \\
\hline None $^{3}$ & $\#$ & 14.7 \\
\hline $1-7$ & 11.7 & 11.1 \\
\hline $8-9$ & 6.6 & 10.5 \\
\hline $10-11$ & 5.0 & 7.0 \\
\hline 12 and above & 8.7 & 3.2 \\
\hline \multicolumn{3}{|l|}{ Worked in last 12 months } \\
\hline Yes & 12.2 & 12.0 \\
\hline No & 5.6 & 8.1 \\
\hline \multicolumn{3}{|l|}{ Wealth quintile } \\
\hline First & 7.6 & 15.3 \\
\hline Second & 4.5 & 12.3 \\
\hline Third & 8.6 & 9.0 \\
\hline Fourth & 8.7 & 6.4 \\
\hline Fifth & 6.7 & 3.9 \\
\hline Total & 7.2 & 9.0 \\
\hline
\end{tabular}

Note: ( ) Based on 25-49 unweighted cases. \# Percentage not shown; based on fewer than 25 unweighted cases. OBC: Other backward caste. SC: Scheduled caste. ST: Scheduled tribe. ${ }^{1}$ Includes Christian, Buddhist, Neo-Buddhist, Sikh, Jain, Jewish, Parsi/ Zoroastrian, Sarana and no specified religion. ${ }^{2}$ Includes all those not belonging to SC, ST or OBC. ${ }^{3}$ Includes those who are nonliterate and literate with no formal schooling. 
Perpetration of forced sex by boys differed by a few background characteristics. Older boys were more likely than younger boys to report having perpetrated forced sex on a girl or woman (14\% versus $4 \%$ ), and boys from scheduled castes most likely and those from general castes least likely to so report (10\% versus $4 \%$ ). Poorly educated boys (those with 1-7 years of schooling) were more likely than other boys to have perpetrated forced sex (12\% versus $5-9 \%)$, and working boys more likely to have done so than other boys (12\% versus $6 \%$ ). Differences were not observed however by religion or household economic status.

\subsection{Sexual experiences within romantic and other relationships}

Aside from the romantic and forced sexual relationships discussed in previous sections, the study also probed adolescents' experiences of sex with other partners, including casual partners, and in situations characterised by exchange of gifts or favours. In addition, boys were asked about their sexual relationships with sex workers and married girls/women.

In this and subsequent sections of this chapter, we present findings on the prevalence of sexual experiences (irrespective of whether such experiences took place within romantic or other partnerships or in forced or consensual relationships) among all adolescents in the sample.

\subsubsection{Extent of sexual experiences}

Table 9.8 reports percentages of respondents reporting sex in any of the situations described above. Findings indicate that for 11 percent of boys and eight percent of girls, sexual relations occurred in a romantic relationship with a person of the opposite sex, significantly higher than the four percent and one percent reported in 2007. Also notable are findings relating to forced sex: as many as five percent of all girls reported the experience of forced sex in the face-to-face format, significantly higher than the 0.2 percent reported in 2007 (not a single boy so reported), and three percent of boys reported the perpetration of forced sex, also significantly more than in 2007 (0.2\%).

Sex in exchange for money or favours was rarely reported (0.1-0.2\%). Casual sex was reported by two percent of boys but hardly any girls. In addition, one percent of boys reported sex with a sex worker; while small, this represents a significant increase over 2007 (0.1\%); one percent of boys, in addition, reported sex with a married woman (up from $0.3 \%$ in 2007 ).

Thus, in all, 12 percent of boys and eight percent of girls reported sexual relations in the course of face-to-face interviews, a significant increase from five percent and one percent, respectively, reported in 2007.

Acknowledging that adolescents may have been reluctant to disclose behaviours perceived as socially unacceptable such as sexual relations, our study also inquired about their sexual experiences through anonymous reporting via the sealed envelope method. Adolescents anonymously reported whether (a) they had ever engaged in sexual relations (in 2007 and 2012); and (b) whether they (girls) had ever been forced to engage in sexual relations)/whether they (boys) had ever forced a girl/woman to engage in sexual relations. We caution that the opportunity to report forced sex in the anonymous format was provided only in 2012, and overall percentages reporting forced sex at the two points in time are therefore not quite comparable.

Percentages of surveyed adolescents reporting the experience of any sex via either method (face-to-face or in response to the question posed in the sealed envelope relating to the experience of sexual relations) are presented in Table 9.8 and confirm that several adolescents who had not disclosed their experience of sex in the face-toface interview did so in the anonymous sealed envelope format. Indeed, compared to the 12 percent of boys and eight percent of girls who admitted sexual relations in the face-to-face interview in 2012, in the anonymous format, percentages increased to 15 and nine, respectively. Corresponding responses in 2007 were significantly lower (6\% and $2 \%$, respectively).

Percentages of adolescents reporting the experience of any sex in the face-to-face format as well as of any sex and/ or forced sex (experienced or perpetrated) in the anonymous format are also presented in Table 9.8. Percentages reporting such experiences ranged from 16 among boys to 11 among girls. Since we had not probed forced sexual experiences anonymously in 2007, comparable percentages for 2007 are not available.

Rural-urban differences were evident. Rural adolescents were more likely than urban adolescents to report sex with a romantic partner (12\% versus $6 \%$ among boys, $10 \%$ versus $3 \%$ among girls). While rural and urban boys were 
Table 9.8 Overall sexual experience

Percentage of adolescents reporting sexual experiences with any partner by different reporting methods, according to residence, Rajasthan, 2007 and 2012

\begin{tabular}{|c|c|c|c|c|}
\hline \multirow[b]{2}{*}{ Sexual experiences and reporting methods } & \multicolumn{2}{|c|}{ Boys (\%) } & \multicolumn{2}{|c|}{ Girls (\%) } \\
\hline & 2007 & 2012 & 2007 & 2012 \\
\hline \multicolumn{5}{|c|}{ Combined } \\
\hline \multicolumn{5}{|l|}{ Reported sexual experience with: } \\
\hline Opposite-sex romantic partner & 3.5 & $10.5^{\star * *}$ & 1.2 & $7.5^{* \star *}$ \\
\hline Someone who forced respondent to have sex & 0.0 & 0.0 & 0.2 & $4.9^{* * *}$ \\
\hline Girl whom respondent forced & 0.2 & $2.9^{* * *}$ & NA & NA \\
\hline Someone in exchange for money/favour & 0.0 & 0.1 & 0.2 & 0.2 \\
\hline Sex worker & 0.1 & $1.2^{* \star}$ & NA & NA \\
\hline Married woman & 0.3 & 0.9 & NA & NA \\
\hline Casual partner & 0.8 & 1.9 & 0.1 & 0.1 \\
\hline Any sexual experience reported in face-to-face interview & 4.6 & $11.8^{* * *}$ & 1.2 & $7.5^{* * *}$ \\
\hline \multicolumn{4}{|c|}{ Any sexual experience reported anonymously in response to the } & $7.3^{* * *}$ \\
\hline \multicolumn{5}{|l|}{ Any sexual experience reported in the face-to-face interview } \\
\hline experience & 6.1 & $15.1^{* * *}$ & 1.8 & $9.1^{* * *}$ \\
\hline \multicolumn{5}{|c|}{ Any forced sex/perpetration of forced sex reported anonymously } \\
\hline in response to the question on experience of forced sex & na & 5.0 & na & 6.1 \\
\hline \multicolumn{5}{|l|}{$\begin{array}{l}\text { Any sexual experience reported in the face-to-face interview } \\
\text { or anonymously in response to questions on both any sexual }\end{array}$} \\
\hline experience and any forced sexual experience & na & 15.6 & na & 11.1 \\
\hline Number of respondents & 774 & 745 & 1,487 & 1,164 \\
\hline
\end{tabular}

Urban

Reported sexual experience with:

Opposite-sex romantic partner

2.5

Someone who forced respondent to have sex

Girl whom respondent forced

Someone in exchange for money/favour

Sex worker

Married woman

Casual partner

Any sexual experience reported in face-to-face interview

Any sexual experience reported anonymously in response to the question on any sexual experience only

Any sexual experience reported in the face-to-face interview or anonymously in response to the question on any sexual experience

Any forced sex/perpetration of forced sex reported anonymously in response to the question on experience of forced sex

Any sexual experience reported in the face-to-face interview or anonymously in response to questions on both any sexual experience and any forced sexual experience

Number of respondents
$6.0^{*}$

0.0

$2.5^{*}$

0.3

2.0

0.6

1.4

8.2*

5.7

9.6

4.9

10.4

369
$3.2^{*}$

$1.3^{*}$

NA

0.0

NA

NA

0.0

3.2*

$1.03 .2^{*}$

$4.9^{\text {** }}$

1.0

1.2

$5.7^{* *}$

na

4.2 
Table 9.8: (Cont'd)

\begin{tabular}{|c|c|c|c|c|}
\hline \multirow[b]{2}{*}{ Sexual experiences and reporting methods } & \multicolumn{2}{|c|}{ Boys (\%) } & \multicolumn{2}{|c|}{ Girls (\%) } \\
\hline & 2007 & 2012 & 2007 & 2012 \\
\hline \multicolumn{5}{|c|}{ Rural } \\
\hline \multicolumn{5}{|l|}{ Reported sexual experience with: } \\
\hline Opposite-sex romantic partner & 3.8 & $12.2^{* * *}$ & 1.2 & $9.7^{* * *}$ \\
\hline Someone who forced respondent to have sex & 0.0 & 0.0 & 0.3 & $6.9^{* * *}$ \\
\hline Girl whom respondent forced & 0.2 & $3.0^{* *}$ & NA & NA \\
\hline Someone in exchange for money/favour & 0.0 & 0.0 & 0.2 & 0.3 \\
\hline Sex worker & 0.0 & 0.9 & NA & NA \\
\hline Married woman & 0.4 & 0.9 & NA & NA \\
\hline Casual partner & 0.9 & 2.0 & 0.1 & 0.2 \\
\hline Any sexual experience reported in face-to-face interview & 5.2 & $13.1^{* *}$ & 1.3 & $9.7^{* * *}$ \\
\hline $\begin{array}{l}\text { Any sexual experience reported anonymously in response } \\
\text { question on any sexual experience only }\end{array}$ & 4.1 & $12.4^{* * *}$ & 1.7 & $8.5^{* * *}$ \\
\hline \multicolumn{5}{|l|}{ Any sexual experience reported in the face-to-face interview } \\
\hline experience & 6.3 & $17.2^{* * *}$ & 2.0 & $10.9^{* * *}$ \\
\hline \multicolumn{5}{|c|}{ Any forced sex/perpetration of forced sex reported anonymously } \\
\hline \multicolumn{5}{|l|}{$\begin{array}{l}\text { Any sexual experience reported in the face-to-face interview } \\
\text { or anonymously in response to questions on both any sexual }\end{array}$} \\
\hline experience and any forced sexual experience & na & 17.5 & na & 13.0 \\
\hline Number of respondents & 447 & 376 & 974 & 626 \\
\hline
\end{tabular}

Note: All Ns are unweighted. *, ** and ${ }^{* * *}$ indicate that differences between 2007 and 2012 are significant at $p \leq 0.05, p \leq 0.01$ and $p \leq 0.001$, respectively. na: Not asked in 2007 survey. NA: Not applicable.

equally likely to report perpetrating forced sex on a girl/woman (3\% each), rural girls were more likely than urban girls to report the experience of forced sex (7\% versus 1\%). Overall, rural adolescents were more likely than the urban to have reported any sexual experience both in the face-to-face format (13\% versus $8 \%$ among boys; $10 \%$ versus 3\% among girls) as well as in the face-to-face format supplemented by the anonymous format (18\% versus $10 \%$ among boys; $13 \%$ versus $8 \%$ among girls; see also Figure 9.4).

Figure 9.4: Percentage of adolescents reporting any sexual experience (in face-to-face interviews or anonymously), according to residence, Rajasthan, 2007 and 2012
Combined
Urban
Rural

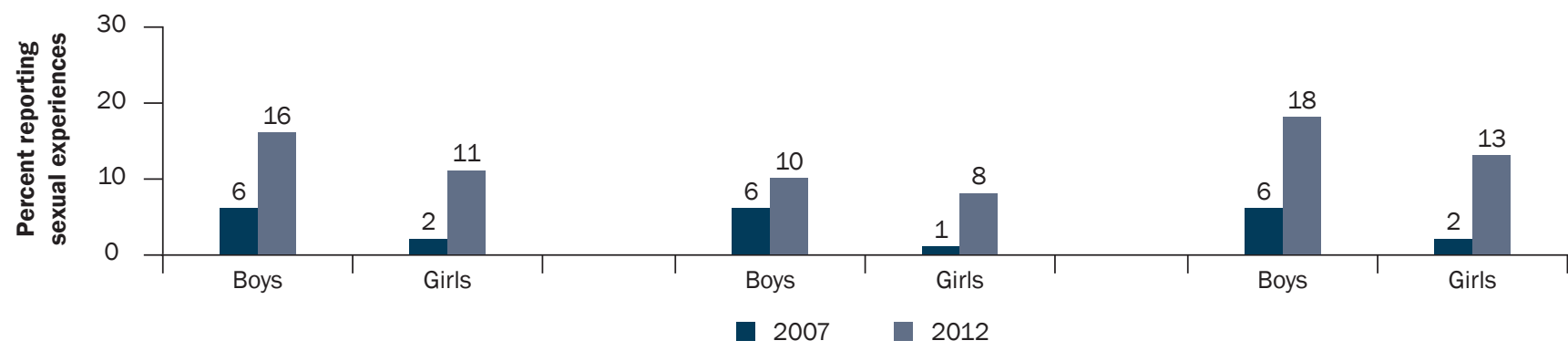

Note: Figures are not entirely comparable, since in 2012, two questions were posed anonymously (any sexual experience and any forced sexual experience) while in 2007, only one question was posed anonymously (any sexual experience). 
Table 9.9 presents percentages of surveyed adolescents reporting sexual experiences by selected sociodemographic characteristics in 2012. As indicated earlier, such background characteristics as work status and household economic status reflect the situation of adolescents at the time of the interview, and not necessarily at the time when sex was experienced.

Age profiles suggest a positive association between age and sexual experience among boys, with those aged 18-19 far more likely than younger respondents to report sexual experience (26\% versus $11 \%)$; older girls, in contrast, were just mildly more likely to have experienced sexual relations than were their younger counterparts (13\% versus $10 \%)$. A similar pattern is observed among rural and urban respondents as well.

Differentials by religion were mild among boys and wide among girls, with Hindu boys moderately more likely than Muslim boys (16\% versus 12\%), and Hindu girls considerably more likely than Muslim girls (13\% versus 5\%) to report their sexual experiences (Table 9.9). Notably, differentials were not evident at all among urban adolescents, but were wide among rural girls (15\% versus $2 \%$ ). Caste-wise differences were also evident. Among boys, those from general castes were least likely and those from scheduled castes and tribes most likely to report their sexual experiences ( $9 \%$ and $19-20 \%$, respectively), although differentials in rural and urban areas, were less stark. Castewise differences among girls were wide: far more girls from scheduled tribes than other caste groups reported sexual experiences (31\% versus $6-12 \%$ ), and patterns were similar in both rural and urban areas.

Table 9.9 further shows that associations between reported sexual experience and educational attainment differed by sex of the respondent and rural-urban residence. Among boys, those with 1-7 and 12 or more years of education were more likely to report sexual experiences ( $25 \%$ and $18 \%$, respectively) than were those with 8-9 or 10-11 years of education (13-14\%); while a similar pattern prevailed in rural areas (25\% and $23 \%$ among boys with $1-7$ and 12 or more years of education, respectively, versus $13-17 \%$ among those with $8-11$ years of education), in urban areas, the least educated were far more likely than other groups to so report ( $28 \%$ versus $6-10 \%)$. Among girls, the association was more consistently inverse, with reported sexual experience falling from 16 percent among uneducated girls to six percent among those with 12 or more years of education, and largely similar patterns evident among rural and urban girls as well.

Working adolescents were consistently more likely than their non-working counterparts to report sexual experience, and this pattern was evident among all boys and all girls as well as among those in rural and urban areas. Overall, 29 percent and 15 percent of working boys and girls, respectively, reported sexual experiences compared to 11 percent and ten percent, respectively, of their non-working counterparts, a finding that may be attributed to the greater mobility and relative freedom from parental supervision experienced by working adolescents as compared to non-working adolescents.

Finally, associations between reported sexual experience and household economic status differed for boys and girls. Among boys, no association could be discerned, with percentages ranging from 14 to 17 across all wealth quintiles; a generally similar pattern was observed among rural boys, but in urban areas boys in the wealthiest two quintiles were less likely to report sexual experiences than less educated boys. Among girls, in contrast, an inverse relationship was observed, with percentages falling from 17 among girls in the poorest (first) quintile to 7-8 among those in the wealthiest two quintiles; while this pattern was observed also in rural areas, an erratic association was observed in urban areas.

\subsubsection{Age at sexual initiation}

Table 9.10 presents cumulative percentages of surveyed adolescents who experienced first sex by age, presented in single ages from 15 to 19 (among all adolescents in the sample) calculated using life table techniques, with censoring taking place at the time of the interview, in 2007 and 2012. For adolescents who reported sexual experiences only through the anonymous sealed envelope method, age at sexual initiation was imputed conservatively, using their current age as the age at sexual initiation.

Several findings are notable. Similar proportions of boys and girls had initiated sex before age $15(2 \%)$ and before age 16 (6-7), in both cases larger percentages than in 2007. Gender differences emerge at age 17: sexual initiation took place below age 17 for 12 percent of boys and nine percent of girls, and differences widened at ages 18 (19\% and 13\%, respectively) and 19 (29\% and 23\%, respectively). At each age, sexual experience was far greater in 2012 
Table 9.9: Overall sexual experience by background characteristics

Percentage of adolescents reporting any sexual experience (in face-to-face interviews or anonymously ${ }^{1}$ ) by selected background characteristics, according to residence, Rajasthan, 2012

\begin{tabular}{|c|c|c|c|c|c|c|}
\hline \multirow[b]{2}{*}{ Background characteristics } & \multicolumn{2}{|l|}{ Combined } & \multicolumn{2}{|l|}{ Urban } & \multicolumn{2}{|l|}{ Rural } \\
\hline & Boys (\%) & Girls (\%) & Boys (\%) & Girls (\%) & Boys (\%) & Girls (\%) \\
\hline \multicolumn{7}{|l|}{ Age (years) } \\
\hline $15-17$ & 10.9 & 10.4 & 6.7 & 6.9 & 12.5 & 12.2 \\
\hline $18-19$ & 25.5 & 13.2 & 17.6 & 9.0 & 28.6 & 15.7 \\
\hline \multicolumn{7}{|l|}{ Religion } \\
\hline Hindu & 16.0 & 12.6 & 10.6 & 7.7 & 17.7 & 14.8 \\
\hline Muslim & 11.9 & 4.7 & 10.0 & 7.3 & $\#$ & 1.6 \\
\hline Other ${ }^{2}$ & $\#$ & (3.9) & $\#$ & $\#$ & $\#$ & $(3.7)$ \\
\hline \multicolumn{7}{|l|}{ Caste } \\
\hline $\mathrm{SC}$ & 18.9 & 12.2 & 16.6 & 13.0 & 19.6 & 11.9 \\
\hline ST & 19.5 & 31.3 & $\#$ & $(20.3)$ & 20.2 & 34.0 \\
\hline OBC & 15.0 & 8.1 & 6.5 & 6.1 & 17.3 & 9.1 \\
\hline General $^{3}$ & 9.3 & 6.2 & 9.8 & 3.8 & (8.5) & 8.3 \\
\hline \multicolumn{7}{|l|}{ Educational level (years) } \\
\hline None $^{4}$ & $\#$ & 15.9 & $\#$ & $\#$ & $\#$ & 16.8 \\
\hline $1-7$ & 25.4 & 13.0 & $(27.6)$ & 10.9 & 24.7 & 13.9 \\
\hline $8-9$ & 12.6 & 14.1 & 10.0 & 10.5 & 13.3 & 15.7 \\
\hline $10-11$ & 13.6 & 7.4 & 6.0 & 2.5 & 16.7 & 10.9 \\
\hline 12 and above & 18.2 & 5.8 & 8.3 & 7.0 & 23.0 & 4.5 \\
\hline \multicolumn{7}{|l|}{ Worked in last 12 months } \\
\hline Yes & 29.2 & 15.3 & 21.9 & 8.6 & 31.9 & 17.9 \\
\hline No & 11.2 & 9.9 & 6.6 & 7.3 & 12.9 & 11.4 \\
\hline \multicolumn{7}{|l|}{ Wealth quintile } \\
\hline First & 14.8 & 17.3 & $\#$ & $(5.8)$ & 14.8 & 18.6 \\
\hline Second & 16.1 & 14.2 & $(12.5)$ & 8.5 & 16.6 & 16.2 \\
\hline Third & 17.4 & 10.9 & $(14.7)$ & 2.5 & 17.9 & 14.1 \\
\hline Fourth & 15.6 & 8.0 & 10.7 & 10.8 & 19.4 & 5.8 \\
\hline Fifth & 14.0 & 6.8 & 8.0 & 7.3 & $\#$ & 6.1 \\
\hline Total & 15.6 & 11.1 & 10.4 & 7.5 & 17.5 & 13.0 \\
\hline
\end{tabular}

Note: ( ) Based on 25-49 unweighted cases. \# Percentage not shown; based on fewer than 25 unweighted cases. OBC: Other backward caste. SC: Scheduled caste. ST: Scheduled tribe. ${ }^{1}$ Anonymous reporting of both any sexual experience and any forced sexual experience. ${ }^{2}$ Includes Christian, Buddhist, Neo-Buddhist, Sikh, Jain, Jewish, Parsi/Zoroastrian, Sarana and no specified religion. ${ }^{3}$ Includes all those not belonging to SC, ST or OBC. ${ }^{4}$ Includes those who are non-literate and literate with no formal schooling.

than in 2007: for example, while 29 percent and 23 percent of boys and girls, respectively, had initiated sexual relations before age 19 in 2012, corresponding percentages were just 13 and 4 in 2007.

Also notable were rural-urban differences. Adolescents in rural areas were more likely to initiate sexual relations earlier than their urban counterparts, and differences were particularly wide among boys. For example, 22 percent of boys in rural areas compared to ten percent of those in urban areas had initiated sexual relations before age 18; corresponding percentages among girls were 15 and 9 . 
Table 9.10: Age at sexual initiation

Cumulative percentage of adolescents by age at first sexual experience, according to residence, Rajasthan, 2007 and 2012

\begin{tabular}{|c|c|c|c|c|}
\hline \multirow[b]{2}{*}{ Age at first sex ${ }^{1}$} & \multicolumn{2}{|c|}{ Boys (\%) } & \multicolumn{2}{|c|}{ Girls (\%) } \\
\hline & 2007 & 2012 & 2007 & 2012 \\
\hline \multicolumn{5}{|c|}{ Combined } \\
\hline \multicolumn{5}{|c|}{ First sex occurred before age (years): } \\
\hline 15 & NC & 2.3 & 0.4 & 2.3 \\
\hline 16 & 0.9 & 6.5 & 1.3 & 5.8 \\
\hline 17 & 3.4 & 12.4 & 1.9 & 9.3 \\
\hline 18 & 5.7 & 18.5 & 2.4 & 13.0 \\
\hline 19 & 13.6 & 29.1 & 3.5 & 22.7 \\
\hline Number of respondents & 774 & 745 & 1,487 & 1,164 \\
\hline \multicolumn{5}{|c|}{ Urban } \\
\hline \multicolumn{5}{|c|}{ First sex occurred before age (years): } \\
\hline 15 & NC & 1.1 & 0.4 & 0.2 \\
\hline 16 & 0.0 & 4.8 & 0.9 & 2.0 \\
\hline 17 & 0.4 & 6.9 & 1.2 & 4.8 \\
\hline 18 & 4.6 & 10.2 & 1.7 & 9.4 \\
\hline 19 & 14.0 & 19.2 & 1.7 & 15.9 \\
\hline Number of respondents & 327 & 369 & 513 & 538 \\
\hline \multicolumn{5}{|c|}{ Rural } \\
\hline \multicolumn{5}{|c|}{ First sex occurred before age (years): } \\
\hline 15 & NC & 2.7 & 0.4 & 3.4 \\
\hline 16 & 1.2 & 7.2 & 1.5 & 7.8 \\
\hline 17 & 4.6 & 14.4 & 2.2 & 11.8 \\
\hline 18 & 6.1 & 21.5 & 2.6 & 14.9 \\
\hline 19 & 13.2 & 32.8 & 4.5 & 26.6 \\
\hline Number of respondents & 447 & 376 & 974 & 626 \\
\hline
\end{tabular}

Note: All Ns are unweighted. NC: No cases on which to base calculation. ${ }^{1}$ Calculated using life table techniques. Age at first sex among those who reported sex only through the anonymous sealed envelope method was imputed conservatively, using current age.

\subsubsection{Sexual risk behaviours}

Table 9.11 presents findings relating to sexual risk behaviours of respondents reporting sexual experiences, including multiple partner relations and inconsistent condom use. Findings confirm that where adolescents engaged in sexual relations, it was generally under unsafe conditions.

More than two-thirds (37\%) of sexually experienced boys reported that they had ever engaged in sex with more than one partner in 2012, and one-fifth had done so in the year preceding the interview; this represents a significant increase from 2007 when just eight percent and five percent, respectively, had so reported. In contrast, few girls reported multiple partner relations: nine percent had ever experienced so, and five percent had experienced so in the year preceding the interview. As before, while not entirely comparable, we note that in 2007,26 percent of sexually experienced unmarried women aged 15-24 had ever engaged in relations with more than one partner, and 12 percent had so engaged in the year preceding the interview (International Institute for Population Sciences and Population Council, 2009), suggesting that multiple partner sex had actually declined among girls. 
The 2012 questionnaire also probed consistent condom use with regard to sex with the first and/or most recent romantic partner (more than two romantic partners was extremely rare) in exchange and casual sex encounters, and in encounters with sex workers and married girls or women. Information on condom use was not obtained from those who reported the experience of forced sex. Likewise, we have no information on condom use among adolescents who reported sexual experiences only in the anonymous format, for obvious reasons. We acknowledge that our consistent condom use indicator may not thus be comprehensive.

Findings suggest that among adolescents who reported sexual experiences in the face-to-face interview, consistent condom use was limited: only 21-22 percent of boys and girls reported that they had always used a condom. Disturbingly, it appears that consistent condom use in all sexual encounters has actually declined among boys, from 31 percent in 2007 to 22 percent in 2012; about as many sexually experienced girls in 2012 reported consistent condom use as did unmarried young women aged 15-24 in 2007 (21\% in both cases) (International Institute for Population Sciences and Population Council, 2009).

Table 9.11: Sexual risk behaviours

Percentage of sexually experienced adolescents who had sex by number of partners and condom use, Rajasthan, 2007 and 2012

\begin{tabular}{|c|c|c|c|c|}
\hline \multirow[b]{2}{*}{ Sexual behaviour } & \multicolumn{2}{|c|}{ Boys (\%) } & \multicolumn{2}{|c|}{ Girls (\%) } \\
\hline & 2007 & 2012 & 2007 & 2012 \\
\hline \multicolumn{5}{|l|}{ Total number of sexual partners } \\
\hline 1 & $(91.9)$ & 62.6 & $\#$ & 91.3 \\
\hline 2 or more & (8.1) & 37.4 & $\#$ & 8.7 \\
\hline Significance level & \multicolumn{2}{|c|}{ * } & ** & \\
\hline \multicolumn{5}{|l|}{ Number of sexual partners in last 12 months } \\
\hline None & $(18.2)$ & 34.8 & \# & 10.2 \\
\hline 1 & $(77.0)$ & 41.8 & $\#$ & 85.0 \\
\hline 2 or more & $(4.8)$ & 21.6 & $\#$ & 4.9 \\
\hline Significance level & \multicolumn{2}{|c|}{ * } & \multicolumn{2}{|c|}{-} \\
\hline Consistent condom use with sexual partners ${ }^{1}$ & $(31.4)$ & 21.5 & $\#$ & 21.3 \\
\hline Number reporting sex in face-to-face interview & 34 & 82 & 17 & 84 \\
\hline
\end{tabular}

Note: All Ns are unweighted. -, ${ }^{*}$ and ${ }^{* *}$ indicate that differences between 2007 and 2012 are not significant, and significant at $p \leq 0.05$ and $p \leq 0.01$, respectively. () Based on 25-49 unweighted cases. \# Percentage not shown; based on fewer than 25 unweighted cases. ${ }^{1}$ Questions on consistent condom use were asked only with regard to sexual relationships with first and/or most recent/last romantic partner, exchange sex partner, sex worker or married woman, and excluded experiences with romantic partners other than first or most recent/last romantic partner, casual partner and experiences of forced sex.

\subsection{Summary}

Findings confirm that despite strict norms prohibiting opposite-sex mixing among the unmarried, opportunities do exist for the formation of romantic relationships among them; indeed, not only had the experience of romantic relationships increased over the five years between the two surveys for both boys and girls, but gender differences had considerably narrowed. For example, 23 percent of boys and 38 percent of girls had made or received a "proposal" for a romantic relationship, and about one-fifth of both boys and girls reported that they had been involved in a romantic partnership. Reports of engaging in a romantic relationship increased considerably over 2007, when just 7-8 percent of boys and girls had reported a romantic relationship. Patterns of romantic partnerships suggest that where such partnerships occurred, they were initiated at an early age, typically around age 15, and were usually hidden from parents but not from peers, and that patterns in 2012 resembled those observed in 2007 for both boys and girls.

Findings confirm that at both times, romantic relationships among surveyed adolescents almost always included some form of physical intimacy. They also confirm that there has been a systematic increase in sexual relations 
among adolescents in a romantic relationship over the five- year period between 2007 and 2012 . There was a clear progression in reported physical intimacy and sexual experience with romantic partners at both times: in 2012, while 86 percent of boys had held hands with a romantic partner, one in two (51\%) had experienced sex with their partner; among girls, while three-quarters had held hands with a romantic partner, two in five (41\%) had engaged in sexual relations. While boys continued to be more likely than girls to report sex with a romantic partner, gender differences had narrowed considerably-from 45 percent versus 16 percent in 2007 to 53 percent versus 41 percent in 2012. This narrowing may suggest both that more boys and girls were engaging in sexual relations with romantic partners closer in age to themselves, and that adolescents, notably girls, may have become more likely than earlier to report reliably about the activities in which they engaged with their romantic partners.

The vast majority of surveyed adolescents who had engaged in sexual relations with a romantic partner had engaged in unprotected sex. Contraceptive use in a romantic relationship remained limited, although there are indications of increases over time. In 2012, more girls than boys reported contraceptive use at first sex with a romantic partner (37\% versus 29\%); consistent condom use was reported by far fewer adolescents (21-22\% of boys and girls). Almost two-thirds of girls reported that their first sexual experience with their boyfriend was forced, a huge increase from the one in six girls who had so experienced sex in 2007.

Verbal harassment, unwanted sexual touch and even forced sex was experienced by considerable proportions of surveyed girls and perpetrated by considerable proportions of surveyed boys. Indeed, in 2012, verbal harassment was experienced by 59 percent of all girls and perpetrated by 27 percent of all boys, a considerable increase from corresponding percentages reported in 2007 (12\% and 14\%, respectively. Non-consensual sexual touch was experienced by nine percent of girls (down from 12 percent in 2007) and was perpetrated by some four percent of boys (4\% also in 2007). Finally, in 2012, in face-to-face and anonymous reporting, nine percent of girls reported the experience of forced sex and seven percent of boys reported perpetrating it.

Sexual experience, thus, was reported by considerably larger proportions of surveyed adolescents in 2012 than in 2007. In total, in 2012, in face-to-face and anonymous reporting, 15 percent of boys and nine percent of girls reported sexual experiences within romantic and/or other partnerships, up from six percent and two percent, respectively in 2007. Early sexual initiation was also evident: 19 percent of boys and 13 percent of girls had initiated first sex before age 18, compared to six percent and two percent, respectively in 2007. As in 2007, however, adolescents in rural areas tended to initiate sexual activity earlier than their urban counterparts.

While sex with a romantic partner characterised experiences for many of the sexually experienced respondents, findings suggest that boys, but not girls, also engaged in sex in other contexts; other partners reported by boys included, mainly, casual partners, sex workers and married women (1-2\% each). Many of the sexual experiences they reported were risky, for example, 37 percent of boys and nine percent of girls reporting sex had experienced sex with more than one partner, and 22 percent and five percent, respectively, reported more than one partner in the 12 months preceding the interview. Moreover, consistent condom use was limited-only 21-22 percent of the boys and girls reported condom use in all sexual encounters. 


\section{Chapter 10 \\ Health and health-seeking behaviour}

This chapter focuses on patterns of substance use among surveyed adolescents, their health status, and careand advice- seeking for the health problems that they experienced. The Rajasthan Adolescent and Youth Study 2012 probed substance misuse, namely, alcohol, drug and tobacco use. It also included questions relating to the experience of symptoms indicative of mental health problems, and self-reported problems in the areas of sexual and reproductive health. Finally, it explored adolescents' care-seeking practices for sexual and reproductive health problems and whether they had undergone an HIV test, and sought to measure their perceived discomfort about seeking contraceptive supplies from a health care provider or pharmacy.

\subsection{Substance use}

Substance misuse among the young is of increasing concern and the need to address it has been highlighted in the Government of India's recently launched adolescent health programme, the Rashtriya Kishor Swasthya Karyakram (RKSK), (Ministry of Health and Family Welfare, 2014). The Youth in India 2006-2007 study indicated wide gender differences, with very few young women, but considerable proportions of young men aged 15-24, reporting substance misuse: for example, 30 percent of young men had consumed tobacco products, 17 percent reported alcohol consumption and one percent had used drugs (International Institute for Population Sciences and Population Council, 2010).

Among surveyed adolescents in Rajasthan in 2012, gender disparities in substance use were wide, and in some instances, increases in substance use over 2007 were evident (Table 10.1). Use of tobacco products had significantly increased for both boys and girls (from $18 \%$ to $24 \%$ and from $3 \%$ to $13 \%$, respectively). Alcohol use at both times was reported by very few adolescents; even so, among boys, its use had increased from three percent to seven percent (corresponding percentages among girls were 0.1 and 0.5$)$. Hardly any adolescents $(0.2-0.3 \%$ of boys and girls) reported drug use (for example, ganja, charas, brown sugar, cocaine and bhang) in 2012. Rural-urban disparities were mild, but notably, rural adolescents were more likely than their urban counterparts to have consumed tobacco products.

Table 10.1: Substance use

Percentage of adolescents reporting lifetime and recent substance use, according to residence, Rajasthan, 2007 and 2012

\begin{tabular}{|c|c|c|c|c|}
\hline \multirow[b]{2}{*}{ Substance use } & \multicolumn{2}{|c|}{ Boys (\%) } & \multicolumn{2}{|c|}{ Girls (\%) } \\
\hline & 2007 & 2012 & 2007 & 2012 \\
\hline \multicolumn{5}{|c|}{ Combined } \\
\hline \multicolumn{5}{|l|}{ Ever consumed } \\
\hline Tobacco and its products & 18.2 & $23.8^{*}$ & 3.0 & $12.5^{* * *}$ \\
\hline Alcohol & 3.3 & 6.9 & 0.1 & $0.5^{*}$ \\
\hline Drugs $^{1}$ & 0.0 & 0.2 & 0.0 & 0.3 \\
\hline \multicolumn{5}{|c|}{$\begin{array}{l}\text { Consumed once a week or more frequently in the month } \\
\text { preceding the interview }\end{array}$} \\
\hline Tobacco and its products & 16.9 & 17.2 & 2.7 & $10.6^{* * *}$ \\
\hline Alcohol & 1.0 & 0.4 & 0.0 & 0.0 \\
\hline Drugs $^{1}$ & 0.0 & 0.0 & 0.0 & 0.2 \\
\hline Number of respondents & 774 & 745 & 1,487 & 1,164 \\
\hline
\end{tabular}




\begin{tabular}{|c|c|c|c|c|}
\hline \multirow[b]{2}{*}{ Substance use } & \multicolumn{2}{|c|}{ Boys (\%) } & \multicolumn{2}{|c|}{ Girls (\%) } \\
\hline & 2007 & 2012 & 2007 & 2012 \\
\hline \multicolumn{5}{|c|}{ Urban } \\
\hline \multicolumn{5}{|l|}{ Ever consumed } \\
\hline Tobacco and its products & 15.1 & 20.5 & 1.8 & $9.9^{* \star *}$ \\
\hline Alcohol & 1.7 & $6.8^{* *}$ & 0.0 & $1.2^{*}$ \\
\hline Drugs $^{1}$ & 0.0 & 0.3 & 0.0 & 0.2 \\
\hline \multicolumn{5}{|c|}{$\begin{array}{l}\text { Consumed once a week or more frequently in the month } \\
\text { preceding the interview }\end{array}$} \\
\hline Tobacco and its products & 14.5 & 15.1 & 1.8 & $8.0^{* * *}$ \\
\hline Alcohol & 1.2 & 1.1 & 0.0 & 0.0 \\
\hline Drugs $^{1}$ & 0.0 & 0.0 & 0.0 & 0.2 \\
\hline Number of respondents & 327 & 369 & 513 & 538 \\
\hline \multicolumn{5}{|c|}{ Rural } \\
\hline \multicolumn{5}{|l|}{ Ever consumed } \\
\hline Tobacco and its products & 19.3 & 25.0 & 3.4 & $13.8^{* * *}$ \\
\hline Alcohol & 3.8 & 6.9 & 0.1 & 0.1 \\
\hline Drugs $^{1}$ & 0.0 & 0.2 & 0.0 & 0.3 \\
\hline \multicolumn{5}{|c|}{$\begin{array}{l}\text { Consumed once a week or more frequently in the month } \\
\text { preceding the interview }\end{array}$} \\
\hline Tobacco and its products & 17.7 & 17.9 & 3.1 & $12.0^{* * *}$ \\
\hline Alcohol & 0.9 & 0.2 & 0.0 & 0.0 \\
\hline Drugs $^{1}$ & 0.0 & 0.0 & 0.0 & 0.2 \\
\hline Number of respondents & 447 & 376 & 974 & 626 \\
\hline
\end{tabular}

Note: All Ns are unweighted. ${ }^{*},{ }^{* *}$ and ${ }^{* * *}$ indicate that differences between 2007 and 2012 are significant at $p \leq 0.05, p \leq 0.01$ and $p \leq 0.001$, respectively. ${ }^{1}$ Includes ganja, charas, brown sugar, cocaine or locally made substances e.g. sulochon, etc.

Frequent tobacco use was also high; in 2012, 17 percent of boys and 11\% of girls (representing most of the boys and girls who had ever consumed tobacco products) reported that they had done so once a week or more frequently in the month prior to the interview. While as many boys so reported in 2007 and 2012, recent tobacco use had increased significantly among girls (from 3\% to 11\%). Rural adolescents were somewhat more likely than the urban to report recent tobacco use (18\% and 15\%, respectively, among boys; 12 percent and eight percent, respectively, among girls); recent alcohol and drug use levels were similar among rural and urban adolescents.

\subsection{Mental health disorders}

The mental health status of surveyed adolescents was assessed based on their responses to the General Health Questionnaire, GHQ-12 (Goldberg, 1992; Patel and Andrew, 2001). This questionnaire, designed to identify the presence of possible mental health disorders, is based on 12 questions that assess the extent to which a respondent experienced, for example, happiness, depression, anxiety and sleep disturbance in the one month preceding the interview. Threshold scores of 2, 3, 4 or more have been variously used to identify the possible presence of common mental health disorders (Bashir et al., 1996; Donath, 2001; Jacob, Bhugra and Mann, 1997). Table 10.2 presents responses on each item of the GHQ-12, and a summary measure indicating the percentage who gave three or more responses suggestive of mental health disorders.

While surveyed boys and girls gave similar responses on about eight of the twelve items in 2012, gender disparities in response patterns were evident. Girls reported responses suggestive of mental health disorders on several more 
Table 10.2: Reported symptoms or behaviours suggestive of mental health disorders

Percentage of adolescents reporting symptoms or behaviours suggestive of mental health disorders experienced in the month preceding the interview, according to residence, Rajasthan, 2007 and 2012

\begin{tabular}{|c|c|c|c|c|}
\hline \multirow[b]{2}{*}{ Reported symptoms/behaviours } & \multicolumn{2}{|c|}{ Boys (\%) } & \multicolumn{2}{|c|}{ Girls (\%) } \\
\hline & 2007 & 2012 & 2007 & 2012 \\
\hline \multicolumn{5}{|c|}{ Combined } \\
\hline Unable to concentrate on whatever he/she doing & 1.5 & $4.6^{* *}$ & 4.8 & $2.5^{* *}$ \\
\hline Lost much sleep over worry & 10.5 & $3.2^{* * *}$ & 9.8 & $4.0^{* * *}$ \\
\hline Felt that he/she was not playing a useful role & 6.9 & 4.1 & 19.3 & 16.4 \\
\hline Felt incapable of making decisions & 5.5 & 10.0 & 22.1 & 22.8 \\
\hline Felt constantly under strain & 14.1 & $6.2^{* * *}$ & 10.6 & $4.5^{* * *}$ \\
\hline Felt that he/she could not overcome his/her difficulties & 4.6 & 7.6 & 15.3 & 14.5 \\
\hline Unable to enjoy normal day-to-day activities & 4.8 & 3.6 & 4.5 & 3.6 \\
\hline Unable to face up to his/her problems & 4.0 & 6.7 & 15.2 & $7.2^{* * *}$ \\
\hline Been feeling unhappy and depressed & 10.7 & $4.0^{* * *}$ & 8.2 & $4.8^{* * *}$ \\
\hline Been losing confidence in himself/herself & 2.3 & 2.5 & 5.8 & $2.1^{* * *}$ \\
\hline Been thinking of himself/herself as a worthless person & 0.9 & 0.9 & 7.4 & $3.6^{* *}$ \\
\hline Not feeling reasonably happy, all things considered & 3.6 & 4.0 & 4.1 & 4.7 \\
\hline Three or more symptoms/behaviours & 8.4 & 7.2 & 17.1 & $11.6^{* *}$ \\
\hline Number of respondents & 774 & 745 & 1,487 & 1,164 \\
\hline \multicolumn{5}{|c|}{ Urban } \\
\hline Unable to concentrate on whatever he/she doing & 1.8 & 2.9 & 4.1 & 2.9 \\
\hline Lost much sleep over worry & 8.2 & 4.1 & 7.9 & $3.7^{* *}$ \\
\hline Felt that he/she was not playing a useful role & 9.7 & 5.2 & 12.8 & 11.7 \\
\hline Felt incapable of making decisions & 5.0 & $10.0^{*}$ & 14.4 & 16.2 \\
\hline Felt constantly under strain & 11.3 & $6.3^{*}$ & 11.6 & $5.1^{* * *}$ \\
\hline Felt that he/she could not overcome his/her difficulties & 3.6 & 7.4 & 10.8 & 10.2 \\
\hline Unable to enjoy normal day to day activities & 2.0 & 2.4 & 5.1 & 4.7 \\
\hline Unable to face up to his/her problems & 4.0 & 5.3 & 9.9 & $4.4^{* * *}$ \\
\hline Been feeling unhappy and depressed & 9.9 & $4.8^{*}$ & 9.0 & 5.6 \\
\hline Been losing confidence in himself/herself & 0.6 & 1.9 & 5.5 & 2.8 \\
\hline Been thinking of himself/herself as a worthless person & 0.6 & 0.8 & 7.2 & 3.9 \\
\hline Not feeling reasonably happy, all things considered & 4.8 & 2.8 & 3.7 & 5.0 \\
\hline Three or more symptoms/behaviours & 6.7 & 7.5 & 12.0 & 9.8 \\
\hline Number of respondents & 327 & 369 & 513 & 538 \\
\hline
\end{tabular}




\begin{tabular}{|c|c|c|c|c|}
\hline \multirow[b]{2}{*}{ Reported symptoms/behaviours } & \multicolumn{2}{|c|}{ Boys (\%) } & \multicolumn{2}{|c|}{ Girls (\%) } \\
\hline & 2007 & 2012 & 2007 & 2012 \\
\hline \multicolumn{5}{|c|}{ Rural } \\
\hline Unable to concentrate on whatever he/she doing & 1.4 & $5.2^{* *}$ & 5.0 & $2.4^{*}$ \\
\hline Lost much sleep over worry & 11.3 & $2.9^{* * *}$ & 10.5 & $4.1^{* * *}$ \\
\hline Felt that he/she was not playing a useful role & 5.9 & 3.7 & 21.6 & 18.8 \\
\hline Felt incapable of making decisions & 5.7 & 10.1 & 24.9 & 26.3 \\
\hline Felt constantly under strain & 15.2 & $6.2^{* * *}$ & 10.3 & $4.2^{* * *}$ \\
\hline Felt that he/she could not overcome his/her difficulties & 5.0 & 7.7 & 16.9 & 16.8 \\
\hline Unable to enjoy normal day to day activities & 5.9 & 4.0 & 4.2 & 3.1 \\
\hline Unable to face up to his/her problems & 4.0 & 7.2 & 17.1 & $8.6^{* * *}$ \\
\hline Been feeling unhappy and depressed & 11.0 & $3.8^{* * *}$ & 7.9 & $4.5^{* * *}$ \\
\hline Been losing confidence in himself/herself & 2.9 & 2.8 & 5.9 & $1.7^{* * *}$ \\
\hline Been thinking of himself/herself as a worthless person & 1.1 & 0.9 & 7.4 & $3.5^{* *}$ \\
\hline Not feeling reasonably happy, all things considered & 3.2 & 4.4 & 4.3 & 4.5 \\
\hline Three or more symptoms/behaviours & 9.0 & 7.1 & 19.0 & $12.6^{*}$ \\
\hline Number of respondents & 447 & 376 & 974 & 626 \\
\hline
\end{tabular}

Note: All Ns are unweighted. *, ${ }^{* *}$ and ${ }^{* * *}$ indicate that differences between 2007 and 2012 are significant at $p \leq 0.05, p \leq 0.01$ and $p \leq 0.001$, respectively.

items than boys. For example, while ten percent of boys reported feeling incapable of making decisions, 23 percent of girls so reported; likewise, while just 4-8 percent of boys reported feeling that they were not playing a useful role and could not overcome their difficulties, as many as 15-16 percent of girls so reported.

Distributions of responses were relatively similar in 2012 and 2007; however, there were significant declines over time in several indicators suggestive of mental health disorders. For example, significantly fewer boys as well as girls in 2012 than in 2007 reported losing sleep over worry, feeling constantly under strain, and feeling unhappy and depressed. Likewise, significantly fewer girls in 2012 than 2007 also reported being unable to concentrate, feeling unable to face up to problems, losing self-confidence and thinking of themselves as worthless. On the other hand, significantly more boys in 2012 than 2007 reported being unable to concentrate and feeling incapable of making decisions.

Rural-urban differences were negligible among boys in 2012, although in 2007, in some instances, boys in rural areas were slightly more likely than their urban counterparts to report symptoms suggestive of mental health disorders. Among girls, rural-urban differences were more evident, with responses of rural girls more likely than those of their urban counterparts to suggest mental health disorders; notably, rural-urban differences were remarkably similar in 2012 and 2007 for many items. For example, rural girls were more likely than the urban to report feeling that they were not playing a useful role (19\% versus $12 \%$ in $2012 ; 22 \%$ versus $13 \%$ in 2007), that they were incapable of making decisions (26\% versus $16 \%$ in $2012 ; 25 \%$ versus $14 \%$ in 2007 ), and that they could not overcome their difficulties (17\% versus $10 \%$ in $2012 ; 17 \%$ versus $11 \%$ in 2007 ).

Overall, our summary measure (percentages reporting three or more of the 12 symptoms/behaviours indicative of mental health disorders) suggests that responses of seven percent of boys and 12 percent of girls were suggestive of mental disorders. Percentages reporting three or more such symptoms were remarkably similar in 2007 and 2012 among boys (7-8\%), but fell significantly from 17 percent to 12 percent among girls (also see Figure 10.1). Rural-urban differences over time were also negligible among boys (7-8\% in 2012; 7-9\% in 2007) but among girls, those in rural areas were moderately more likely than their urban counterparts to display scores indicative of mental disorders (13\% versus 10\% in 2012), however, differences in 2012 were much narrower than in 2007 (19\% versus $12 \%)$. 
Figure 10.1: Percentage of adolescents reporting symptoms/behaviours suggestive of mental health disorders in the month preceding the interview, according to residence, Rajasthan, 2007 and 2012

Combined Urban Rural

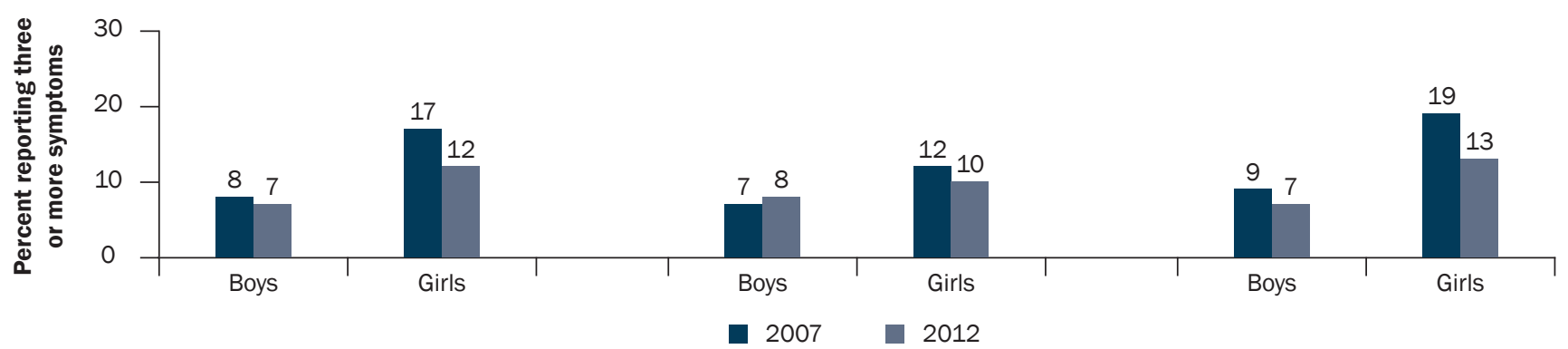

\subsection{Sexual and reproductive health problems}

In order to assess the experience of sexual and reproductive health problems, the boys and girls who participated in the survey were asked if they had experienced, in the three months preceding the interview, such problems in their private parts as genital ulcers, genital itching or swelling in the groin; burning sensation while passing urine, and/ or genital discharge. In addition, girls were asked whether they had experienced menstrual problems. Findings of the recent experiences of sexual and reproductive health problems reported by adolescents in 2007 and 2012 are presented in Table 10.3. We note that these findings are based on self-reports and not on clinical examination or laboratory testing and, therefore, must be interpreted with caution.

As seen in Table 10.3, percentages of adolescents reporting symptoms of genital infection increased significantly between 2007 and 2012, from two percent to eight percent among boys, and from five percent to 13 percent

Table 10.3: Self-reported sexual and reproductive health problems

Percentage of adolescents reporting recent experiences of selected sexual and reproductive health problems, according to residence, Rajasthan, 2007 and 2012

\begin{tabular}{|c|c|c|c|c|}
\hline \multirow[b]{2}{*}{ Sexual and reproductive health problems experienced } & \multicolumn{2}{|c|}{ Boys (\%) } & \multicolumn{2}{|c|}{ Girls (\%) } \\
\hline & 2007 & 2012 & 2007 & 2012 \\
\hline \multicolumn{5}{|c|}{ Combined } \\
\hline Symptoms of genital infection in last 3 months $^{1}$ & 1.9 & $7.6^{* * *}$ & 5.4 & $12.8^{* * *}$ \\
\hline Menstrual problems in last 3 months & NA & NA & 4.0 & 3.6 \\
\hline Any of the above reproductive health problems & NA & NA & 8.4 & $14.6^{* * *}$ \\
\hline Number of respondents & 774 & 745 & 1,487 & 1,164 \\
\hline \multicolumn{5}{|c|}{ Urban } \\
\hline Symptoms of genital infection in last 3 months $^{1}$ & 0.6 & $4.3^{* *}$ & 5.8 & $17.1^{* * *}$ \\
\hline Menstrual problems in last 3 months & NA & NA & 5.9 & 4.5 \\
\hline Any of the above reproductive health problems & NA & NA & 10.2 & $19.4^{* * *}$ \\
\hline Number of respondents & 327 & 369 & 513 & 538 \\
\hline \multicolumn{5}{|c|}{ Rural } \\
\hline Symptoms of genital infection in last 3 months $^{1}$ & 2.4 & $8.9^{* * *}$ & 5.2 & $10.6^{* * *}$ \\
\hline Menstrual problems in last 3 months & NA & NA & 3.3 & 3.2 \\
\hline Any of the above reproductive health problems & NA & NA & 7.7 & $12.0^{* *}$ \\
\hline Number of respondents & 447 & 376 & 974 & 626 \\
\hline
\end{tabular}

Note: All Ns are unweighted. ${ }^{* *}$ and ${ }^{* * *}$ indicate that differences between 2007 and 2012 are significant at $p \leq 0.01$ and $p \leq 0.001$, respectively. NA: Not applicable. ${ }^{1}$ Includes genital ulcers, genital itching, swelling in the groin, burning during urination, etc. 
among girls. Clearly, girls were more likely than boys to report symptoms of genital infection at both times. Among boys, somewhat more of those in rural than in urban areas reported such symptoms ( $9 \%$ and $4 \%$, respectively); in comparison, girls in urban settings were more likely than their rural counterparts to have experienced these symptoms (17\% versus $11 \%$ ). In addition, in 2012 , as in 2007 , four percent of girls reported menstrual problems, with little variation between rural and urban areas at both times (3-6\% in 2007; 3-5\% in 2012).

\subsection{Care and/or advice-seeking}

Adolescents who reported sexual and reproductive health problems were probed about whether they had sought care and/or advice for the problem and the source of such care and/or advice. Findings suggest that care- and/ or advice-seeking was far from universal. For example, among boys, just 54 percent of those who had experienced symptoms of genital infection had sought care (not shown in table because of small numbers). Among girls, as evident from Table 10.4, of those who had experienced a genital or menstrual problem, just 27 percent had sought care in both 2012 and 2007. Findings further suggest that in 2012, among girls who had experienced a reproductive health problem, about one-third sought care from a public sector facility (33\%), about two in five from a private facility, private doctor or registered medical practitioner (RMP) (39\%), 12 percent from an unregistered medical practitioner or a traditional healer (vaid) and, finally, about 15 percent sought remedies at home or medication obtained directly from a chemist or pharmacy. We note that in comparison to adolescents in 2007 when not a single adolescent with symptoms of reproductive health problems had sought care from unregistered or traditional providers, by 2012 , as many as one in eight (12\%) had done so, and advise caution in interpreting this finding, given the small number of cases so reporting.

Table 10.4: Care and/or advice-seeking by girls for reported health problems

Percentage of girls who experienced selected health problems by reported care and/or advice-seeking, Rajasthan, 2007 and 2012

\begin{tabular}{lrc}
\hline Care and/or advice-seeking & $\mathbf{2 0 0 7}$ & $\mathbf{2 0 1 2}$ \\
\hline Sought treatment for reproductive health problem & 27.0 & 26.8 \\
Number of respondents reporting symptoms of a reproductive health problem & $\mathbf{1 2 7}$ & $\mathbf{1 8 2}$ \\
Place treatment sought for symptoms of reproductive health problems & & \\
Government facility/doctor & $(42.1)$ & 33.3 \\
Private facility/doctor/registered medical practitioner & $(55.1)$ & 39.3 \\
Unregistered medical practitioner/traditional healer (Vaid) & $(0.0)$ & $12.0^{* *}$ \\
Home remedies or direct purchase from chemists & $(5.1)$ & 14.9 \\
Number of respondents who sought treatment for symptoms of reproductive health problems & $\mathbf{3 6}$ & $\mathbf{5 1}$ \\
\hline
\end{tabular}

Note: All Ns are unweighted. ${ }^{* *}$ indicates that the difference between 2007 and 2012 is significant at $p \leq 0.01$. () Based on 25-49 unweighted cases.

Adolescents who were aware of HIV/AIDS were also asked whether they had ever undergone an HIV test (not shown in table form). Findings suggest that hardly any adolescents had undergone an HIV test: 0.9 percent of boys and even fewer $(0.2 \%)$ girls. While percentages were similar at both times for boys $(0.6-0.9 \%)$, there is some suggestion of a reduction in HIV testing among girls in this age group (from 1.6\% in 2007). Differences by rural-urban residence were negligible.

\subsection{Hesitation to access contraceptive supplies}

In order to capture the extent to which young people perceived that they could approach health care professionals for sexual and reproductive health services, the survey probed whether the respondent would feel shy to approach a health care provider or a pharmacist for contraceptives. Findings are presented in Table 10.5 and confirm that large proportions of surveyed adolescents would indeed feel shy to do so. Findings also reiterate that percentages who 
would feel shy to approach these sources of contraceptive supplies remained virtually unchanged between 2007 and 2012. For example, 56 percent of boys interviewed in 2012 reported discomfort in accessing contraceptives from a health care provider or medical shop compared to 53 percent in 2007; among girls, 61 percent of those interviewed at both times reported such discomfort. Gender disparities were not wide at both times.

Rural-urban differences were narrow in 2012, and suggest some narrowing since 2007 for girls. In 2012, for example, 53 percent of boys in urban areas and 58 percent of those in rural areas reported discomfort in obtaining contraceptives from a health care provider or pharmacist (compared to $48 \%$ and 55\%, respectively in 2007). Among girls, in 2012, differences were negligible (61\% of rural girls and $60 \%$ of urban girls reported discomfort), indicating a considerable narrowing from 2007 when $65 \%$ and $49 \%$ so reported. It is disturbing to note, moreover, that among girls in urban areas, percentages reporting discomfort increased significantly over the five-year period, from 49 percent to 60 percent; changes were negligible in contrast, among boys in urban areas and adolescents in rural areas.

Table 10.5: Hesitation to access contraceptive supplies

Percentage of adolescents reporting hesitation to access contraceptive supplies from a health care provider or medical shop, according to residence, Rajasthan, 2007 and 2012

\begin{tabular}{|c|c|c|c|c|}
\hline \multirow[b]{2}{*}{ Hesitation to access contraceptives } & \multicolumn{2}{|c|}{ Boys (\%) } & \multicolumn{2}{|c|}{ Girls (\%) } \\
\hline & 2007 & 2012 & 2007 & 2012 \\
\hline \multicolumn{5}{|c|}{ Combined } \\
\hline $\begin{array}{l}\text { Would feel shy to approach an HCP or } \\
\text { contraceptives }\end{array}$ & 52.8 & 56.4 & 60.7 & 60.6 \\
\hline Number of respondents & 774 & 745 & 1,487 & 1,164 \\
\hline \multicolumn{5}{|c|}{ Urban } \\
\hline $\begin{array}{l}\text { Would feel shy to approach an HCP or } \\
\text { contraceptives }\end{array}$ & 47.8 & 52.7 & 48.8 & $59.7^{* *}$ \\
\hline Number of respondents & 327 & 369 & 513 & 538 \\
\hline \multicolumn{5}{|c|}{ Rural } \\
\hline $\begin{array}{l}\text { Would feel shy to approach an HCP or } \\
\text { contraceptives }\end{array}$ & 54.6 & 57.7 & 65.0 & 61.0 \\
\hline Number of respondents & 447 & 376 & 974 & 626 \\
\hline
\end{tabular}

Note: All Ns are unweighted. ${ }^{* *}$ indicates that the difference between 2007 and 2012 is significant at $p \leq 0.01$. HCP: Health care provider.

\subsection{Summary}

Findings show that about one-quarter of surveyed boys and about one in eight surveyed girls reported the consumption of tobacco, seven percent of boys and hardly any girls had consumed alcohol, and hardly any adolescents had used drugs in 2012. Tobacco consumption in the recent past was reported, moreover, by almost all adolescents who reported ever having consumed tobacco products, and had increased significantly among both boys and girls.

Although adolescence is a generally healthy period of life, significant minorities reported experiencing symptoms suggestive of both mental, and sexual and reproductive health problems in the period preceding the interview. With regard to mental health for example, in 2012, seven percent of boys and 12 percent of girls reported symptoms suggestive of mental health disorders in the month prior to the interview (reported three or more problems in the GHQ-12). Among all boys and among those residing in rural and urban areas, percentages were remarkably similar over the five-year period, but among girls, there was a significant decline in reporting of symptoms over time (from 
$17 \%$ to $12 \%)$, and those in rural areas remained slightly more likely than their urban counterparts to report scores indicative of mental disorders (13\% versus $10 \%)$.

With regard to sexual and reproductive health problems, that is, symptoms of genital infection and, among girls, menstrual problems, in the three months prior to the interview, eight percent of boys and 13 percent of girls reported the experience of symptoms of genital infection, and four percent of girls reported menstrual problems. A significant increase was observed over time among both boys and girls in reported symptoms of genital infection; percentages of girls reporting menstrual problems were, in contrast, identical both in 2007 and in 2012 . HIV testing was rarely undertaken by both girls and boys at both times $(0-2 \%)$.

Care and/or advice-seeking among respondents reporting sexual and reproductive health problems was far from universal. For example, among the small number of boys reporting a problem, just 54 percent of those who had experienced symptoms of genital infection had sought care, while among girls who had experienced one or more symptoms of genital infection or a menstrual problem, only about one-quarter (27\%) had done so. Leading sources of treatment among girls who had experienced such problems in 2012 were a public (33\%) or private (39\%) sector facility or provider.

Findings suggest that surveyed adolescents were shy about seeking sexual and reproductive health services. For example, many adolescents, girls (61\%) and boys (56\%) alike, reported that they would indeed hesitate to approach a health care provider, or a pharmacy or medical shop for contraceptive supplies. There was no evidence that levels of discomfort had reduced over time; on the contrary, in urban areas, significantly more adolescent girls reported discomfort in 2012 than in 2007. 


\section{Chapter 11 \\ Participation in civil society and political life}

The National Youth Policy 2014, and its predecessor, the National Youth Policy 2003, have underscored the role of India's adolescents and youth in political decision-making, and argued for priority to be placed on the representation of this sub-population in appropriate bodies, community engagement of adolescents, participation in politics and government and more extensive participation in programmes designed for them (Ministry of Youth Affairs and Sports, 2003; 2014). While the focus is on all those aged 15-29, it acknowledges adolescents as a special group. Indeed, there is a recognition that today's generation of young people, who have better access to skills and information than those of earlier generations, can play an important role in influencing political processes and the socioeconomic development of the country.

This chapter presents a profile of the involvement of surveyed adolescents in various government-sponsored programmes, such as scholarships to pursue their education, programmes intended to build leadership skills, and programmes addressing girls' sexual and reproductive health concerns, and the economic empowerment of women and families. It also assesses adolescents' participation in community activities on the one hand and community level violence on the other. Finally, it explores their perceptions about and participation in political matters.

Adolescents who participated in the survey were asked whether they were aware of specific adolescent-focused programmes in their village or urban neighbourhood. In 2007, a general question was asked that sought information from adolescents about any programme about which they were aware and in which they had participated, and if so, a general question inquiring about the kinds of programmes about which they were aware or in which they had participated, leaving it to the respondents to describe the specific programme. In 2012, in contrast, we listed a specific set of government programmes-those intended to build leadership and life-skills development, address health concerns, overcome education-related barriers, and enhance economic empowerment. In the area of leadership and life skills development, the specific programmes listed were the SABLA programme (or Kishori Shakti Yojana) and Youth Clubs supported by the Nehru Yuva Kendra Sangathan (NYKS). Among health-related programmes, we focused on frontline community based health workers (ASHA), and schemes through which women and girls may obtain free sanitary napkins. With regard to economic empowerment programmes, we probed employment generation schemes (the Mahatma Gandhi National Rural Employment Guarantee Act (MNREGA) and Ioan facilities available to women to start or expand a business of their own. For each programme listed, surveyed adolescents were asked whether they had heard about the programme, and if so, whether, in the five years preceding the interview, they had participated in or benefitted from the programme; in the case of MNREGA, we also asked whether a family member had benefitted from the programme.

\subsection{Awareness and use of scholarships and other secondary education-related schemes}

In 2012, we listed two types of programmes-scholarship schemes for girls and boys in secondary and higher secondary classes and bicycle schemes for school-going girls-and explored the extent to which eligible adolescents had heard of and availed of these schemes. With regard to the bicycle scheme, we asked eligible girls, namely those residing in rural areas who were currently in Classes 9 and 10 (see, for example, Government of Rajasthan, 2013; Government of Rajasthan Finance Department, 2011) about their awareness and use of the bicycle scheme. Likewise, we asked both girls and boys about their awareness and receipt of scholarships. Given the lack of comparability, we focus here on the situation in 2012 only, and in view of the fact that these schemes are available only for those satisfying various eligibility criteria, we restrict this analysis to those satisfying the eligibility requirements of various schemes. Findings are presented in Table 11.1.

As mentioned above, only rural girls entering Classes 9 or 10 are eligible for the free bicycle scheme. As seen in Table 11.1, every single eligible girl was aware of the bicycle scheme for secondary school girls. Far fewer, just 16\%, however, had received a bicycle under the scheme. 
Almost all adolescents-95 percent of boys and 91 percent of girls-had heard about scholarship programmes, with little rural-urban disparity (92-97\% among boys versus $89-95 \%$ among girls). Although, in general, families are more likely to cite financial obstacles in keeping their daughters in school than their sons, more boys than girls reported availing of scholarships. Indeed, almost one-third of boys (30\%) and one-quarter of girls (24\%) had availed of scholarships in the five years preceding the interview, with more rural than urban adolescents having benefitted from a scholarship (36\% versus $13 \%$ among boys; $27 \%$ versus $20 \%$ among girls). Further, more Hindu than Muslim adolescents reported the receipt of scholarships and this was the case in both rural and urban areas.

Table 11.1: Awareness of and access to government schemes to support education of adolescents

Percentage of adolescents reporting awareness of and access to government schemes to support education of adolescents, and percent distribution of adolescents who had received a scholarship in the five years preceding the interview, by selected background characteristics, according to residence, Rajasthan, 2012

\begin{tabular}{|c|c|c|c|c|c|c|}
\hline \multirow{2}{*}{$\begin{array}{l}\text { Awareness and utilisation of government } \\
\text { education schemes }\end{array}$} & \multicolumn{2}{|c|}{ Combined } & \multicolumn{2}{|c|}{ Urban } & \multicolumn{2}{|c|}{ Rural } \\
\hline & Boys (\%) & Girls (\%) & Boys (\%) & Girls (\%) & Boys (\%) & Girls (\%) \\
\hline $\begin{array}{l}\text { Ever heard of a government scheme that prov } \\
\text { bicycle/scooter to adolescent girls for pursu } \\
\text { secondary education }\end{array}$ & NA & NA & NA & NA & NA & 100.0 \\
\hline $\begin{array}{l}\text { Received bicycle/scooter in the last } 5 \text { years } \\
\text { under the scheme }\end{array}$ & NA & NA & NA & NA & NA & 16.4 \\
\hline $\begin{array}{l}\text { Number of adolescent girls who are current } \\
\text { Class } 9 \text { or have at least completed Class } 9\end{array}$ & NA & NA & NA & NA & NA & 357 \\
\hline $\begin{array}{l}\text { Ever heard of scholarship schemes for } \\
\text { adolescent boys and girls }\end{array}$ & 95.2 & 91.2 & 91.6 & 95.4 & 96.6 & 89.1 \\
\hline $\begin{array}{l}\text { Received any money from scholarships in the } \\
5 \text { years }\end{array}$ & 29.5 & 24.4 & 12.7 & 19.9 & 35.7 & 26.7 \\
\hline Number of respondents & 745 & 1,164 & 369 & 538 & 376 & 626 \\
\hline Received any scholarship in the last 5 years & & & & & & \\
\hline Religion & & & & & & \\
\hline Hindu & 30.8 & 25.1 & 13.4 & 20.9 & 36.2 & 27.0 \\
\hline Muslim & 8.1 & 16.6 & 9.9 & 17.5 & \# & 15.5 \\
\hline Other ${ }^{1}$ & \# & $(34.7)$ & \# & $\#$ & $\#$ & $(44.4)$ \\
\hline Caste & & & & & & \\
\hline SC & 57.5 & 51.5 & 30.4 & 53.3 & 66.7 & 50.7 \\
\hline ST & 51.2 & 41.7 & \# & $(38.8)$ & 53.1 & 42.4 \\
\hline OBC & 18.1 & 16.1 & 10.4 & 13.1 & 20.2 & 17.7 \\
\hline General $^{2}$ & 3.6 & 8.5 & 4.0 & 6.5 & (3.1) & 10.1 \\
\hline Wealth quintile & & & & & & \\
\hline First & 36.7 & 26.6 & $\#$ & $(24.4)$ & 37.9 & 26.8 \\
\hline Second & 34.8 & 28.5 & $(23.7)$ & 32.5 & 36.2 & 27.0 \\
\hline Third & 39.1 & 25.9 & $(20.5)$ & 30.4 & 43.0 & 24.3 \\
\hline Fourth & 24.1 & 22.8 & 16.7 & 17.5 & 30.0 & 27.0 \\
\hline Fifth & 6.5 & 19.4 & 5.1 & 12.1 & \# & 29.4 \\
\hline
\end{tabular}

Note: All Ns are unweighted. () Based on 25-49 unweighted cases. \# Percentage not shown; based on fewer than 25 unweighted cases. NA: Not applicable. OBC: Other backward caste. SC: Scheduled caste. ST: Scheduled tribe. ${ }^{1}$ Includes Christian, Buddhist, Neo-Buddhist, Sikh, Jain, Jewish, Parsi/Zoroastrian, Sarana and no specified religion. ${ }^{2}$ Includes all those not belonging to SC, ST or OBC. 
Many scholarships are restricted to certain groups of adolescents; for example, those who belong to socially excluded castes and tribes, and those whose households fall under the poverty line. Table 11.1 further shows that in 2012, adolescents belonging to scheduled caste and tribe households were indeed more likely to have availed of scholarships than other adolescents. For example, almost three in five boys (58\%) and more than one-half of all girls (52\%) from scheduled caste households and one-half (52\%) and two-fifths (42\%) of those from scheduled tribe households had availed of scholarships,. In contrast, fewer than ten percent of adolescents from households belonging to general castes so reported. Rural-urban differences were apparent among boys but not among girls: 67 percent and 53 percent of boys from rural scheduled caste and rural scheduled tribe households, respectively, compared with 30 percent of those from urban scheduled caste households (fewer than 25 boys from scheduled tribes lived in urban areas, and percentages are thus not shown). Among girls, differences were not observed: 51-53 percent among those belonging to urban scheduled caste households, and 42 percent of those from scheduled tribe households in rural areas.

Differences were also evident with regard to household economic status in 2012. Among boys, almost two in five (37\%) boys from the poorest households (first quintile) compared to seven percent from the wealthiest households (fifth quintile) had received a scholarship, and a similar pattern was observed among boys in rural and urban areas. Among girls, differences were narrower, with reports of receipt of scholarships ranging from 27-29 percent among those from the poorest households (first and second quintiles) to 19 percent among those from the wealthiest (fifth) quintile. While an inverse association was observed among girls in urban areas, in rural areas, girls from all wealth quintiles were about as likely to report the receipt of scholarships (24-29\%).

\subsection{Awareness of and participation in government-sponsored youth leadership programmes}

Awareness of government-sponsored programmes intended to build leadership and life skills among the young was not widespread. Table 11.2, which presents findings on awareness of and participation in such programmes by surveyed adolescents in 2012, shows that fewer than one-half (47\%) of all girls were aware, for example, of the SABLA scheme for adolescent girls (or the Kishori Shakti Yojana (KSY) that preceded it), and surprisingly, awareness was more widespread among urban than rural girls (57\% versus 41\%). Even fewer adolescents-just 19 percent of boys and 14 percent of girls-had heard of NYKS and the youth clubs organised under it, with rural and urban boys about as likely to report such awareness (18-19\%), and urban girls slightly more likely than their rural counterparts to report such awareness (17\% versus $12 \%$ ). We acknowledge the possibility that adolescents had heard of these programmes but were not aware of their names. However, the limited participation of adolescents in these programmes would seem to affirm their overall lack of awareness about them. The coverage of these programmes was disturbingly small: just one percent of girls, irrespective of rural-urban residence, had participated in SABLA (or KSY) activities, and just one percent of boys and 0.1 percent of girls had been members of an NYKS club, reaching two percent among rural boys.

Table 11.2: Awareness of and access to government-sponsored adolescent leadership development programmes

Percentage of adolescents reporting awareness of and access to government-sponsored leadership development programmes in the five years preceding the interview, according to residence, Rajasthan, 2012

\begin{tabular}{lrrrrrr}
\hline \multirow{2}{*}{$\begin{array}{l}\text { Awareness of and participation in leadership } \\
\text { programmes }\end{array}$} & \multicolumn{2}{c}{ Combined } & \multicolumn{2}{c}{ Urban } & \multicolumn{2}{c}{ Rural } \\
\cline { 2 - 6 } & Boys (\%) & Girls (\%) & Boys (\%) & Girls (\%) & Boys (\%) & Girls (\%) \\
\hline Ever heard of SABLA/KSY & NA & 46.6 & NA & 57.1 & NA & 41.0 \\
Ever been a member of SABLA/KSY in the last 5 years & NA & 1.0 & NA & 1.1 & NA & 0.9 \\
Ever heard of youth clubs supported by NYKS & 18.9 & 13.8 & 17.8 & 16.6 & 19.4 & 12.3 \\
Ever been a member of a NYKS club in the last 5 years & 1.1 & 0.1 & 0.0 & 0.2 & 1.5 & 0.0 \\
Number of respondents & $\mathbf{7 4 5}$ & $\mathbf{1 , 1 6 4}$ & $\mathbf{3 6 9}$ & $\mathbf{5 3 8}$ & $\mathbf{3 7 6}$ & $\mathbf{6 2 6}$
\end{tabular}

Note: All Ns are unweighted. NA: Not applicable. KSY: Kishori Shakti Yojana. NYKS: Nehru Yuva Kendra Sangathan. 


\subsection{Rural adolescents' awareness of and participation in government-sponsored economic empowerment programmes}

Programmes such as the Mahatma Gandhi National Rural Employment Guarantee Act (MNREGA) and women's self-help groups (SHGs) are implemented in rural areas and hence this section focuses on surveyed adolescents' awareness of and their family's or their own access to these programmes in 2012. With regard to economic empowerment programmes, as seen in Table 11.3, the large majority of adolescents had heard about the MNREGA. Gender differences in awareness were narrow (95-97\%), and while as many as 72 percent of boys and 55 percent of girls reported that a family member had obtained employment through the programme, very few adolescents themselves had obtained employment through it (6-9\%). Table 11.3, which also gives a percent distribution of the households of adolescents who themselves or whose family members had been employed under MNREGA in the five years preceding the interview, indicates that access to MNREGA was more likely to be reported by adolescents from socially excluded castes and tribes than those from general castes, and those from poorer households (first and

Table 11.3: Awareness of and access to government-sponsored economic empowerment programmes for rural adolescents

Percentage of rural adolescents reporting awareness of and their own or a family member's access to government-sponsored economic empowerment programmes in the five years preceding the interview, by selected background characteristics, Rajasthan, 2012

\begin{tabular}{|c|c|c|}
\hline Awareness and utilisation of government economic schemes & Boys (\%) & Girls (\%) \\
\hline Aware of any self-help group (SHG) for women in village/neighbourhood & NA & 29.6 \\
\hline Ever been a member of a SHG in the last 5 years & NA & 0.5 \\
\hline Ever heard of MNREGA & 97.4 & 94.7 \\
\hline Got employment under MNREGA in the last 5 years & 9.4 & 6.4 \\
\hline $\begin{array}{l}\text { Any family member including the respondent got employment under MNREGA in the last } \\
5 \text { years }\end{array}$ & 71.7 & 54.8 \\
\hline Number of respondents & 376 & 626 \\
\hline \multicolumn{3}{|l|}{$\begin{array}{l}\text { Adolescents from whose family one or more members, including the respondent, got } \\
\text { employment under MNREGA in the last } 5 \text { years by: }\end{array}$} \\
\hline \multicolumn{3}{|l|}{ Religion } \\
\hline Hindu & 72.3 & 57.9 \\
\hline Muslim & \# & 27.8 \\
\hline Other ${ }^{1}$ & $\#$ & $(51.8)$ \\
\hline \multicolumn{3}{|l|}{ Caste } \\
\hline SC & 75.7 & 73.9 \\
\hline ST & 76.9 & 74.1 \\
\hline OBC & 74.8 & 47.1 \\
\hline General $^{2}$ & (31.1) & 37.0 \\
\hline \multicolumn{3}{|l|}{ Wealth quintile } \\
\hline First & 84.4 & 74.5 \\
\hline Second & 83.2 & 65.7 \\
\hline Third & 66.0 & 50.5 \\
\hline Fourth & 49.7 & 42.7 \\
\hline Fifth & $\#$ & 26.8 \\
\hline
\end{tabular}

Note: All Ns are unweighted. () Based on 25-49 unweighted cases. \# Percentage not shown; based on fewer than 25 unweighted cases. SHG: Self-help Group. MNREGA: Mahatma Gandhi National Rural Employment Guarantee Act. NA: Not applicable. OBC: Other backward caste. SC: Scheduled caste. ST: Scheduled tribe. ${ }^{1}$ Includes Christian, Buddhist, Neo-Buddhist, Sikh, Jain, Jewish, Parsi/Zoroastrian, Sarana and no specified religion. ${ }^{2}$ Includes all those not belonging to SC, ST or OBC. 
second wealth quintiles) than those from economically better off households. Even so, 31-37 percent of adolescents from general castes, and 27-50 percent of those from households in the wealthiest quintiles (fourth and fifth) reported that they or someone in their household had received employment through the MNREGA scheme.

Table 11.3 further shows that almost one-third (30\%) of girls were aware of SHGs for women in their village or neighbourhood, but hardly any girl $(0.5 \%)$ had been a member of an SHG at any time in the five years preceding the interview.

\subsection{Adolescents' awareness and use of government-sponsored health-related services}

Information from the survey shows that adolescents' awareness of the presence of frontline community-based health workers (ASHAs) in their village, and girls' awareness about schemes through which women and girls may obtain free sanitary napkins, was also far from universal. Indeed, as indicated in Table 11.4, in 2012, just 69 percent of girls and 39 percent of boys were aware of the presence of an ASHA in their village. Awareness levels were similar in rural and urban areas (38-40\% among boys, $66-71 \%$ among girls). At the same time, hardly any girls had received information or services from an ASHA or had attended a meeting organised by her: just four percent and two percent, respectively, with little variation between girls in rural (2-5\%) and urban (1-2\%) areas.

Table 11.4 also shows that just 26 percent of surveyed girls knew about government schemes which distribute sanitary napkins. Awareness levels differed widely among girls in rural and urban areas, with those in urban areas far more likely than their rural counterparts to report awareness of the scheme (44\% versus $17 \%$ ). As in the case of access to the ASHA's services, far fewer (just $8 \%$ ) had received sanitary napkins under this scheme over the previous five years and, again, rural girls were far more disadvantaged than their urban counterparts ( $3 \%$ of rural girls and $17 \%$ of urban girls had obtained sanitary napkins through this scheme).

\subsection{Participation in community- or panchayat-sponsored programmes}

In many villages and urban neighbourhoods, community-led activities include, for example, cleanliness drives, health promotion activities, and the celebration of festivals and national days. As part of the Adolescents and Youth Study, adolescents were asked whether they had participated in any community-led activities organised by the panchayat/ community leaders in the 12 months prior to the interview. Findings, reported in Table 11.5 for both 2007 and 2012, suggest that the participation of surveyed adolescents in such activities was limited and that girls were far less likely

Table 11.4: Awareness of and access to government-sponsored health services

Percentage of adolescents reporting awareness of and access to government-sponsored health services in the five years preceding the interview, according to residence, Rajasthan, 2012

\begin{tabular}{|c|c|c|c|c|c|c|}
\hline \multirow{2}{*}{$\begin{array}{l}\text { Awareness and utilisation of government health } \\
\text { services }\end{array}$} & \multicolumn{2}{|c|}{ Combined } & \multicolumn{2}{|c|}{ Urban } & \multicolumn{2}{|c|}{ Rural } \\
\hline & Boys (\%) & Girls (\%) & Boys (\%) & Girls (\%) & Boys (\%) & Girls (\%) \\
\hline Ever heard of ASHA & 39.4 & 69.3 & 37.6 & 66.2 & 40.0 & 71.0 \\
\hline $\begin{array}{l}\text { Received any health information/services from an } \\
\text { ASHA in the last } 5 \text { years }\end{array}$ & na & 3.9 & NA & 2.2 & na & 4.8 \\
\hline $\begin{array}{l}\text { Ever attended any group meeting organised by an } \\
\text { ASHA in the last } 5 \text { years }\end{array}$ & na & 1.5 & NA & 1.1 & na & 1.7 \\
\hline $\begin{array}{l}\text { Ever heard of a government scheme which distributes } \\
\text { sanitary napkins to adolescent girls }\end{array}$ & na & 26.4 & NA & 44.2 & na & 17.0 \\
\hline $\begin{array}{l}\text { Received sanitary napkins under the government } \\
\text { scheme in the last } 5 \text { years }\end{array}$ & na & 7.7 & NA & 17.3 & na & 2.6 \\
\hline Number of respondents & 745 & 1,164 & 369 & 538 & 376 & 626 \\
\hline
\end{tabular}

Note: All Ns are unweighted. ASHA: Accredited Social Health Activist. NA: Not asked of boys. 
than boys to have participated in these activities. Almost one-third of boys (32\%) compared to 20 percent of girls reported having participated in a community-led programme in the last year. While boys were just slightly more likely to have reported such participation in 2012 than in 2007 (28\%), far fewer girls had participated in 2012 than in 2007 (29\%). Rural-urban differences were negligible (32-33\% for boys and 19-21\% for girls).

Table 11.5: Participation in community-led programmes

Percentage of adolescents who attended community-led programmes in the village/urban neighbourhood by type of programme attended in the 12 months preceding the interview, according to residence, Rajasthan, 2007 and 2012

\begin{tabular}{|c|c|c|c|c|}
\hline \multirow[b]{2}{*}{ Participation in community-led programmes } & \multicolumn{2}{|c|}{ Boys (\%) } & \multicolumn{2}{|c|}{ Girls (\%) } \\
\hline & 2007 & 2012 & 2007 & 2012 \\
\hline \multicolumn{5}{|l|}{ Combined } \\
\hline Attended any programme organised by the community/panchayat & 27.8 & 32.1 & 29.4 & $19.7^{* * *}$ \\
\hline Number of respondents & 774 & 745 & 1,487 & 1,164 \\
\hline \multicolumn{5}{|l|}{ Specific programme attended } \\
\hline Cleanliness/Sanitation drive & 4.0 & 7.9 & 4.6 & 3.8 \\
\hline Health promotion activity & 0.8 & 2.0 & 3.2 & 0.7 \\
\hline Festival celebration & 2.8 & $9.0 *$ & 33.8 & $3.7^{* * *}$ \\
\hline National day celebration & 91.9 & $79.8^{*}$ & 66.9 & 62.3 \\
\hline Other & 0.3 & $5.0 * * *$ & 0.5 & 1.2 \\
\hline Number of respondents who attended any of the above programmes & 210 & 243 & 449 & 230 \\
\hline \multicolumn{5}{|l|}{ Urban } \\
\hline Attended any programme organised by the community/panchayat & 25.0 & 33.2 & 33.2 & $21.4^{*}$ \\
\hline Number of respondents & 327 & 369 & 513 & 538 \\
\hline \multicolumn{5}{|l|}{ Specific programme attended } \\
\hline Cleanliness/Sanitation drive & 2.3 & $10.0^{*}$ & 4.2 & 2.5 \\
\hline Health promotion activity & 1.2 & 1.6 & 0.6 & 0.0 \\
\hline Festival celebration & 2.4 & $10.2^{*}$ & 34.3 & $6.0^{* * *}$ \\
\hline National day celebration & 92.0 & $76.2^{*}$ & 67.3 & 57.2 \\
\hline Other & 1.1 & 4.8 & 0.0 & $3.2^{*}$ \\
\hline Number of respondents who attended any of the above programmes & 81 & 123 & 171 & 113 \\
\hline \multicolumn{5}{|l|}{ Rural } \\
\hline Attended any programme organised by the community/panchayat & 28.9 & 31.6 & 28.1 & $18.8^{*}$ \\
\hline Number of respondents & 447 & 376 & 974 & 626 \\
\hline \multicolumn{5}{|l|}{ Specific programme attended } \\
\hline Cleanliness/Sanitation drive & 4.5 & 7.1 & 4.8 & 4.6 \\
\hline Health promotion activity & 0.7 & 2.1 & 4.3 & 1.2 \\
\hline Festival celebration & 3.0 & 8.6 & 33.5 & $2.3^{* * *}$ \\
\hline National day celebration & 91.9 & 81.1 & 66.7 & 65.3 \\
\hline Other & 0.0 & $5.1^{*}$ & 0.8 & 0.0 \\
\hline Number of respondents who attended any of the above programmes & 129 & 120 & 278 & 117 \\
\hline
\end{tabular}

Note: All Ns are unweighted. *and ${ }^{* *}$ indicate that differences between 2007 and 2012 are significant at $p \leq 0.05$ and $p \leq 0.001$, respectively. 
Findings from the surveys suggest that the activity in which the largest percentage of adolescents participated was the celebration of national days (80\% of boys and 62\% of girls in 2012; 92 percent and 67 percent, respectively, in 2007). Other events, such as cleanliness drives, health promotion activities, festival celebrations and so on, were attended by small percentages (typically under $10 \%$ at both times, except that in 2007 , many more girls (34\%) reported participation in festivals). Differences by rural-urban residence were negligible.

\subsection{Participation in political activities and perceptions of political matters}

Table 11.6 reports the participation of surveyed adolescents in political activities and perceptions about political processes, notably the extent of disillusionment with the ability of any political party to achieve change at the community level and the extent to which respondents believed that people could vote freely and without fear, pressure or influence. The 2007 survey sought adolescents' perceptions about political processes only and not their involvement in political activities.

In 2012, fewer than one per cent of surveyed boys and girls reported being a member of any political party, and this was so irrespective of rural-urban residence. However, some 23 percent of boys compared to just two percent of girls reported being engaged in political activities such as protests and rallies. Again, rural-urban disparities were negligible. Considerable proportions of surveyed adolescents reported disillusionment with political processes and gender differences were apparent. Larger proportions of girls than boys ( $66 \%$ and $56 \%$, respectively), agreed that there would be no improvement in their village/neighbourhood irrespective of the political party governing the state. We note that gender differences were reversed in 2007 , with fewer girls than boys so reporting (54\% versus $59 \%$ ). Differences by rural-urban residence in adolescents' perceptions about the commitment of political parties to work for change at the community level were negligible, although in 2007 , more urban than rural girls reported such disillusionment (58\% versus $52 \%$ ).

While many adolescents reported disillusionment with the political process, the overwhelming majority believed in the fairness of the electoral process. For example, in 2012, 97 percent and 89 percent of boys and girls, respectively, felt that one could vote freely and without fear or pressure, up from 85 percent and 77 percent, respectively, in 2007. Rural-urban differences were once again negligible among boys, but among girls, slightly more urban than rural residents believed in the electoral process in both 2007 (82\% versus 75\%) and in 2012 (91\% versus 87\%).

Table 11.6: Participation in political activities and perceptions about political processes

Percentage of adolescents who participated in political activities and their perceptions about political processes, according to residence, Rajasthan, 2007 and 2012

\begin{tabular}{|c|c|c|c|c|}
\hline \multirow{2}{*}{$\begin{array}{l}\text { Involvement in political activities and views on political } \\
\text { processes }\end{array}$} & \multicolumn{2}{|c|}{ Boys (\%) } & \multicolumn{2}{|c|}{ Girls (\%) } \\
\hline & 2007 & 2012 & 2007 & 2012 \\
\hline \multicolumn{5}{|c|}{ Combined } \\
\hline Currently active member of a political party & na & 0.2 & na & 0.6 \\
\hline \multicolumn{5}{|l|}{ Involved in any political activities ${ }^{1}$} \\
\hline Never & na & 76.6 & na & 97.9 \\
\hline Regularly & na & 1.4 & na & 0.2 \\
\hline Somewhat regularly & na & 9.5 & na & 0.5 \\
\hline Rarely & na & 12.6 & na & 1.4 \\
\hline $\begin{array}{l}\text { Agree that irrespective of the political party governing the state, } \\
\text { there would be no improvement in the village/neighbourhood }\end{array}$ & 59.2 & 56.2 & 53.5 & $65.8^{* * *}$ \\
\hline $\begin{array}{l}\text { Agree that one can vote freely, without fear, pressure or } \\
\text { influence }\end{array}$ & 85.3 & $97.3^{* * *}$ & 77.1 & $88.8^{* * *}$ \\
\hline Number of respondents & 774 & 745 & 1,487 & 1,164 \\
\hline
\end{tabular}




\begin{tabular}{|c|c|c|c|c|}
\hline \multicolumn{5}{|c|}{ Urban } \\
\hline Currently active member of a political party & na & 0.9 & na & 0.7 \\
\hline \multicolumn{5}{|l|}{ Involved in any political activities ${ }^{1}$} \\
\hline Never & na & 75.2 & na & 96.8 \\
\hline Regularly & na & 1.7 & na & 0.2 \\
\hline Somewhat regularly & na & 11.0 & na & 0.8 \\
\hline Rarely & na & 12.1 & na & 2.2 \\
\hline $\begin{array}{l}\text { Agree that irrespective of the political party governing the state, } \\
\text { there would be no improvement in the village/neighbourhood }\end{array}$ & 60.2 & 56.7 & 58.3 & 66.1 \\
\hline $\begin{array}{l}\text { Agree that one can vote freely, without fear, pressure or } \\
\text { influence }\end{array}$ & 85.0 & $97.7^{* * *}$ & 81.8 & $91.4^{* *}$ \\
\hline Number of respondents & 327 & 369 & 513 & 538 \\
\hline \multicolumn{5}{|c|}{ Rural } \\
\hline Currently active member of a political party & na & 0.0 & na & 0.5 \\
\hline \multicolumn{5}{|l|}{ Involved in any political activities ${ }^{1}$} \\
\hline Never & na & 77.1 & na & 98.5 \\
\hline Regularly & na & 1.2 & na & 0.2 \\
\hline Somewhat regularly & na & 8.9 & na & 0.3 \\
\hline Rarely & na & 12.7 & na & 1.0 \\
\hline $\begin{array}{l}\text { Agree that irrespective of the political party governing the state, } \\
\text { there would be no improvement in the village/neighbourhood }\end{array}$ & 58.9 & 56.1 & 51.7 & $65.7^{* * *}$ \\
\hline $\begin{array}{l}\text { Agree that one can vote freely, without fear, pressure or } \\
\text { influence }\end{array}$ & 85.4 & $97.1^{* * *}$ & 75.4 & $87.4^{* * *}$ \\
\hline Number of respondents & 447 & 376 & 974 & 626 \\
\hline
\end{tabular}

Note: All Ns are unweighted. ${ }^{* *}$ and ${ }^{* *}$ indicate that differences between 2007 and 2012 are significant at $p \leq 0.01$ and $p \leq 0.001$, respectively. NA: Not asked in 2007 survey. ${ }^{1}$ Political activities like attending political protests, participating in election rallies etc.

\subsection{Physical fights in the village or urban neighbourhood}

All respondents were asked whether physical fights-more specifically, adolescents engaging in beating, slapping or pulling the hair of others-were common among boys and girls, respectively, in their village or neighbourhood. Findings, presented in Table 11.7, suggest that physical fights were reported to be more common among boys than girls. Indeed, in 2012, 68 percent of boys and 80 percent of girls reported that boys engaged in physical fights sometimes or often. In contrast, 32 percent of boys and 64 percent of girls reported the same for girls. Rural-urban differences were evident, with more rural than urban adolescents reporting occasional or frequent physical fights among both boys (70\% versus $63 \%$, as reported by boys; and $82 \%$ versus $76 \%$, as reported by girls) and among girls ( $33 \%$ versus $29 \%$, and $67 \%$ versus $60 \%$ as reported by boys and girls, respectively); similar patterns were observed for 2007 as well.

Adolescents were also asked a direct question about their own involvement in physical fights with anyone within the village or urban neighbourhood in the 12 months preceding the interview. The question did not probe further and hence we acknowledge that responses may include fights among family members and others. Few adolescents reported involvement in physical fights in 2012: seven percent of boys and three percent of girls, almost identical to percentages observed in 2007 (7 and 2, respectively). Rural-urban differences were evident; now, however, more urban adolescent boys and girls were likely to report participation in violence than their rural counterparts (12\% versus $5 \%$ among boys; $6 \%$ versus $2 \%$ among girls), and among urban adolescents, percentages engaged in violence were significantly higher in 2012 than in 2007, both among boys (12\% versus 4\%) and girls (6\% versus $2 \%$ ). 
Table 11.7: Physical fights in the village/neighbourhood

Percent distribution of surveyed adolescents reporting perceptions of involvement of adolescents in general, in physical fights in their village/neighbourhood, and percentage of surveyed adolescents themselves involved in physical fights in the last 12 months, according to residence, Rajasthan, 2007 and 2012

\begin{tabular}{|c|c|c|c|c|}
\hline \multirow{2}{*}{$\begin{array}{l}\text { Perceptions/experiences of involvement in } \\
\text { physical fights }\end{array}$} & \multicolumn{2}{|c|}{ Boys (\%) } & \multicolumn{2}{|c|}{ Girls (\%) } \\
\hline & 2007 & 2012 & 2007 & 2012 \\
\hline \multicolumn{5}{|c|}{ Combined } \\
\hline \multicolumn{5}{|l|}{ Respondent's perception of the extent to which: } \\
\hline \multicolumn{5}{|l|}{ Boys in the area are engaged in physical fights } \\
\hline Never & 26.1 & 32.1 & 38.8 & 19.6 \\
\hline Sometimes & 72.5 & 63.7 & 53.7 & 72.2 \\
\hline Often & 1.2 & 4.2 & 7.5 & 8.2 \\
\hline Significance level & \multicolumn{2}{|c|}{ * } & \multicolumn{2}{|c|}{$* * *$} \\
\hline \multicolumn{5}{|l|}{ Girls in the area are engaged in physical fights } \\
\hline Never & 41.6 & 68.2 & 54.7 & 35.6 \\
\hline Sometimes & 57.9 & 31.5 & 43.1 & 58.8 \\
\hline Often & 0.4 & 0.3 & 2.3 & 5.5 \\
\hline Significance level & \multicolumn{2}{|c|}{$* * *$} & \multicolumn{2}{|c|}{ *** } \\
\hline $\begin{array}{l}\text { Respondent himself/herself was involved in physical fights } \\
\text { in last } 12 \text { months }\end{array}$ & 6.7 & 7.0 & 1.9 & $3.4^{*}$ \\
\hline Number of respondents & 774 & 745 & 1,487 & 1,164 \\
\hline \multicolumn{5}{|c|}{ Urban } \\
\hline \multicolumn{5}{|l|}{ Respondent's perception of the extent to which: } \\
\hline \multicolumn{5}{|l|}{ Boys in the area are engaged in physical fights } \\
\hline Never & 31.3 & 37.5 & 48.0 & 23.6 \\
\hline Sometimes & 68.4 & 57.5 & 43.9 & 65.2 \\
\hline Often & 0.3 & 5.0 & 8.2 & 11.2 \\
\hline Significance level & \multicolumn{2}{|c|}{ ** } & \multicolumn{2}{|c|}{$* * *$} \\
\hline \multicolumn{5}{|l|}{ Girls in the area are engaged in physical fights } \\
\hline Never & 47.8 & 71.2 & 61.3 & 40.2 \\
\hline Sometimes & 52.2 & 28.1 & 36.6 & 52.1 \\
\hline Often & 0.0 & 0.7 & 2.1 & 7.7 \\
\hline Significance level & \multicolumn{2}{|c|}{$* * *$} & \multicolumn{2}{|c|}{ *** } \\
\hline $\begin{array}{l}\text { Respondent himself/herself was involved in physical fights } \\
\text { in last } 12 \text { months }\end{array}$ & 3.8 & $11.6^{* * *}$ & 2.1 & $5.5^{* *}$ \\
\hline Number of respondents & 327 & 369 & 513 & 538 \\
\hline
\end{tabular}


Table 11.7: (Cont'd)

\begin{tabular}{|c|c|c|c|c|}
\hline \multirow{2}{*}{$\begin{array}{l}\text { Perceptions/experiences of involvement in } \\
\text { physical fights }\end{array}$} & \multicolumn{2}{|c|}{ Boys (\%) } & \multicolumn{2}{|c|}{ Girls (\%) } \\
\hline & 2007 & 2012 & 2007 & 2012 \\
\hline \multicolumn{5}{|c|}{ Rural } \\
\hline \multicolumn{5}{|l|}{ Respondent's perception of the extent to which: } \\
\hline \multicolumn{5}{|l|}{ Boys in the area are engaged in physical fights } \\
\hline Never & 24.1 & 30.1 & 35.6 & 17.4 \\
\hline Sometimes & 74.1 & 66.0 & 57.2 & 75.8 \\
\hline Often & 1.5 & 3.9 & 7.3 & 6.6 \\
\hline Significance level & \multicolumn{2}{|c|}{-} & \multicolumn{2}{|c|}{ *** } \\
\hline \multicolumn{5}{|l|}{ Girls in the area are engaged in physical fights } \\
\hline Never & 39.3 & 67.1 & 52.3 & 33.1 \\
\hline Sometimes & 59.9 & 32.7 & 45.4 & 62.3 \\
\hline Often & 0.5 & 0.2 & 2.3 & 4.4 \\
\hline Significance level & \multicolumn{2}{|c|}{$* * *$} & \multicolumn{2}{|c|}{$* * *$} \\
\hline $\begin{array}{l}\text { Respondent himself/herself was involved in physical fights } \\
\text { in last } 12 \text { months }\end{array}$ & 7.8 & 5.3 & 1.8 & 2.3 \\
\hline Number of respondents & 447 & 376 & 974 & 626 \\
\hline
\end{tabular}

Note: All Ns are unweighted. -, * , ** and ${ }^{* * *}$ indicate that differences between 2007 and 2012 are not significant, and significant at $p \leq 0.05, p \leq 0.01$ and $p \leq 0.001$, respectively. Columns total may not equal $100 \%$ due to missing cases or "don't know" responses.

\subsection{Summary}

While a number of programmes and schemes are available that provide scholarships and conditional cash transfers to enable adolescents to pursue their education; build leadership and life skills; enable adolescents to access health information, services and supplies, and provide employment and economic empowerment opportunities, surveyed adolescents were aware of just a few, and had benefitted from even fewer. Specifically, awareness of programmes and schemes varied considerably, from about $90 \%$ or more reporting awareness of scholarship schemes and the MNREGA employment guarantee scheme, to less than 20 percent reporting awareness about NYKS Youth Clubs. At the same time, very few adolescents had availed of the benefits and services offered by these schemes. Indeed, while 55-72 percent of adolescents reported that a family member had benefitted from the employment generation scheme, just 24-30 percent of adolescents had availed of scholarships, five percent and three percent, respectively, of girls had availed of the services of ASHAs and had received sanitary napkins distributed by the government, and one percent or fewer had been members of SABLA (or KSY) clubs or SHGs.

Findings highlight the limited participation of surveyed adolescents in civil society. Although a number of programmes are organised by the government or NGOs at the community level in which adolescents can participate, just about one-third (32\%) of boys and one-fifth (20\%) of girls reported participating in such programmes in 2012. Most of these adolescents (62-80\%) participated in the celebration of national days, with fewer than ten percent reporting participation in other events, such as cleanliness drives, health promotion activities, celebrations of festivals and so on.

Few surveyed adolescents had participated in political activities: in 2012, fewer than one percent were members of a political party and almost one-quarter of boys, but hardly any girls (3\%), had participated in a political rally or protest. Considerable proportions of adolescents reported disillusionment with the political process. More specifically, 56 percent of boys and 66 percent of girls agreed that there would be no improvement in their village/neighbourhood irrespective of the political party governing the state. Disillusionment had increased among girls but remained about the same as in 2007 among boys; rural-urban differences were negligible. Notwithstanding these high levels of disillusionment with the political process, the overwhelming majority of adolescents believed in the fairness of the 
electoral process. Indeed, 97 percent and 89 percent of boys and girls, respectively, felt that one could vote freely and without fear or pressure.

Considerable proportions of surveyed boys and girls acknowledged that physical fights among boys and, to a lesser extent, among girls did occur in their village or urban neighbourhood; however, in 2012, just seven percent of boys and three percent of girls reported that they had been involved in a physical fight in the year preceding the interview. Although more rural than urban adolescents perceived that boys and girls, respectively, engaged in physical fights among themselves, more urban than rural adolescents reported having participated in physical fights in the year preceding the interview. 


\section{Chapter 12 \\ Looking forward}

The findings of the Adolescents and Youth in Rajasthan 2012: Changing Situation and Needs study, presented in earlier chapters, highlight the situation of adolescent boys and girls aged 15-19 in Rajasthan. They underscore that in many respects, adolescents aged 15-19 in 2012 resembled those aged 15-19 five years earlier but, at the same time, that in many respects, they were different and faced new challenges while making the transition to adulthood. The findings suggest several key programme areas for action as well as directions for future research, which are highlighted in this chapter.

\subsection{Recommendations for programmes}

Challenges facing adolescents, described in earlier chapters, call for multi-pronged programme interventions at the individual, family, community, school and health system levels, for example. Key programme recommendations emerging from this study are highlighted below.

\section{Ensure a secondary school education for all}

The achievement of a minimum of a secondary school education is well recognised as necessary to equip adolescents to make a successful transition to adulthood. Indeed, in recognition of this imperative, the Rashtriya Madhyamik Shiksha Abhiyan (RMSA) was launched in 2009 with the goal of promoting universal completion of secondary education by 2020. Findings suggest that in Rajasthan, while huge strides have been made in the achievement of educational milestones over the five-year period under study, these strides fall short of ensuring universal secondary education. Indeed, even by 2012, just 53 percent of surveyed boys and 39 percent of surveyed girls had completed a secondary school education, up from 38 percent and 22 percent, respectively, five years earlier. Moreover, the gender gap prevails, with secondary school attainment among girls in 2012 reaching levels achieved by boys in 2007. At the pace of change observed in our study, the goals of the RMSA may not be reached by 2020. Efforts must be made to both hasten the pace of universalising secondary school completion and narrowing the gender gap.

A number of factors have been identified in the Adolescents and Youth in Rajasthan 2012 study that inhibit secondary school enrolment and completion. Gender differences were apparent, although lack of interest in studies was a leading obstacle for both boys and girls. In addition, boys cited academic failure and wage work requirements, and girls cited the inability of parents to cover the cost of their education, housework requirements and perceptions of parents' concerns about their safety. Multiple activities are needed to address these barriers. Clearly, many adolescents are first-generation students, and efforts are needed that enable them to prioritise the need to complete their education, provide them special coaching as appropriate, and recognise the need for flexibility given the competing demands on their time. Efforts are also needed that engage parents in prioritising the education of their children; that emphasise the importance of regular school attendance, of communicating with children about their school life, about carving time for children to complete their homework; and that place special value on educating daughters. Conditional grants and targeted subsidies that encourage school continuation and completion and dissuade parents from marrying their daughters off early, must also be made more easily available. School-related obstacles must also be overcome; as recommended in the RMSA, secondary schools must be available in closer proximity to adolescents' residences, and other barriers, such as poor infrastructure, paucity of teachers and quality of education must be addressed. The inclusion of livelihood skills building opportunities within the school setting would clearly enhance perceptions about the value of education.

\section{Fulfill the skilling needs of the next generation}

Although relatively few surveyed adolescents reported wage work before they were aged 15, about one-quarter had been engaged in wage work in the year preceding the interview. For the most part, wage work comprised agricultural and unskilled non-agricultural labour and exposure to livelihood skills building opportunities, and was reported by just 15-18 percent of boys and girls. While increasing proportions of boys had obtained training in computer skills, 
skills in which girls, in particular, had received training - tailoring, for example - were not linked with market needs. These findings raise questions about the need to prioritise livelihood skills training opportunities for adolescents, both those in school and those who have discontinued their education. Formal mechanisms must be developed that provide opportunities to adolescents to acquire skills for which there is an established demand, and that link eligible adolescents to market opportunities. Providing such opportunities for school-going adolescents would have the added advantage of addressing the concerns of parents and adolescents about the utility of a secondary education. Also required are efforts to ensure that existing programmes aimed at addressing the skilling needs of India's population do indeed reach adolescents, and pay particular attention and adapt to the special constraints faced by girls in acquiring skills and accessing employment opportunities.

\section{Ensure that the transition to sexual life is safe and wanted}

Percentages of surveyed boys and girls reporting pre-marital sexual experience had more than doubled over the cohorts of 2007 and 2012. Pre-marital sexual experiences were, moreover, largely unsafe - experienced with both romantic partners as well as, for boys, married women and sex workers, with consistent condom use being reported by no more than a minority. These findings, together with those highlighting that adolescents tended to initiate sexual activity uninformed, reinforce the need for the RKSK and call for multipronged action - sexuality education, counselling, provision of contraceptive supplies and so on - that is adolescent friendly and emphasises the importance of informed choice. Findings suggest persistent misconceptions about the condom, calling for bold and imaginatively designed messages that communicate the importance of condoms and the location of supplies.

Also disturbing are widespread reports of the perpetration (boys) and experience (girls) of non-consensual sexual relations and attitudes. Comprehensive sexuality education, counselling and other efforts are needed that convey the importance of consensuality to boys and girls; these may include the dissemination of information on the penalties boys may face for violations; the development of safety plans that provide girls a road map to follow in case of potential harassment; and the engagement of adolescents, parents and communities to support and not blame girls who report the experience of sexual harassment and violence.

\section{Promote safe social spaces for adolescent girls}

Although by 2012, many more surveyed girls reported agency in terms of decision-making, freedom of movement, and access to and control over financial resources, percentages who reported such agency continued to be limited. Marriage-related planning had commenced early for far too many girls. Peer networks continued to be small for girls, and about one-fifth reported not having a single close friend. Clearly, few girls have access to safe and social spaces outside their homes and schools in which they can make and meet friends and strengthen peer support networks. What is needed is to shape programmes for girls, including such existing programmes as SABLA, to offer girls a safe social space apart from home and school; a friendship network; mentors and role models; life skills education; agency-building activities; information about services and health, social, and economic rights; financial literacy and savings; self-protection plans; livelihood skills building opportunities and knowledge of what community resources exist to access when needed.

\section{Develop new concepts of masculinity among boys}

Findings have suggested that while surveyed boys were not as disadvantaged as surveyed girls, many were not able to exercise agency in their everyday life; at the same time, far more boys than girls expressed inegalitarian gender role attitudes and justified violence against women and girls, and changes in these attitudes were far less marked among boys than girls. In particular, findings have highlighted the extent to which boys perpetrate violence - by way of physical fights with other boys, and by way of harassment and sexual violence perpetrated on women and girls. Thus far, programmes have, by and large, neglected boys, and what is needed are school and community-based programmes that encourage boys to question traditional gender norms, adopt new behaviours, such as supporting their mothers and sisters in housework, encouraging sisters to complete schooling, underscoring the unacceptability of the perpetration of violence and adopting nonviolent forms of conflict resolution, and more generally, respecting new and egalitarian concepts of masculinity. Platforms such as, for example, the NYKS programme and the proposed SAKSHAM programme, and other NGO schemes must focus on building boys' life skills, prosocial values, and promote new concepts of masculinity and femininity. To reinforce new notions of masculinity among young people, 
corresponding efforts to break down traditional notions of masculinity must be directed at the adults who influence young people - ranging from community leaders to teachers and health care providers, to parents.

\section{Reinforce commitment to 'no tolerance for violence'}

Findings from our survey have highlighted that adolescents grow up in a culture of considerable violence, at the community, family and individual levels. They witness parental violence and violence among young people in their communities. They experience corporal punishment inflicted by parents as a form of discipline and a few admit participating in such violence. Girls experience various forms of sexual violence - verbal harassment, unwanted touch and forced sex, and boys admit perpetrating these forms of violence on girls. In many instances - for example, the experience of verbal harassment and forced sex among girls, and the perpetration of these acts by boys reports of sexual violence have increased over the five years between the two surveys. The alarming situation of sexual violence among young people has drawn the attention of the nation, and most recently of the Prime Minister himself, who spoke out against violence against women and girls in his Independence Day address to the nation.

Action is needed at many levels. Comprehensive sexuality education must emphasise non-violent forms of conflict resolution while at the same time, breaking down accepted norms of femininity and masculinity that perpetuate gender stereotypes, and underscoring the equal right of boys and girls to exercise choice. Other forums, including the RKSK's peer educator model, the NYKS structure, the SABLA programme, and girls' and boys' groups more generally, provide appropriate opportunities to instil new norms and ensure that adolescents commit themselves to a "no tolerance for violence' community.

At the same time, behaviour change communication activities must reach parents and communities more generally with messages about their various roles in halting the acceptability and perpetration of violence. Parents must themselves be oriented not only about egalitarian spousal relations, but also about egalitarian socialisation of sons and daughters on the one hand and the effect of parental violence on their children's healthy development, and the need to protect their children from sexual exploitation on the other. Health sector outreach workers, PRIs and influential individuals in each community, and even teachers may be tasked with promoting these messages and taking action to stop violence taking place in their communities; at the same time, their capacity to deal sensitively and non-judgementally with reports and experiences of violence against women and girls must be sharpened. Finally, mechanisms for reporting violence against women and girls must become more adolescent and youth friendly, respecting young people's confidentiality and enabling reporting procedures in a non-threatening environment.

\section{Promote comprehensive sexuality education for all adolescents}

Adolescent girls and boys in our surveys continued to be generally uninformed or misinformed about their bodies, sexuality and health-promoting behaviours. This limited awareness persisted notwithstanding some impressive increases in 2012 over 2007 among both boys and girls, and notwithstanding the huge increase in percentages of adolescents reporting exposure to sexuality education in the school setting or at the community level through the Adolescent Reproductive and Sexual Health programme (the precursor to the RKSK). These findings suggest that exposure to comprehensive sexuality education is not universal or comprehensive and raise questions about the quality of the school-based programmes imparted to adolescents.

Concerns about the appropriateness of sexuality education programmes and suggestions about discontinuing such education must be reconsidered in light of findings that awareness is limited while early and unsafe sex is experienced by growing numbers of adolescents. Comprehensive sexuality education programmes are needed that go beyond addressing only the human biology of pregnancy, or only HIV/AIDS, or abstinence only until marriage. What is needed is to learn from available curricula that provide information about biology and maturation, sexuality, contraception, prevention of STIs and HIV/AIDS, relationships and marriage, as well as skills building for gender equality, non-violence, and respect for human rights. Such programmes not only reduce misinformation but also help adolescents to make informed decisions about engaging in sex and using contraception. In addition, special attention needs to be paid to the training of trainers. It is important that teachers, health care providers and others engaged in educating adolescents undergo training that enables them to overcome their reluctance to communicate with adolescents on sensitive sexual and reproductive matters, that dispels their misconceptions on these matters, and that enhances their technical knowledge of these issues. There is no evidence that comprehensive sexuality 
education, appropriately delivered, can lead to increased risk taking; rather, it has positive health outcomes, including reductions in STls and unintended pregnancies.

\section{Ensure that the RKSK addresses adolescents' health information, counselling and service needs}

Our survey has highlighted that considerable proportions of adolescents have experienced symptoms suggestive of mental health as also sexual and reproductive health problems. Yet, not only are adolescents poorly informed about health-promoting practices and the location of available services, but few are aware of or have accessed Adolescent Friendly Health Clinics for information, counselling or services. Numerous obstacles to health-promoting practices are evident from our findings. For one, many boys and especially girls are not permitted to visit a health centre unescorted, suggesting that few youth would be able to attend Adolescent Friendly Health Clinics for sexual and reproductive health counselling or services. Several adolescents, moreover, expressed shyness about accessing health services, and few had received information or counselling from a health care provider.

The recently launched RKSK promises to overcome these obstacles. It has outlined a comprehensive strategy that addresses key aspects of adolescent health: physical maturation and sexual and reproductive health, noncommunicable diseases and lifestyle issues, mental health, nutrition, violence and substance misuse, in particular. It is to be delivered through community-based peer educators and clinic-based facilities, including a strengthened network of Adolescent Friendly Health Clinics. It has emphasised the need for service delivery in ways that are appealing to adolescents, that pay attention to the training of providers from periphery to facility, that underline the importance of non-judgemental and confidential services for adolescents, and make provision for appropriate referral as necessary. Our findings underscore the need for such a comprehensive programme and call for its rollout and careful monitoring.

\section{Engage parents}

Findings highlight that parenting practices are typically hierarchical, controlling and gender inegalitarian. Many adolescents witness and experience violence in the home. Parent-child interaction and communication are limited, and communication about sexual and reproductive health matters is virtually non-existent. While some changes had taken place over the five-year period, by and large, effective parenting practices were reported by very few surveyed adolescents at both times. Efforts must be made to raise parental awareness about adolescent health and development, and change traditional attitudes about the socialisation of children. Programmes are needed that encourage parents to adopt gender-egalitarian socialisation practices and openness in their relations with their children, and enable them to play an active role in educating their children about physical maturation and sexual and reproductive health matters. Interventions that address parents are scarce. However, given the key role parents play and given evidence that adolescents wish to engage with their parents on issues of sexual and reproductive health, what is needed are activities that support parents with information, skills and resources, notably about adolescent health and development, sex, substance use, communication skills, and information about local resources.

\section{Intensify efforts to eliminate the practice of early marriage}

Findings indicate that marriage-related planning had already been initiated for about two in five surveyed girls; for one in five, it had been initiated even before they were aged 15; and for one in seven, the marriage had already been fixed and was almost entirely the choice of parents. These findings call for measures that go beyond information campaigns to address the underlying factors - social norms and economic constraints - driving early marriage and to better enforce existing laws prohibiting early marriage in the state. Strategies are needed that mobilise communities and influential community leaders to help parents resist pressures that foster the practice of early marriage. Conditional cash transfer programmes that incentivise families for keeping girls in school and/or not marrying them till after they are aged 18 need to be implemented and their effectiveness reviewed. Efforts to delay marriage also require providing girls with viable alternatives to marriage, in the form of accessible schools and livelihood skills training opportunities. Equally important is the need to ensure greater commitment on the part of law enforcement agencies to enforce existing laws on the minimum age at marriage and the registration of marriages, and to levy penalties on violators. Allowing anonymous reporting, making law enforcement agencies and others aware that the practice of early marriage is not a minor violation, and making the guidelines for penalties clear to enforcement agencies and the wider community are possible steps in this direction. 


\section{Capitalise on parents' and adolescents' access to mobile phones and the internet}

Findings have shown a phenomenal increase in mobile phone ownership at household level, from 40 percent in 2007 to 95 percent in 2012, and in internet access among surveyed adolescents who had five or more years of schooling from five percent to 37 percent among boys and from four percent to 11 percent among girls. Findings suggest that mobile phones and the internet may be promising ways of reaching adolescents, particularly boys, and their parents with news ideas and information, and call for new strategies and messaging techniques through which to convey information of relevance to adolescent health and development to both parents and adolescents themselves. Schools must be better equipped to build adolescents' skills in using the internet, and the school curriculum must enable adolescents opportunities to become familiar with the use of the internet.

\section{Expand the reach of programmes for adolescents}

While a number of programmes and schemes are available to enable adolescents to further their education; build leadership skills; access health information, services and supplies; and gain economic empowerment opportunities, surveyed adolescents were aware of just a few, and very few had benefited from these programmes and schemes. Reasons underlying this limited use must be sought. At the same time, efforts must be undertaken to raise awareness among adolescents themselves, as well as parents, teachers, health care providers and community leaders about the availability of these programmes, and remove barriers inhibiting adolescents from availing of them; for example, with regard to proving eligibility for various schemes and facilitating enrolment.

\subsection{Directions for future research}

Findings presented in this report provide a broad picture of the situation and needs of adolescents in Rajasthan, and highlight that the availability of successive cross-sectional data permits rich insights into areas of rapid changes experienced by adolescents over a five-year span, and areas in which change has been imperceptible. A number of key changes were observed over the five-year period: secondary school completion increased hugely; access to mobile phones and the internet improved, particularly among boys; and pre-marital sexual relations were reported by far more adolescent girls and boys in 2012 than in 2007, for example. At the same time, gender role attitudes did not become uniformly more egalitarian, parent-child relations continued to be hierarchical, sexually active adolescents continued to engage in unprotected sex, and violence continued to pervade the life of many adolescents. Given the dynamic nature of adolescent life, a key recommendation is to institutionalise such successive surveys on a regular basis that enables researchers to track and explain changes and their correlates, and analyse factors impeding change in critical issues.

A general research recommendation is the urgent need for prospective or panel study designs that follow a cohort of adolescents at regular intervals up to age 24. Prospective study designs would enable researchers to take a life course approach; identify, with compelling data, the factors responsible for healthy transitions to adulthood; and point to the ways in which the situation and experiences of youth in adolescence influence their life course at later ages.

More specifically, research is needed that explores adolescents' access to the various programmes and schemes implemented by the government to enhance their health, education, skill acquisition, economic opportunities, leadership skills and citizenship roles, and those that aim to change traditional norms of masculinity and femininity and provide comprehensive sexuality education, for example. Additionally, research is needed that addresses the extent to which adolescents have made use of these opportunities, their assessment of the quality of these programmes and obstacles faced in accessing them, and above all, objective indicators of the impact of participation in these programmes, preferably measured not only immediately following exposure to the programme but also some years thereafter. 


\section{References}

Abraham, L. 2001. "Redrawing the lakshman rekha: Gender differences and cultural constructions in youth sexuality in urban India," South Asia 24:133-56.

Abraham, L. 2002. "Bhai-behen, true love, time pass: Friendships and sexual partnerships among youth in an Indian metropolis," Culture, Health and Sexuality 4(3):337-53.

Abraham, L. and K. A. Kumar. 1999. "Sexual experiences and their correlates among college students in Mumbai city, India," International Family Planning Perspectives 25(3):139-46.

Alexander, M., L. Garda, S. Kanade et al. 2006a. Formation of Partnerships among Young Women and Men in Pune District, Maharashtra. New Delhi: Population Council.

Alexander, M., L. Garda, S. Kanade et al. 2006b. "Romance and sex: Pre-marital partnership formation among young women and men, Pune district, India," Reproductive Health Matters 14(28):144-55.

Awasthi, S., M. Nichter and V.K. Pande. 2000. “Developing an interactive STD prevention programme for youth: Lessons from a north Indian slum," Studies in Family Planning 31(2):138-50.

Bashir, K., R. Blizard, R. Jenkins et al. 1996. "Validation of the 12-item General Health Questionnaire in British general practice," Primary Care Psychiatry 2:4-7.

Bhuiya, I., U. Rob, M.E. Khan et al. 2003. "Reproductive health services for adolescents: Recent experiences from a pilot project in Bangladesh," in Towards Adulthood: Exploring the Sexual and Reproductive Health of Adolescents in South Asia, eds. S. Bott, S.J. Jejeebhoy, I. Shah et al. Geneva: World Health Organisation, pp. 203-6.

Department of Education, Government of Rajasthan. n.d. Rajasthan Education Initiative. Accessed on 11 March, 2014 at http:// www.rajshiksha.gov.in/reimain.htm.

Department of Medical, Health and Family Welfare, Government of Rajasthan. 1999. Population Policy of Rajasthan. Jaipur: Department of Medical, Health and Family Welfare, Government of Rajasthan.

Department of Planning, Government of Rajasthan. 2006. Gender Responsive Budgeting for the Department of Women and Child Development. Jaipur: Department of Planning, Government of Rajasthan.

Department of Women and Child Development, Government of Rajasthan. 2006. State Policy for Women, Jaipur: Department of Women and Child Development, Government of Rajasthan.

Donath, S. 2001. "The validity of the 12-item General Health Questionnaire in Australia: A comparison between three scoring methods," Australian and New Zealand Journal of Psychiatry 35(2):231-35.

Goldberg, D. 1992. General Health Questionnaire (GHQ-12). Windsor: NFER-Nelson.

Government of Rajasthan. n.d. Development Location Data. Accessed on 28 October 2009 at http://www.gis.rajasthan.gov.in/ jsp/public/location/DevelopmentData.jsp

Government of Rajasthan. n.d. Economic Review 2012-13. Planning Department, Directorate of Economics \& Statistics Rajasthan, Jaipur. Accessed on 24 April, 2014 at http://statistics.rajasthan.gov.in/English2013/index.htm.

Government of Rajasthan. 2012. Twelfth Five-year Plan. Accessed on 11 March, 2014 at http://www.planning.rajasthan.gov.in/ Twffyplanc.htm.

Government of Rajasthan. 2013. Rising Rajasthan Progress, Inclusive Growth Prosperity. Jaipur: Government of Rajasthan.

Government of Rajasthan, Finance Department 2011. Budget 2011-2012, Press Release. Jaipur: Government of Rajasthan.

International Institute for Population Sciences (IIPS) and Macro International. 2007a. National Family Health Survey (NFHS-3), 2005-06: India, Volume I. Mumbai: IIPS.

International Institute for Population Sciences (IIPS) and Macro International. 2007b. National Family Health Survey (NFHS-3), 2005-06: India, Volume II. Mumbai: IIPS.

International Institute for Population Sciences (IIPS) and Macro International. 2008. National Family Health Survey (NFHS-3), India, 2005-06: Rajasthan. Mumbai: IIPS. 
International Institute for Population Sciences (IIPS) and Population Council. 2009. Youth in India: Situation and Needs 2006-2007, Rajasthan. Mumbai: IIPS.

International Institute for Population Sciences (IIPS) and Population Council. 2010. Youth in India: Situation and Needs 2006-2007. Mumbai: IIPS.

Jacob, K.S., D. Bhugra and A.H. Mann. 1997. "The validation of the 12-item General Health Questionnaire among ethnic Indian women living in the United Kingdom," Psychological Medicine 27(5):1215-17.

Jejeebhoy, S.J. and K.G. Santhya. 2011. Parent-child communication on sexual and reproductive health matters: Perspectives of mothers and fathers of youth in India. New Delhi: Population Council.

Laird, R.D., G.S. Pettit, K.A. Dodge et al. 2003. “Change in parents' monitoring knowledge: Links with parenting, relationship quality, adolescent beliefs, and antisocial behaviour," Social Development 12(3):401-19.

Lambert, H. and K. Wood. 2005. "A comparative analysis of communication about sex, health and sexual health in India and South Africa: Implications for HIV prevention," Culture, Health and Sexuality 7(6):527-41.

Marta, E. 1997. "Parent-adolescent interactions and psychosocial risk in adolescents: An analysis of communication, support and gender," Journal of Adolescence 20(5):473-87.

Mathur, S.C. 2008. “Developing district health action plan in Rajasthan,” paper presented at 3rd Asia-Pacific Action Alliance on Human Resources for Health Conference, Colombo, October.

Ministry of Finance. n.d. Economic Survey 2012-13: Statistical Appendix. Accessed on 24 April, 2014 at http://indiabudget.nic. in/es2012-13/estat1.pdf.

Mehra, S., R. Savithri and L. Coutinho. 2002. "Sexual behaviour among unmarried adolescents in Delhi, India: Opportunities despite parental controls," Paper presented at the IUSSP Regional Population Conference, Bangkok, June.

Ministry of Health and Family Welfare (MOHFW). 2000. National Population Policy 2000. New Delhi: Department of Family Welfare, MOHFW, Government of India.

Ministry of Health and Family Welfare (MOHFW). 2006. Implementation Guide on RCH II: Adolescent Reproductive Sexual Health Strategy, for State and District Programme Managers. New Delhi: MOHFW, Government of India.

Ministry of Health and Family Welfare (MOHFW). 2014. Rashtriya Kishor Swasthya Karyakram Strategy Handbook. New Delhi: MOHFW, Government of India.

Ministry of Human Resource Development (MOHRD). 2012. Statistics of School Education, 2010-11. New Delhi: Government of India. Accessed on 23 April, 2014 at http://mhrd.gov.in/sites/upload_files/mhrd/files/SES-School_201011_0.pdf.

Ministry of Human Resource Development (MOHRD). 2014. Statistics of school education, 2009-2010. New Delhi: Ministry of Human Resource Development. Accessed on 10 March, 2014 at http://mhrd.gov.in/sites/upload_files/mhrd/files/SESSchool_200910F.pdf

Ministry of Statistics and Programme Implementation (MOSPI). 2012. Statement: Gross State Domestic Product at Current Prices. Accessed on 12 March, 2014 at http://mospi.nic.in/Mospi_New/upload/State_wise_SDP_2004-05_14mar12.pdf.

Ministry of Youth Affairs and Sports (MOYAS). n.d. a. Nehru Yuva Kendra Sangathan. Accessed on 20 August, 2014 at http://www. nyks.org/aboutus/About-nyks.html.

Ministry of Youth Affairs and Sports (MOYAS). n.d. b. Details of Functional Youth Clubs in Rajsthan. Accessed on 20 August, 2014 at http://www.nyks.org/PDF\%20File/rajasthan.pdf.

Ministry of Youth Affairs and Sports (MOYAS). 2003. National Youth Policy 2003. New Delhi: Government of India.

Ministry of Youth Affairs and Sports (MOYAS). 2014. National Youth Policy 2014. New Delhi: MOYAS, Government of India.

National Sample Survey Organization (NSSO). 2014. Employment and Unemployment Situation in India, NSS 68th Round (July 2011-June 2012). New Delhi: NSSO, Government of India.

Office of the Registrar General, India. 2013. Sample Registration System: Statistical Report 2012. Report No. 1 of 2013. New Delhi: Office of the Registrar General, India.

Office of the Registrar General and Census Commissioner, India. n.d. Five Year Age Group Data-C14 Table. Accessed on 21 April, 2014 at http://www.censusindia.gov.in/2011census/Age_level_Data/India/Age_data.xls. 
Office of the Registrar General and Census Commissioner. 2001a. Primary Census Abstract, Total Population: Table A-5, Series 1. New Delhi: Office of the Registrar General and Census Commissioner.

Office of the Registrar General and Census Commissioner. 2001b. Religious Compositions. Accessed on 27 November 2008 at <http://www.censusindia.gov.in/Census_Data_2001/Census_Data_Online/Social_and_cultural/Religion.aspx>.

Office of the Registrar General and Census Commissioner. 2001c. Duration of Residence for Migrants by Last Residence. Accessed on 27 November 2008 at <http://www.censusindia.gov.in/Census_Data_2001/Census_Data_Online/Online_ Migration/Duration_of_Residence_By_LastResidence.aspx $>$.

Office of the Registrar General and Census Commissioner. 2006. Population Projections for India and States 2001-2026 (Revised December 2006). New Delhi: Office of the Registrar General and Census Commissioner.

Office of the Registrar General and Census Commissioner, India. 2013. Census of India 2011: Primary Census Abstract, Data Highlights, India, Series 1. New Delhi: Office of the Registrar General and Census Commissioner, India. Accessed on 25 March, 2014 at http://www.censusindia.gov.in/2011census/PCA/PCA_Highlights/pca_highlights_india.html.

Office of the Registrar General and Census Commissioner and United Nations Population Fund (UNFPA). 2014. Profile of Adolescents and Youth in India: State of Literacy among Adolescent and Youth Population. New Delhi: Office of the Registrar General and Census Commissioner.

Patel, V. and G. Andrew. 2001. "Gender, sexual abuse and risk behaviours: A survey of school-based adolescents in Goa," National Medical Journal of India 14:263-67.

PHD Research Bureau. 2011. Rajasthan: The State Profile. New Delhi: PHD Chamber of Commerce and Industry.

Planning Commission. 2006. Towards Faster and More Inclusive Growth: An Approach to the 11th Five Year Plan (2007-2012). New Delhi: Government of India.

Planning Commission. 2011. Faster, Sustainable and More Inclusive Growth: An approach to the twelfth Five Year Plan. New Delhi: Government of India. Accessed on 21 April, 2014 at http://planningcommission.gov.in/plans/planrel/12appdrft/ appraoch_12plan.pdf.

Planning Commission. 2012. Press Note on Poverty Estimates, 2009-10. Accessed on 11 March, 2014 at http:// planningcommission.nic.in/news/press_pov1903.pdf.

Press Information Bureau. 2012. Beneficiaries Covered Under SABLA 2011-12. Accessed on 11 March, 2014 at http://pib.nic. in/newsite/pmreleases.aspx?mincode $=64$.

Rajasthan Council of Secondary Education. 2013. Annual Report 2012-2013: Rashtriya Madhyamik Shiksha Abhiyan. Jaipur: Rajasthan Council of Secondary Education.

Registrar General, India. n.d. Annual Health Survey (n.d.). Annual Health Survey Bulletin 2012-2013: Tables, Rajasthan. Accessed on 24 April, 2014 at http://www.censusindia.gov.in/vital_statistics/ AHSBulletins/AHS_Bulletin_2012_13/ Rajasthan/Rajashthan.pdf.

Registrar General, India. 2012. SRS Based Abridged Life Tables 2003-07 to 2006-10: SRS Analytical Studies, Report No. 1 of 2012. New Delhi: Registrar General India. Accessed on 23 April, 2014 at http://www.censusindia.gov.in/vital_statistics/ SRS_Based/SRS_Based.html.

Sachdev, P. 1998. "Sex on campus: A preliminary study of knowledge, attitudes and behaviour of university students in Delhi, India," Journal of Biosocial Science 30:95-105.

Santhya, K.G., N. Haberland and A. K. Singh. 2006. 'She knew only when the garland was put around her neck': Findings from an Exploratory Study on Early Marriage in Rajasthan. New Delhi: Population Council.

Santhya, K.G. 2009. Understanding Pregnancy-related Morbidity and Mortality Among Young Women in Rajasthan. New Delhi: Population Council.

Santhya, K.G., R. Prakash, S.J. Jejeebhoy et al. 2014. Accessing Adolescent Friendly Health Clinics in India: The Perspectives of Adolescents and Youth. New Delhi: Population Council.

Sroufe, J.W. 1991. "Assessment of parent-adolescent relationships: Implications for adolescent development," Journal of Family Psychology 5(1):21-45. 
UI Haque, M. and A. Faizunnisa. 2003. "Access to reproductive health information in Punjab and Sindh, Pakistan: The perspectives of adolescents and parents," in Towards Adulthood: Exploring the Sexual and Reproductive Health of Adolescents in South Asia, eds. S. Bott, S.J. Jejeebhoy, I. Shah et al. Geneva: World Health Organisation, pp. 153-55.

United Nations Development Programme (UNDP). 2000. Millennium Development Goals. United Nations website. Accessed on 8 January 2008 at <http://www.un.org/millenniumgoals/goals.html>. 


\section{Authors}

Shireen J. Jejeebhoy, Senior Associate, Population Council, New Delhi

Rajib Acharya, Associate I, Population Council, New Delhi 


\title{
List of investigators
}

\author{
Hemraj Daima \\ Subham Daima \\ Madhulata Gupta \\ Uma Gupta \\ Ravi Kumar Jain \\ Binit Jha \\ Urmila Kanwariya \\ Manisha Kaushal \\ Shveta Khandelwal \\ Najma Khan \\ Pappulal Meena \\ Irshad Mohammad \\ Hrishikesh Pandey \\ Dileep Kumar Parashar \\ Vinesh Kumar Pillai \\ Premlata Rathore \\ Roshani Sahu \\ Laxmi Saini \\ Poonam Saini \\ Anju Sharma \\ Sarita Sharma \\ Dipu Kumar Sharma \\ Anil Kumar Sinha \\ Jaishankar Tiwari \\ Priti Verma \\ Shiv Vijaywargiy
}


Printed at :

systemsvision@gmail.com 

Zone 5A, Ground Floor India Habitat Centre, Lodi Road New Delhi, India 110003

Phone: 91-11-24642901 Email: info.india@popcouncil.org

Ideas. Evidence. Impact. 